\title{
The geomorphology of Farewell Spit and its sensitivity to sea-level rise
}

Helen M. Tribe

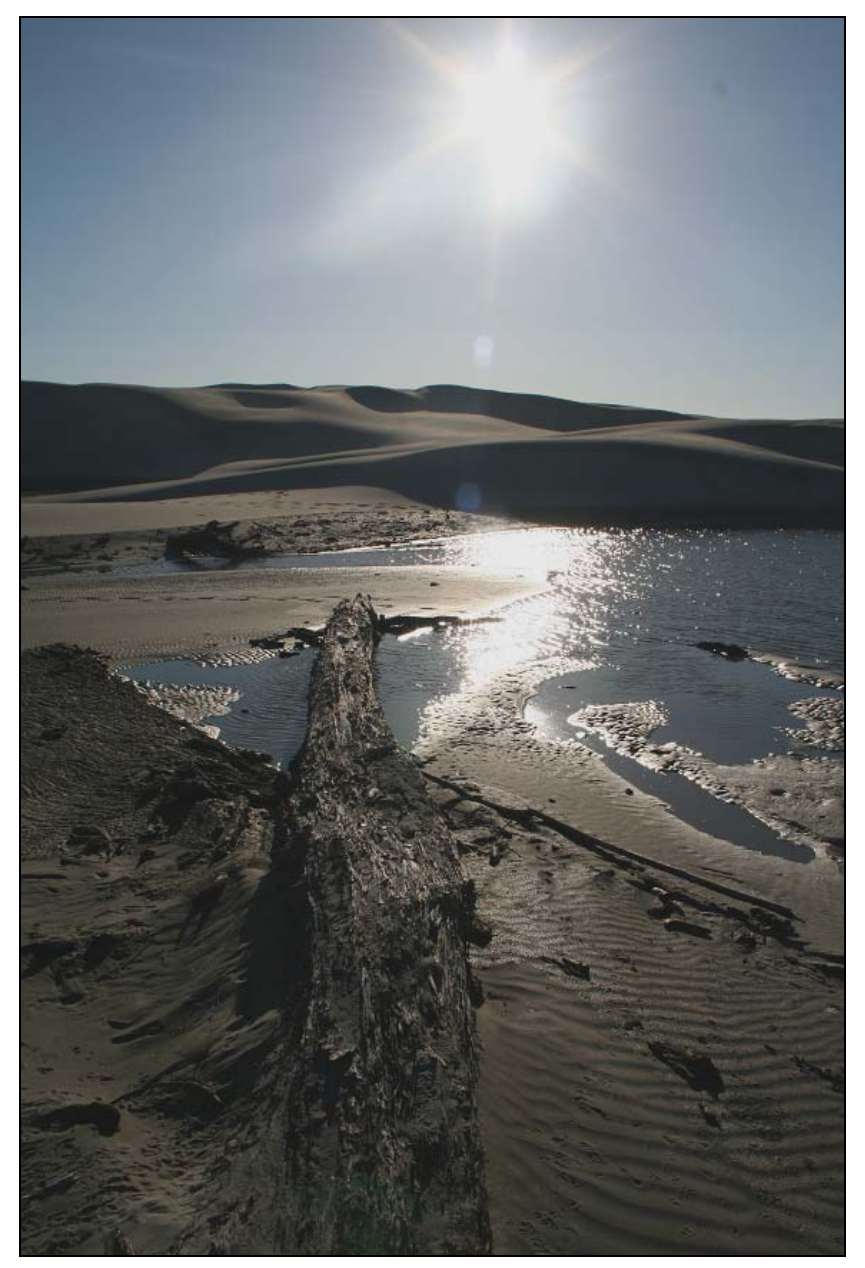

A thesis submitted as partial fulfilment of the requirements for the degree of Masters of Science (Hons) in Physical Geography

School of Geography, Environment and Earth Sciences, Victoria University of Wellington

June 2008 



\section{Abstract}

Sand-dominated barriers are highly sensitive coastal systems which alter their morphology in response to rising sea level, undergoing extensive sediment reworking as wave activity reaches further inland. Farewell Spit, South Island, New Zealand, is a sand-dominated barrier spit which extends $25 \mathrm{kms}$ eastward from the mainland, enclosing the northwestern corner of the macro-tidal Golden Bay. During spring tide cycles low-lying areas of the Spit become completely inundated. The aim of this study is to establish the morphological stability of Farewell Spit and its potential response to the latest IPCC projected eustatic sealevel rise of $0.48 \mathrm{~m}$ (A1B scenario) by the end of this century.

GIS analysis of aerial photographs and the identification of ${ }^{137} \mathrm{Cs}$ signatures within the dunes have shown a high degree of mobility in the Spit's features over the past 55 years. Vegetation increased by $75 \%$, mainly due to the introduction of $A$ arenaria, which has also led to the development of foredunes prograding up to $142 \mathrm{~m}$ over the tidal flats. Barchan dunes on the Spit are also highly mobile migrating at up to $30 \mathrm{~m} / \mathrm{y}$. The high amount of sediment movement along the spit is reflected in the sedimentology of the tidal flats, which show layers of aeolian transported fine, well-sorted sand several centimetres thick. The predominance of medium sand shows that reworking appears to have occurred on these flats due to storm events in Golden Bay, and like the dunes, ${ }^{14} \mathrm{C}$ dating indicates they are very young features

Projected sea-level rise was modelled to assess the vulnerability of low-lying areas of the Spit to tidal flooding. Deeper water levels in the two tidal channels which currently flood across the Spit are expected and there is a risk of additional channels opening, one being very near to the contact between the Spit and mainland. The mobility of the dune systems may however buffer some of these processes by providing natural defences against the sea. Barrier roll over does not appear to be an important process as it appears to be too wide to allow for washover. It is concluded that under current sea-level rise predictions Farewell Spit will not transgress landward but will be subject to exacerbated erosion. 


\section{Acknowledgements}

This thesis is dedicated to my parents Marianna and Michael whose encouragement and support has made it possible to further my studies.

The author would like to acknowledge the Foundation for Research, Science and Technology who funded this research through an Envirolink Grant to Tasman District Council, and the Department of Conservation Nelson/ Marlborough Conservancy who provided the necessary permits. Thanks also go to DoC Golden Bay Area Office for their local knowledge and the use of accommodation on the Spit.

A thousand thank-yous to Dr David Kennedy for his excellent supervision throughout this project. His guidance, patience, encouragement, field assistance and availability throughout the journey have been much appreciated. Dr Mairéad de Róiste's GIS advice and comments have also been invaluable for this thesis and greatly appreciated. Credit also goes to the geography department academics and fellow students, for their wisdom and banter throughout my studies; generally over the 'cooking' wine.

To Rod my 'brother in arms', for field assistance above and beyond the call of duty, laughter throughout our studies, and sanity over the many procrastination cuppers, I am forever grateful. Also a special mention to those cheering wildly from the sidelines: Lloyd, Dr's Hill, Fiona, Kim, KJ, Oren, Shelley and Caroline, thank-you for your support over the years. Finally, to my ever-patient fiancé Matt, who I thank so much for his field assistance, proof reading and 'computer whispering' skills, while also keeping me fed and focussed to help me to persevere and distracting me when needed.

Thanks to all for helping me ascertain that Farewell Spit is indeed made out of sand. 
ABSTRACT I

ACKNOWLEDGEMENTS II

TABLE OF CONTENTS III

FIGURES VIII

LIST OF TABLES XII

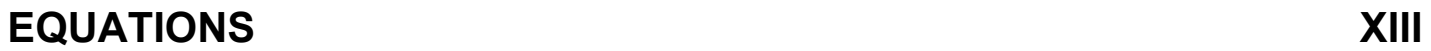

CHAPTER ONE: INTRODUCTION 1

1.1 Background and Justification 1

1.2 Aim and Objectives 5

1.2.1 Aim 5

1.2.2 Objectives 5

1.3 Outline of Thesis Structure 5

CHAPTER TWO: CONCEPTS AND COASTAL PROCESSES

$\begin{array}{ll}2.1 \text { Introduction } & 7\end{array}$

2.2 Barrier types and evolution $\quad 11$

2.2.1 Transgressive barriers 14

2.2.2 Stillstand barriers $\quad 19$

2.2.3 Regressive barriers $\quad 21$

$\begin{array}{ll}2.3 \text { Storms and barrier modification } & 22\end{array}$

2.4 Sea-level rise and barrier/ sandy shoreline response 23 
2.4.1 The Bruun rule 23

2.4.2 Barrier Island Model 25

2.4.3 Storm wave susceptibility Quotient 27

$\begin{array}{ll}2.5 \text { Vegetation } & 28\end{array}$

$\begin{array}{ll}\text { 2.6 Summary } & 30\end{array}$

CHAPTER THREE: THE STUDY AREA 31

$\begin{array}{ll}3.1 \text { Introduction } & 31\end{array}$

3.2 Historical background 33

3.2.1 Maori and European settlement 33

3.2.2 Sanctuary 33

3.3 Physical setting $\quad 35$

3.3.1 Geology 35

3.3.2 Vegetation 39

3.3.3 Oceanography 40

3.3.4 Weather/ Climate 43

$\begin{array}{ll}3.4 \text { Summary } & 44\end{array}$

CHAPTER FOUR: METHODS $\quad 45$

4.1 Introduction 45

4.2 Topographic Methods $\quad 45$

4.2.1 Surveying 45

4.3 GIS mapping 46

4.3.1 Aerial Photograph Analysis $\quad 46$

4.3.2 Photograph set pre-treatment 48

4.3.3 Photograph Georeferencing 48

$\begin{array}{ll}\text { 4.3.4 Digitising features and analysis } & 50\end{array}$ 
4.4 Sedimentological Methods $\quad 57$

4.4.1 Subsurface sediment collection $\quad 57$

4.4.2 Grain size analysis $\quad 59$

4.4.3 Treatment samples 60

4.4.4 Removal of organic material 60

4.4.5 Removal of carbonate 60

4.4.6 Removal of salts 61

4.4.7 Removal of muds 61

4.4.8 Rapid Sediment Analyser (RSA) 61

4.4.9 Dry Sieve 64

4.5 Chronology 68

4.5.1 Optically Stimulated Luminescence (OSL) 68

4.5.2 Caesium $137\left({ }^{137} \mathrm{Cs}\right) \quad 70$

$\begin{array}{ll}\text { 4.5.3 Carbon }\left({ }^{14} \mathrm{C}\right) & 71\end{array}$

$\begin{array}{ll}\text { 4.6 Summary } & 74\end{array}$

$\begin{array}{ll}\text { CHAPTER FIVE: RESULTS } & 75\end{array}$

$\begin{array}{ll}5.1 \text { Introduction } & 75\end{array}$

5.2 Geomorphic zones $\quad 76$

5.2.1 Ocean Beach 76

5.2.2 Northern Dune System 77

5.2.3 Southern Dune System 84

5.2.4 The Salt marshes $\quad 91$

5.2.5 Tidal Flats 93

5.2.6 The Shellbanks 95

$\begin{array}{ll}\text { 5.3 Shoreline change } & 98\end{array}$

5.3.1 Bush End Point 98

$\begin{array}{ll}\text { 5.3.2 Stockyard Point } & 99\end{array}$

$\begin{array}{ll}\text { 5.3.3 Average total shoreline change } & 99\end{array}$ 
5.4 Sedimentology

5.4.1 General grain size:

5.4.2 Stratigraphy

5.5 Projected sea-level rise and inundation of Farewell Spit

6.1 Introduction

6.2 Geomorphology of spit

6.3 Topography and inundation

6.3.1 Sea-level rise

6.3.2 Vulnerable zones

6.3.3 Overwash and inlet breaching potential

6.3.4 The Barrier Island Model

6.4 Geomorphic stability of Features

6.4.1 Ocean Beach

6.4.2 Northern dune system

6.4.3 Southern dune system

6.5 Summary

7.1 Introduction 
REFERENCES:

APPENDICES:

Appendix 1 Results of grain size analysis of cores along the Stockyard Point transect

Appendix 2 Results of grain size analysis of the Mullet Creek core 164

Appendix 3 Results of grain size analysis of the hand augered cores on the vegetated dunes

Appendix 4 Results of grain size analysis of the Lighthouse transect

Appendix 5 Radiocarbon dating results 
2.1 Barrier island system portraying the relationship between the six elements of a barrier island.

2.2 Morphology of barrier islands in a) wave dominated and

b) mixed energy environments.

2.3 New Zealand regional Holocene eustatic sea-level curve.

2.4 Sequence model of sediment layers within a transgressive barrier.

2.5 Formation of a barrier island through the breaching of sand spit. 17

2.6 The break up of Isle Derniere, Louisiana.

2.7 Formation of barrier islands by submergence of beach or dune ridge.

2.8 Generalised morphology and stratigraphy of major stillstand barrier types.

2.9 Formation of a barrier islands through the emergence of offshore bars.

2.10 Sequence model of sediment layers within a regressive barrier. 22

2.11 Sea-level rise induced beach profile change according to the Bruun Rule.

2.12 Sea-level rise induced profile change according to the Barrier Island Model.

2.13 Transect of the Trabucador Bar showing variables included in the storm wave susceptibility quotient.

3.1 Map of Golden Bay.

3.2 Bathymetry map of Golden Bay. 32

3.3 Bar-tailed godwits feeding on the tidal flat. 34

3.4 Generalised geological map of northwest Nelson. 36

3.5 The lighthouse pines. 40

3.6 Dominant ocean currents in northwest Nelson. 41

3.7 Swell rose from observations near Maui Platform 1980-1981. 42

3.8 Farewell Spit wind rose. 43 
4.1 Surveying across Mullet Creek using a Sokkia SET 4010 EDM. 46

4.2 Before and after aerial photos illustrating the effect of georeferencing the 2004 photo to the Farewell Spit topographic map.

4.3 Map of the Mullet Creek area which illustrates width-ways error from georeferencing issues.

4.4 Process of creating polygons and polylines.

4.5 Detail of the mid section of the Spit showing the different photo quality of each aerial photograph set.

4.6 The process of measuring barchan dune movement. 56

4.7 Stainless steel OSL tube attached to the auger shaft. 57

4.8 Vibracorer in use on the Farewell Spit tidal flats. 58

4.9 Rapid sediment analyser. 62

4.10 Fritsch dry sieve stack. 65

4.11 Bivariate plot of skewness and mean grain size of the vegetated dune sand samples.

4.12 Bivariate plot of sorting and skewness of stable dune sand samples.

5.1 Areas of data collection (or of specific mention) on Farewell Spit.

5.2 Multiple shore parallel bars along Ocean Beach. 77

5.3 The sand bar opposite the lighthouse. 77

5.4 Barchan dune \#17. 78

5.5 Surveyed transects of barchan dunes and beach face along the northern dune system.

5.6 Progression of the barchan dunes as they move east along Farewell Spit from 1950 to 2004.

5.7 The average yearly movement and the average total movement rates of the barchan dunes.

5.8 The average per annum migration rate of each barchan dune on Farewell Spit.

5.9 Direction and speed of the maximum wind gusts along Farewell 
Spit. A) For the $2003-2004$ period. B) For the $2001-2008$ period.

5.10 Surveyed transects of the vegetated dunes across the tip of the Spit near the Airstrip.

5.11 The linear dune sequences on the eastern end of Farewell Spit. 86

5.12 Profiles of the southern dune system from the base to the tip of Farewell Spit.

5.13 Froggies semi-permanent fresh water lake. 89

5.14 Hummocky dune terrain showing a dune blow-out. 89

5.15 Map showing the extent of vegetation for each aerial photograph set.

5.16 Map of same area showing the subsequent decrease of sand cover for comparison with figure 5.15. 90

5.17 Southern Airstrip profile, showing the vegetation succession. 92

5.18 Environments within the salt marsh area around the Airstrip. 93

5.19 The extensive tidal flats looking S-E towards the Tasman Mountains.

5.20 Composite aerial photograph (2003) of Farewell Spit showing the channel cut tidal flats extending into Golden Bay. 94

5.21 Profile of erosion on The Shellbanks. 95

5.22 Map of the Shellbanks from 1950, 1984 \& 2004.

5.23 Map of the changing shoreline of Bush End Point $1950-2004.98$

5.24 Map of the changing shoreline profile of Stockyard Point. 99

5.25 Bivariate plot of mean and sorting for surface sediments collected from the northern dunes, beaches and tidal flats.

5.26 Bivariate plot of mean and sorting for subsurface and surface sediments collected from the northern and southern environments.

5.27 Bivariate plot of sorting and skewness for subsurface sediments collected within the southern environments.

5.28 Map of core transects along Farewell Spit.

5.29 Froggies transect indicating the position of each vibracore site 
and depth of muddy layer.

5.30 Core logs of the Froggies subsurface transect.

5.31 Results of grain size analysis of cores along the Froggies transect.

5.32 Core logs of the Stockyard Point subsurface transect including the salt marsh, beach and tidal flat.

5.33 Stockyard Point transect indicating the position of each vibracore site and depth of muddy layer.

5.34 Core log of Mullet Creek.

5.35 Airstrip transect indicating the position and depth of each auger site and the water table level.

5.36 Core logs of the Lighthouse subsurface transect.

5.37 Mullet Creek at low tide and spring high tide.

5.38 Sea-level rise as modelled on MHWS and HAT for Mullet Creek.

5.39 Sea-level rise as modelled on MHWS and HAT for The Roadway, Stockyard Lake and The Airstrip.

6.1: Illustration showing the growth of Farewell Spit from 6.5ka to present.

6.2: Composite aerial photograph (2003) of Farewell Spit showing bulges and recurves.

6.3: Direction of the hourly surface winds on Farewell Spit for the period 10 - 12 January, 1997.

6.4: Map of Bush End Point and the Shellbanks showing morphological change from 1950 - 2004.

6.5: Vegetation aiding in the capturing of sand at Stockyard Point. 123

6.6: Maps showing shoreline and vegetation limits of Stockyard Point and west of Mullet Creek from 1950 - 2004.

6.7: Sea-level rise as modelled on potential storm surge, La Nina, MHWS and HAT water levels for Mullet Creek, The Roadway and Stockyard Lake. 
6.8: Map of Zones along Farewell Spit identified as areas of concern in regards to inundation.

6.9: Photo of one of the smaller creeks east of Mullet Creek.

6.10: Looking eastward across the Stockyard Lake foredune, with the rush-land, salt marsh and tidal flats on the right.

6.11: Examples of dune scarping along the Roadway and Froggies dunes.

6.12: The sandbar as seen from the Lighthouse.

6.13: The sandbar opposite the lighthouse showing flat and small dune morphologies.

6.14: Schematic drawing illustrating the smaller barchan dune 'sideswiping' dune 4.

6.15: Sandstorm on Farewell Spit during October 2007.

6.16: Active parabolic dune near Froggies Lake as seen in 1950, 1975 and 2004.

6.17: Sediment map of Golden Bay.

\section{List of tables}

2.1 Morphological features of barriers developed from differing energy regimes as classified by Davis and Hayes.

4.1 Description of identifying outlines when creating polygons/ polylines of features on the Spit.

4.2 Core depths corrected for compaction

4.3 Results of the Duplicate samples run through both RSA and sieve stack.

5.1 Size parameters of barchan dunes as they march eastward along Farewell Spit.

5.2 Calculated coverage of vegetation and bare sand on Farewell Spit from aerial photographs. 
5.3 Calculated coverage of the Shellbanks from aerial photograph analysis.

5.4 Average accretion of Farewell Spit from Spit width data.

5.5 Mann-Whitney $U$ test results for sieved grain size parameters at different sand source areas.

5.6 Radiocarbon dates from Froggies tidal flat core shells including conventional and calibrated ages.

5.7 Levels of ${ }^{137} \mathrm{Cs}$ within samples taken along the vegetated dunes for OSL dating.

6.1 Parameters used in the storm wave susceptibility quotient. 133

6.2 Parameters used in the Barrier Island Model.

6.3 Wave breaking and significant motion depths for wave energy generated from maximum fetch within Golden Bay from the south and west.

\section{Equations}

2.1 The Bruun Rule. 24

2.2 The simplified version of the Bruun Rule. 24

2.3 The Barrier Island Model. 26

2.4 Ammended Barrier Island Model. 26

2.5 The storm wave susceptibility quotient. 28

4.1 Optically stimulated luminescence dating age equation. 69

$\begin{array}{lll}4.2 & \text { Carbon dating. } & 72\end{array}$ 


\section{Chapter One: Introduction}

\subsection{Background and Justification}

There is an increasing amount of evidence that human activities, especially since the industrial revolution, have led to heightened atmospheric concentrations of greenhouse gases and aerosols (IPCC, 2001). In 2005 the atmospheric concentrations of carbon dioxide $\left(\mathrm{CO}_{2}\right)$ and methane $\left(\mathrm{CH}_{4}\right)$ were recorded at $379 \mathrm{ppm}$ and $1774 \mathrm{ppb}$ respectively, exceeding the natural range (determined from ice core analysis) of these gases over the last 650,000 years [180 - 300 ppm for $\mathrm{CO}_{2}$ and $320-790 \mathrm{ppb}$ for $\mathrm{CH}_{4}$ ] (IPCC, 2007). This increase is thought to cause most of the recorded global mean surface temperature rise of $0.75 \pm 0.18^{\circ} \mathrm{C}$ over the last century and has been related to the amplified usage of fossil fuels and recent agricultural practices (IPCC, 2007). The Intergovernmental Panel on Climate Change (IPCC) Fourth Assessment Report (2007) states that the current 'best estimate' projections for global mean surface temperature rise by 2100 is between $1.8-4.0^{\circ} \mathrm{C}$, a considerable acceleration of temperature rise over the past two centuries.

Oceans act as heat reservoirs and are therefore a key component of the global climate system. Thermal expansion of the water column and accrual of water from other reservoirs such as glaciers are two key responses to a warming atmosphere which in turn causes sea-level rise. Bindoff et al. (2007) estimates that total sea-level rise during the twentieth century has been $0.17 \mathrm{~m}$, rising at an average rate of $1.8 \mathrm{~mm} / \mathrm{y}$ between 1961 - 2003. New Zealand data shows the average sea-level rise has been $1.6 \pm 0.2 \mathrm{~mm} / \mathrm{y}$ over the past century (Hannah, 2004). It is expected that relative sea-level (excluding the effects of vertical land movement because of tectonics or landsliding) around New Zealand will 
be similar to the global average projections (MfE, 2007) of sea-level rise between $0.21-0.48 \mathrm{~m}$ by 2100 (IPCC, 2007).

Sandy shorelines are highly dynamic coastal systems and respond quickly to changing boundary conditions (Klien \& Lichter, 2006). Increased coastal erosion, dune-face retreat, exacerbated storm surge, greater coastal flooding as well as salt contamination of ground water have been well documented to occur as a result of sea-level rise (Healy, 1991). Predicting how a given coastal system will respond is therefore key in effective management.

The Bruun Rule, and its variations, are commonly used in the management of sandy shores as a conceptual model to quantitatively predict shoreline retreat and seaward sediment deposition in relation to sea-level rise (Healy, 1991). Although useful, this tends to be a "2D oversimplification of a 3D system" (Woodroffe, 2002 p466). Furthermore, in the case of barriers, which occur along $10-20 \%$ of the world's coastlines (Stauble, 1989), the model does not account for the net shoreward transgression of the system (Dubois, 2002). There is therefore a need to understand whole coastal systems such as sand barriers, in particular in terms of predicting their response to sea-level rise.

Barriers and spits are some of the most dynamic and sensitive coastal landforms (Aagaard et al., 2004b). They undergo extensive reworking in response to waves especially under periods of rising sea-level, or during stillstands, periods of inactivity where the barriers may be drowned, stranded above sea-level or buried by other sediments (Woodroffe, 2002). Therefore barriers (where preserved) provide a useful depositional record of past coastal processes and evolution of the beach, backshore and dune environments (Woodroffe, 2002; Shepherd \& Hesp, 2003). Evidence of how the barriers have changed in the past can provide proxies for predicting their response to sea-level 
rise; a critical issue in contemporary coastal management (van Heteren \& van de Plassche, 1997).

Evolution of Holocene barriers in New Zealand relate to the rise in sealevel from the last glacial maximum (LGM) where the coastline was $\sim 120$ - 130m below that of the present (Fairbridge, 1976, Hilton \& Nichol, 2003). It commenced its rise from $20 \mathrm{ka}$ at a rate of $\sim 10 \mathrm{~mm} / \mathrm{y}$ (Gibb, 1979) until the current stillstand was reached $\sim 6.5 \mathrm{ka}$, with decimetre scale sea-level fluctuations until present (Gibb, 1986). During this sea-level transgression conditions were favourable for erosion and onshore sediment flow, leading to the growth of barriers which in-filled entrances to embayments and inlets (Gibb, 1979; Shepherd \& Hesp, 2003). Some barriers such as Farewell Spit formed away from old river valleys and at the end of littoral drift compartments.

Spits are common accretional features (Komar, 1998) their morphology being narrow, subaerial extensions of sediment projecting into a large body of water (Whittow, 1984) while welded to the mainland at one end. These often occur at abrupt directional changes of shorelines where sediment accumulates as a result of longshore drift (Woodroffe, 2002). Farewell Spit, although fitting this description, also exhibits a seaward beach face and landward facing backbarrier slope; the two morphodynamic units which define a barrier (Orford, 2004). Woodroffe (2002) further states that barriers can adopt spit morphology through a transgressive reworking of a seaward sediment source. Farewell Spit is a sand dominated barrier (SDB) which includes vast transgressive dune fields near its base, and so Shepherd and Hesp's (2003) use of the term 'transgressive dune field barrier' is appropriate for this landform.

Situated on the northwest tip of the South Island; Farewell Spit arcs in a west-east direction, enclosing the northwestern part of Golden Bay. This coastline experiences a macro-tidal range of $\sim 5 \mathrm{~m}$ and during 
spring tide cycles low lying areas of the spit become completely inundated. It is an area that is therefore potentially highly vulnerable to sea-level rise which could cause the Spit's low lying areas and associated tidal flats to be permanently inundated and lead to major erosion of the supratidal areas. Furthermore, breaching of the Spit could induce flow-on effects into Golden Bay which is currently protected from the high energy wave regime of the Tasman Sea by the barrier rise. Legislation such as The New Zealand Coastal Policy Statement 1994 (NZCPS) recognises sea-level rise and promotes the identification of vulnerable sand systems such as Farewell Spit in relation to it (Hilton \& Nicol, 2003).

\section{Policy 3.4.2}

Policy statements and plans should recognise the possibility of a rise in sea-level, and should identify areas which would as a consequence be subject to erosion or inundation. Natural systems which are a natural defence to erosion and/or inundation should be identified and their integrity protected (DoC, 2008).

Farewell Spit lies in an area of relatively little tectonic uplift and is therefore an ideal case study for barrier change in respect sea-level rise. Farewell Spit is also a globally recognised 'Wetland of International Importance' (Ramsar, 1992) and a unique landform within New Zealand. Furthermore, it has been submitted to the United Nations Educational, Scientific and Cultural Organisation (UNESCO) tentative list for nomination to become a 'World Heritage Site' (UNESCO, 2007). Although it is commonly assumed that the origin of the Spit is consistent with the stabilisation of the current sea-level (Gibb, 1979; Harris, 1990), no chronological studies have confirmed this. In fact, very few scientific investigations have been conducted in regard to this landform, with none quantitatively investigating its stability and sensitivity to sea-level 
change. This thesis intends to improve the understanding of the dynamic nature of Farewell Spit through the assessment of its evolution and past morphological change which will indicate its stability and therefore vulnerability to projected sea-level rise.

\subsection{Aim and Objectives}

\subsubsection{Aim}

The aim of this study is to establish the morphological stability of Farewell Spit and its potential response to projected eustatic sea-level rise.

\subsubsection{Objectives}

To achieve this, the following objectives have been set:

1. Provide a detailed geomorphic description of Farewell Spit.

2. Establish the geomorphic stability of the features on the Spit.

3. Establish an age chronology of spit and tidal flat development.

4. Establish areas vulnerable to seawater inundation and potential future inflow channels into Golden Bay.

\subsection{Outline of Thesis Structure}

This thesis is comprised of seven chapters. Chapter two reviews literature on the morphology and evolution of barriers and the processes involved with their response to sea-level rise, providing the theoretical context for this research. Chapter three provides the regional background of Farewell Spit, outlining its history and physical setting. Chapter four describes the field and laboratory techniques used to conduct this research and Chapter five presents the results obtained 
from these methods. Chapter six discusses the relevance of past morphological change on Farewell Spit from the field and lab evidence and its potential response to projected sea-level rise. Finally chapter seven presents the conclusions drawn from this research and recommends studies for future research. 


\section{Chapter Two: Concepts and Coastal Processes}

\subsection{Introduction}

Barriers are coastal landforms which function as a 'barrier' between fully marine and terrestrial environments (Hesp \& Short, 1999), providing protection from direct ocean energy (Stauble, 1989). These landforms can form over multiple sea-level cycles and occur along $10-20 \%$ of the world's coastline (Stauble, 1989). A barrier may be defined as: a shoreparallel, elongated bank composed of sand to cobble sized sediment, formed by wave, tide and aeolian processes; exhibiting both a seaward beachface and a landward facing backbarrier slope which are not tidally submerged (Fisher, 1982; Whittow, 1984; Shepherd \& Hesp, 2003; Orford, 2004). While a range of sediments can form barriers, this review will concentrate on sand dominated barriers (SDB), the focus of this study.

Leatherman (1979) describes the major environments of a barrier island system being beaches, dunes, dune ridges, barrier flats, salt marshes, washover fans, subaerial spits and tidal flats. Oertal (1985) extended this to also include the mainland, inlets, flood and ebb tide deltas, barrier platform and the entire shoreface (figure 2.1). Exploring how these systems have responded to previous sea-level fluctuations is critical to understand if their future response is to be predicted. 


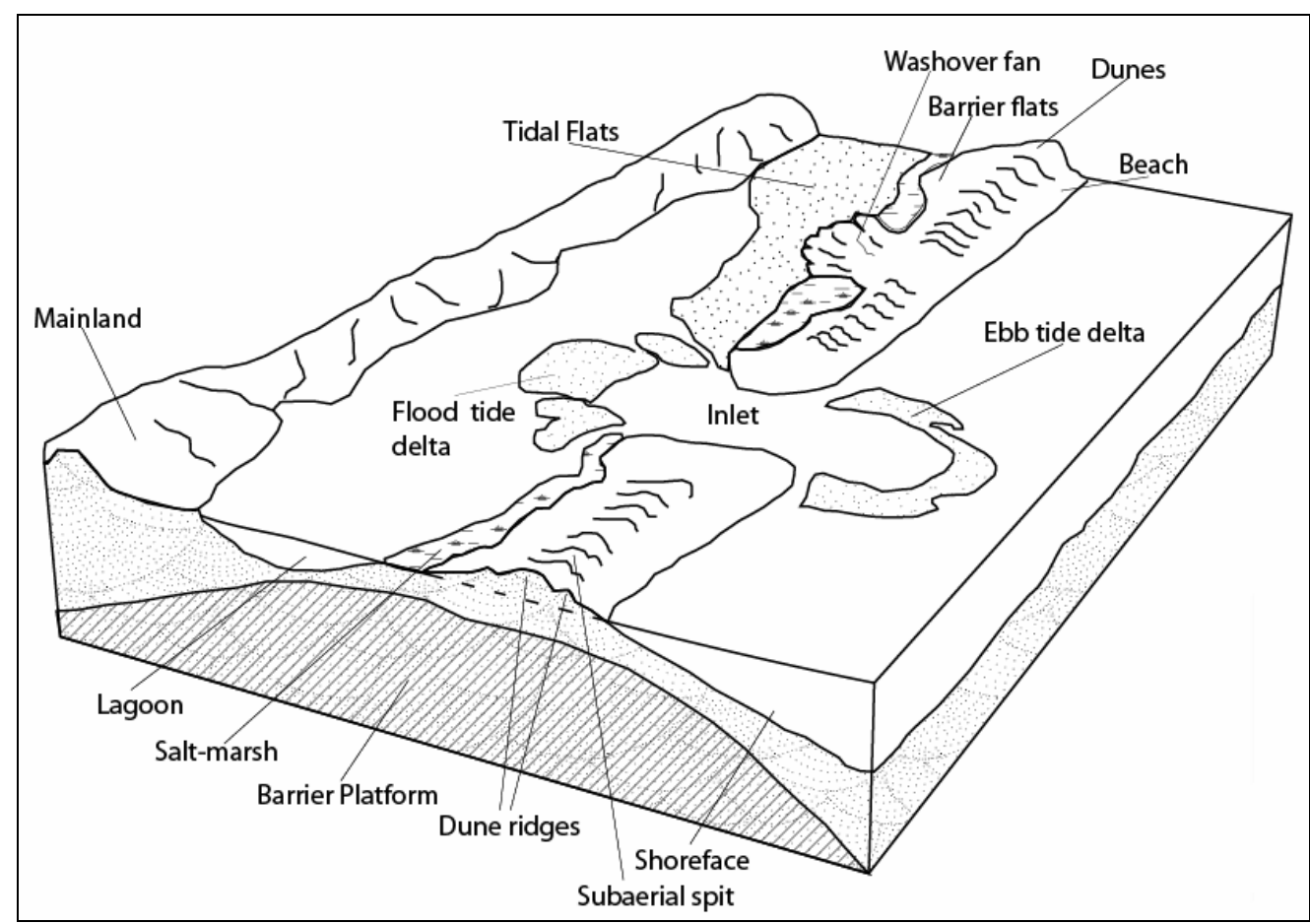

Figure 2.1: Barrier island system portraying the relationship between the six elements of a barrier island (after Cooper, 1994 In Carter \& Woodroffe, 1994).

When a sufficient sediment supply is maintained the general morphology of a barrier system is primarily controlled by the region's hydrographic regime (Fitzgerald et al., 1984), where wave energy is sufficient enough to transport sediment (Woodroffe, 2002). In relation to sediment transport processes, wave dominated shorelines occur where wave action dominates over the tidal action (Heward, 1981). These barriers are characteristically long and either straight or smoothly arcuate (figure 2.2A), generally with moderate to very well sorted sand (Davis \& Hayes, 1984).

After a barrier is formed tides can modify its shape (Orford, 2004), for example, as tidal range increases drumstick shaped barriers form with more inlets than their wave dominated counterparts (figure 2.2B). Table 2.1 shows a simplified classification for the general characterisation of barrier morphology based on tidal range, for coasts with moderate wave energy. During stillstand conditions tidal energy may become influential. Large tidal prisms (volumetric difference of the water between high and low tides) in the backbarrier lagoon area create a greater tidal energy 
acting on the morphology of barriers (Davis \& Hayes, 1984; Woodroffe, 2002). An increase in size or numbers of inlets along the barrier coasts occurs as the volume of water, dictated by the tidal prism and size of the backbarrier lagoon, increases (Davis \& Hayes, 1984). The energy of which can scour out sediment from the inlets base, creating ebb tide deltas on the ocean side of the barrier. In this way larger tidal prisms can also prevent the mending of post storm breaches (Orford, 2004), forming it into another inlet for water discharge. Conversely, inlets between the East Frisian Islands have narrowed since 1650 due to a $30 \%$ reduction of backbarrier region through infilling by both natural and unnatural means (Fiztgerald et al., 1984).

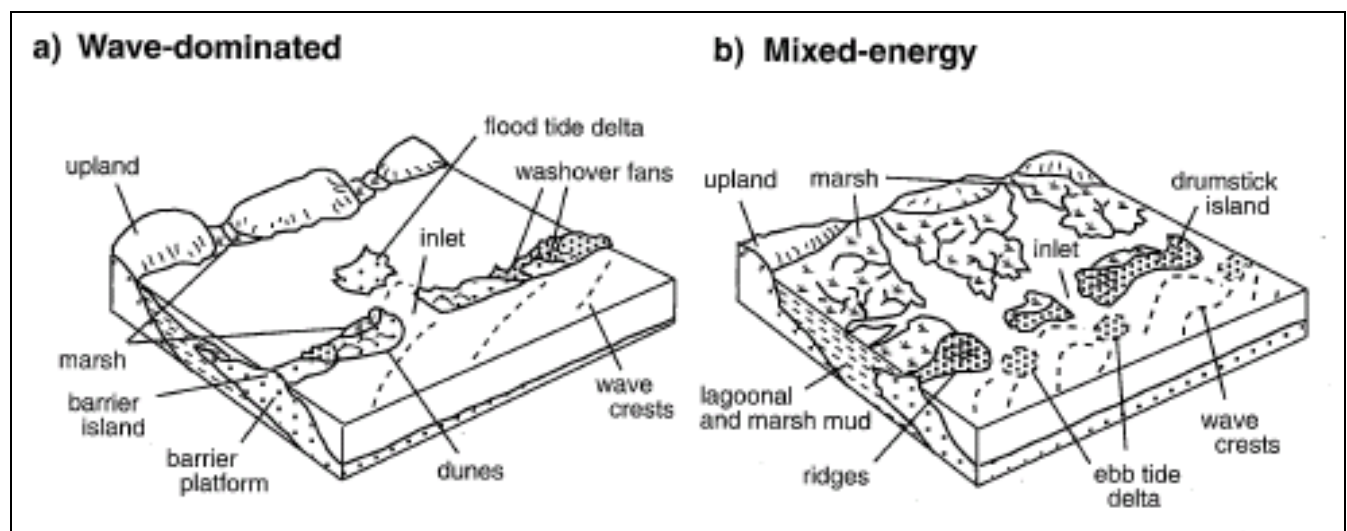

Figure 2.2: Morphology of barrier islands in A) waved dominated and B) mixed energy environments (Woodroffe, 2002) 
Table 2.1: Morphological features of barriers developed from differing energy regimes as classified by Davis \& Hayes (1984).

\begin{tabular}{|c|c|c|c|c|}
\hline Classification & $\begin{array}{l}\text { Tidal } \\
\text { range }\end{array}$ & $\begin{array}{l}\text { Dominant } \\
\text { process }\end{array}$ & Morphological features & Examples \\
\hline Microtidal & $<1 \mathrm{~m}$ & Waves. & $\begin{array}{l}\text { Long and straight. } \\
\text { Prominent washover } \\
\text { features. } \\
\text { Widely spaced inlets. } \\
\text { Developed flood tide } \\
\text { deltas. } \\
\text { Small or nonexistent ebb } \\
\text { deltas. }\end{array}$ & $\begin{array}{l}\text { Gulf of } \\
\text { Mexico } \\
\text { Coast. }\end{array}$ \\
\hline $\begin{array}{l}\text { Low- } \\
\text { mesotidal }\end{array}$ & $1-2 m$ & $\begin{array}{l}\text { Mixed tidal } \\
\text { and wave } \\
\text { energy, } \\
\text { however } \\
\text { wave } \\
\text { energy is } \\
\text { dominant. }\end{array}$ & $\begin{array}{l}\text { Short wide barriers. } \\
\text { Drumstick configuration. } \\
\text { Closely spaced inlets } \\
\text { increasing in number. } \\
\text { Diminishing washovers. } \\
\text { Well-developed ebb } \\
\text { deltas. }\end{array}$ & $\begin{array}{l}\text { New Jersey } \\
\text { Coast. }\end{array}$ \\
\hline $\begin{array}{l}\text { High- } \\
\text { mesotidal }\end{array}$ & $2-3.5 m$ & $\begin{array}{l}\text { Mixed tidal } \\
\text { and wave } \\
\text { energy, } \\
\text { however } \\
\text { tide } \\
\text { energy is } \\
\text { dominant. } \\
\end{array}$ & $\begin{array}{l}\text { Drumstick configuration. } \\
\text { Abundant tidal inlets. } \\
\text { Large ebb tide deltas. }\end{array}$ & $\begin{array}{l}\text { Georgia and } \\
\text { South } \\
\text { Carolina } \\
\text { Coasts. }\end{array}$ \\
\hline $\begin{array}{l}\text { Low- } \\
\text { macrotidal }\end{array}$ & $3.5-5 m$ & Tidal. & $\begin{array}{l}\text { Wave built bars may be } \\
\text { present. } \\
\text { Barriers not developed. }\end{array}$ & $\begin{array}{l}\text { North Sea, } \\
\text { German } \\
\text { Bight. }\end{array}$ \\
\hline Macrotidal & $5 \mathrm{~m}$ & Tidal. & $\begin{array}{l}\text { Tidal-current formed } \\
\text { ridges. } \\
\text { Extensive tidal flats and } \\
\text { marshes. } \\
\text { Barriers not developed. }\end{array}$ & $\begin{array}{l}\text { Bay of } \\
\text { Fundy, } \\
\text { Canada. }\end{array}$ \\
\hline
\end{tabular}

Over timescales of years to decades sandy barriers are reasonably stable and with sufficient sediment supply will grow with a rising sealevel (Eitner, 1996). Long-term barrier behaviour however, depends on sediment supply rates, sea-level rise and wave and tidal dynamics (SCOR, 1991; Eitner, 1996; Klein \& Lichter, 2006). Although numerous factors can cause morphological change in sandy barriers, 'isolating the influence of sea-level rise from these is perhaps the biggest challenge in discerning its impact' (Cooper \& Pilkey, 2004 p158). 


\subsection{Barrier types and evolution}

Barriers can be defined on their evolution in relation to sea-level; specifically transgressive, stillstand and regressive. In New Zealand the last period of major sea-level change occurred during the late Pleistocene and Holocene when seas rose $>120 \mathrm{~m}$ from the LGM (figure 2.3) (Fairbridge, 1976; Gibb, 1986; Hilton \& Nichol, 2003). This postglacial marine transgression ceased around 7ka in New Zealand and was the major driver behind contemporary barrier development.

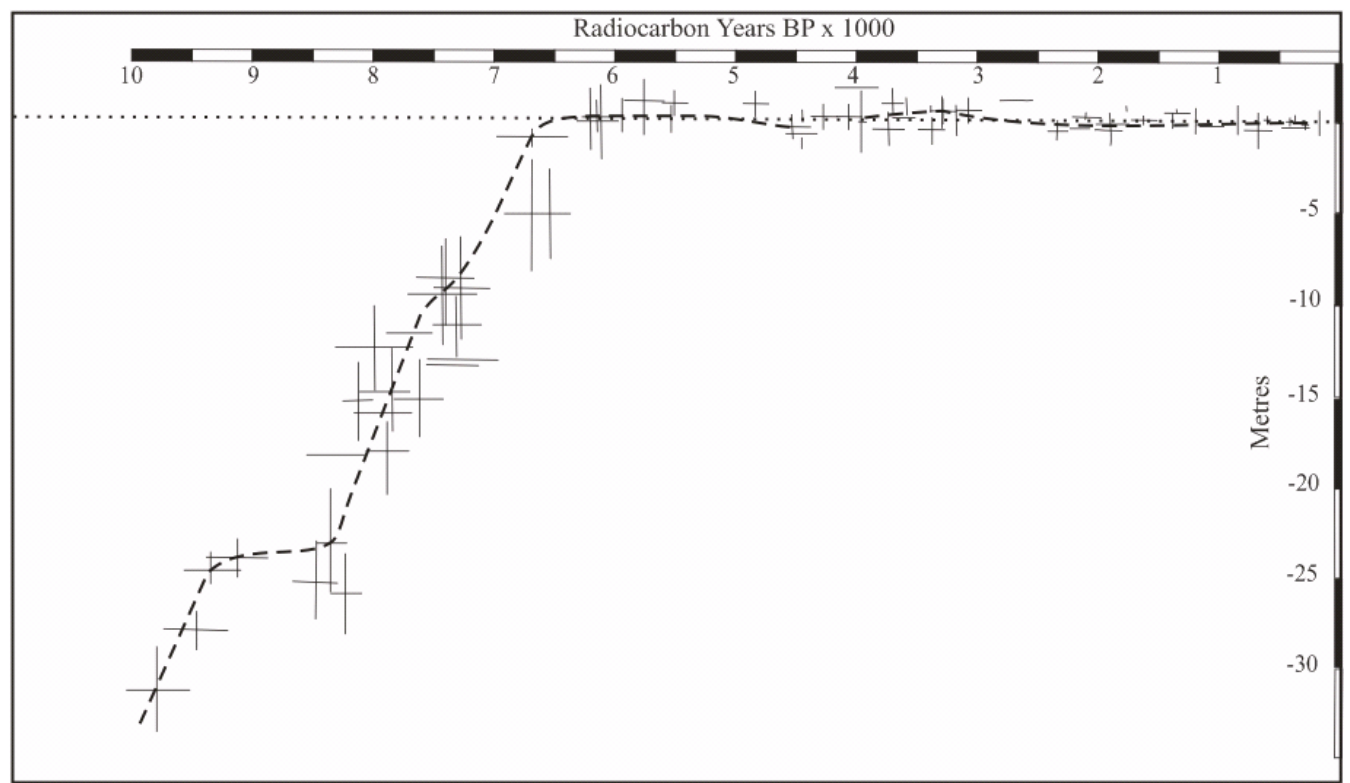

Figure 2.3: New Zealand regional Holocene eustatic sea-level curve, from 10ka to present (after Gibb, 1986).

Whether a barrier forms during sea-level movements depends on; A) the shelf slope, B) the antecedent topography and C) the sediment supply. SDB require initial shelf slopes of low angle $\left(<1^{\circ}\right)$ to allow for sediment accumulation (Shepherd \& Hesp, 2003; Orford, 2004). However, barriers will not develop on these low angled shelves if the longshore sediment transport equals or exceeds inflows (Shepherd \& Hesp, 2003). Offshore gradients $\left(>1^{\circ}\right)$ result in attached strandplains or net offshore sediment transport (Roy et al., 1994; Shepherd \& Hesp, 2003) as the steeper substrate does not allow for sediment accumulation. 
Certain coastal configurations also favour barrier formation, such as embayments and projecting headlands which trap sediment, for example Kaitorete Spit abutting against Banks Peninsula, New Zealand (Shepherd \& Hesp, 2003). Coastal salients formed by refracting waves and abrupt changes in shoreline direction cause sediment accumulation like the cuspate foreland extending out in the lee of New Zealand's Kapiti Island and Farewell Spit respectively (Woodroffe, 2002, Shepherd and Hesp, 2003). Barrier form should also be considered a palimpsest, as the contemporary landform is influenced by the configuration of the underlying platform (Orford, 2004). For example, antecedent topography such as Pleistocene outwash plains provides the substrate for barriers to overlie the Skallingen barrier spit complex, Denmark, is a good example of this (Christiansen, 2004).

Local sediment budgets are determined by rates of sea-level rise, sources of sediment supply and wind and wave generated energy (Shepherd \& Hesp, 2003; Chang et al., 2006). During the last marine transgression large volumes of fluvial, coastal and near shore sediments were eroded and then reworked landward to be deposited onshore, forming depositional landforms (Hilton \& Nichol, 2003). During stillstand conditions sediment transport on the inner shelf and nearshore is more a function of regional-scale currents and wave derived longshore transport (Boyd \& Penland, 1984; Goodwin, 2005) carrying sediment into the barrier system. Losses from the barrier occur through inlets, overwash, wind, longshore and off shore transport (Pierce, 1969; Sanchez-Arcilla \& Jimenez, 1994), although most of this migrates into the backbarrier lagoon and therefore not lost to the barrier system altogether. Of the estimated $90,000 \mathrm{~m}^{3} / \mathrm{y}$ sand supply emerging along the $13 \mathrm{~km}$ long Skallingen spit from the mid-lower shoreface, $\sim 65,000 \mathrm{~m}^{3} / \mathrm{y}$ is transported to the dunes, while the remainder is diverted to the tidal inlet (Aargaard et al., 2004a). This spit also lost an average of $641,000 \mathrm{~m}^{3} / \mathrm{y}$ of sediment through longshore drift from $1970-1999$, 
with especially large losses during high storm period 1980 - 1989 (Christiansen et al., 2004). This has led to an overall deficit in the total sediment budget for this spit, whereas 30 years ago it was positive. Aargaard et al. (2004b) consider this sediment loss by increased net transport to be due to long term changes in wind climate and dredging around the inlet. Not all sediment lost from the tip is lost to the system however; with a proportion transported to the tidal flat which has a recorded volume gain of $460,000 \mathrm{~m}^{3}$ from 1952 - 1999 (Christiansen et al., 2004). The long term accumulation of the tidal flat $(\sim 1 \mathrm{~mm} / \mathrm{y})$ is close to the average sea-level rise for this area (Christiansen et al., 2004).

As most systems are open to modern sediment input, large scale continental shelf and inner shelf reservoirs are important offshore sediment sources for high energy coasts (Hilton \& Nichol, 2003). Skallingen has experienced a persistent onshore sediment supply over the last 30 years from the nearshore bars migrating up the shoreface and into the intertidal zone; mainly driven by major storms. These move $\sim 20-30 \mathrm{~m} / \mathrm{y}$, eventually welding onto the beach-face at intervals of 8yrs (Aargaard et al., 2004a). This bar welding creates short periods of shoreline progradation where the subaerial sand becomes dry and available for wind transport and dune building.

Sediment supply rates can also dictate the elevation of a barrier. Where sediment supplies are small, low profile (low relief) barriers occur (Komar, 1998) such as the Chandeleur Isles and Isles Derniere, Louisiana (Culver et al., 2007). These are vulnerable to overwash from storm surge and consequential landward migration or collapse. Whereas, high profile barriers like Mustang Island, Texas, are closer to the sediment source and form higher dune ridges (Komar, 1998). These are less susceptible to storm surge and as the dunes are effective in preventing barrier breaching from all but the most extreme storms, less 
material delivery to the backbarrier environment occurs (Simms et al., 2006).

\subsubsection{Transgressive barriers}

"Transgressive barriers are essentially transitory features which maintain themselves in dynamic equilibrium with rising sea-levels" (Roy et al., 1994. p131). Once the barrier has developed, continued sea-level rise can activate a landward recycling of sand where seaward sediments roll-over landward through overwash processes. This causes the shoreface to retreat (Boyd \& Penland, 1984; Komar, 1998). In an ideal state the vertical stratigraphic sequences of a transgressive barrier would be; fringing marsh at the bottom overlain by lagoon, sublagoonal sands, backbarrier marsh, washovers and dunes at the top (figure 2.4) (Kraft \& John, 1979). However, sediment signatures of a transgressive barrier are difficult to define because as sea-level rise continues, erosion of the shoreline and nearshore persists. In addition, transgressive sequences from past sea levels are commonly intermixed with regressive ones (Kraft \& John, 1970). Thus recognition of muds from the lagoon or nearshore within a core is the only way of proving transgression or regression from a single stratigraphic section (Kraft \& John, 1979). 


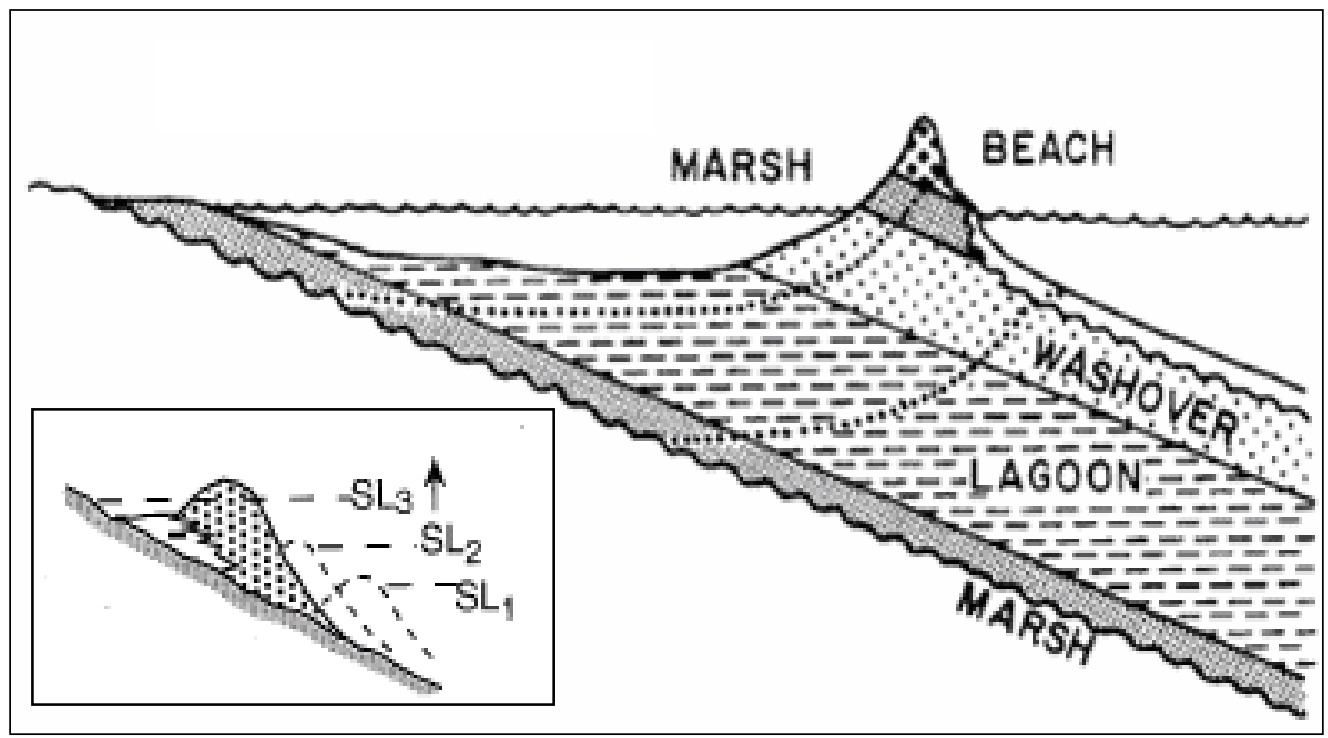

Figure 2.4: Sequence model of a transgressive barrier showing stratigraphic layers of seaward sediment overlying more landward ones (Simms et al., 2006). Inset: the inland progression of a barrier under marine transgression (Woodroffe, 2002).

Two phases of sea level related erosion can occur on barrier coasts (Sanchez-Archilla \& Jimenez, 1994), the first phase is wave energy moving sediment offshore when the water level is less than the barrier height. As the intensity of storms increases the second phase occurs where the wave swash crosses the threshold of the barrier in a unidirectional flow, causing an onshore sediment movement (SanchezArchilla \& Jimenez, 1994; Orford, 2004; Matias et al., 2007). Overwash events occur with super-elevation of the sea level in relation to barrier height which is particularly prevalent during extreme and severe storms and within washout channels and dune depressions on low lying barriers (Matias et al., 2007). The process redistributes sand within the barrier system, often breaching the primary dune, moving sediment from the beach onto the barrier top/rear, forming a fan or sheet-like like washover (figure 2.1) (Leatherman, 1979). Overwash may also act simultaneously with offshore and longshore transport to produce barrier breaching, which can produce new inlets (Sanchez-Arcilla \& Jiminez, 1994). The long term result of these processes is the shoreline retreat and landward movement of the entire barrier (SCOR, 1991). 
Washovers can provide a substantial amount of sediment to the subaerial barrier, especially in non vegetated stages of barrier development, and can open way for substantial sediment supply from continued overwash for many years (Zaremba \& Leatherman, 1986; Christiansen et al., 2004). They also result in a subaqueous sedimentation base build-up in the backbarrier bay which creates an area where the barrier can migrate landward over; the potential speed of this migration becomes faster as the backbarrier area becomes shallower (Orford, 2004). More than $50 \%$ of the total sediment on Skallingen is made up of overwash deposits, where its landward migration has been recorded as $3.5 \mathrm{~m} / \mathrm{y}$, concurrent with an average sea-level rise of $1.3 \mathrm{~mm} / \mathrm{y}$ over the last 100 years (Christiansen et al., 2004). The development of dunes which may either block or spatially reduce the consistency of overwash episodes can significantly reduce this sedimentation (Orford, 2004; Matias et al., 2007). Greater dune complexity can develop on mixed energy barrier islands such as along the coast of Georgia, United States, because of their higher elevation (Stallins, 2002).

Severe washovers which breach barriers can either infill, remaining as washover features, or, become new inlets if the breach is hydraulically efficient (Matias et al., 2007). Barrier islands developed from the breaching of sand spits was suggested by Gilbert as a theory barrier island evolution in 1885 (figure 2.5) (Oertal, 1985). This assumes overwash events lead to inlets breaking through the spit barrier, ultimately creating islands (Shepard, 1963; Fisher, 1968; Bird, 1969; Eitner, 1996). Penk used the term nehrungsinsel (spit islands) in 1894 to describe the Frisian barrier islands, off the Netherlands and German coasts, which were formed by this process (Woodroffe, 2002). 


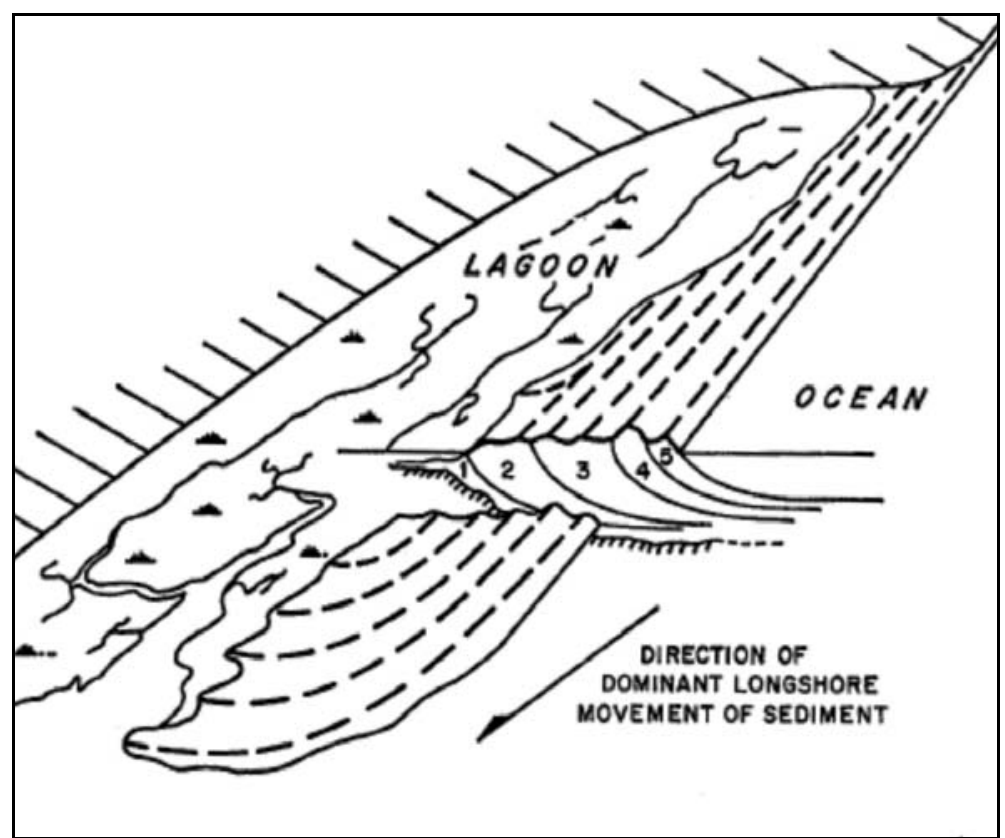

Figure 2.5: Formation of a barrier islands through the breaching of sand spit (Fisher, 1968 in Schwartz, 1971).

Barrier breaching is an important driving force in the evolution of a barrier coast as it can also modify the original sediment budget and transport system, thereby altering the coastal morphology (SanchezArcilla \& Jimenez, 1994). An extreme case of change in coastal morphology occurred in the former Isle Dernier, Louisianna, United States, which broke up to the current Isles Derniers over 100 years, through the formation of inlets, in response to a subsidence induced relative sea-level rise of $0.9 \mathrm{~m}$ per century (figure, 2.6) (Titus, 1990). 


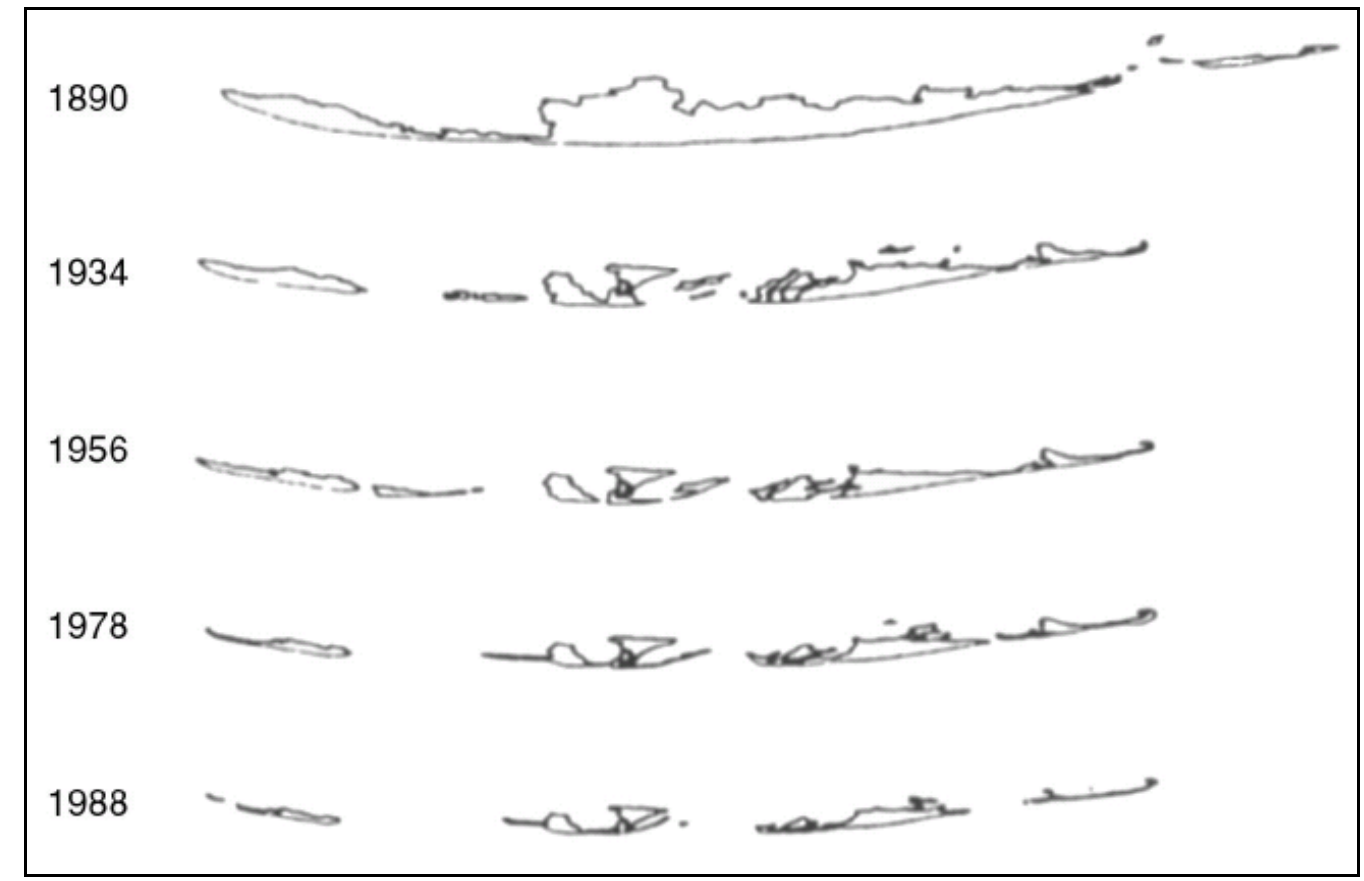

Figure 2.6: The break up of Isle Derniere, Louisiana, from local subsidence induced RSL rise of $0.9 \mathrm{~m}$ per century (Titus, 1990).

Barrier evolution has historically been placed into three main theories; sand spit breaching, drowning of coastal features and emerging offshore bars. However, the discrepancy in the literature, particularly citing the same regions as examples of more than one of the above hypotheses (Hoyt, 1967; Otvos, 1970) shows that these theories are not mutually exclusive. Individual barriers proving each of these theories are most likely to be locally significant case studies, rather than globally applicable. While research during the latter half of the twentieth century has shown that these models may work independently or together to form barriers (Schwartz, 1971). Schwartz (1971) although recognised each of the barrier evolution theories as being valid, advocated the importance of accepting multiple causality of barrier island emergence.

The East Frisian Islands, Netherlands, development likely occurred as a two stage model. First the transgression of the North Sea inundated the lower coastal valleys such as suggested by McGee's 1890 classic theory of barrier development by in situ drowning of coastal ridges (figure 2.7) (Oertel, 1985; Schwartz, 1971; Woodroffe, 2002), with wave 
action transforming the Pleistocene ridges into sand spits (Eitner, 1996). Secondly these spits then detached from the mainland through modification by further ocean transgression to form the islands (Eitner, 1996).

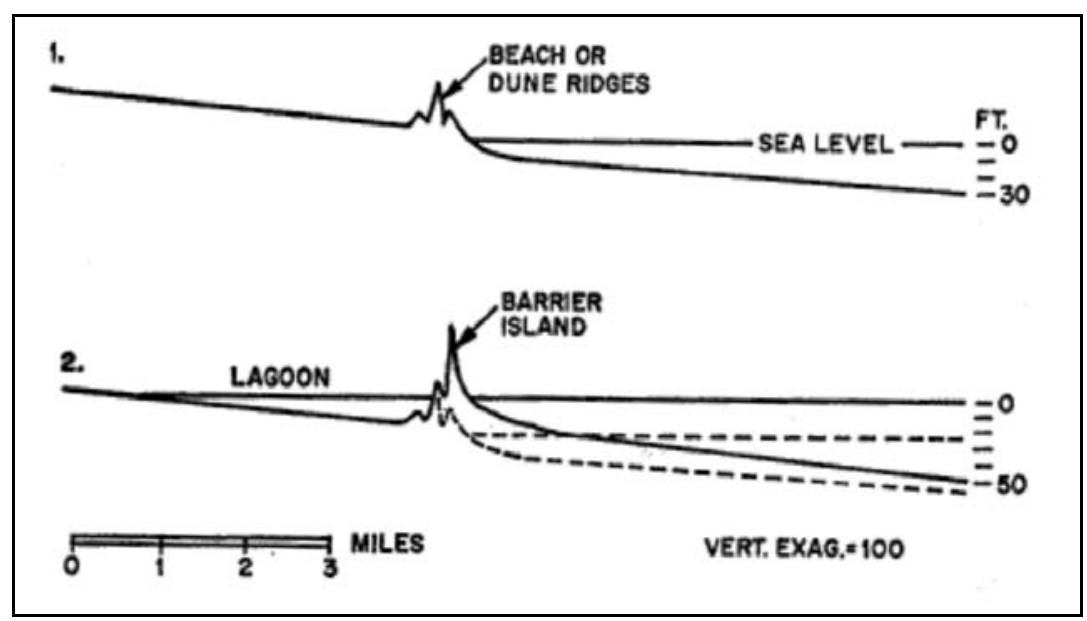

Figure 2.7: Formation of barrier islands by submergence of beach or dune ridge (Hoyt, 1967).

\subsubsection{Stillstand barriers}

Stillstand barriers include those formed at current sea-levels, such as barrier spits, as well as modifications of those which have transgressed from the shelf. The major stillstand barriers can take the form of transgressive, prograded, stationary, receeded barriers or headland spits (figure 2.8)

Transgressive barriers during stillstand conditions refer to the landward movement of the barrier in the form of aeolian sand sheets, which can include complex foredunes (Woodroffe, 2002). Stationary barriers usually have a complex foredune structure and form through the rapid accretion of sand from an offshore supply which then becomes depleted (Woodroffe, 2002). Whereas, if the supply remains constant prograded barriers (strandplains) occur, such as Galveston and Matagorda Islands, Gulf of Mexico, which grow in a seaward direction in a series of ridges (Roy et al., 1994; Blum et al., 2002; Woodroffe, 2002). Receded barriers 
occur because of a negative sediment imbalance during stillstand conditions (Roy et al., 1994). They are narrow and retreat landward over backbarrier sediments which may become exposed on the foreshore (Woodroffe, 2002).

Barrier spits are attached to the mainland at one end, extending into open water. These can have prograded, stationary and receded morphologies depending on the onshore and longshore sediment supply balances (Roy et al., 1994), and can form across the mouths of estuaries, or like Farewell Spit at abrupt changes in shoreline direction. Headland spits form during a stillstand, growing alongshore in response to a dominant littoral drift direction. The barrier sand of headland spits can overlie bay or shallow shelf facies, while barrier island spits are superimposed on old eroded substrates or lagoonal backbarrier strata (Roy et al., 1994

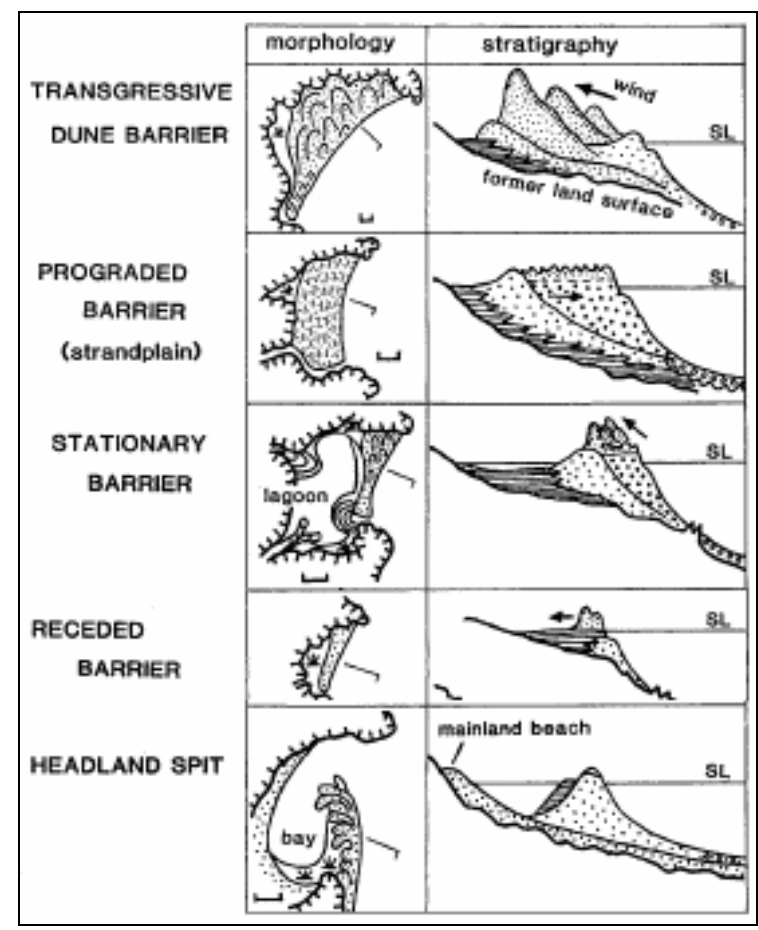

Figure 2.8: Generalised morphology and stratigraphy of major stillstand barrier types (Roy et al., 1994). 
Several young barriers have formed along the northern and eastern Gulf of Mexico Coast since 1960, displaying evidence of upward shoaling barrier evolution (Otvos, 1970; Davis et al., 2003). These are examples of de Beaumont's 1845 emerging offshore bar theory which suggests that the continual accumulation of sediment upon offshore bars elevate these features above sea-level, ultimately forming barriers (figure 2.9) (Shepard, 1963; Bird, 1969; Schwartz, 1971; Oertel, 1985; Eitner, 1996). Evans (1942) however, has argued the breaking of waves on bars and platforms more readily erodes sediment than builds it up and may thereby inhibit barrier formation (Woodroffe, 2002).

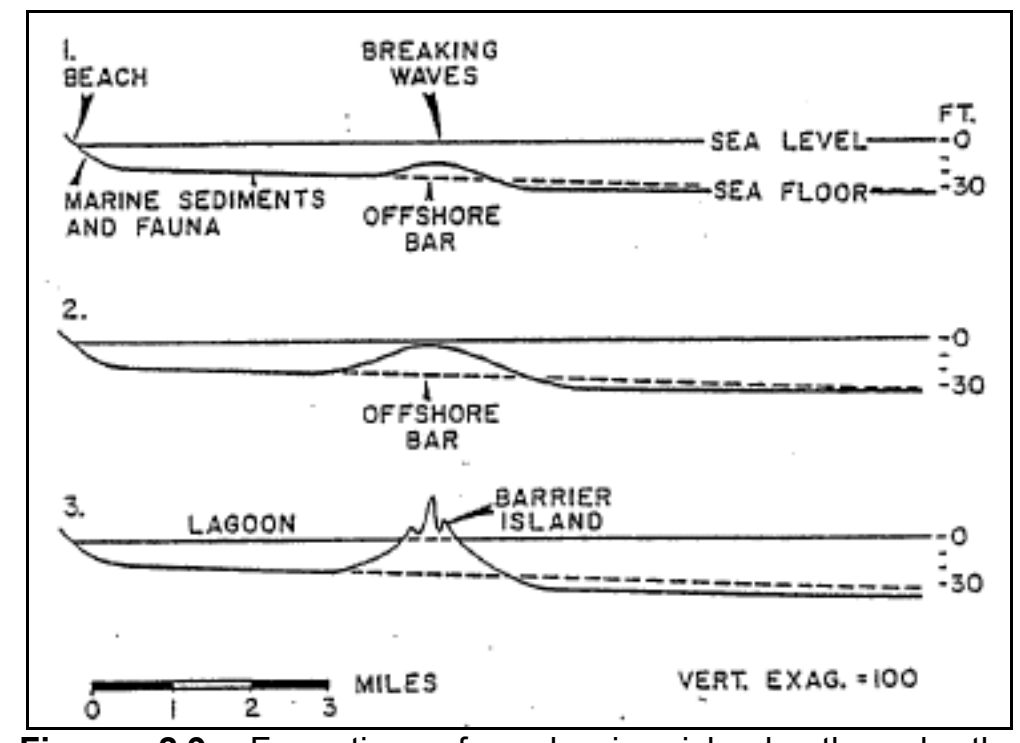

Figure 2.9: Formation of a barrier islands through the emergence of offshore bars (Hoyt, 1967).

\subsubsection{Regressive barriers}

Little is known about barriers in terms of the effects of marine regression and most field evidence comes from coasts undergoing tectonic or isostatic uplift (Roy et al., 1994). Under these conditions the barrier tends to move seaward (figure 2.10 inset) leaving a seaward dipping stratigraphic sequence of dune and beach sediments on top of shallow marine units (figure 2.10) (Kraft \& John, 1979; Komar, 1998). However, this stratigraphic sequence can result purely because of an excess in sediment supply (Eitner, 1996). 


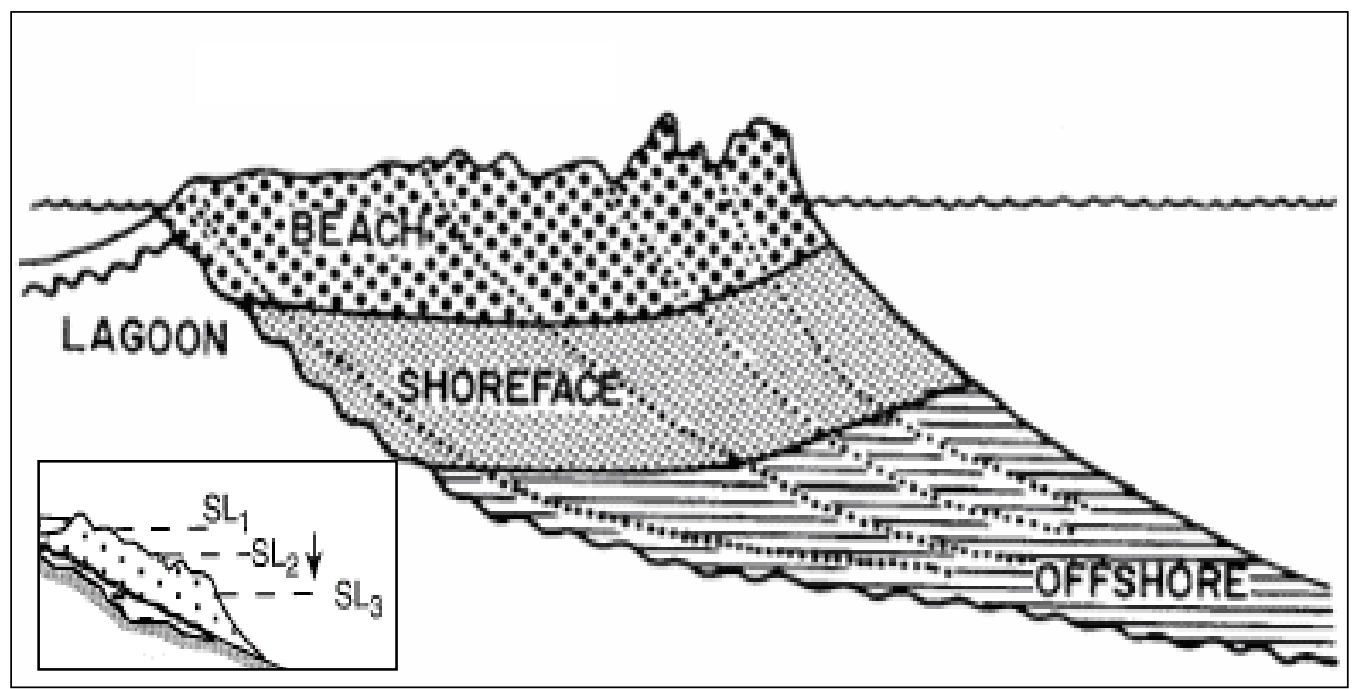

Figure 2.10: Sequence model of a regressive barrier showing stratigraphic sequences of landward sediment overlying marine sediments (Simms et al., 2006). Inset: the seaward progression of a barrier under marine regression (Woodroffe, 2002).

\subsection{Storms and barrier modification}

Large scale barrier modification can occur through storm events, this may especially occur on those which are sediment starved or subject to significant human modification. The collapse of parts of the Chandeleur Isles, Gulf Coast, which were eroded to below sea-level, by the effects of Hurricanes Ivan (2004) and Katrina (2005), illustrates the ephemeral nature of some low profile barriers (Culver et al., 2007). The temporal diversity in the magnitude and frequency of storm events also has significant effects on the relative importance of wind and washover processes. The high winds related to the Little Ice Age period (16 - 19 $9^{\text {th }}$ centuries) induced storm surge activity which initiated transgressive dune building in Western Europe (Knight et al., 2002). The beginning of dune formation on Skallingen for example directly correlates to the major peak in storm surge frequency from 1820 - 1850 (Aargaard et al., 2007). 


\subsection{Sea-level rise and barrier/ sandy shoreline response}

While barriers may form during periods of sea-level rise, how they respond to changes such as associated with projected human induced climate change is less well understood. Predicting future shoreline change relating to sea-level rise forecasts is a key area for coastal scientists and managers to prepare appropriate policy. Quantitative predictions of shoreline erosion are used as coastal management tools, although with so many uncertainties involved it is unwise to assume the results as absolute (Healy, 1991). However, the potential for barrier erosion, translation and potential destruction in relation to sea-level rise are important issues for continued investigation.

\subsubsection{The Bruun rule}

One of the most common tools used to assess the potential change of a sandy shoreline in respect to sea-level rise is the Bruun Rule (Cooper \& Pilkey, 2004). This is a two dimensional model which assumes equilibrium of both initial and resultant shoreline profiles in the upward and landward movement of both the beach and shallow offshore environments (figure 2.11) (Komar 1998; McLean,). It assumes that the shape of the profile is constant throughout the erosion process as sediment is transported to the lower shoreface but not lost from the system (Komar 1998; McLean, 2004). The profile therefore maintains a constant water depth as the profile rises with sea-level. Bruun's relationship for shoreline retreat to sea-level rise is represented as equation 2.1. 


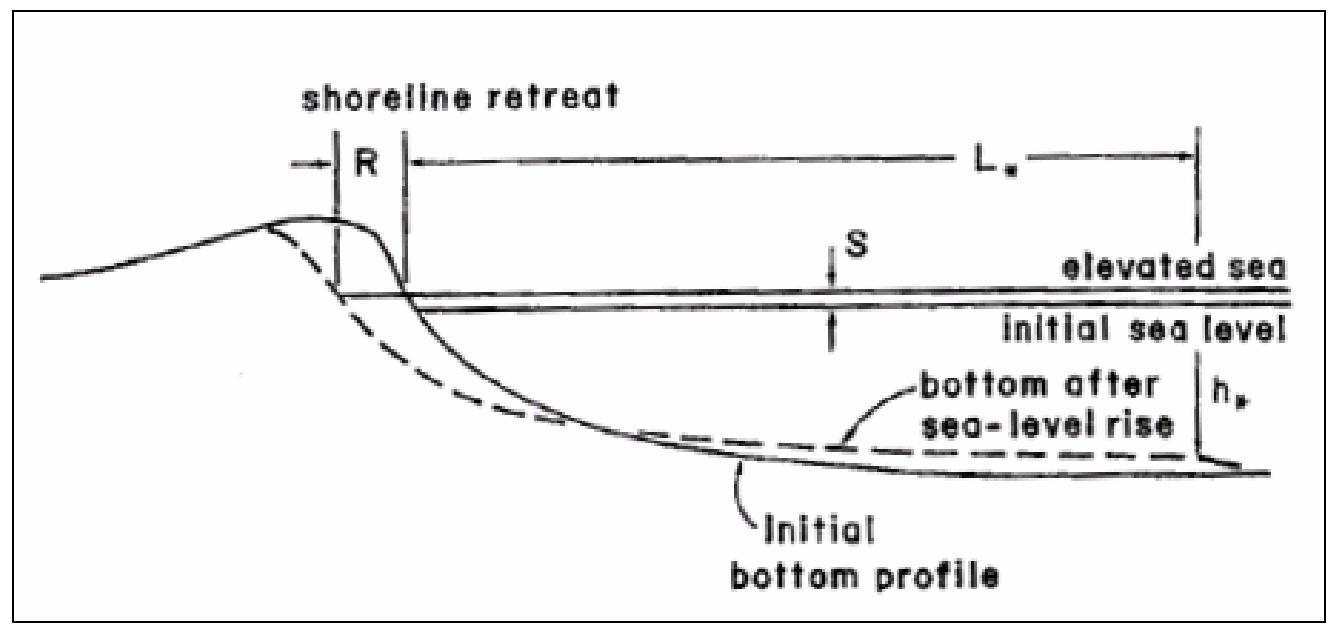

Figure 2.11: Sea-level rise induced beach profile change according to the Bruun rule (Komar, 1998).

$$
R=\frac{L_{\star}}{B+h_{\star}} S
$$

Where $R$ is shoreline retreat, $L$ * the cross-shore distance to $h$ * (water depth in which nearshore sediments occur), $B$ height of eroded area such as the berm or dunes and $S$ the sea level increase (Komar, 1998). A more simplified version of this is expressed in equation 2.2:

$$
R=\frac{1}{\tan \theta} S
$$

Here $\tan \theta=(B+h *) / L *$ represents the average slope of the crossshore width profile $(L *)$; generally most coastal sites lie within the range of $\tan \theta \approx 0.01-0.02$ (Komar, 1998). This simple concept for quantifying shoreline retreat gives a general ratio of erosion being 50 to 100 times the rise in sea level (McLean, 2004). Therefore the IPCC predicted rise in sea level of $0.48 \mathrm{~m}$ would result in a maximum beach recession of $\sim 48 \mathrm{~m}$. 
The Bruun rule is however contentious because of it's 'one model fits all' over simplicity, as it is assumed to work on all sandy coastlines regardless of local controlling factors such as geomorphological or sedimentological characteristics (Cooper \& Pilkey, 2004). Other major issues related to the Bruun rule include, the potential of shoreline accretion under sea-level rise due to the possibility of large amounts of sediment in the nearshore zone (Thom, 1983); the lack of consideration for the loss of sediment offshore, especially under storm conditions (Wright et al., 1991); the lack of criteria for establishing the dynamic equilibrium of the shoreline (Healy, 1991); and it accounts only for the offshore removal of sediment, which is not appropriate for the case of barriers where overwash processes occur (Oertal, 1985; Dubois, 2002). However, the Bruun rule has provided a flexible enough basis for a number of other models to be derived from it. Several of the adapted models include the landward deposition of sediment (Dubois, 1977), and the storm erosion of dunes and beaches (van de Graaff, 1977; Vellinga, 1982; Kreibel \& Dean, 1985).

\subsubsection{Barrier Island Model}

Dean and Maurmeyer (1983) produced a model for overwash and inlet processes moving sediments from the beach to the backbarrier environment. This results in the landward and upward movement of sediment within the Barrier Island Model (figure 2.12); expressed as equation 2.3. 


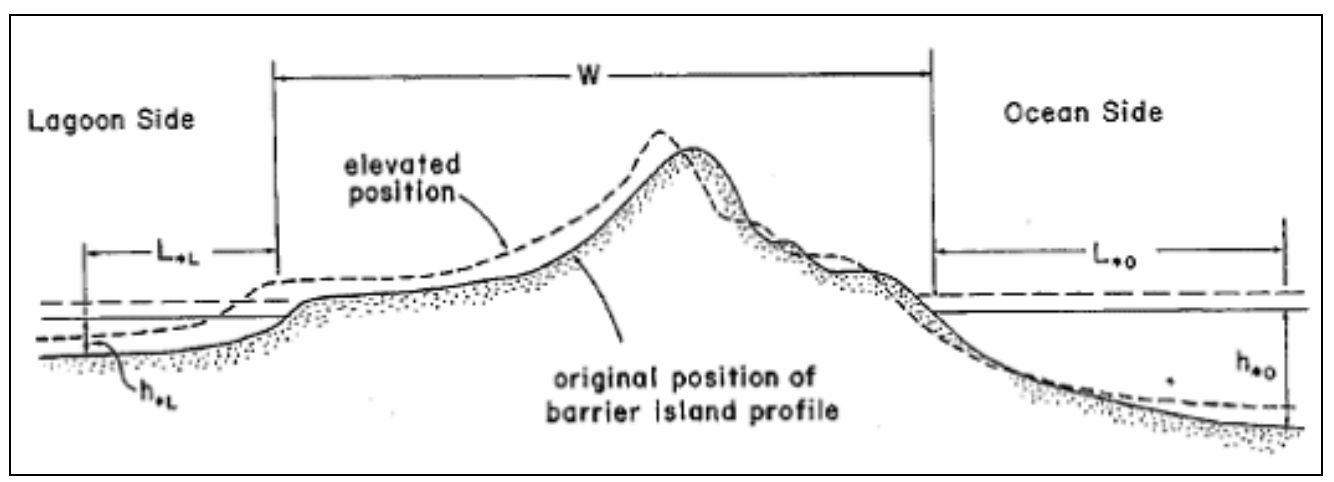

Figure 2.12: Sea-level rise induced profile change according to the Barrier Island Model (Komar, 1998).

$$
R=\frac{L_{\star 0}+W+L_{* L}}{\left(h{ }^{\prime} 0-h \times L\right)} S
$$

(Equation 2.3)

Where $L{ }^{*}$ and $L{ }^{*} L$ represent the active nearshore zone widths of the ocean and lagoon sides, while $h *^{*}$ and $h{ }^{*}$ are their respective water depths, and $W$ is the barrier islands width (SCOR, 1991). The above models however remain $2 \mathrm{D}$, where the sand volume remains in the system of the profile considered (SCOR, 1991). The third dimension was established by Hands (1980 In SCOR, 1991) and was later amended by Dean and Maurmeyer (1983) (equation 2.4), by including the sediment movement within the longshore as well as accounting for offshore losses of finer material.

$$
R=\frac{L_{*}}{P\left(B+h_{\star}\right)} S+\frac{\left(\partial Q_{s} / \partial \gamma\right) \Delta t}{\left(B+h_{*}\right)}
$$

Where $P$ is the decimal fraction of surf-zone compatible eroded sediment, and $ə Q_{S} / \partial y$ is the longshore gradient of the littoral drift (SCOR, 1991 p906). Increasing sediment transport within the littoral drift is indicated by $ә Q_{s}$ əy $<0$, producing erosion and therefore an 
increasing $R$ due to sea-level rise (SCOR, 1991). Komar (1998) states that the time lag between beach response to the rise in sea level cannot be accounted for in this model, which in climate change response times (decades to centuries) of barriers is not a large drawback as the lag time will eventually catch up. However, within shorter time spans such as EI Niño Southern Oscillation (ENSO) sea-level increases (months to years) this could be harder to account for as the lag time could be longer than the actual event.

Some recent computer models which are developed to simulate large scale coastal behaviour use the general shoreline movement of the Bruun model as an underlying principal (Cowell et al., 1995). These can include local coastal parameters such as substrate erodibility, sediment composition, density and porosity as well as sediment production and losses (Cowell et al., 1995; Stopler et al., 2005). The Shoreline Translation Model for example, is valid over longer time scales and modified to incorporate continuity of mass and the migration of shorelines as sea-level rises (Woodroffe, 2002), has been used to predict shoreline change in Australia.

\subsubsection{Storm wave susceptibility Quotient}

While estimating shoreline and barrier recession is imperative in coastal management, assessing a barriers vulnerability to erosion could be an equally important factor. Morgan and Stone developed the Storm Wave Susceptibility Quotient in 1985 (Sanchez-Arcilla \& Jiminez, 1994) which estimated the erosion susceptibility (ES) (equation 2.5) for barrier islands along the Florida coast. The resultant ES numbers range from 0 -1 , where higher numbers indicate a greater likelihood of erosion and barrier breaching. Sanchez-Arcilla and Jiminez (1994) Spanish study proved this to be useful, showing the index to be highest $(0.81)$ at the barrier section which suffered serious breaching, $800 \mathrm{~m}$ wide and $0.4 \mathrm{~m}$ deep (below MSL), resulting in the erosion of $70,000 \mathrm{~m}^{3}$ of sand from the 
beach face. The index calculates the vulnerability of a barrier to be eroded, higher values indicating a higher susceptibility (Sanchez-Arcilla \& Jiminez, 1994).

$$
E S=\frac{Z_{t}}{B_{h}^{2}+\sqrt{\left(X_{b w}+X_{b}\right) / 100}}
$$

Where $B_{h}$ is barrier height above mean sea level; $X_{b w}$, barrier width; $Z_{t}$, depth of the longshore bar top in front of barrier and $X_{b}$, the distance between longshore bar and shoreline (figure 2.13). $Z_{t}$, and $X_{b}$ limit the incidence wave height and wave energy dissipation respectively, thus are representative of wave energetics. Whereas $B_{h}$, and $X_{b w}$ represent the morphology of the barrier (Sanchez-Arcilla \& Jiminez, 1994).

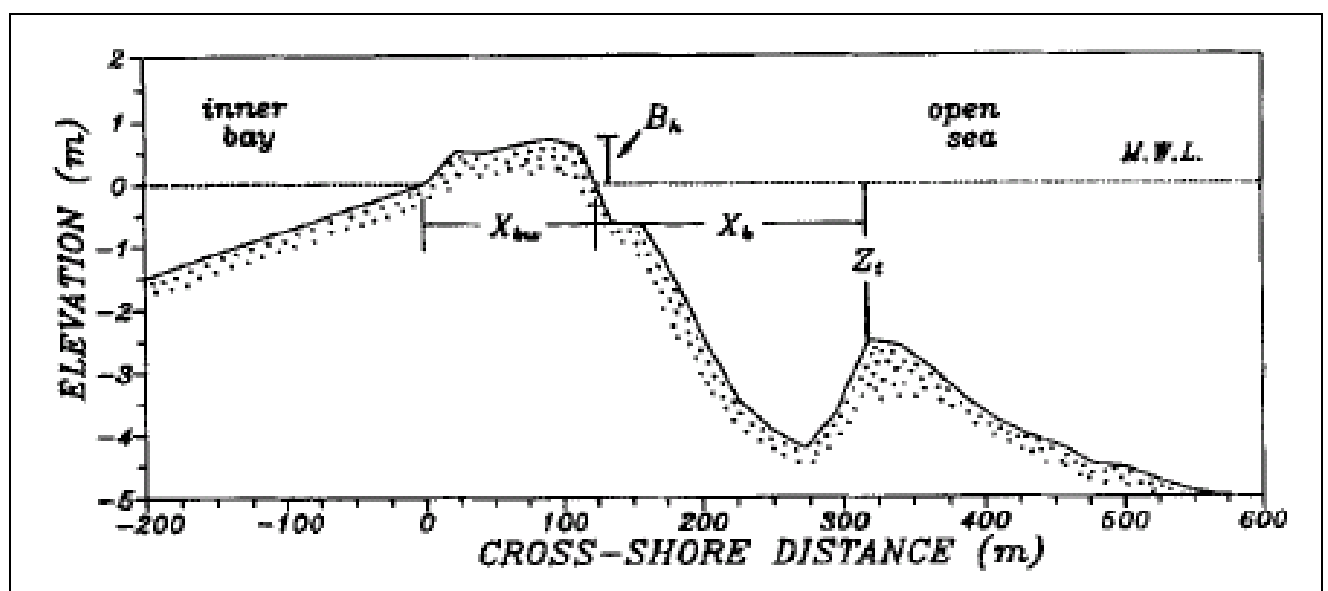

Figure 2.13: Transect of a typical cross section of the Trabucador Bar (Spain) showing variables included in the storm wave susceptibility quotient. Where $B_{h}$ is barrier height above mean sea-level; $X_{b w}$, barrier width; $Z_{t}$, depth of the longshore bar top and $X_{b}$, the distance between longshore bar and shoreline (Sanchez-Arcilla \& Jiminez, 1994).

\subsection{Vegetation}

Although vegetation is not a major controlling factor of barrier morphology and development, it does play an important role in sediment trapping, sculpting and stabilisation of the subaerial barrier (Oertel, 1985; Sherman \& Hotta, 1990; Hesp, 2004). The primary influence of 
the increased surface roughness caused by vegetation is the reduction of bed shear stress; this affects the transport potential of the wind becoming less able to carry the sediment load (Sherman \& Hotta, 1990).

Dune vegetation often develops in zones parallel to the shoreline where the primary factors of salt spray exposure, incremental sediment mobility, and soil moisture are found at desirable levels for growth (Stallins \& Parker, 2003). On dissipative beaches wide zones of vegetation with low species diversity develop as result of the high sediment supply and salt spray environment (Hesp, 2004). Oertal (1985) states that dune ridges, which develop from sand accumulation along the shore parallel lines of drift and vegetation, may illustrate past shoreline positions.

Stallins (2002) notes the following three dune plant types which have differing morphological functions within barrier islands along the Atlantic Coast. Dune builder grasses grow upright responding well to burial, producing steep dune slopes due to slow lateral spread. Burial tolerant grass and herb species also respond well to burial but grow laterally to stabilise sand masses. Whereas, a number of inland growing grasses, herbs and shrubs are burial intolerant stabilisers, binding sand in swales by their dense and compact growth patterns.

Grasses are often used for stabilising dunes and can promote low profile barriers into high profiles (Komar, 1998). The use of Ammophila arenaria (marram grass) has been widespread throughout New Zealand and the rest of the world (Hilton et al., 2005) as an effective dune builder and stabiliser (Hobbs et al., 1983). Rapid sediment deposition occurs as eddies created by the $A$. arenaria tussock habits deposit sediment in lee of the plant, developing pyramidal shaped shadow dunes (Hesp, 1981). As a result of the sand binding ability of $A$. arenaria, associated dunes are steeper and higher than those formed with other native grass 
species (Hilton et al., 2005). In Mason Bay, Stewart Island, A. arenaria has been associated with producing a new dune morphology; from low, hummocky, sparsely vegetated foredunes to uniform and continuous, taller foredunes which are densely vegetated (Hilton et al., 2006).

Management regimes such in the Outer Banks, North Carolina, United States, which formed higher dunes, using entrapment by vegetation, redistributed the finite available sand within the barrier system. This resulted in narrower beaches as a consequence and although the dunes resisted overwash they did suffer high erosion in which the sand moved offshore because the shorter run up enhanced the erosive power of the waves (Komar, 1998). In the long term, barriers may be destroyed if they are unable to modify their positioning and morphology in response to sea-level rise (Komar, 1998, Hilton et al., 2006).

\subsection{Summary}

SDB's can evolve under sea-level transgression, regression or stillstand and many factors are involved in their development such as sediment supply, hydrographic regime and antecedent topography. Three main theories for barrier island evolution exist; sand spit breaching, submergence of beach ridges and emerging offshore bars. However, as the development of SDB's is so complex, Schwartz (1971) advocates the idea of multiple causality when analysing barrier island emergence. Sea-level rise may change the morphology and positioning of a current barrier or in more extreme cases ultimately break it up. Although the Bruun Rule has been proven problematic, the basic concept is flexible enough for other barrier response to sea-level rise models, such as the Barrier Island Model, to be based on it, The theories and concepts introduced in this chapter provide a context to help with the study of the barrier spit featured in this thesis. 


\section{Chapter Three: The Study Area}

\subsection{Introduction}

Farewell Spit forms an arcuate transgressive dune field barrier (Shepherd \& Hesp, 2003), containing barchan dune formations which are rare in New Zealand (Ramsar, 1992). It encloses the northern section of Golden Bay, northwest South Island, New Zealand $\left(172^{\circ} 50^{\prime} \mathrm{E}\right.$ $40^{\circ} 31$ 'S) (figure 3.1). It is the largest of many spit and tombolo formations within Golden and Tasman Bays (Rattenbury et al., 1998) and is attached to the mainland between Fossil and Puponga Points extending eastwards $25 \mathrm{~km}$. At low tide sand flats extend a maximum of $\sim 8 \mathrm{~km}$ southward of the Spit into Golden Bay and continue a further $6 \mathrm{~km}$ eastward of the high tide mark at the tip (Petyt 1999). The total landmass is $11389 \mathrm{ha}$; comprising of 1960ha above high-water and an intertidal zone of 9429ha (Muirhead, 1981).

Golden Bay is very shallow (figure 3.2), with a maximum depth of $37 \mathrm{~m}$ at its entrance (Ridgeway, 1977) $\sim 30 \mathrm{~km}$ offshore. This contrasts to the open ocean side of the Spit where there is a rapid increase in depth to $50 \mathrm{~m}$ within $\sim 3 \mathrm{~km}$ from the beach. Due to the low lying nature of the Spit it has been a significant shipping hazard leading to the first lighthouse being erected in 1870 (Petyt, 1999). The highest barchan dunes reach up to $25 \mathrm{~m}$ above sea-level (ASL) (McLean, 1978) and the vegetated dunes vary from $\sim 50 \mathrm{~m}$ ASL at Puponga Farm Park to $<10 \mathrm{~m}$ at Bush End Point. 


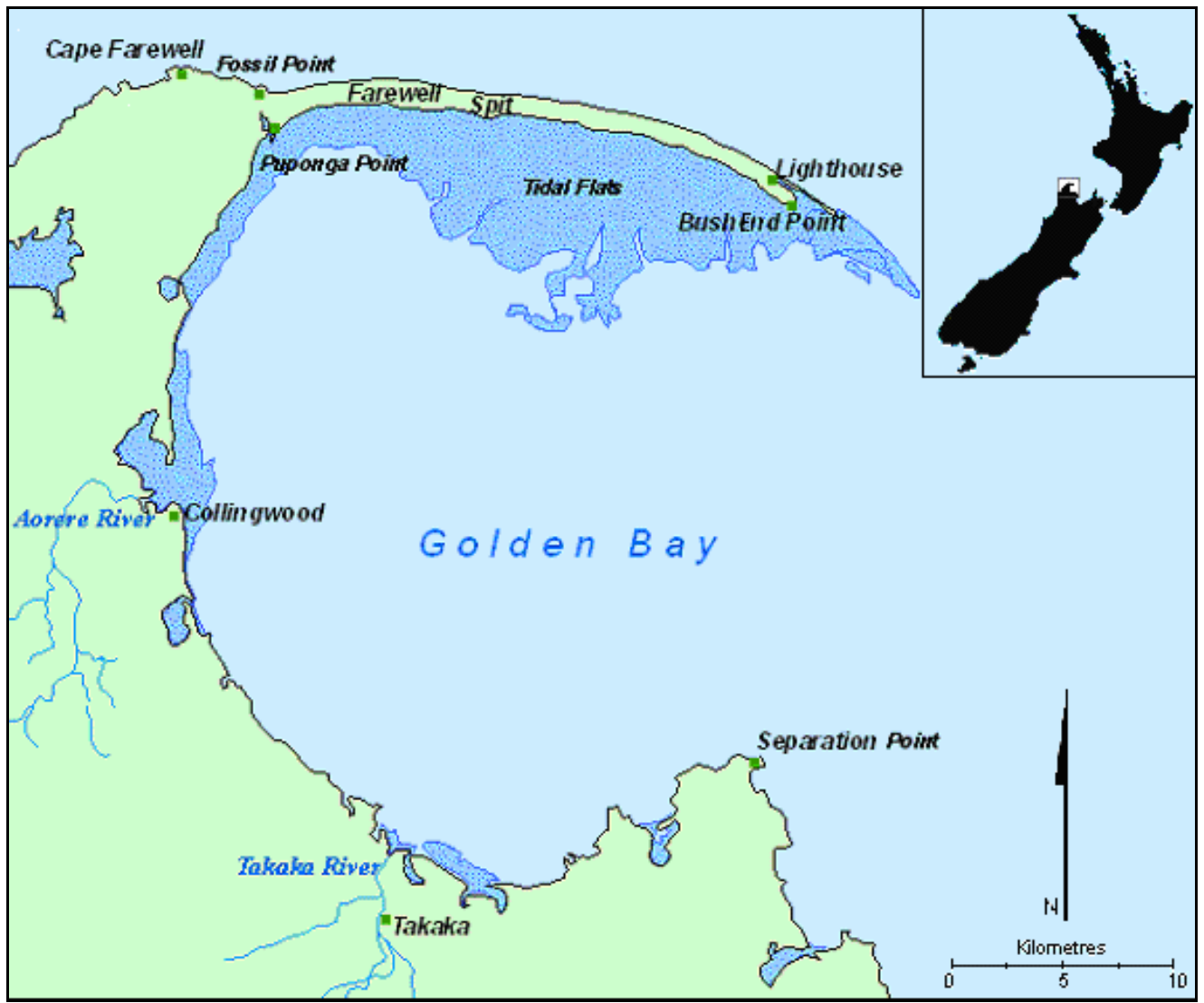

Figure 3.1: Map of Golden Bay.

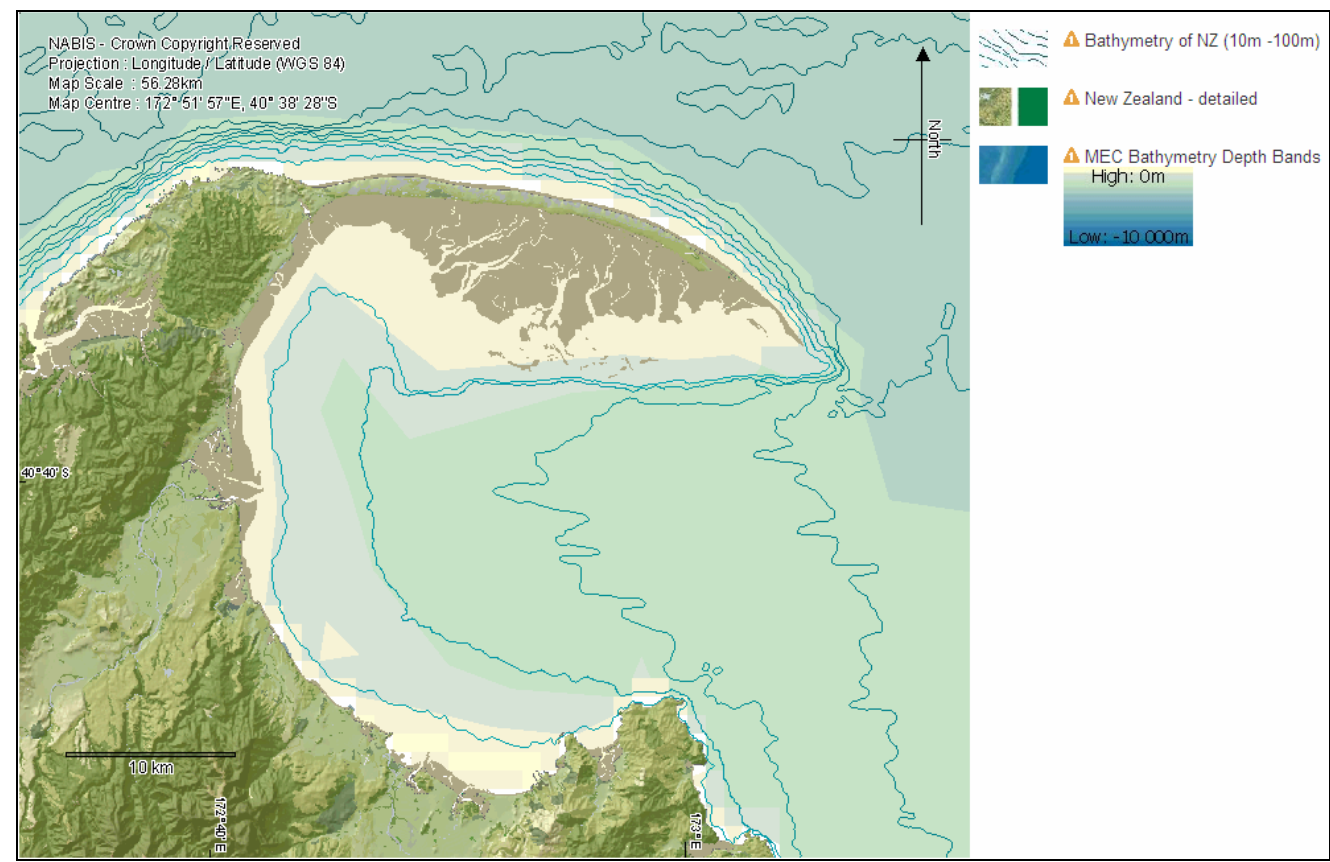

Figure 3.2: Bathymetry of Golden Bay, bathymetry lines are shown at 10m intervals (NABIS, 2007). 


\subsection{Historical background}

\subsubsection{Maori and European settlement}

Farewell Spit is known as Onetahua (sand formation) to Maori who are thought to have been present around this region since at least the fifteenth century (Mitchell \& Mitchell, 2004). Artefacts such as tools (e.g. adzes) from the early moa hunter era through to the later styles have been found around the base of the Spit (Walton \& Bagly, 2000). There are several midden sites along the Spit and a significant pa site was situated upon Abel Head Peninsula (near Puponga Point) (Court, 1978). This area was part of the 'greenstone trails' to the West Coast, therefore would have been an important seasonal food gathering source for shellfish, birds, fish and periodically stranded whales (Mitchell \& Mitchell, 2004). Today the tangata whenua of this region are Te Ati Awa, Ngati Rarua and Ngati Tama (Nelson City Council, 2007).

The first European explorers in the area were Abel Tasman in 1642 and James Cook in 1770 who named 'Cape Farewell'; following these were a number of sealers and whalers from around 1790 onwards (Petyt, 1999). Cape Farewell and the Spit remained in native title until January 1852 , when it and the surrounding land was purchased and leased out as a sheep and cattle run (Petyt, 1999).

\subsubsection{Sanctuary}

In 1938 the Spit was declared a Flora and Fauna Reserve and the adjacent tidal flats a Sanctuary for the Preservation of Wildlife (Ramsar, 1992), although a fence was built in 1966, it wasn't until 1975 that the remainder of the feral cattle were fully removed (Petyt, 1999). In 1976 Farewell Spit was designated a 'Wetland of international importance especially as waterfowl habitat' on account of the importance of the site to the $>83$ species of wetland birds regularly recorded there (Ramsar, 1992). The Spit supports an assemblage of vulnerable species of endemic avifauna including Charadrius obscurus (New Zealand 
dotterel) and Charadrius bicinctus (banded dotterel) and is also an important stopover for migratory wading bird species (figure 3.3), the population of which reaches around 33,000 during December - January (Ramsar, 1992; Williams et al., 2006). Threatened endemic plants are also present, including Euphorbia glauca (sand milkweed), Pimelea arenaria (sand daphne) and Desmoschoenus spiralis (pingao) (Ramsar, 1992).

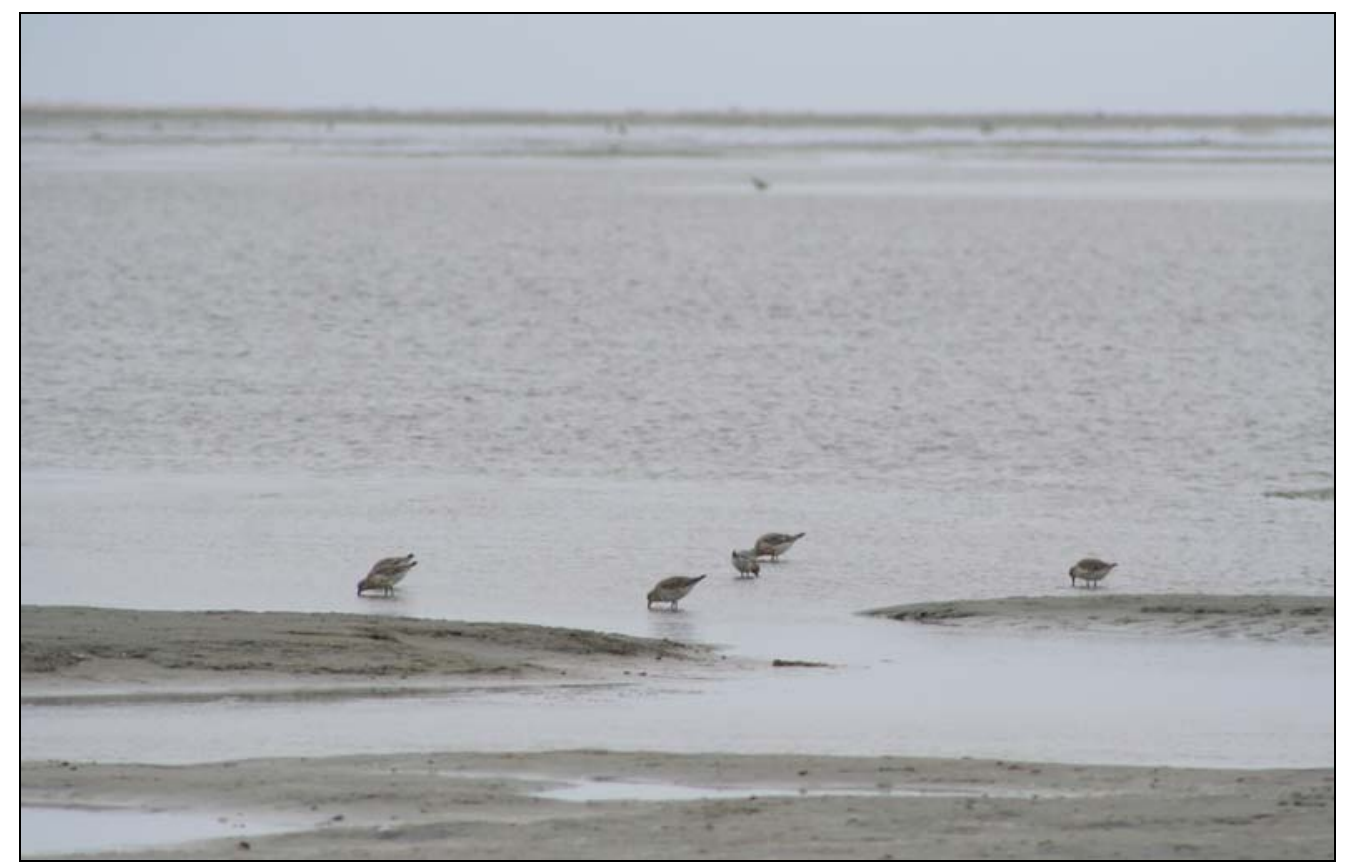

Figure 3.3: Bar-tailed godwits feeding on the tidal flats (Photograph: Rod Boys, 2007).

In 1980 the Spit and tidal flats were also classified as a Nature Reserve for the Sanctuary and Preservation of Wildlife. Management policy 4.2.1 of the Farewell Spit Nature Reserve Management Plan states "the reserve will be managed so as to protect as far as possible all landforms and ecosystems from unnatural disturbance" (Muirhead, 1981). Access restrictions have been placed on the Spit to minimise the disturbance to flora and fauna; the general public has walking access for $4 \mathrm{~km}$ along Ocean Beach (Northern side of the Spit) and for $2.5 \mathrm{~km}$ along the inner beach, with access beyond this being by guided tours or permit only. 


\subsection{Physical setting}

\subsubsection{Geology}

The Cape Farewell area is dominated by the NNE trending Wakamarama anticline formed during the late Miocene by compressional tectonic movement (Clark \& Thoms, 1978; Bal \& Lewis, 1994). The inactive Wakamarama Fault runs parallel to this anticline forming its SE boundary, and continues across Farewell Spit near its base (Rattenbury et al., 1998) and at least $\sim 40 \mathrm{~km}$ offshore towards Taranaki.

The Paleozoic basement rock (van der Linden, 1968; Leask, 1993; Rattenbury et al., 1998) in the area is comprised of folded submetamorphic and metamorphic slates and schists, formed around fine grained granite intrusions (Ongley \& Macpherson, 1923). Overlaying this are partially exposed late Cretaceous sedimentary deposits, of the Rakopi and North Cape Formations (Wizevich et al., 1992; Rattenbury et al., 1998), collectively known as the Pakawau Group (figure 3.4) (Ongley \& Macpherson, 1923). The lowest of these, the Rakopi Formation is predominantly terrestrial in its origin consisting of Otimataura Conglomerate, overlain by sandstone intermittently interbedded with carbonaceous mudstone and thin coal seams (Rattenbury et al., 1998). The overlying North Cape Formation is primarily composed of shallow-marine sandstones interbedded with siltstone, conglomerate and coal seams (Rattenbury et al., 1998).

The Pakawau Group was initially thought to have been a non-marine sedimentary formation due to the Puponga Member Coal Measures (Bal \& Lewis, 1994; Rattenbury et al., 1998) which feature in the upper boundary. However, Wizevich et al. (1992) used sedimentological and micropaleontological analyses to conclude that the formation is in fact of a marginal-marine origin. 


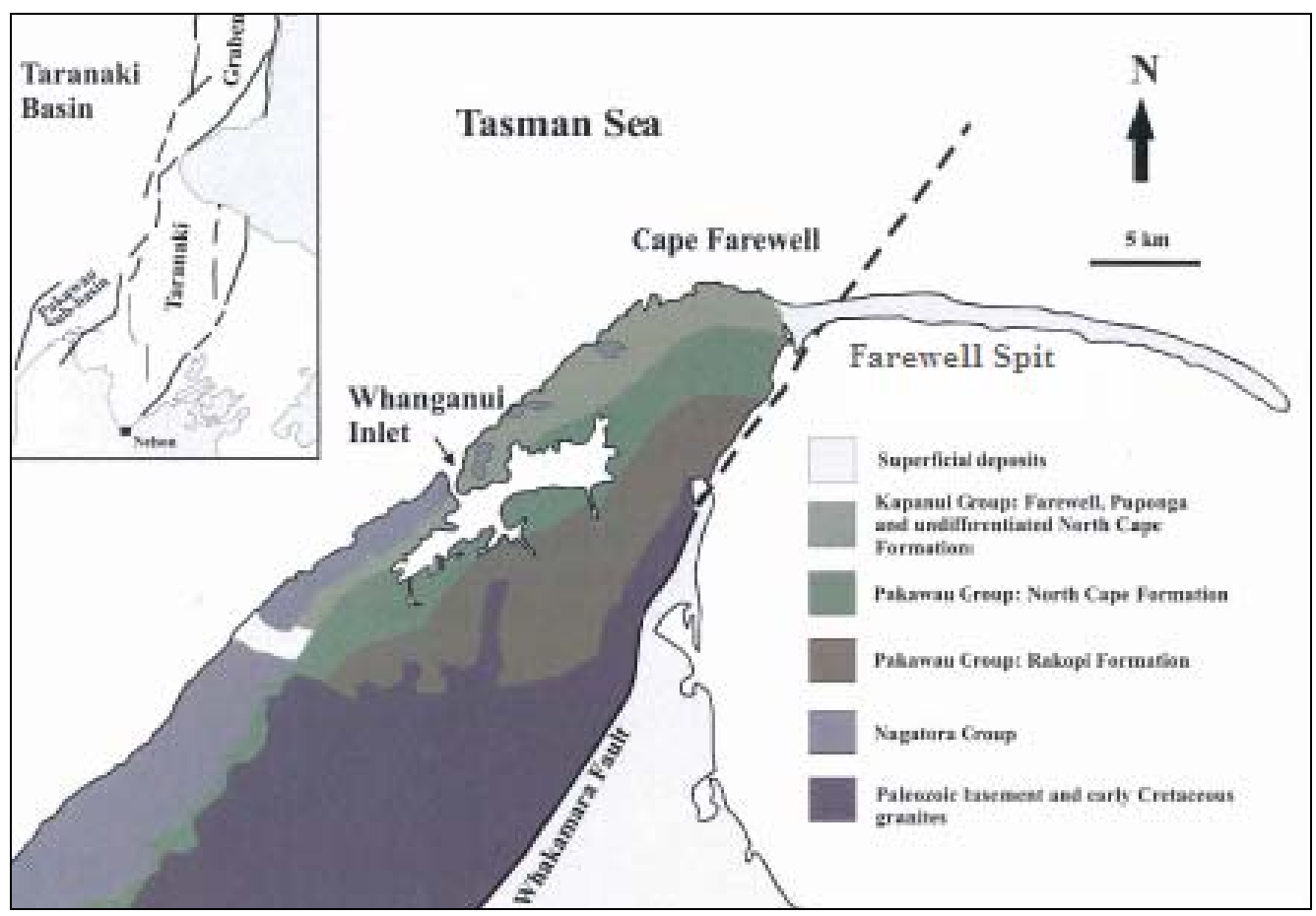

Figure 3.4: Generalised geological map showing northwest Nelson, the Farewell Spit study area and the proximity to the Taranaki Graben (inset) (Paulik, 2006; modified after Bal \&Lewis, 1994).

The Pakawau Group is overlain by the Kapuni Group comprising of the Farewell Formation and Brunner Coal Measures. The Farewell Formation, dated Cretaceous-Tertiary boundary (King \& Thrasher 1996), locally consists of fluvial quartzofeldspathic sandstone and pebbly conglomerate (Rattenbury et al., 1998). An extensive unconformity then separates it from the overlying Eocene Brunner Coal measures (previously named Motupipi) (Leask, 1993; Bal \& Lewis, 1994). Evidence of this erosional unconformity is shown by deeply leached surfaces and decomposed less resistant minerals such as feldspar and biotite (Rattenbury et al., 1998).

The Kapuni Group is in turn overlain by the Ngatoro Group, consisting of the Abel Head formation, Takaka Limestone and Tarakohe Mudstone (Clark \& Thoms, 1978; Bal \& Lewis, 1994). The Abel Head Formation is a thin sequence of shallow marine sandstones and mudstones dated late Oligocene (Clark \& Thoms, 1978; Leask, 1993). It is exposed at the immediate Western end of Farewell Spit as well as the southern edge of 
Cape Farewell to Puponga Point during low tides. The overlaying Takaka Limestone dates from the late Oligocene to early Miocene (Leask, 1993) and is visible in outcrops where Cape Farewell meets the Spit. The early-middle Miocene Tarakohe Mudstone (Leask, 1993) is found as an isolated outcrop at low tide NE of Puponga Point and it is postulated as a possible the basement for the connection of Farewell Spit to Cape Farewell (Grindley, 1971). Despite this Kennedy and Paulik (2007) thought the area had been stable for the past few thousand years when describing elevated shore platforms related to sea-level change in Whanganui Inlet.

The northwest Nelson region is considered to have undergone negligible recent uplift. Using evidence from speleothems in caves near Patarau and Takaka which are believed to be older than 690ka, Williams (1991) showed a maximum rate of uplift to be between 0.07 $0.09 \mathrm{~m} / \mathrm{ka}$. However, some lighthouse damage occurred in December 1928 due to an earthquake and the Murchison earthquake in June 1929 produced a $2.5 \mathrm{~m}$ tsunami wave which over-washed parts of the Spit at the tip and base (de Lange \& Healy, 1986).

van der Linden (1968) suggests the most likely foundation of the Spit is a Pleistocene peneplain on top of which sand dunes have been deposited. This sand is mainly quartz derived from the Southern Alps (McLean 1978), including the heavy minerals, garnet, magnetiteilmenite, and amphibole-pyroxene (Sevon, 1964). Farewell Spit lies on the SW edge of the Taranaki Graben, the western margin of which is a sandy band running from Farewell Spit to Cape Egmont where water depths do not exceed depths of 100m (Harris, 1990). This is probably the vestiges of the detritus carried northward from the Southern Alps by the Westland Current. Furkett (1947) estimated the quantity of detritus flowing northward past Cape Fowlwind to be $3.8 \mathrm{M} \mathrm{m} / \mathrm{y}$, of this $3.4 \mathrm{M}$ $\mathrm{m}^{3} / \mathrm{y}$ deposited to the Spit itself; the rest distributed on the shelf west of New Zealand. However, these amounts were questioned by van der 
Linden (1965) who, using seismic reflection profiles, considered the total sediment carried to the shelf alone to be $\sim 4.5-5.4 \mathrm{M} \mathrm{m} / \mathrm{y}$. Later, Gibb (1979) assuming the age of the Spit to be 6500 years old, calculated that the Spit had accumulated $2.2 \mathrm{M} \mathrm{m} / \mathrm{y}$ within this time (Harris, 1990). Ballance et al. (2006) calculated a total of $\sim 5.7 \mathrm{~km}^{3}$ of postglacial sand within the Farewell Spit system; consisting of $\sim 4 \mathrm{~km}^{3}$ within the tidal flats (assuming a mean thickness of $\sim 20 \mathrm{~m}$ ) and $\sim 1.7 \mathrm{~km}^{3}$ within the Spit itself.

The assumption that Farewell Spit's sediment comes from a single source at the western end of the Spit is supported by a consistent variation of mean grain size, increasing from west to east due to the preferential entrainment of fines in wind or water and the similarity in heavy mineral quantities further supports this assumption (Sevon 1964; Kasper-Zubillaga et al., 2006). A lack of the maximum grain size variation within the foreshore sand along the Spit also showed that no large grains are added to the Spit from a secondary source (Sevon 1964).

Grain size analysis of sand across the Spit has shown distinct differences within the size parameters of mean, sorting and skewness between the foreshore, backshore and dune environments (Sevon, 1964). This is attributed to signatures of the different agents of transportation and deposition required for each environment (Sevon 1964); wind related backshore and dune sands and wave action related to foreshore sands. The tidal flats are shown to be derived from dune sand moving in a north-south direction through evidence that these sands maintain most of the dune sand characteristics and distribution of heavy minerals (Sevon, 1964). van der Linden (1965) described these sands as having 'passed though cycles of beach and dune formation since at least the Pleistocene' (p91). This recycling of sand from beach to dune to tidal flats infers that little sand is lost from the system once it is caught into it (Clark \& Thoms, 1978). 
The Aorere and Takaka Rivers are the main sediment supply of the remainder of Golden Bay (van der Linden, 1965), receiving alluvial sediment discharges of 1.59 and $1.11 \mathrm{t} / \mathrm{y} \times 10^{6}$ respectively (Griffiths \& Glasby, 1985). These rivers dissect the ranges to the south which are comprised of siltstone, sandstone and limestone (Mount Arthur, Golden Bay and Haupiri Groups), schist (Golden Bay group), basalt (Devil River Volcanic Group) and conglomerate (Haupiri Group) (Rattenbury et al., 1998). Some of these poorly sorted, coarser river sediments are picked up by currents and deposited onto the Spit's tidal flats (van der Linden, 1965; Ballance et al., 2006).

\subsubsection{Vegetation}

The initial native vegetation on the spit is thought to be light coastal bush and scrub, predominantly Cassinia leptophylla (tauhinu), native grasses such as Desmoschoenus spiralis (pingao), Spinifex sericeus and Phorium tenax (flax) with large Podocarpus totara (totara) occurring at the base of the Spit (Ramsar, 1992; Petyt, 1999).

Fires and stock grazing severely affected the Spit during European settlement. The introduction of exotic species such as $A$. arenaria and Lupinus arboreus (lupins) helped stabilise wastes of drifting sand in the early twentieth century (Brown, 1978). Also in high abundance is Rubus fruticosus (blackberry) and Ulex europaus $L$. (gorse). Some native flora such as Leptospermum scoparium (manuka), Kunzea ericoides (kanuka), P. tenax (flax), Cortaderia spp. (toetoe), Pteridium aquilinum var esculentum (bracken) and herbs are also regenerating within the vegetated dunes since the removal of sheep and cattle in 1975 (Ramsar, 1992). Threatened endemic species such as Euphorbia glauca (sand milkweed), Pimelia arenaria (sand daphne) and D. spiralis are also found among these vegetated sand dunes (Ramsar, 1992). 
Species such as Miriophyllum spp (milfoil) Glossostigma elatinoides (glosso), Gunnera arenaria (sand gunnera), Carex spp. (sedges), Juncus spp. (rushes) and $P$. tenax occur in the dune hollows and small lakes (Ramsar, 1992). While the salt marsh vegetation progresses from $P$. tenax at the dune edges, through zones of Leptocarpus simplex (jointed rush), Juncus maritimus var australiensis (sea rush), Salicornia spp. (glasswort) to Zostera muelleri (eelgrass) at the lower water limit (Watkins, 1978; Ramsar, 1992).

The Pinus radiata (pines) and Cupressus macrocarpa (macrocarpa) (figure 3.5) trees occur in the vicinity of the lighthouse. These were first planted around 1889 (Petyt, 1999) to provide shade and shelter for the keepers' dwellings and are now over $20 \mathrm{~m}$ in height.

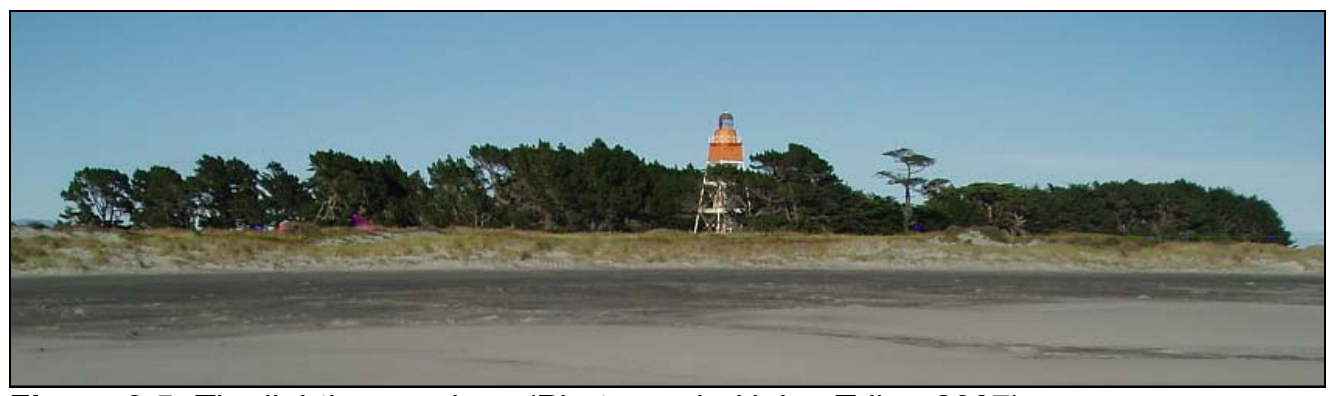

Figure 3.5: The lighthouse pines (Photograph: Helen Tribe, 2007).

\subsubsection{Oceanography}

The northward flowing Westland Current branches off from the Tasman Current (van der Linden, 1968) where it dominates the surface water circulation over the northwest Nelson shelf and feeds into the eastward flowing D'Urville Current which rounds the Spit and into Cook Strait (van der Linden, 1968). The D'Urville Current splits as it nears Separation Point; one branch flowing back into Golden Bay creating a slow (0.01 $0.06 \mathrm{~m} / \mathrm{s}$ ), tidally dominated, clockwise moving gyre (Heath, 1969; Ridgeway, 1977) while the other enters Tasman Bay in an anticlockwise current (figure 3.6). 


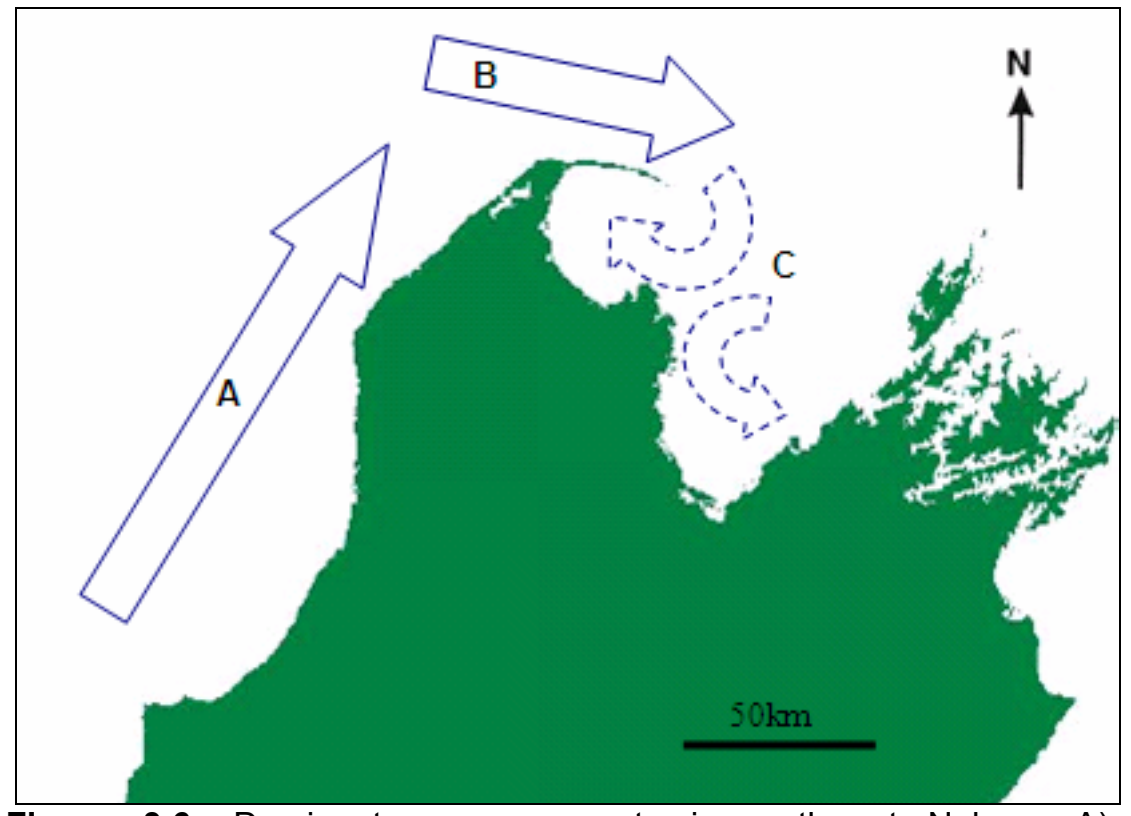

Figure 3.6: Dominant ocean currents in northwest Nelson. A) Northward flowing Westland Current, B) Eastward flowing D'Urville Current, C) the D'Urville Current split into clockwise moving gyre within Golden Bay and anticlockwise moving current within Tasman Bay.

Cook Strait has strong tidal flows of up to $3.6 \mathrm{~m} / \mathrm{s}$ funnelling through at the narrowest channel $(23 \mathrm{~km})$ between the North and South Islands (Heath, 1970). Golden Bay at the western extremity of greater Cook Strait is a macro-tidal environment. Collingwood (figure 3.1), the closest tide gauge to the southern edge of the Spit, has the highest tidal range in the country of $\sim 5 \mathrm{~m}$ (de Lange et al., 2003) with a $\sim 4.7 \mathrm{~m}$ mean high water spring (MHWS) (LINZ, 2007a). Tidal speeds within Golden Bay have been recorded at $0.15-0.30 \mathrm{~cm} / \mathrm{sec}$ (Harris, 1990). The closest tide gauge to the northern edge (at the western end) is at Whanganui Inlet which is high meso-tidal, recording a tidal range and MHWS of $\sim 2.9 \mathrm{~m}$ (LINZ, 2007b).

Farewell Spit is influenced by both sea and swell waves. Within Golden Bay the sea waves that affect the Spit are from the south, southwest and west; the height of these waves are controlled by their respective maximum fetches of $34.9 \mathrm{~km}, 34.2 \mathrm{~km}$ and $21.6 \mathrm{~km}$ (figure 3.5 ). The maximum significant wave heights generated within the Bay are calculated (using a nomograph) as $\sim 1.7 \mathrm{~m}$ ( $\mathrm{T}=5.3$ seconds), and based 
on the longest fetch distance $(\sim 35 \mathrm{~km})$ and $17.5 \mathrm{~m} / \mathrm{s}$ winds which occur at $0.001 \%$ from the south (figure 3.8 ).

The swell waves that affect the Spit's Ocean Beach arrive predominantly from the west and southwest developing in the Southern Ocean and Tasman Sea (Harris, 1990). The Maui A Platform, off the Taranaki Coast $\left(173^{\circ} 433^{\prime} \mathrm{E} 39^{\circ} 5^{\circ} \mathrm{S}\right) \sim 115 \mathrm{~km}$ to the northeast of the Spit lighthouse, has the longest and most continuous wave recording in New Zealand (Pickrill \& Mitchell, 1979), and as such is representative of the deep water wave climate around the Spit (figure 3.7). The average significant wave height from the Maui Platform records is $2.5 \mathrm{~m}$ ( $\mathrm{T}=6$ - 9 seconds) with very little seasonality being evident (Pickrill \& Mitchell, 1979). A similar wave climate is seen in the Westcoast where the average significant wave height is $1-3 m(T=6-8 s e c)$ from the south and southwest (Pickrill \& Mitchell, 1979).

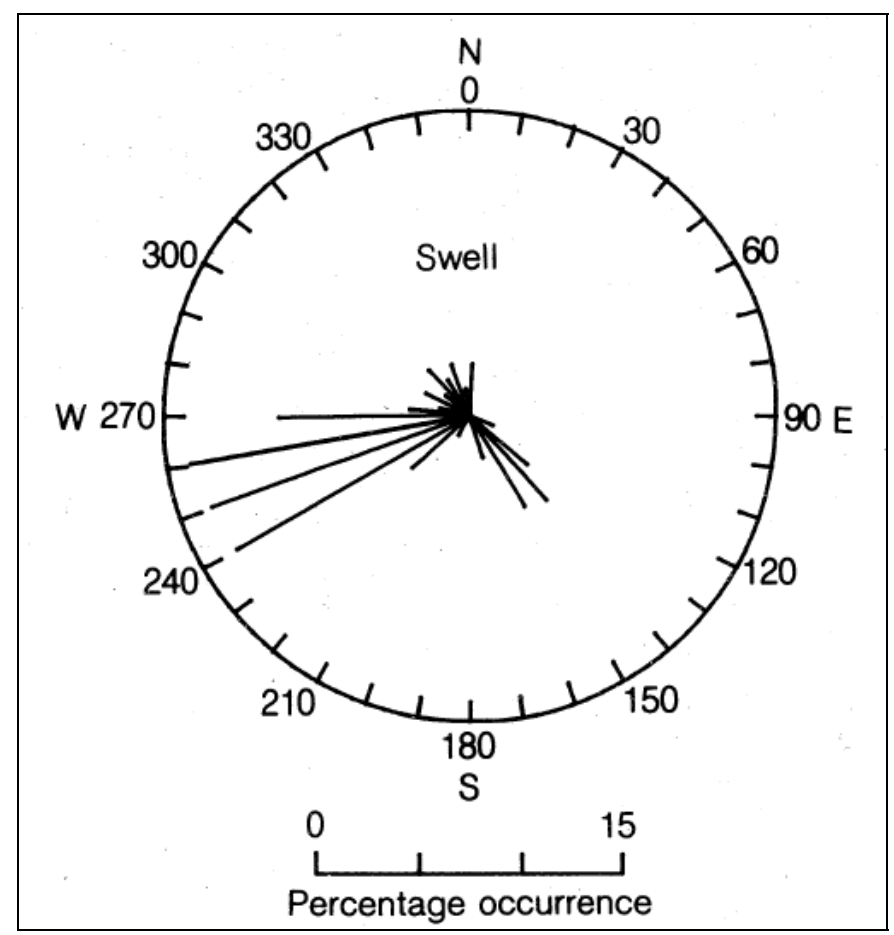

Figure 3.7: Swell rose from observations near Maui Platform 1980 - 1981 (Harris, 1990) 


\subsubsection{Weather/ Climate}

Farewell Spit lies at $40.5^{\circ} \mathrm{S}$ and is therefore exposed to the prevailing westerly wind belt. The general climate of the area is influenced by the maritime environment and low lying topography (Muirhead, 1981).

Climate data from the airstrip at the eastern end of the Spit from 1982 present shows that the annual mean air temperature is $13.8^{\circ} \mathrm{C}$, the winter months averaging $10.2^{\circ} \mathrm{C}$ and summer $17.5^{\circ} \mathrm{C}$ (NIWA, 2007a). The Spit receives an average yearly rainfall of $1207 \mathrm{~mm}$, the monthly average being $100.6 \mathrm{~mm}$ and the wettest months being May September; the average mean wind speed is $6.01 \mathrm{~m} / \mathrm{s}$, the windiest month being November at $7.3 \mathrm{~m} / \mathrm{s}$ (NIWA, 2007a). The majority (almost $60 \%$ ) of the wind recorded at Farewell Spit comes from the westerly quarter (SW, W \& NW) the next most prevalent being $E$ and SE at $14 \%$ and $12.14 \%$ respectively (figure 3.8 ).

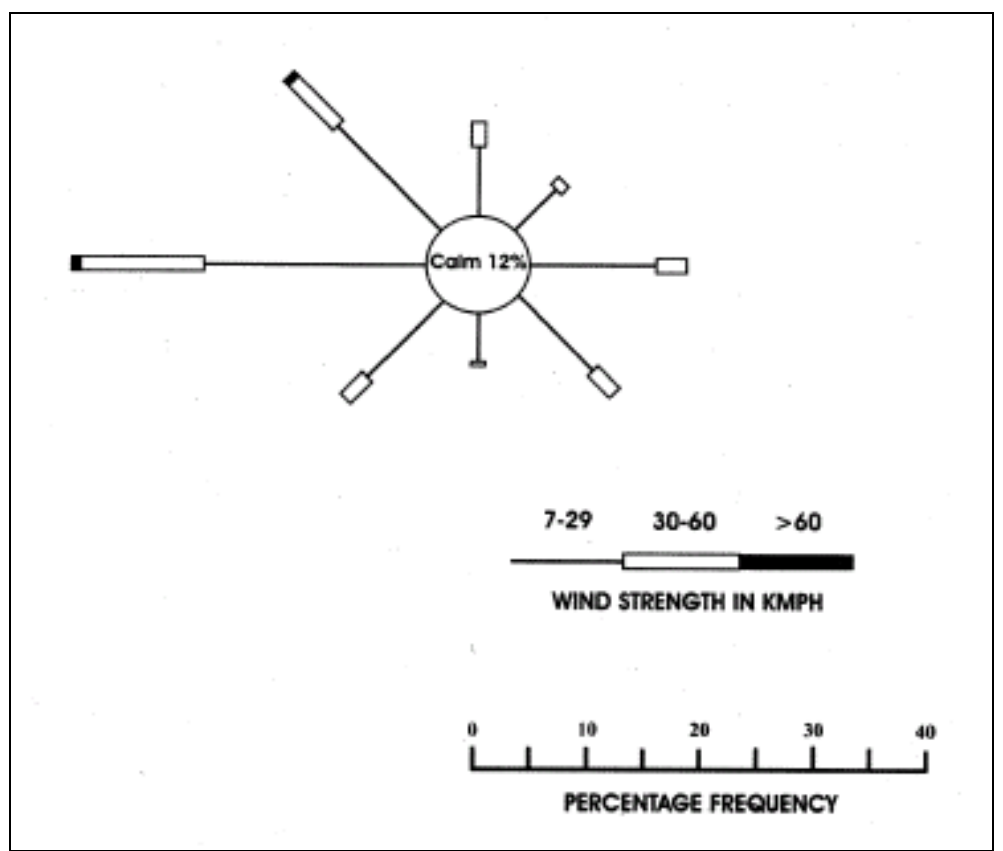

Figure 3.8: Farewell Spit wind rose, NIWA wind data 1978 - 2002 (Paulik, 2006) 


\subsection{Summary}

Farewell Spit is a fragile landform with a rich Maori and European history and is currently a wildlife sanctuary of international importance. This chapter has given an overview of the area including the geology, vegetation, oceanography and weather. Farewell Spit is thought to be $6.5 \mathrm{ka}$ and made up of quartz sand, derived from the Southern Alps and carried by the Westland and D'Urville currents. The Spit has a mixture of native and introduced flora of which $A$. arenaria, $R$. fruticosus and $U$. europaus $L$. are in high abundance. The Spit shelters Golden Bay from the high energy Tasman Sea wave regime and is affected by the prevailing westerly winds of the 'roaring forties'. 


\section{Chapter Four: Methods}

\subsection{Introduction}

To understand the response of Farewell Spit to sea-level change it is necessary to comprehend its stability, past and present. Therefore this thesis has undertaken topographic, GIS mapping, sedimentological and chronological techniques to satisfy each of the objectives outlined in Chapter 1.

\subsection{Topographic Methods}

\subsubsection{Surveying}

A Sokkia SET 4010 Electronic Distance Meter (EDM) (figure 4.1) was used to survey a total of 14 profiles along Farewell Spit between 8 - 20 February and 25 - 30 October 2007. Data was processed using Mapsuite+ software and plotted in Micrsoft EXCEL. As fixed benchmarks are not present on the Spit, all surveys were corrected to the mean sea-level (MSL) of Collingwood ( 2.6m (LINZ, 2007)) or Whanganui Inlet ( 1.4m (LINZ, 2007)). Tidal heights were calculated using TUMONZ Tide Viewer 3.2 software for the appropriate time of surveying using the Collingwood or Whanganui Inlet tide gauges depending on which was closer to the transect end. The tide levels were visually ground truthed on subsequent high tides as the tidal flats tide levels can lag the official Collingwood tide gauge by at least an hour on an average tide and longer during spring or neap cycles (McCleod, 2008. pers comm.). 


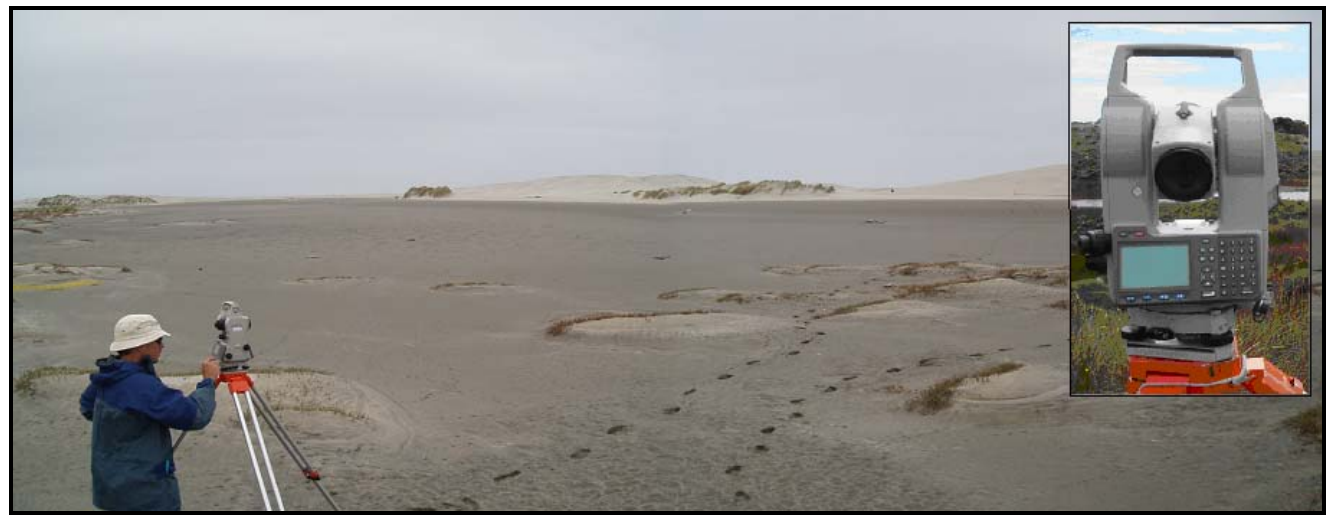

Figure 4.1: Surveying across Mullet Creek using a Sokkia SET 4010 EDM (detailed in inset) (Photographs: Helen Tribe, 2007).

In the lab projected sea-level rise was modelled on surveys traversing the lower lying zones of the Spit including the Roadway, Stockyard Lake, Mullet Creek and Airstrip transects. The Collingwood tide gauge high water spring water level (MHWS) $4.7 \mathrm{~m}$ and the highest astronomical tide (HAT) 5.02m (occurring on 28 September 2007) levels were used, and the IPCC predicted $0.48 \mathrm{~m}$ sea-level rise added to these for comparison.

\subsection{GIS mapping}

Aerial photographic analysis provides a detailed set of imagery over different temporal scales and is widely used to examine changes in landforms since the 1930's when aerial photography began (eg Gibb, 1978; Ihse, 1995; Gay, 1999). More recently, aerial photography has been incorporated into GIS analysis which digitises images and allows for easier manipulation of data and processing of thematic maps (Zharikov, et al., 2005).

\subsubsection{Aerial Photograph Analysis}

Aerial photographs of Farewell Spit from 1950, 1975, 1984, 2003 and 2004 were obtained from NZ Aerial Mapping Ltd. These were analysed to establish the stability of features on the Spit such as vegetation, sand dunes and the Shellbanks, and also its overall shape and positioning. 
Aerial photographs are expressions of antecedent conditions such as tides, recent storms and seasons (Leatherman, 1983), thus changes between photographs could be temporary, recoverable events and not necessarily long term alterations. Consequently this possibility should be kept in mind when deciding on the features and parameters to be measured.

When analysing aerial photographs several sources of error exist which can affect the accuracy of calculations (Gibb, 1978); variations in height and tilt of the aeroplane can create an inconstant scale between photographs (Leatherman, 1983). This can create more room for error in measuring change where a smaller scale increases the significance of error when looking at shoreline displacements of only a few metres (Gibb, 1978). The radial distortion away from the centre where only the middle of the photograph is true so can also misrepresent measurements (Gibb, 1978).

Geographic Information System (GIS) software (ArcGIS version 9.1) was employed to minimise these issues by digitising and georeferencing the images to a comparable map (section 4.3.3). Although these photograph sets may still have some of the inherent errors from the issues outlined above and some absolute measurements may be incorrect compared to the national grid. However, these will be relative to Farewell Spit and more accurate calculations are achieved through measuring change compared to previous years resulting in percentage change over the photograph sets. 


\subsubsection{Photograph set pre-treatment}

The photograph sets were scanned in colour at photographic quality to 600dpi into JPEG files; using Corel PHOTOGRAPH-PAINT 12 software. These were then cropped to remove the frames. The photograph sets were then stitched together using Canon Photostitch v3.1 to generate a continuous aerial photograph of the Spit for each year.

\subsubsection{Photograph Georeferencing}

The 1:50 000 M24 \& N24 topographic map of Farewell Spit was scanned in two parts and stitched together. This was then entered into ArcMap where it was registered to the grid using coordinates printed on the map in a raster format using the New Zealand Map Grid Projection to achieve a co-ordinate system (figure 4.2A). As all of the aerial photograph sets had been taken at differing altitudes and oblique angles, the map was used as the base against which the 2004 photograph was georeferenced. The lighthouse, roads and fence lines and a small number of marked vegetation were used as comparable points across the Spit on both images. This essentially flattened the 2004 photograph to an overhead shot (figure 4.2B \& C), with an horizontal accuracy of \pm 3 . $3 \mathrm{~m}$. 


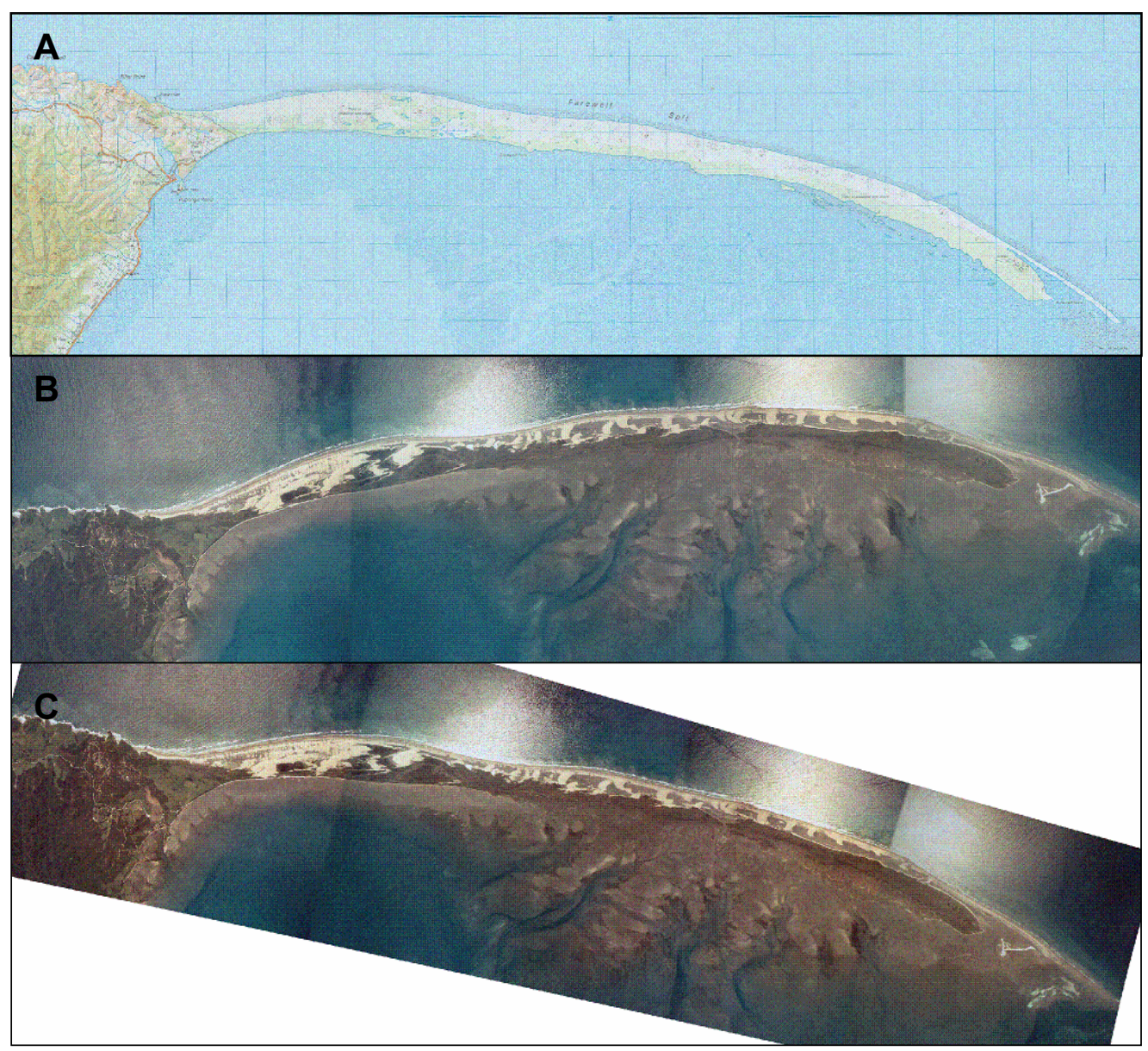

Figure 4.2: Before and after aerial photographs illustrating the effect of georeferencing an aerial photograph to a topographic map. A) 1:50 000 M24 \& N24 topographic map of Farewell Spit (LINZ, 2000). B) 2004 aerial photograph set of Farewell Spit (Photograph: NZ Aerial Mapping Ltd, 2007). C) 2004 aerial photograph set georeferenced to topographic map.

The georectified 2004 photograph was then chosen as the base reference for the other photograph sets to be rubber-sheeted against as it is closest to today's conditions and because of the difficulties of locating sufficient recognisable features on the map and all of the photographs. At least ten comparable points were used for rubbersheeting each of the photograph runs to the georeferenced 2004 image, which were as evenly spaced across the Spit as possible. Consistency of these points between photograph runs is ideal (Heywood, et al., 2002); however, as the Spit has only a few stable points some of these were based on vegetation. Subsequently these were not necessarily the same ten points for each year because of the major vegetation changes on the Spit throughout the time frame. However, these point changes 
were kept to a minimum and the residual error for each georeferenced image was kept below $\pm 4 \mathrm{~m}$, which is likely to be the correct error for the Spit's length. In spite of this, the narrow width of the Spit meant few reference points could be used to stretch the image accordingly and has resulted in a much larger width error, especially in areas between comparable points. This is illustrated in the change in shoreline around Farewell Spit especially evident in the 1985 photograph which is consistently much thinner $(>100 \mathrm{~m})$ than the rest (figure 4.3$)$. As such north/south shoreline change, indicating erosion or accretion in specific areas was not considered accurate enough to be analysed correctly.

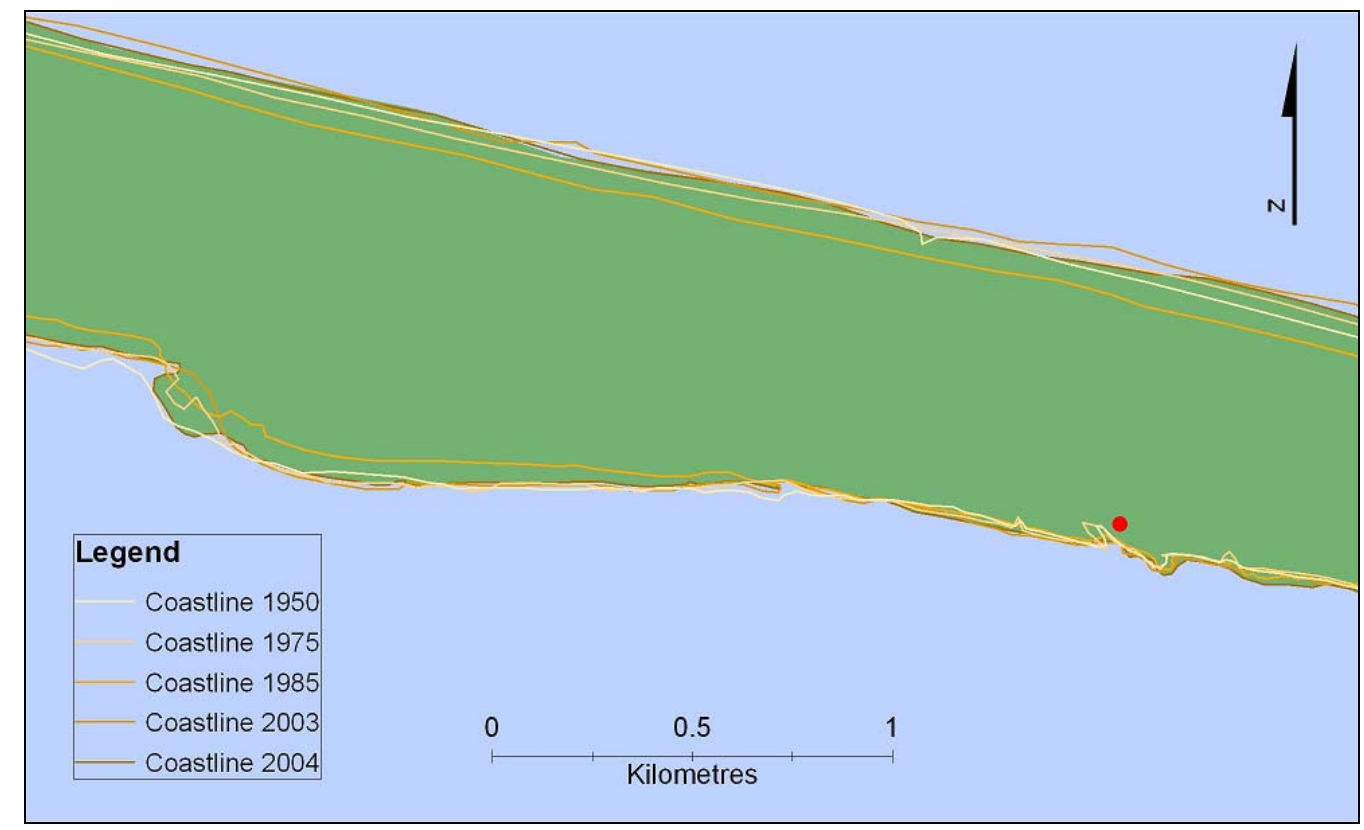

Figure 4.3: Map of the Mullet Creek area on Farewell Spit which illustrates width-ways error from georeferencing issues. The red dot indicates a point of common georeferencing through all photograph sets. Here the coastlines are reasonably matched, although these become less so further away from this point. To the left of the photograph the difference in coastlines is up to $95 \mathrm{~m}$ on the low energy Golden Bay coast.

\subsubsection{Digitising features and analysis}

The vegetation, bare sand and Shellbanks features were identified (table 4.1) and digitised using complex multipart polygons on separate layers to create maps for each photograph set. The polygon areas of each of the features were calculated in the attributes table and totalled 
for all photograph sets. Multipart polygons were used because the error of the area coverage decreases as the complexity of a polygon increases (Hill, 2006). Figure 4.4 outlines the digitising process and highlights the details which were taken into account. Only the bare (dry) sand was chosen as it is readily available for aeolian transport compared to $<1 \%$ of the wet sand or sand with a well developed crust from sea water evaporation, such as found on the salt pans (Sherman \& Hotta 1990).

Table 4.1: Description of identifying outlines when creating polygons/polylines of features on the Spit.

\begin{tabular}{|l|l|}
\hline Feature & Outline of polygon/ polyline defining this feature identified by \\
\hline Vegetation & Edge of vegetation. \\
\hline Bare sand & Boundary between light (dry) sand and dark (wet) sand. \\
\hline Shellbanks & $\begin{array}{l}\text { Boundary between light coloured Shellbank material and dark (wet) } \\
\text { sand. }\end{array}$ \\
\hline Shoreline & High water line delineated by light dry sand and darker wet sand. \\
\hline
\end{tabular}




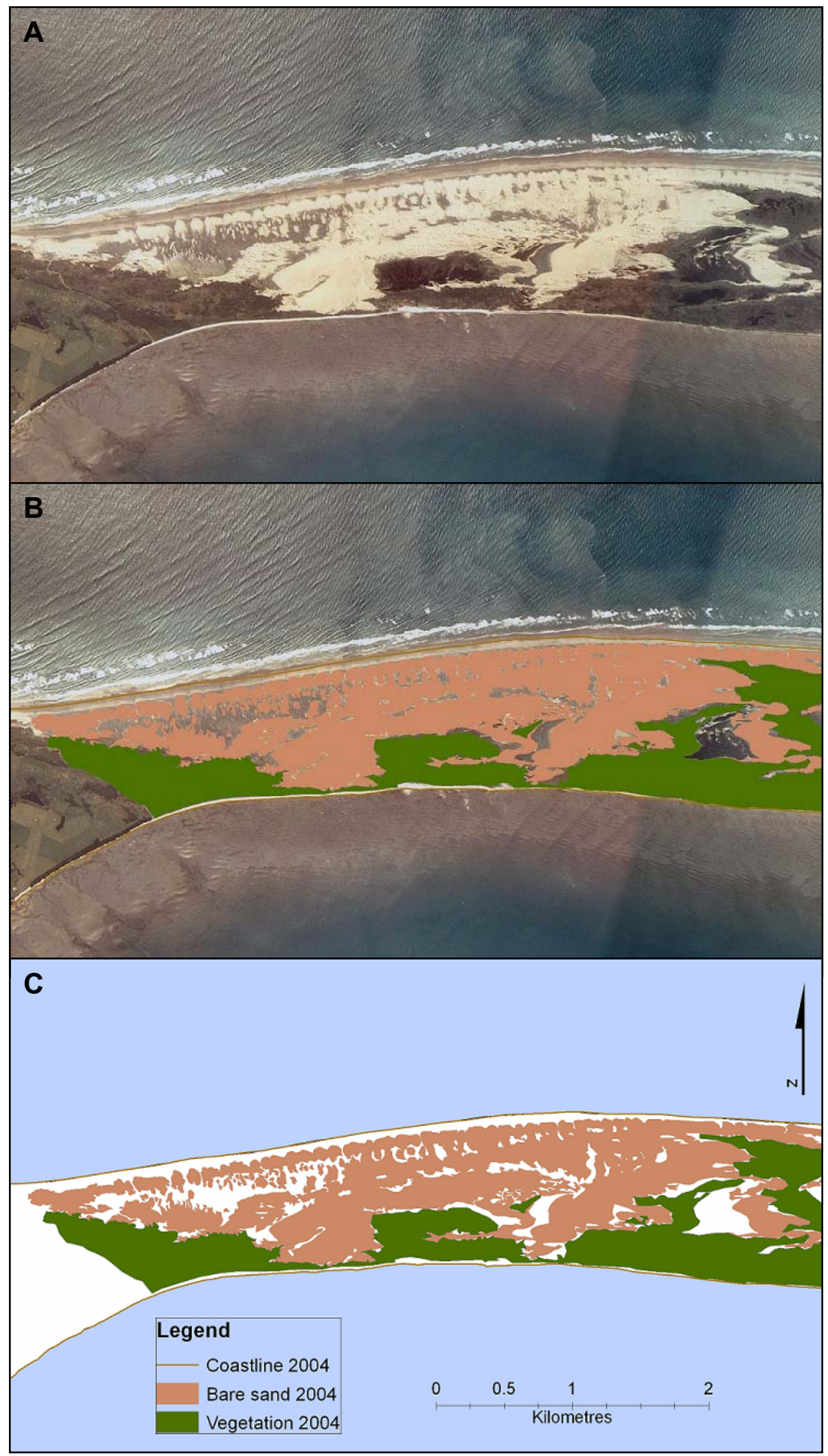

Figure 4.4: Process of creating polygons and polylines. A) 2004 Photograph of section at the base of Farewell Spit. B) Polygons depicting the vegetation and bare sand and a polyline outlining shoreline of the Spit. C) Map of these layers for clearer analysis. Note that only bare sand that is associated with the dunes is included 
To monitor shoreline change a polyline outlining the presumed high water line of the Spit was drawn for each of the photograph runs; and created as separated layers for comparison. At high tide, the high water line and swash terminus are almost the same, and the recession of the high water line is much slower than the outgoing tide. Therefore there is little horizontal displacement of this line (Klein \& Lichter, 2006) compared to that of the water edge. Although errors do occur in measurements with this line due to factors such as wave height, winds, tides and seasonality (Klein \& Lichter, 2006) it was chosen as it is a well defined repeatable line over all photograph sets.

The overall average accretion or erosion on Farewell Spit was measured using only 2004, 1975 and 1950 due to widthways georefencing errors. The width of the Spit was measured at $1 \mathrm{~km}$ increments, starting from the Roadway with straight lines $90^{\circ}$ to the Ocean Beach shoreline. The shoreline polylines of each aerial photograph set were used for this analysis and kept at a scale of 1:10,000 where, according to Gibb (1978), small shoreline displacements of $2-5 \mathrm{~m}$ become insignificant. This also helped to avoid systematic human error.

The photograph runs were not of a constant quality (figure 4.5A-E) therefore those years with poorer quality images produced less well defined polygons. The 2003 photograph run was taken on a particularly bright day and a very low tide which made discerning the true shape of the windward side of the barchan dunes difficult, therefore creating the possible illusion of greater bare sand than there actually was. It also led to further difficulties in distinguishing between vegetation and shadow. This resulted in the vegetation, sand and Shellbanks area calculations being 44.3ha, 80.2ha and 0.33ha more than in 2004 respectively. No other events such as fire or obvious sand sheet smothering vegetation 
explain this irregularity, thus the 2003 calculated area results were omitted from the analysis.

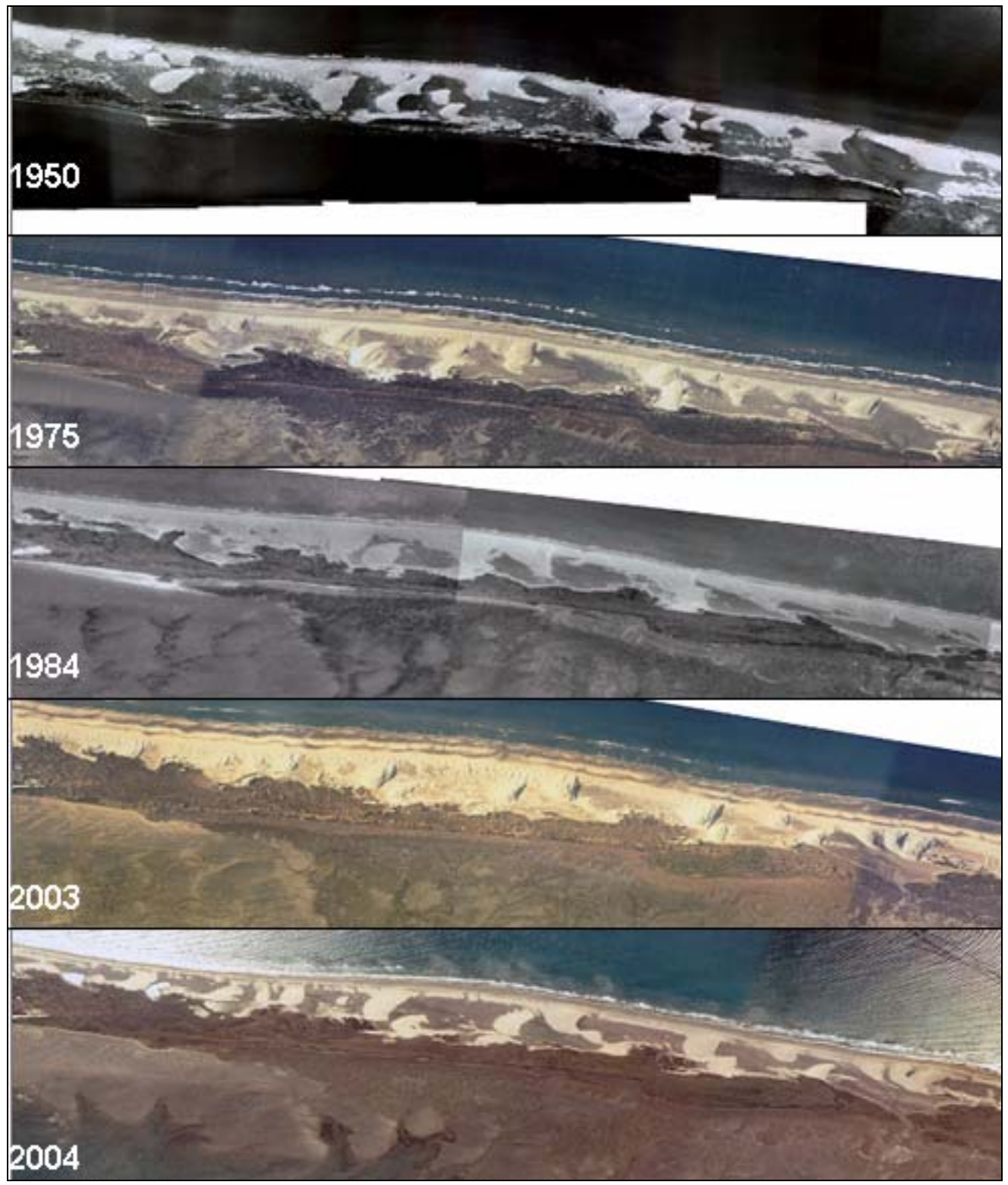

Figure 4.5: Detail the mid section of the Spit showing the different photograph quality of each aerial photograph set. 2003 is particularly bright compared to the other years.

Although the northern dune system runs along almost the length of the Spit, the classic crescent shapes of the barchan dunes do not form until almost half way along (figure 4.6A). The most recent photograph sets have the best clarity of dune forms, thus it was less complicated to identify the corresponding dunes by looking back through the years. As such these distinct dunes were numbered on the 2004 layer (figure 
4.6B), the 2003 layer was then overlain and movement measured (figure 4.6C), using the GIS measure tool. This process was repeated with the 1984 layer overlying the 2003 and so forth. The 2003 data was retained despite the photograph quality because shadows cast on the leeward side of the dunes did not hinder their measurement. The leading edges of the slip face (being the most distinct boundaries) were located for each dune and at least three lines between these measured as near as possible at right angles to the direction of movement (figure $4.6 \mathrm{C})$. The average length of these lines represents the average distance travelled by the dunes over the successive years (Levin \& BenDor, 2004). The errors were set at the maximum rubber sheeting error being $\pm 16 \mathrm{~m}$ for total distance travelled and $\pm 4 \mathrm{~m}$ for average yearly distance. 


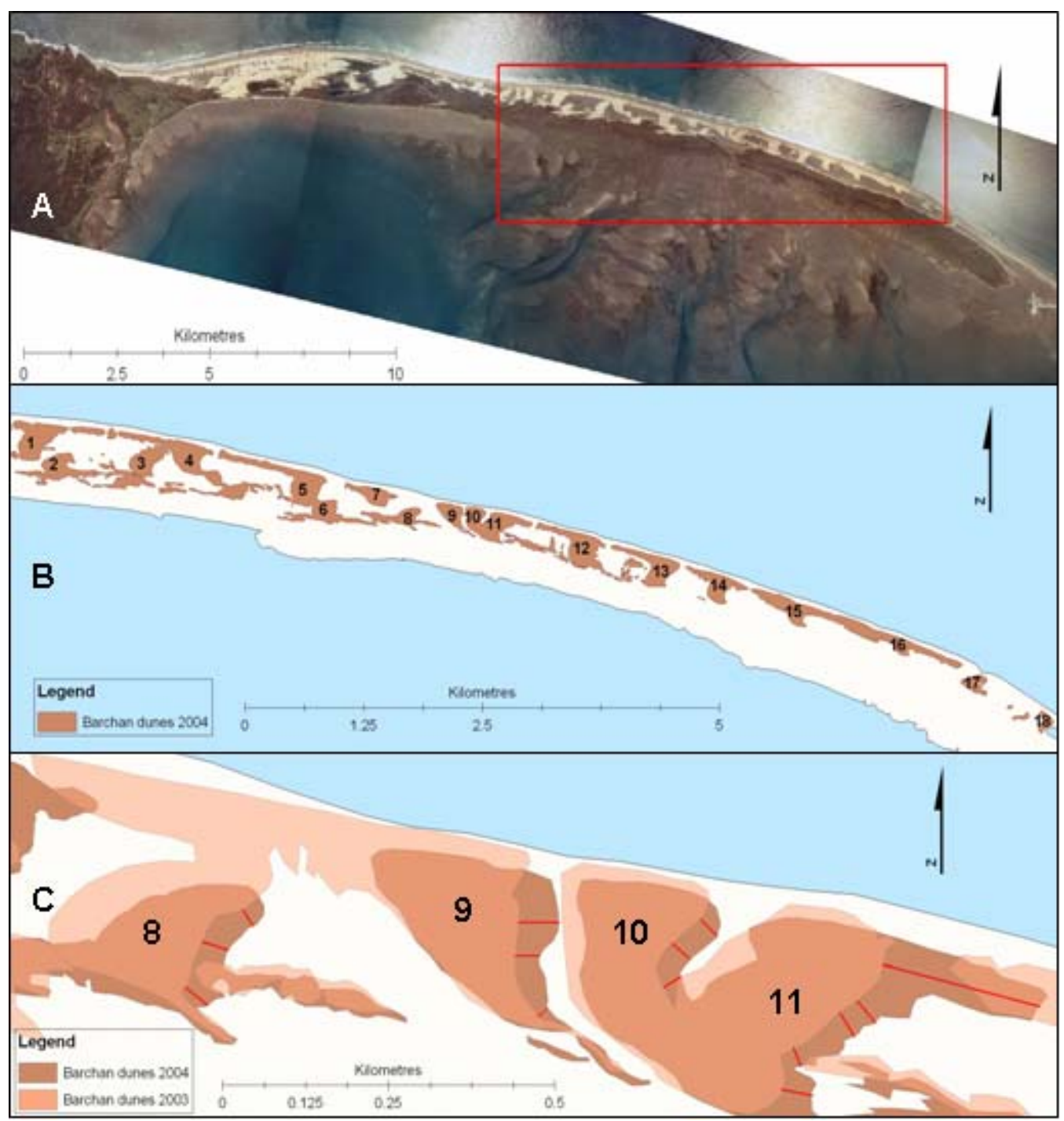

Figure 4.6: The process of measuring the movement of barchan dunes. A) The red box indicates the area of barchan dunes on Farewell Spit which was focused on. B) Digitised image of dunes with numbers indicating each measured dune. C) The red lines indicate the measurement process, calculating the movement of the leading edge of the dunes between years.

An overestimation of the rate of advance is expected in this calculation because this method does not take into account those parts of the dunes that do not advance (Levin \& Ben-Dor, 2004). Interpretation can become problematical from the branching of some dunes (Goudie, 1990 ) as seen in dune 8 (figure 4.6C); in this instance only the main slip face was taken into account. To further avoid systematic errors with the accuracy of the measuring tool within GIS the photograph sets were kept to the same magnification. 


\subsection{Sedimentological Methods}

\subsubsection{Subsurface sediment collection}

Sand samples for grain size analysis and Optically Stimulated Luminescence (OSL) ages were obtained from the vegetated dunes using a hand auger. Eleven holes were augered at various points across the length of the southern side of the spit during February 2007 their location recorded using a Garmin eTREX vista handheld GPS (generally to $4 \mathrm{~m}$ horizontal accuracy).

Samples for grain size analysis were taken at intervals of interest, such as change in sand colour or texture, directly from the auger barrel in the field and placed within a labelled bag. OSL samples were taken at $2 \mathrm{~m}$ intervals, obtained with the use of $25 \mathrm{~cm}$ stainless steel tube (figure 4.7 ) attached to the auger shaft which was then hammered into the dune. The tube was recovered, capped and labelled in the field. These samples were analysed later in the laboratory (section 4.4.1)

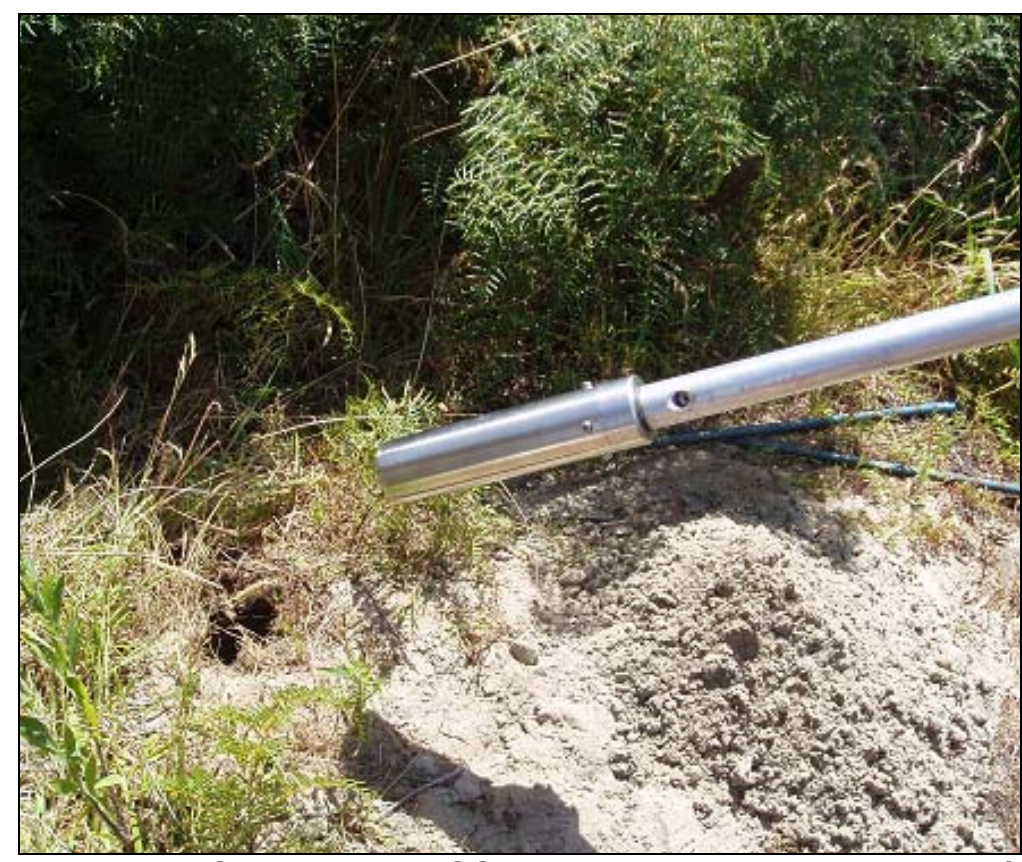

Figure 4.7: Stainless steel OSL tube attached to the auger shaft (Photograph: Helen Tribe, 2007). 
Subsurface samples from the tidal flat and lacustrine environments were obtained through vibracoring. A $20 \mathrm{~kg}$ concrete vibrator head was attached to a 3" diameter aluminium pipe and sunk into the sediment (figure 4.8). Sediment was collected in a HDPE plastic sleeve within the barrel which was extracted in the field and sealed for later analysis. Ten core samples from four transects along the southern side of Farewell Spit were collected. Each transect included a core from the inter-dune hollow lake, salt marsh or swamp, the high tide mark on the beach and tidal flat; except the Mullet Creek core which was from within the intertidal zone. Sand compaction within the cores was accounted for (table 4.2) and the percentage compaction used to correct the depths of the samples for analysis. It was assumed that the cores experienced uniform compaction throughout their length.

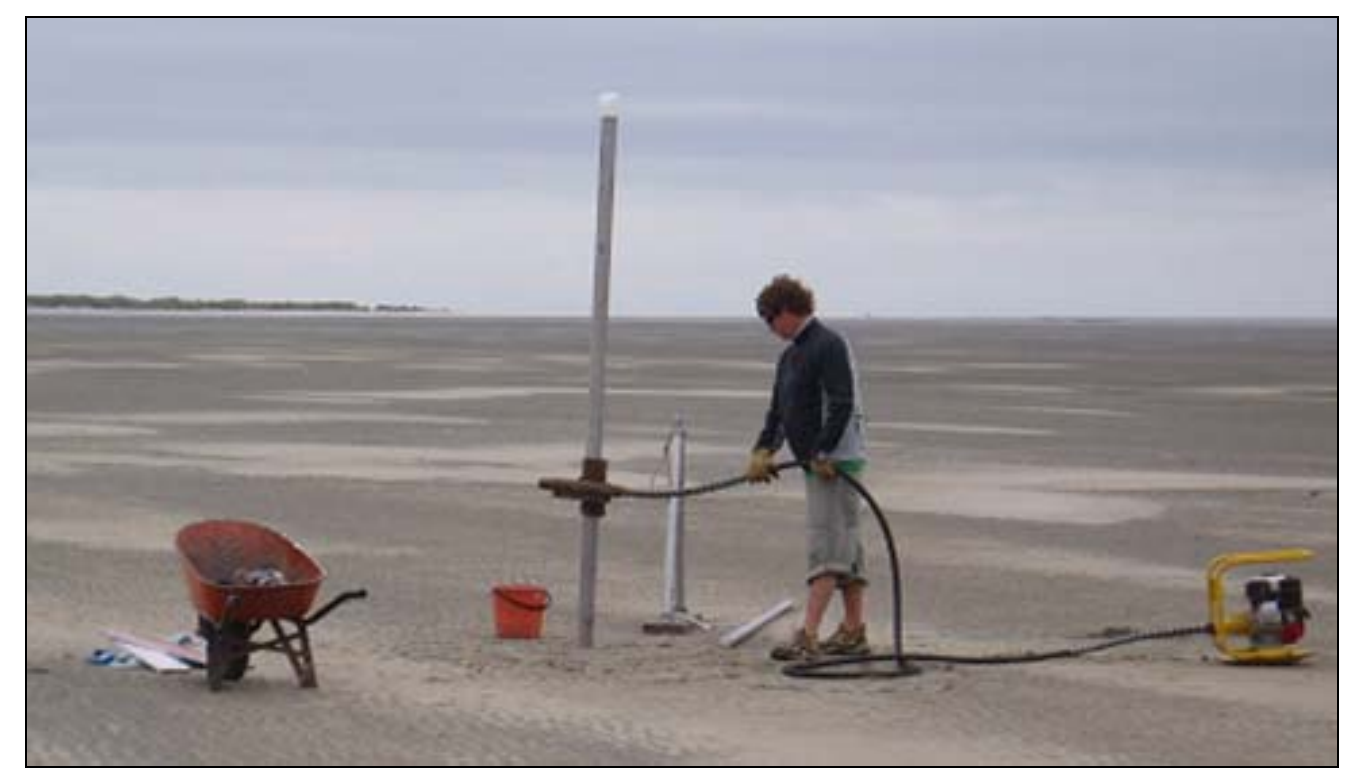

Figure 4.8: The vibracorer in use on the tidal flats of Farewell Spit. (Photograph: Helen Tribe, 2007). 
Table 4.2: Compaction within cores used to correct the depths for graphical purposes. Note the mean compaction of all cores was used for core FS7, the original compaction of which had not been recorded in the field.

\begin{tabular}{|c|c|c|c|c|c|}
\hline & Core number & $\begin{array}{l}\text { Penetration } \\
\text { depth (m) }\end{array}$ & $\begin{array}{l}\text { Core } \\
\text { recovery } \\
\text { (m) }\end{array}$ & $\begin{array}{c}\text { Compaction } \\
(\mathrm{m})\end{array}$ & $\begin{array}{c}\% \\
\text { Compaction } \\
\text { (m) }\end{array}$ \\
\hline FS1 & Stockyards Beach & 1.83 & 1.65 & 0.18 & 9.86 \\
\hline FS2 & Stockyards Tidal flat & 1.57 & 1.27 & 0.30 & 19.11 \\
\hline FS3 & Stockyards Salt Marsh & 2.10 & 1.50 & 0.35 & 23.33 \\
\hline FS4 & Froggies Tidal Flat & 2.11 & 1.91 & 0.20 & 9.48 \\
\hline FS5 & Froggies Beach & 1.30 & 1.23 & 0.30 & 23.08 \\
\hline FS6 & Froggies Lake & 2.73 & 2.41 & 0.32 & 11.74 \\
\hline FS7 & Lighthouse Beach & - & 1.33 & - & 17.50 \\
\hline FS8 & Lighthouse Tidal Flat & 1.80 & 1.52 & 0.28 & 15.60 \\
\hline FS9 & Lighthouse Swamp & 1.24 & 0.98 & 0.26 & 21.05 \\
\hline FS10 & Mullet Creek 1 & 2.17 & 1.76 & 0.41 & 18.94 \\
\hline FS11 & Mullet Creek 2 & 2.18 & 1.61 & 0.57 & 26.15 \\
\hline
\end{tabular}

\subsubsection{Grain size analysis}

The determination of particle size distributions identifies distinctively different grain sizes as a result of varying depositional environments. Therefore it is useful tool to help reconstruct these past environments (Lario et al., 2002), in terms of energy regimes required to move certain particle sizes. However, Gale and Hoare (1991) recognise that palaeoenvironmental reconstruction by this means is controversial and generally only of local application. Thus such results should therefore be used in conjunction with other evidence to establish the depositional environment of sediment (Lario et al., 2002).

Grain size analysis was carried out on 31 samples from 10 of the 11 vegetated dune augers, at approximately $1 \mathrm{~m}$ intervals. The same analysis was carried out on 71 samples from the 10 vibracores, where one core from each of the interdune hollow, beach face and tidal flats were sampled at high resolution (every $10-20 \mathrm{~cm}$ ). The remainder were sampled where a change in sediment or colour occurred. 


\subsubsection{Treatment samples}

Dune samples were air dried at $47^{\circ} \mathrm{C}$ then split using a $6 \mathrm{~mm}$ riffle box to 30 - 40g for grain size analysis. The vibracored sand samples were collected from the mid part of the core, taking care not to collect sand from the edges which may have been contaminated during the coring process. The samples were then dried and split in the same manner.

\subsubsection{Removal of organic material}

Beakers were labelled and weighed $\left(M_{1}\right)$ the sub-sample was then transferred into the appropriate beaker and weighed $\left(M_{2}\right)$. Visible plant matter was removed from the sub-sample using tweezers and weighed separately $\left(M_{3}\right)$, and the sub-sample weighed again $\left(M_{4}\right) .27 \% \mathrm{v} / \mathrm{v}$ hydrogen peroxide $\left(\mathrm{H}_{2} \mathrm{O}_{2}\right)$ was added to the sub-sample which was placed in a water bath and stirred until effervescence ceased. The water bath then was heated to over $70^{\circ} \mathrm{C}$, at which point the $\mathrm{H}_{2} \mathrm{O}_{2}$ decomposes (Gale \& Hoare, 1991), for approximately four hours and occasionally stirred. The samples were left over night to cool.

The sub-samples were recovered by washing with filtered water and centrifuging for ten minutes at 5000rpm, this process was repeated three times. The sub-samples were then dried at $47^{\circ} \mathrm{C}$ and weighed $\left(M_{5}\right)$.

The mass of the organic matter $\left(M_{6}\right)$ was obtained by

$$
M_{6}=\left(M_{4}-M_{5}\right)+M_{3}
$$

\subsubsection{Removal of carbonate}

The weighed sub-sample $\left(M_{5}\right)$ was saturated with Hydrochloric Acid $(\mathrm{HCl}) 10 \% \mathrm{v} / \mathrm{v}$ and left overnight to remove carbonates. The subsamples were recovered and dried in the same manner as outlined in section 4.5.2, then weighed $\left(M_{7}\right)$. 
The mass of the carbonate matter $\left(M_{8}\right)$ was obtained by

$$
M_{8}=M_{5}-M_{7}
$$

\subsubsection{Removal of salts}

Marine sediments may contain salts in large quantities. These salts must be removed from the sand samples because in solution the sodium ions often cause the flocculation of clay minerals (Gale \& Hoare, 1991). The six washes involved in the centrifuging process were considered sufficient to remove any salts present within the sand samples to be analysed.

\subsubsection{Removal of muds}

$0.1 \%$ Sodium Hexametaphosphate (NaHP) solution (calgon) was added to the sub-sample $\left(M_{7}\right)$ and agitated in an ultrasonic tank for at least 15 minutes, after which it was wet sieved at the $62 \mu \mathrm{m}(4 \Phi)$ boundary. Material coarser than $62 \mu \mathrm{m}$ was dried in the oven at $47^{\circ} \mathrm{C}$, then weighed $\left(M_{9}\right)$.

The mass of the muds and silts $\left(M_{10}\right)$ was obtained by

$$
\left(M_{10}\right)=M_{7}-M_{9}
$$

The mass of the final dry sample $\left(M_{11}\right)$ was obtained by

$$
\left(M_{11}\right)=M_{9}-M_{1}
$$

\subsubsection{Rapid Sediment Analyser (RSA)}

Settling tubes are increasingly used as measures of grain size as they incorporate the properties of size, shape and density. These are the controlling factors of the settling rates and entrainment thresholds of sand (Le Roux, 1998). The settling velocities of the grains are measured by the time it takes to reach the bottom of the water column. These are then converted to determine sphere diameters, generally using formulae as used in Komar \& Cui (1984). 
The Rapid Sediment Analyser (RSA) (figure 4.9) provides a more realistic gauge of sediments in a hydrodynamic environment (Syvisky et al, 1991; de Lange et al., 1997) such as Farewell Spit, as the properties of size, shape and density play a critical function in the entrainment of sediment in water (Le Roux, 1998). After being released into the water column, the grains settle out individually according to their hydrometric properties and it is assumed that they are not affected by other settling particles,

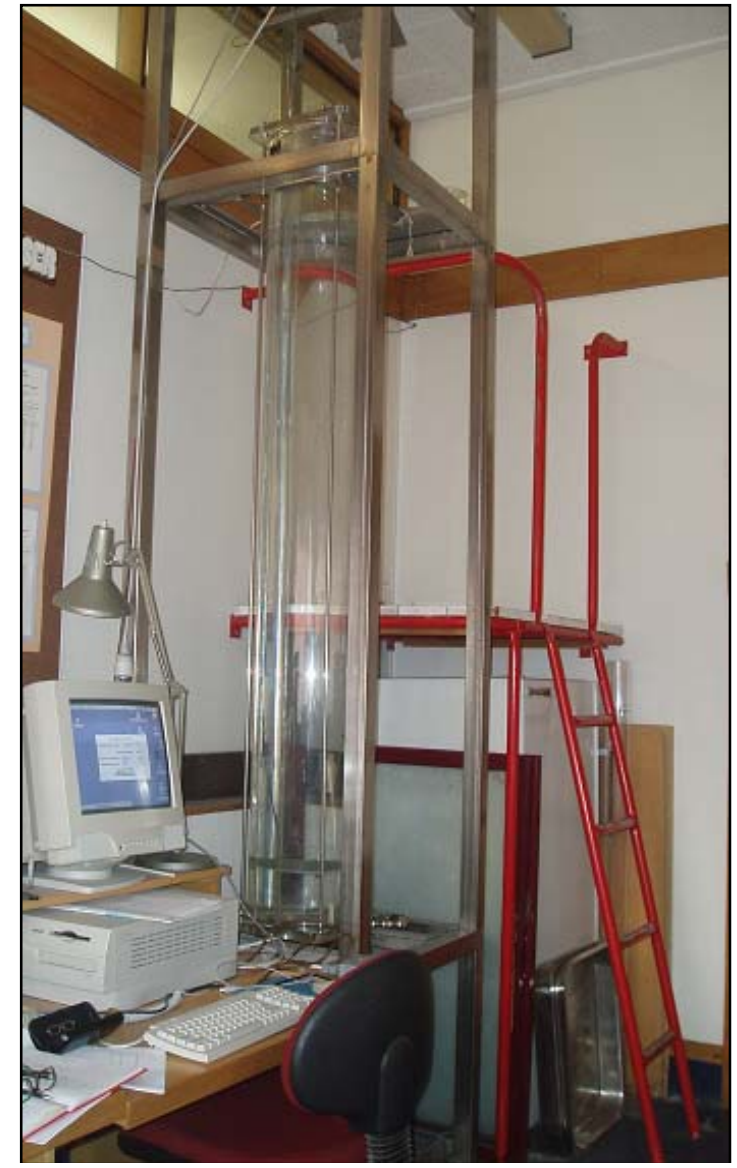

Figure 4.9: Rapid sediment analyser (Photograph: Helen Tribe, 2007) convective plumes or the up-flow of displaced fluid (Syvisky et al., 1991). However as sand grains are not perfect spheres, these assumptions can be affected as the settling behaviour of non spherical sediments such as mica flakes, may result in slower settling velocities and thus apparently smaller grains. Conversely heavy minerals tend to be finer yet heavier grains which settle out quickly indicating larger grains. There is no simple correction for this and therefore extensive examination of distribution of heavy minerals is required (Komar \& Cui, 1984).

The RSA consists of a $2 \mathrm{~m}$ settling tube within a water filled outer tube which provides insulation against temperature fluctuations. The subsamples were split using a $6 \mathrm{~mm}$ riffle box to approximately $10 \mathrm{~g}$; a sample size small enough to minimise the effect of particle 'bunching' 
within the cloud of settling sand (McManus, 1988) which can hinder the process. The settling distance within the tube was $1.76 \mathrm{~m}$ to a pan which weighed the mass at 1 second intervals to an accuracy of $\pm 0.01 \mathrm{~g}$. The data was then processed by Operating System Version 7.2 software.

To check for consistency the first and every fifth sample was run in duplicate. The first four of these comparative results (covering a total of 19 samples) showed only slight differences in the graphical (Folk) method measures of mean $( \pm 0.02 \Phi)$, sorting $( \pm 0.05 \Phi)$, while skewness had higher discrepancy $( \pm 0.24)$. The errors between samples were deemed unacceptable and the RSA unreliable when a standard known sample $(3 \Phi)$ was also tested in duplicate, the results of which also showed inconsistencies for the skewness $( \pm 0.23 \Phi)$ (table 4.3 ). Technical problems with the timing switch, which was at times not responding immediately to the release of sediment; was also causing problems with this method; 2 samples (FSA1 11m \& FSA3 3.79m) were lost as a result of this issue. As the inconsistencies in results were deemed too great to continue with this technique, the dry sieving method was employed instead. 
Table 4.3: Results of the duplicate samples run through both RSA and sieve stack. The large differences shown in the graphic (Folk) measures of skewness at FSA3, FSA5 and the known 3 phi sample represent the unacceptable RSA variation in the duplicated samples. The duplicated sieves results are more acceptable.

\begin{tabular}{|c|c|c|c|c|c|c|c|}
\hline \multirow{2}{*}{$\begin{array}{l}\text { Repeated } \\
\text { samples }\end{array}$} & \multirow[b]{2}{*}{ Method } & \multicolumn{3}{|c|}{$\begin{array}{l}\text { Moment } \\
\text { measure }\end{array}$} & \multicolumn{3}{|c|}{ Graphic (Folk) Measure } \\
\hline & & Mean & Std dev & Skew & Mean & Std dev & Skew \\
\hline FSA1 0.32 a & RSA & 2.45 & 0.24 & -1.49 & 2.44 & 0.16 & 0.38 \\
\hline FSA1 $0.30 \mathrm{~b}$ & RSA & 2.47 & 0.23 & 0.44 & 2.47 & 0.15 & 0.38 \\
\hline FSA1 0.30 & Sieved & 2.50 & 0.39 & 0.23 & 2.49 & 0.34 & 0.01 \\
\hline FSA1 5.60a & RSA & 2.36 & 0.24 & 0.81 & 2.34 & 0.19 & 0.30 \\
\hline FSA1 $5.60 \mathrm{~b}$ & RSA & 2.35 & 0.26 & -3.90 & 2.34 & 0.12 & 0.28 \\
\hline FSA2 1.00a & RSA & 2.35 & 0.27 & -1.55 & 2.34 & 0.21 & -0.22 \\
\hline FSA2 $1.00 \mathrm{~b}$ & RSA & 2.30 & 0.33 & -2.60 & 2.32 & 0.23 & -0.14 \\
\hline FSA3 1.12a & RSA & 2.46 & 0.31 & -3.68 & 2.47 & 0.19 & -0.06 \\
\hline FSA3 1.12 b & RSA & 2.41 & 0.30 & -3.62 & 2.44 & 0.19 & 0.30 \\
\hline FSA5 1.00a & RSA & 2.44 & 0.26 & -1.18 & 2.45 & 0.22 & -0.11 \\
\hline FSA5 1.00b & RSA & 2.46 & 0.34 & -4.89 & 2.49 & 0.17 & 0.05 \\
\hline FSA5 1.00 & Sieved & 2.39 & 0.34 & 0.21 & 2.39 & 0.30 & 0.00 \\
\hline 3 phi a & RSA & 2.76 & 0.23 & -0.12 & 2.76 & 0.21 & -0.10 \\
\hline 3 phi b & RSA & 2.73 & 0.43 & -4.58 & 2.76 & 0.20 & 0.13 \\
\hline FSA7 2.98a & Sieved & 2.42 & 0.34 & 0.42 & 2.42 & 0.29 & 0.02 \\
\hline FSA7 2.98 b & Sieved & 2.42 & 0.34 & 0.37 & 2.42 & 0.29 & 0.04 \\
\hline FSA11 1.50a & Sieved & 2.47 & 0.34 & 0.45 & 2.47 & 0.28 & 0.03 \\
\hline FSA11 1.50b & Sieved & 2.47 & 0.33 & -0.02 & 2.47 & 0.28 & 0.02 \\
\hline
\end{tabular}

\subsubsection{Dry Sieve}

Sieving is the most widely used method for determining grain size for analysis and results have proven to be highly reproducible (Gale \& Hoare, 1991); thus data from this study are easily comparable to similar studies elsewhere. Grain sizes are determined in terms of the smallest sieve diameters which catch them; these are then equated to equivalent sphere sizes (Le Roux, 1998). The assumption of grains being spheres results in a degree of systematic error (McLaren, 1981) as sieve stacks (figure 4.10) sort particles by shape as well as size (Komar \& Cui, 1984) and it is generally assumed that the clasts b-axis is equivalent to the sieve aperture (Gale \& Hoare, 1991). As the effects of particle shape on hydraulic behaviour is not accounted for in sieving (Gale \& Hoare, 
1991), this can distort the interpretation of depositional and energy processes operating (Le Roux, 1998).

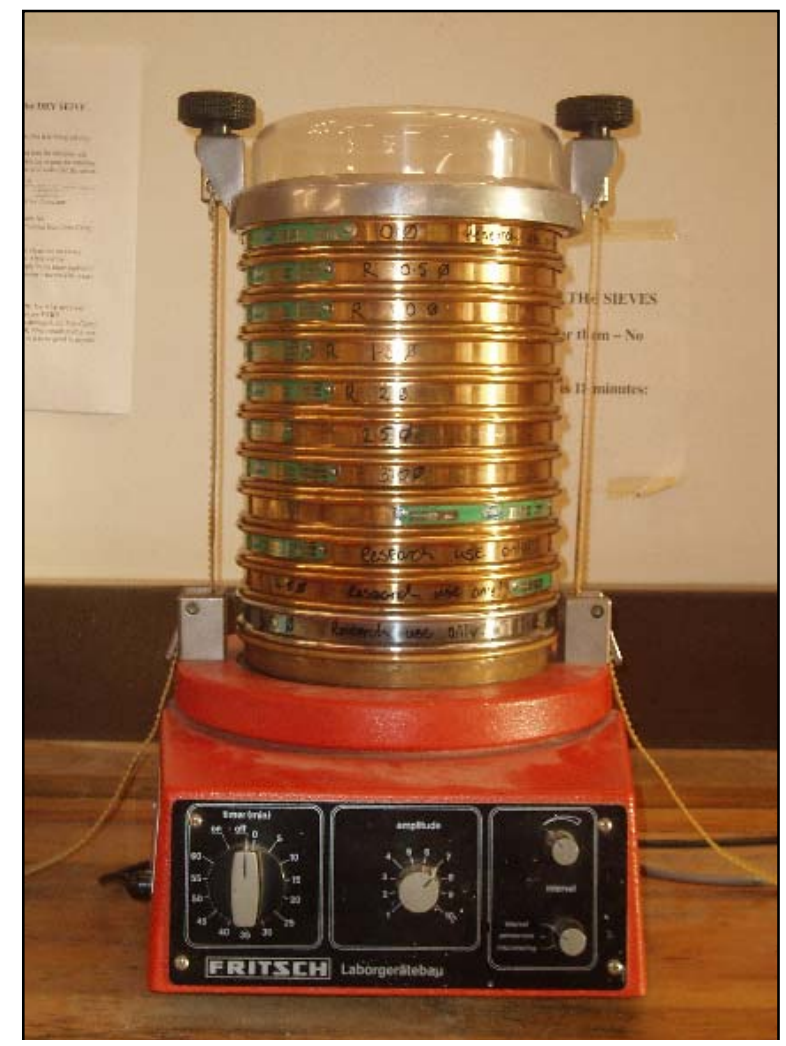

Figure 4.10: Fritsch dry sieve stack (Photograph: Helen Tribe. 2007)

The dry sub-samples were sieved at half phi intervals from $0 \Phi-5.0 \Phi$ stacked from top to bottom and shaken automatically for 18 minutes. The standard graphical procedures of Folk and Ward (1957) were used to determine sediment size characteristics of mean grain size $(\Phi)$, sorting (standard deviation, $\Phi$ ) and skewness. Kurtosis has not been included for interpretation of grain size distribution as it is not considered a measure that can provide any further information (McLaren, 1981).

The first and last duplicate samples from the RSA were sieved, to compare results (table 4.3). Two samples from A7 0.98m were also run in duplicate and given a similarity in these results the sieve remained the favoured method for grain size analysis. 
Because the settling tube and sieves measure different physical properties, textural data results can often result in considerable variation when comparing data from the two methods (de Lange et al., 1997). Inconsistent sample sizes may also distort results. All 31 samples of the vegetated dunes were split to $\sim 10 \mathrm{~g}(11.36 \pm 0.1 \mathrm{~g})$ for RSA analysis. The final 10 of these samples were however sieved instead; thus their masses were smaller than the recommended 20 - 40g for dry sieve analysis (Komar \& Cui, 1984). However, de Lange et al. (1997) found that a $10 \mathrm{~g}$ sample size gave the closest agreement for mean grain size classification between the two methods, while having only a minor affect to sorting (trended slightly to less sorted) and skewness (slightly more coarsely skewed). As sieves became the preferred method for grain size analysis the vibracored samples were split to $\sim 20 \mathrm{~g}(21.75 \pm 4.94 \mathrm{~g})$; effectively doubling the sample size of the vegetated dune samples that were sieved. However, de Lange et al. (1997) also found that increasing the mass for replicate samples within the sieves showed better sorting and finer skew but no significant change in mean grain size measurements. Therefore only the mean grain sizes within all samples would be comparable, while the skewness is shown to be the most affected by the different methods and sample sizes (figures 4.11 \& 4.12). 


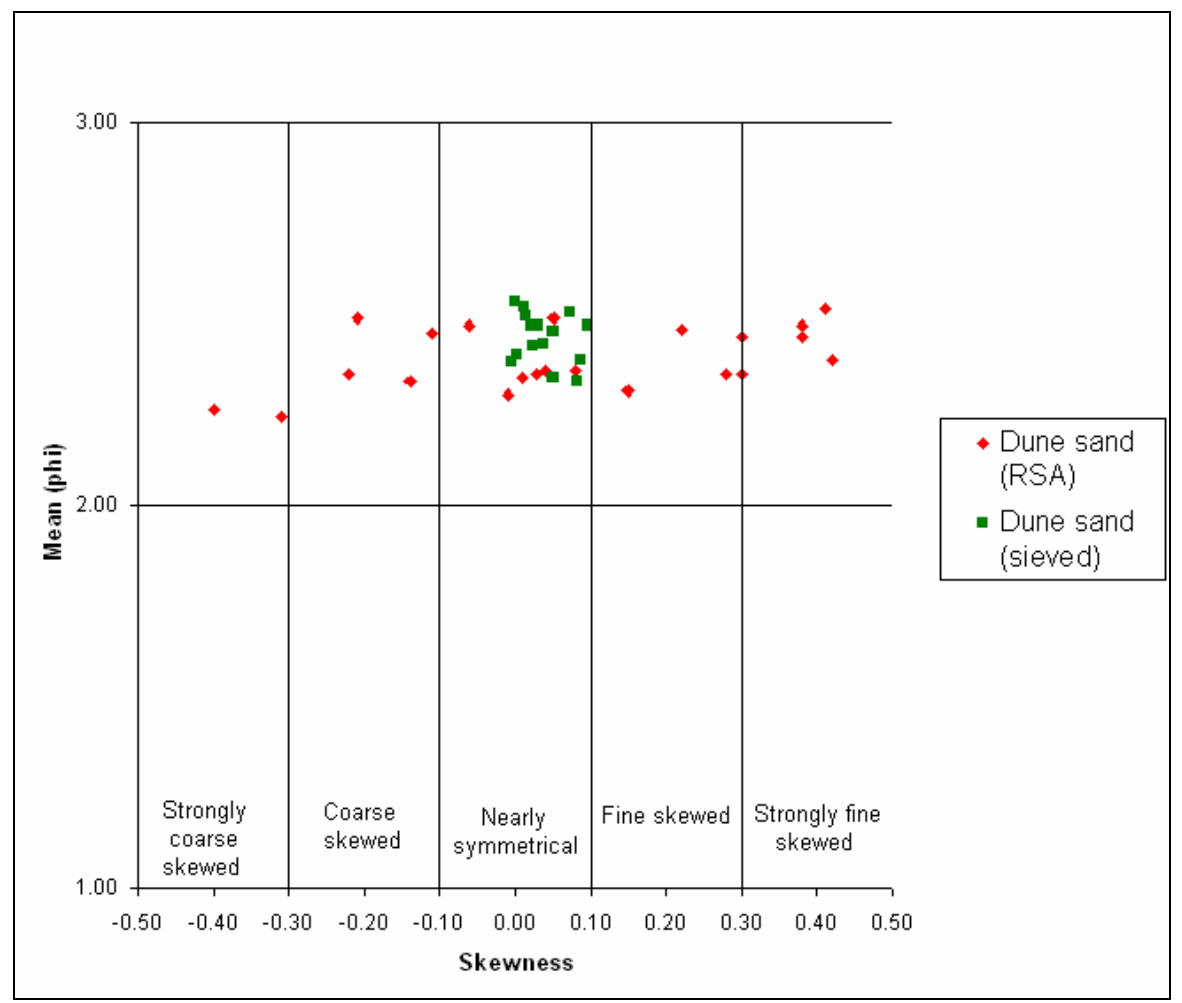

Figure 4.11: Bivariate plot of skewness and mean grain size of the vegetated dune sand samples.

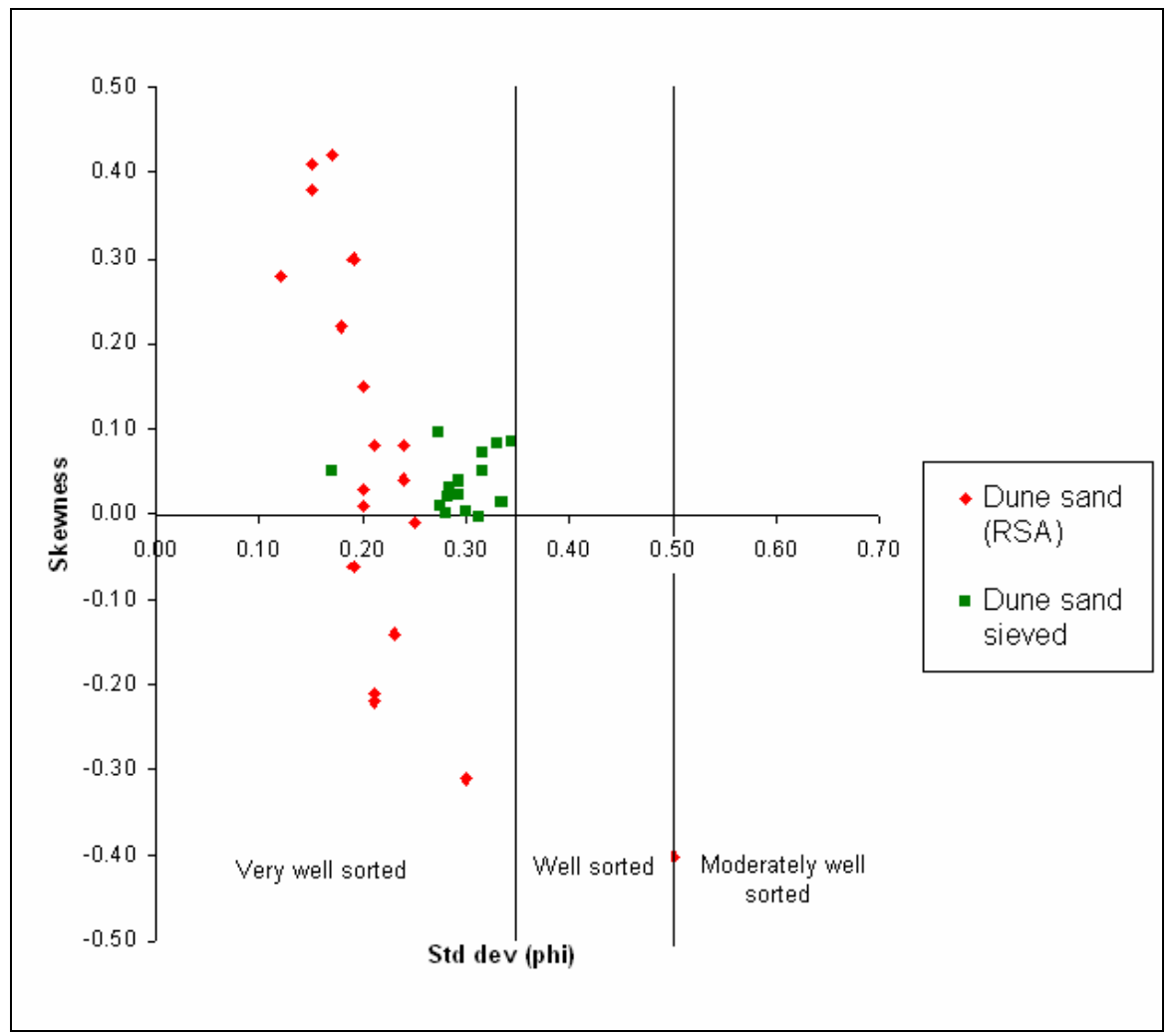

Figure 4.12: Bivariate plot of sorting and skewness of stable dune sand samples. 
Core logs were created for each vibracored sample, summarising the results of grain size analysis and the organics, carbonates and mud content. Bivariate plots were created to analyse the grain size parameters of the sand samples from differing source areas. The MannWhitney $U$ test was also employed to test whether the parameters of mean, sorting and skewness of the sand samples from the different source areas were significantly different. This test was chosen due to the small sample sizes and non-normal nature of the data sets, although only the sieved vegetated dune data was included in the statistical analysis to eliminate the possibility of measurement bias resulting from the technical faults related to the RSA.

\subsection{Chronology}

Two methods were used to establish a chronology of deposition on the Spit. Optically Stimulated Luminescence (OSL) dating of sand was used to achieve a chronology of the vegetated dunes across the length of the Spit and Radiocarbon $\left({ }^{14} \mathrm{C}\right)$ for the development of the tidal flats. Using these different dating techniques is beneficial for this study as although OSL dating can be imprecise the results are usually correct, whereas ${ }^{14} \mathrm{C}$ results are precise but can often be incorrect, requiring calibration. Therefore comparative results from these methods will support the general age determination of Farewell Spit by being both relatively precise and accurate. As such, this will offer a more detailed view on the evolutionary history of this site (Prescott \& Robertson, 1997).

\subsubsection{Optically Stimulated Luminescence (OSL)}

The OSL dating technique directly targets sediment deposition (Feathers, 2003); determining the time span after the sediments last exposure to light. This provides an age of the last period of sediment reworking (Lang \& Hönscheidt, 1999), in this instance dune activity. 
OSL dating has a wide age-range $\sim 100-100,000$ years and is applicable to inorganic material (Reiser, 2007).

As a mineral is exposed to light electrons within it become excited and move through the lattice until becoming trapped in the crystals defects; the longer it is exposed to light the more electrons accumulate in traps until all are filled (Reiser, 2007). When such a mineral is exposed to stimulation from additional energy input they can emit luminescence, the intensity of which is related to the original light dose the mineral received (Reiser, 2007). The age determination of the mineral is calculated from equation 4.1; where the paloedose is the absorbed radiation dose of a mineral and annual dose (dose rate) is the radiation dose naturally occurring in the sedimentary and cosmogenic environments.

\section{Luminescence age $=\frac{\text { Paleodose }}{\text { Annual dose }}=\frac{P}{D_{\text {tot }}} \quad($ Equation 4.1)}

Quartz and feldspar materials exhibit a variety of luminescence properties which are ideal for mineral specific measurements (Wintle, 1993) and as such are the most commonly used minerals for this method (Reiser, 2007). Sands which have been well exposed to sunlight during cycles of beach washing and aeolian transport should be well bleached at their time of burial. This enables their luminescence signal to be easily zeroed (Wintle, 1993) and reduces error involved from insufficient bleaching, which is a serious complication leading to the overestimation of ages (Ballarani et al., 2003; Reiser, 2007). However, this is unlikely as investigations have shown that weakly or briefly illuminated sediments reset the OSL signal after only a few minutes of exposure (Reiser, 2007). 
Analyses were undertaken at the Victoria University of Wellington School of Geography, Environment and Earth Sciences laboratory. Optically stimulated luminescence ages were obtained by an adapted Single Aliquot Regenerative dose (SAR) protocol for 4 sand samples following the technique described by Murray and Wintle (2000). Pretreatment of the samples included removal of carbonates and organics with $10 \% \mathrm{HCl}$ and $10 \% \mathrm{H}_{2} \mathrm{O}_{2}$ respectively with distilled water rinsing in between. The 90 - 200 $\mu u$ grain size was extracted by sieving and heavy liquid mineral separation was carried out in Lithium-polytungstate, followed by HF ( $40 \%)$ etching and washing. The quartz grains were then fixed on aluminium disks with silicon oil. All luminescence measurements were carried out using a standard Riso TL-DA-15 system, equipped with 3 Hoya U340 optical filters for irradiation and green halogen light source for stimulation (Reiser, 2007).

Significant success has been achieved for dating dunes and this method is becoming standard for chronologies from decadal (Smith et al., 1990 in Wintle, 1993; Ballarani et al., 2003) to wider time frames (up to 100,000 years) (Wintle, 1993; Reiser, 2007). Hawke and McConchie (2006) found reliable results in dating the sand dunes in the southern Manawatu which lies roughly $200 \mathrm{~km}$ east of Farewell Spit at a similar latitude, using the same laboratory and OSL procedures used for the samples in this thesis.

\subsubsection{Caesium $137\left({ }^{137} \mathrm{Cs}\right)$}

Caesium $137\left({ }^{137} \mathrm{Cs}\right)$ is a radio nuclide by-product of the atmospheric nuclear bomb testing which began in 1945 and ended in 1980 (Matthews, 1995). ${ }^{137} \mathrm{Cs}$ reaches the ground surface through rainfall or gravitational settling and has a half life of 30.17years (Owens et al., 1996) and is strongly absorbed by silt, clay particles or organic matter, contaminating only the top few millimetres of the soil (Bishop et al., 
1991). Gamma-spectrometry used in the initial stages of OSL dating directly determines the presents of this radio nuclide.

Using ${ }^{137} \mathrm{Cs}$ as a dating technique was pioneered in the 1970's (Whitehead et al., 1998) and since has been extensively used as a stratigraphic marker for determining geomorphic processes such as sediment erosion and deposition (Vanden et al., 2001). It is useful in this respect as the radio nuclide is essentially non exchangeable and has a limited mobility by chemical processes (Owens et al., 1995) and so leaves a distinct signature within the soil profile.

Concentrations of radio nuclides have varied over time; their peak deposition occurred in the mid 1960's, corresponding to the peak of atmospheric bomb testing (Whitehead et al., 1998). The nuclear fallout peak in New Zealand occurred in 1964, 2 - 3 years after the northern hemisphere (Matthews, 1995), receiving only a tenth of the northern hemisphere fallout (Bishop et al., 1991). After this time fallout declined rapidly before another peak occurred between 1966 - 1974 resulting from atmospheric bomb tests at Mururoa Atoll (Matthews, 1995). The identification of these peaks is useful to help date sediment with ${ }^{137} \mathrm{Cs}$ signatures. Where ${ }^{137} \mathrm{Cs}$ is evident within the sample it is understood that it would have been at or very near the surface $\sim 1952$ (Bishop et al., 1991) and an age can be established according to the half life. No evidence of ${ }^{137} \mathrm{Cs}$ in the sample indicates that the sand was covered before 1952 thus giving us a minimum age for the depth of the sample.

\subsubsection{Carbon $\left({ }^{14} \mathrm{C}\right)$}

All living organisms maintain a constant ratio of the three naturally occurring carbon isotopes ${ }^{12} \mathrm{C}$ to ${ }^{13} \mathrm{C}$ to ${ }^{14} \mathrm{C}$, of which ${ }^{14} \mathrm{C}$ is produced by cosmic ray neutrons in the upper atmosphere and is radioactive (half life of $5730 \pm 40 \mathrm{y}$ ) (Prior, 2007). ${ }^{14} \mathrm{C}$ combines with other atmospheric carbon and oxygen to form $\mathrm{CO}_{2}$ and is assimilated into organisms 
through photosynthesis or water absorption (Worsley, 1990). When an organism dies ${ }^{14} \mathrm{C}$ is not replenished and will steadily decay while the ratio of the stable isotopes ${ }^{13} \mathrm{C}$ to ${ }^{12} \mathrm{C}$ (represented as $\delta^{13} \mathrm{C}$ ) remains the same (Worsley, 1990; Prior, 2007). Conventional Radiocarbon Age (CRA) calculates the age of an organism at the time of its death by measuring the current ${ }^{14} \mathrm{C}$ content against that which it had when it was alive (equation 4.2) as dictated by the $\delta^{13} \mathrm{C}$ ratio (Turney, 2006).

$$
C R A=-8033 \ln \left(\frac{A_{S N}}{A_{O N}}\right)
$$

Where $A_{S N}$ is the sample activity and $A_{O n}$ the modern oxalic standard. Both of which are normalised for isotopic fractionation which is correcting $\delta^{13} \mathrm{C}$ to $-25 \%$ (Prior, 2007).

There are two methods of measuring ${ }^{14} \mathrm{C}$; decay counting which involves counting the beta particles emitted as ${ }^{14} \mathrm{C}$ decays, and Accelerated Mass Spectrometry (AMS) which directly counts the carbon isotopes. The AMS technique speeds up the negatively charged molecular ions of the sample through an accelerator which are then separated by a series of magnets, according to their mass, and counted by a detector (Elmore \& Phillips, 1987). As each carbon isotope will have a different mass they can be counted separately and ages determined by their ratios.

Two Autrovenus stutchburyi (New Zealand cockle) shells from differing depths $(0.42 \mathrm{~m} \& 0.68 \mathrm{~m})$ within the Froggies tidal flat core $(\sim 300 \mathrm{~m}$ seaward of MSL mark) were chosen for ${ }^{14} \mathrm{C}$ dating using AMS. A. stutchburyi is most abundant between MSL and mean low water spring (MLWS) and it remains within the same small area for its $10-15$ year lifespan, feeding within 2 - 3mm of the surface (Gibb, 1986). The cockle has a shallow natural burrowing depth of $<25 \mathrm{~mm}$ (Schmechel, 2001) 
and the sudden influx of either fresh or pure seawater, or rapid sedimentation may cause the organisms death (Gibb, 1986). Intact shells are therefore assumed to have died in situ and sediment amassed above them. Thus the dates achieved from the intact shell at $0.42 \mathrm{~m}$ will be applicable to the maximum age of the tidal flat at this depth.

The samples were sent to the Radiocarbon Laboratory at the University of Waikato where they were cleaned and chemically pre-treated using $0.1 \mathrm{~N}$ hydrochloric $(\mathrm{HCl})$ acid wash, before being converted to $\mathrm{CO}_{2}$ by reaction with phosphoric acid $\left(\mathrm{H}_{3} \mathrm{PO}_{4}\right)$ which was then reduced to graphite with Zinc $(\mathrm{Zn})$ at $600^{\circ} \mathrm{C}$ using an iron catalyst (University of Waikato, 2008). The graphite was then sent to the Rafter Radiocarbon Dating Laboratory for AMS analysis. The results were based on the Libby half-life of $5568 \pm 30$ years for consistency with other publications and were corrected for isotopic fractionation. The results are Conventional Ages or \% Modern as per Stuiver and Polach (1977). Calibrated Ages using OxCal v3.10. (Bronk Ramsey, 2005) are also recorded; with marine data from Hughen et al. (2004).

Goudie et al. (1990) notes that marine shells are predisposed to contamination from additional ${ }^{14} \mathrm{C}$ infiltrating the shell after its death from ocean water due to the marine reservoir effect. Although this can result in significant variations in ${ }^{14} \mathrm{C}$ concentrations and ages, it is well documented (Ascough et al., 2005). Extensive databases (which include Farewell Spit) exist to allow for calibrating results to the local marine reservoir values (Prior, 2007). Also, the deeper layers of the shell are less susceptible to this effect and are thus more appropriate for dating, notwithstanding this; all results should be regarded as maximum ages (Goudie et al. 1990). 


\subsection{Summary}

The methods used in this thesis were presented and discussed in this chapter. Surveying was used to ascertain the subaerial profile of sections of the Spit and corrected to the Collingwood or Whanganui Inlet MSL. GIS mapping of aerial photograph sets was used to analyse the rates of change and stability of features on the Spit. The sand samples were obtained from the vegetated dunes using a hand auger and from lacustrine environments using a vibracorer. A series of acid washes and wet sieving determined the organic, carbonate and mud contents of the sand samples. Due to technical problems with the RSA, the dry sieves became the preferred method for grain size analysis. Ages of samples taken from sand dunes were determined by OSL and tidal flat shells using ${ }^{14} \mathrm{C}$. 


\section{Chapter Five: Results}

\subsection{Introduction}

Farewell Spit is a dynamic environment, from the high energy open ocean Tasman Sea side along its northern edge, to the low energy tidal flats within the more sheltered, southern, Golden Bay side. Active dunes extend along the northern side forming a vast sand sheet near the Spit's base, and barchan forms towards the east. Vegetated dunes form a series of linear ridges along the southern side with salt marshes marking the limit of the intertidal zone which extends southward as broad sand flats. Areas of interest to this chapter are identified in figure 5.1 .

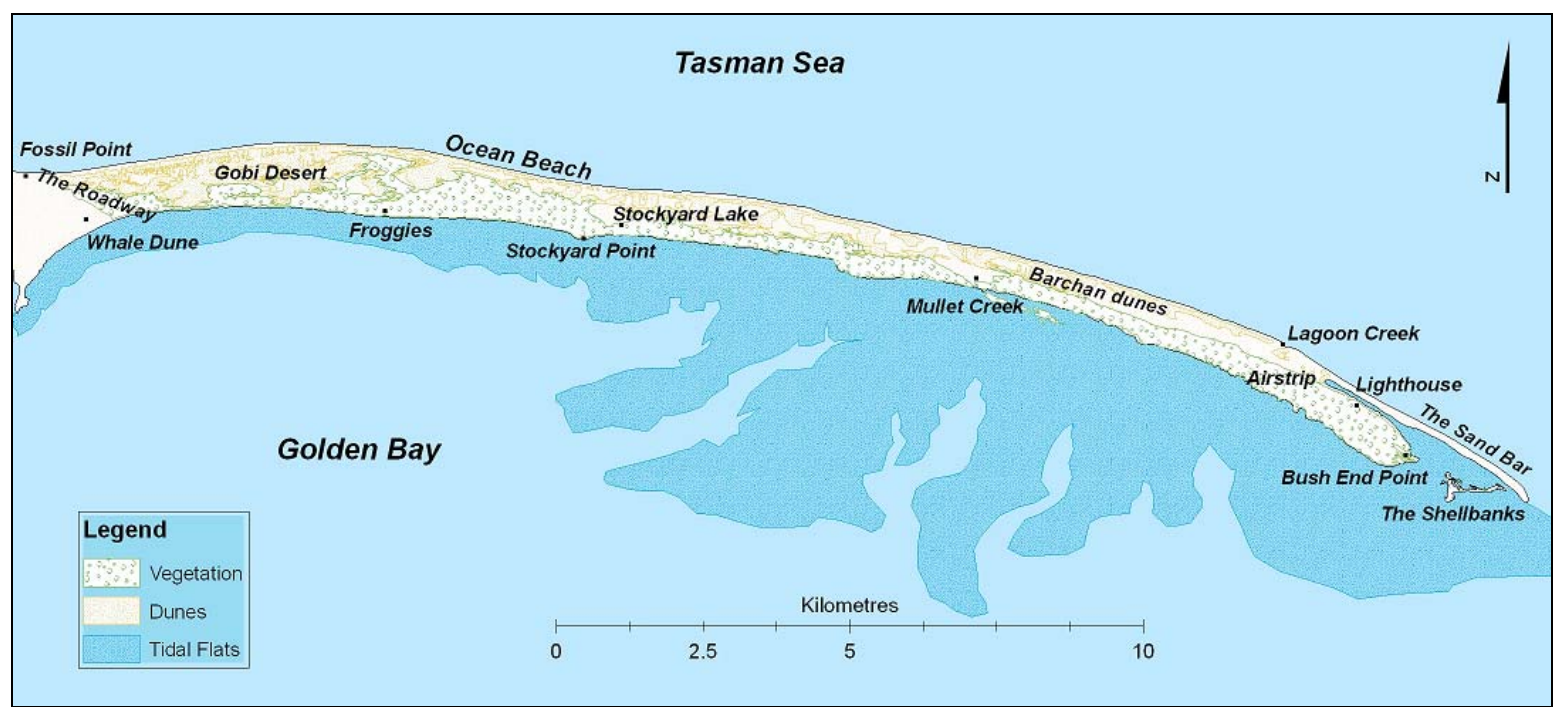

Figure 5.1: Map of areas of data collection (or of specific mention) on Farewell Spit within this chapter. 


\subsection{Geomorphic zones}

\subsubsection{Ocean Beach}

The Ocean Beach system is exposed directly to the Tasman Sea forming the northern margin of the Spit. It is characterised by wide, subdued, multi-bar beach-faces similar to the barred dissipative modes described in Masselink and Short (1993) (figure 5.2). The beach varies in width from $\sim 320 \mathrm{~m}$ close to Fossil Point, narrowing to between $\sim 10$ $80 \mathrm{~m}$ along the band of surveyed dunes, before widening again to $\sim 250 \mathrm{~m}$ at the Airstrip. Up to four shore parallel bars occur in the inshore zone (figure 5.2). The high tide bar varies in height between $0.3-0.6 \mathrm{~m}$ and $40-95 \mathrm{~m}$ in width, the distance between high and low tide bars ranges from $25-70 \mathrm{~m}$. Rip channels intermittently cut the bars which sinuously run the length of the beach. Periodically the high tide bar trails off as the Spit curves, forming into the low tide bar as a new high tide bar develops on the inner edges (figure 5.2). The beach itself transforms into a bar which subaerially extends past Bush End Point for $\sim 2 \mathrm{~km}$ and is activated during spring tides (figure 5.3A \& B).

The beach face has a low gradient, averaging $1.15^{\circ}$ from the foreshore towards the backshore and active dunes; in places storm berms are also evident along the beach. Further to the east, larger channels, such as Mullet and Lagoon Creeks, cut across the beach, draining the salt pans which form in the backshore between the dunes where the sand surface has deflated to high water elevations. Water pools in these during perigean tides and may take months to dry out. 


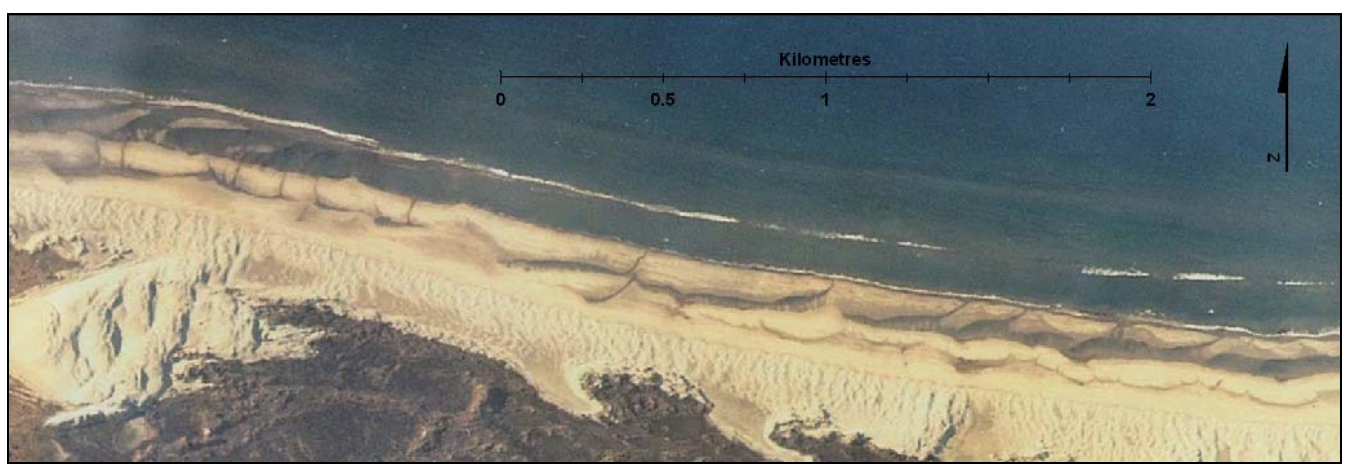

Figure 5.2: Detail of 2003 aerial photograph, showing multiple shore parallel bars along Ocean Beach. Note the high tide bar seen at the left of the photograph becomes the low tide bar as the Spit curves towards the right of the picture as a new high tide bar forms.

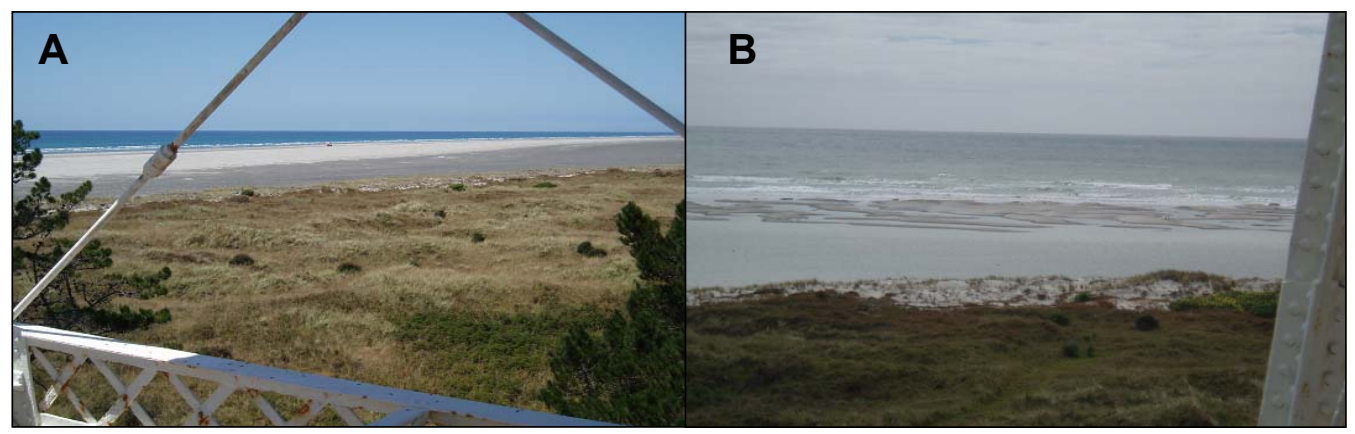

Figure 5.3: The sand bar opposite the lighthouse A) Photographed from the lighthouse during mid-tide 13 February 2007 . B) The same bar is activated by a $5.1 \mathrm{~m}$ tide 27 October 2007 (Photographs: Helen Tribe, 2007)

\subsubsection{Northern Dune System}

The northern dune system consists of expansive unvegetated, mobile sand running the length of Farewell Spit (figure 5.3). At the landward end a transgressive sand sheet locally known as the Gobi Desert, is up to $872 \mathrm{~m}$ wide, almost reaching across to the low energy Golden Bay side. Further east along the Spit barchan shaped dunes dominate. Their classic crescent shapes occur in regions with a steady prevailing wind direction and limited sand supply (Whittow 1984; Schwammle \& Hermann, 2005). The windward/stoss-side (western end) typically slopes between $8^{\circ}-20^{\circ}$ and the slip face/lee-side (eastern end) has a maximum angle of $32^{\circ}$, being the angle of repose for quartz sand (Bagnold, 1941 In Gay, 1999) (figure 5.4). At the western end of this dune belt the barchans are large; dune 4 (figure 5.5A) rises to an elevation of $19.4 \mathrm{~m}$ above the Collingwood mean sea-level (AMSL) 
(table 5.1). They reduce in size towards the eastern tip where dune 4 is 9.2m AMSL (figures 5.5A-E \& table 5.1).

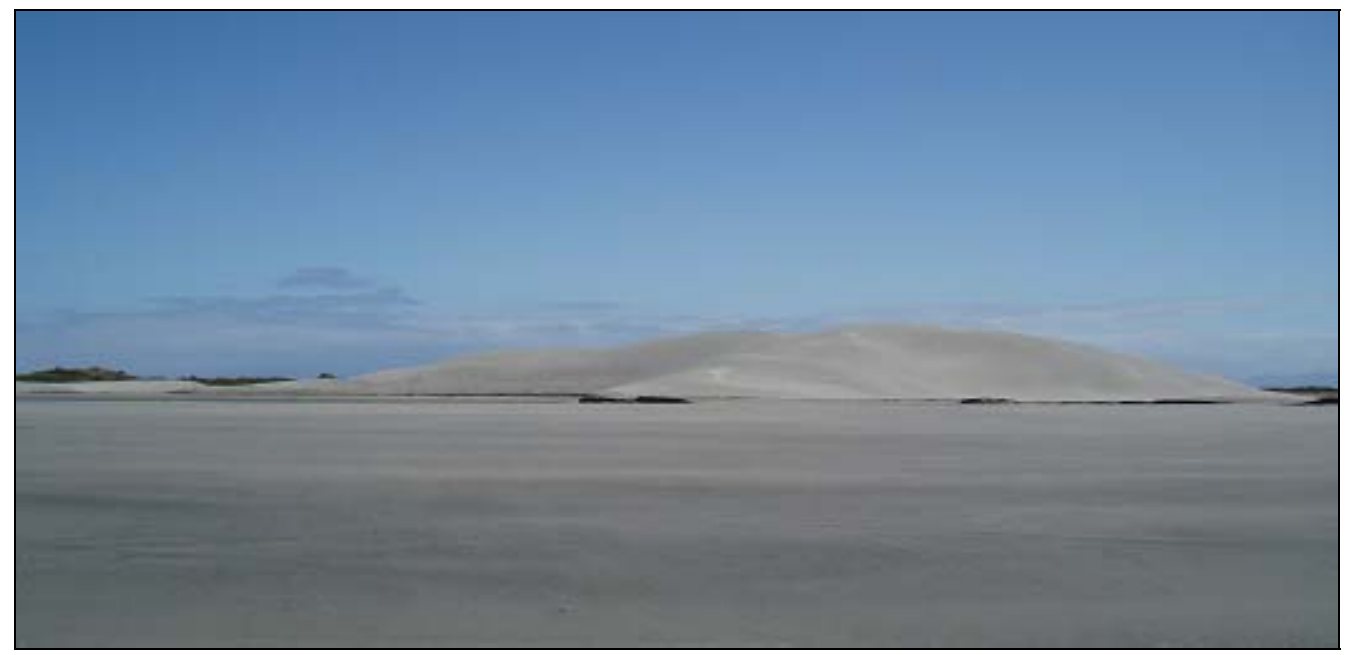

Figure 5.4: The northern side of barchan dune 17 facing south. Note the steep leeward side indicating movement toward the left (east) (Photograph: Helen Tribe, 2007).

Table 5.1: Size parameters of barchan dunes as they march eastward along Farewell Spit. See figure 5.6 a for dune locations

\begin{tabular}{|l|c|c|c|c|}
\hline${ }^{*}$ Dune & $\begin{array}{c}\text { Height ASL } \\
(\text { surveyed) } \\
(\mathbf{m})\end{array}$ & $\begin{array}{c}\text { Length } \\
\text { (surveyed to } \\
\text { highest point) } \\
(\mathbf{m})\end{array}$ & $\begin{array}{c}\text { Width } \\
\text { (surveyed) } \\
(\mathbf{m})\end{array}$ & $\begin{array}{c}\text { Length of entire } \\
\text { dune (measured } \\
\text { on 2004 aerial } \\
\text { photograph) }(\mathbf{m})\end{array}$ \\
\hline $\mathbf{4}$ & 19.4 & 181.7 & 307.6 & 284.8 \\
$\mathbf{1 2}$ & 17.8 & 211.0 & 250.6 & 337.4 \\
$\mathbf{1 4}$ & 15.4 & 184.7 & 193.2 & 274.5 \\
$\mathbf{1 5}$ & 9.9 & 51.0 & 318.8 & 174.7 \\
$\mathbf{1 7}$ & 9.2 & 46.5 & 269.5 & 90.6 \\
\hline
\end{tabular}




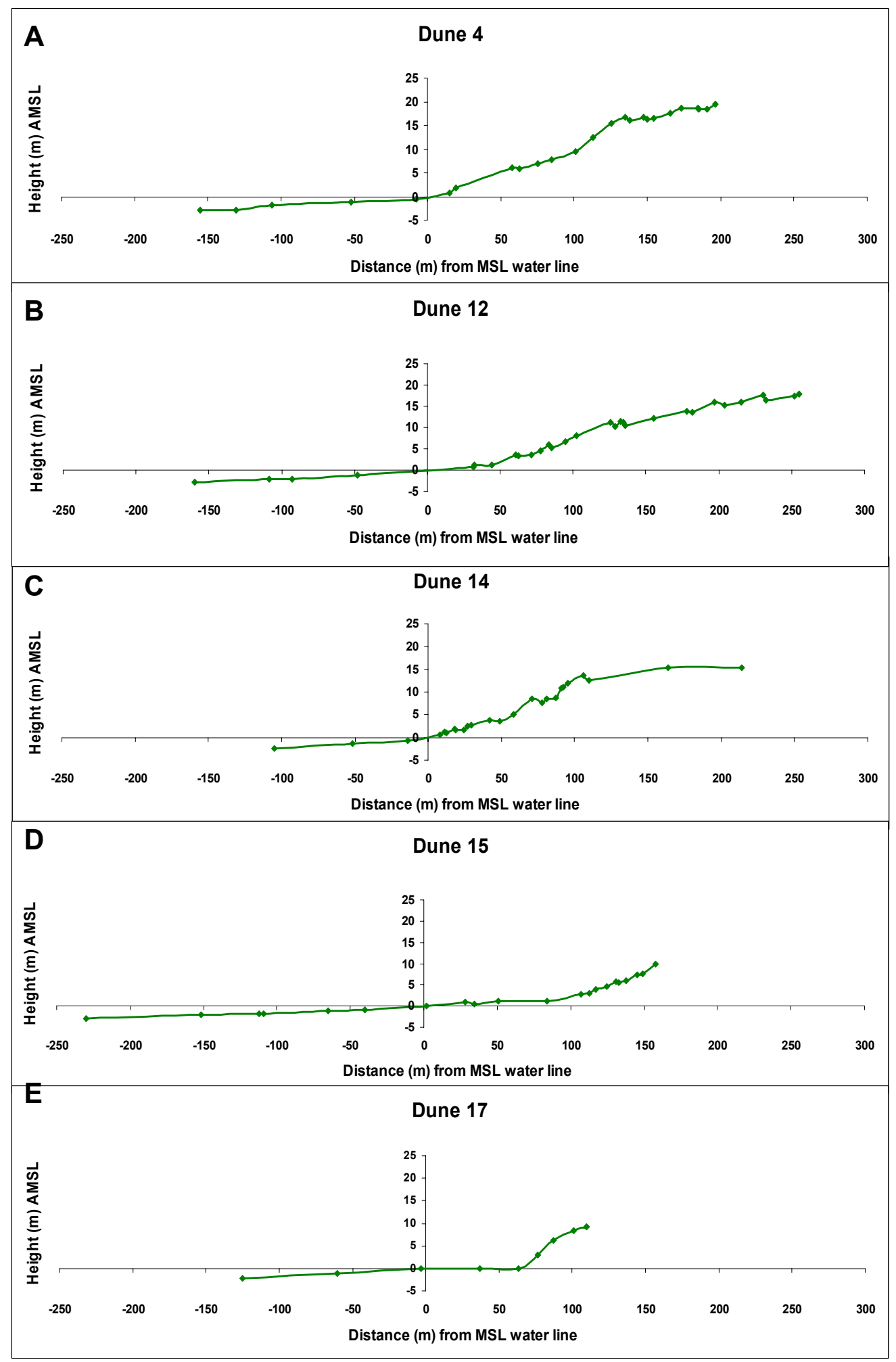

Figure 5.5: Surveyed transects of barchan dunes and beach face along the northern dune system. The intersection of the $X$ and $Y$ axes represents the Collingwood MSL of $2.6 \mathrm{~m}$. See figure $5.6 \mathrm{~A}$ for dune locations. 
Digitised images of the barchan dunes, illustrating their shape and positioning on each of the aerial photograph sets are displayed in figure 5.6. Their eastward march is evident as the position of the numbered dunes moves towards the end of the Spit over the 54.5 year time frame. Analysis of the dunes eastward advance shows that those towards the end of the spit move further and faster (figure 5.6), which is related to their reduction in height and volume (Bagnold, 1941 In Gay, 1999). Figure 5.7 shows a relatively smooth rise in travelling distance from dune 11 , which travels $795 \pm 16 \mathrm{~m}$, to dune 18 covering a distance of $1810 \pm 16 \mathrm{~m}$ over the total time span. The dunes at the beginning of the barchan belt, however, experience more varied travelling distances. These range from dune 1 travelling $611 \pm 16 \mathrm{~m}$ to dune 8 which moves $1030 \pm 16 \mathrm{~m}$. The average yearly movement data follow the same pattern as the average total movement to several orders of magnitude less.

The rates of dune movement are shown to be more erratic at the shorter time frames when the data is measured between each aerial photograph set (figure 5.8). The 1.7 years between the 2003 and 2004 photographs show the greatest rates of movement and also the greatest fluctuations, indicating that much of this movement is wind event based. Wind data has shown this period to have had some extreme gusts of $\sim 100 \mathrm{~km} / \mathrm{h}$ from the northern and southerly quarters (figure 5.9A \& B); where on at least three occasions these were the highest wind speeds recorded in the seven year record. Although the movement of dune 2 during $2003-2004$ is very rapid $(63.4 \pm 4 \mathrm{~m})$, much of this represents one of the horns forming a runner, accelerating quickly away from the rest of the dune. Dune 12 appears to have the most consistency with the distances travelled, ranging between $\sim 12.6-19.5 \mathrm{~m}$, over all the time frames (1.7 years -25.5 years). While dune 8 is the least consistent, ranging between $\sim 9.7-32.2 \mathrm{~m}$. 


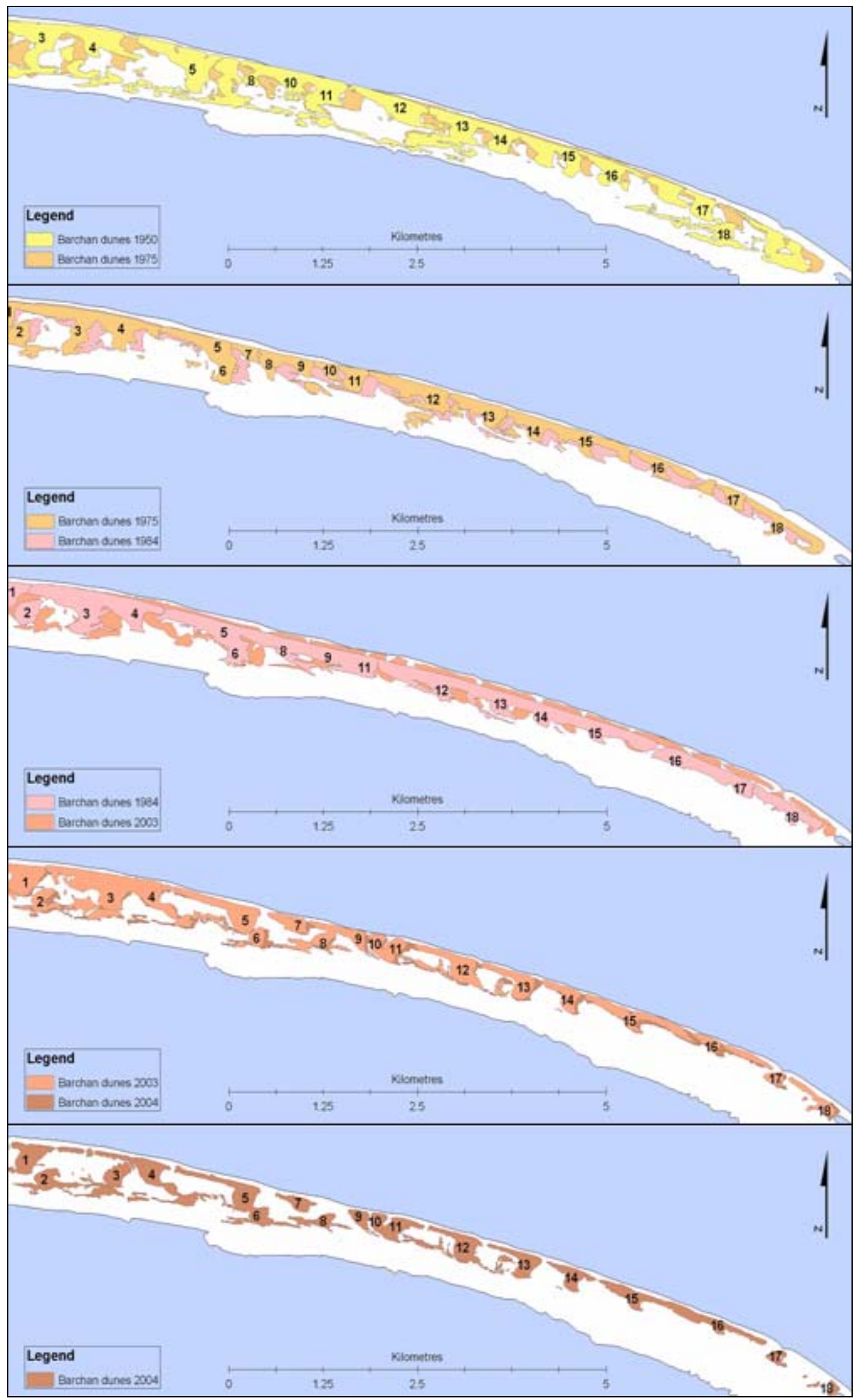

Figure 5.6: Progression of the barchan dunes as they move east along Farewell Spit. Each dune is numbered and monitored over the aerial photograph sets to measure distances travelled. Note several dunes were difficult to identify on some photographs and have been omitted. 


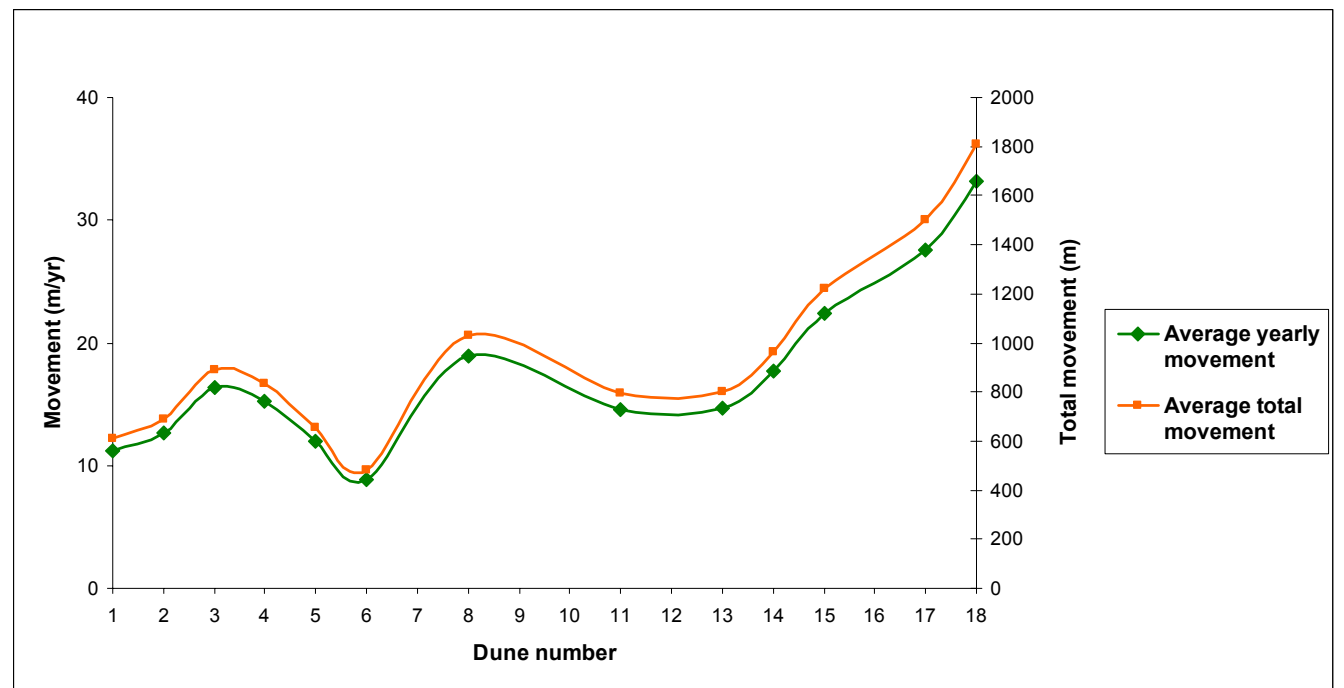

Figure 5.7: The average yearly movement and the average total movement rates of the barchan dunes analysed for the $54.5 \mathrm{y}$ period of the photograph runs. Only dunes with data sets covering all photograph runs were included in the total dune movement graphs. The average total movement has an error of $\pm 16 \mathrm{~m}$ and the average yearly movement has an error of $\pm 4 \mathrm{~m}$.

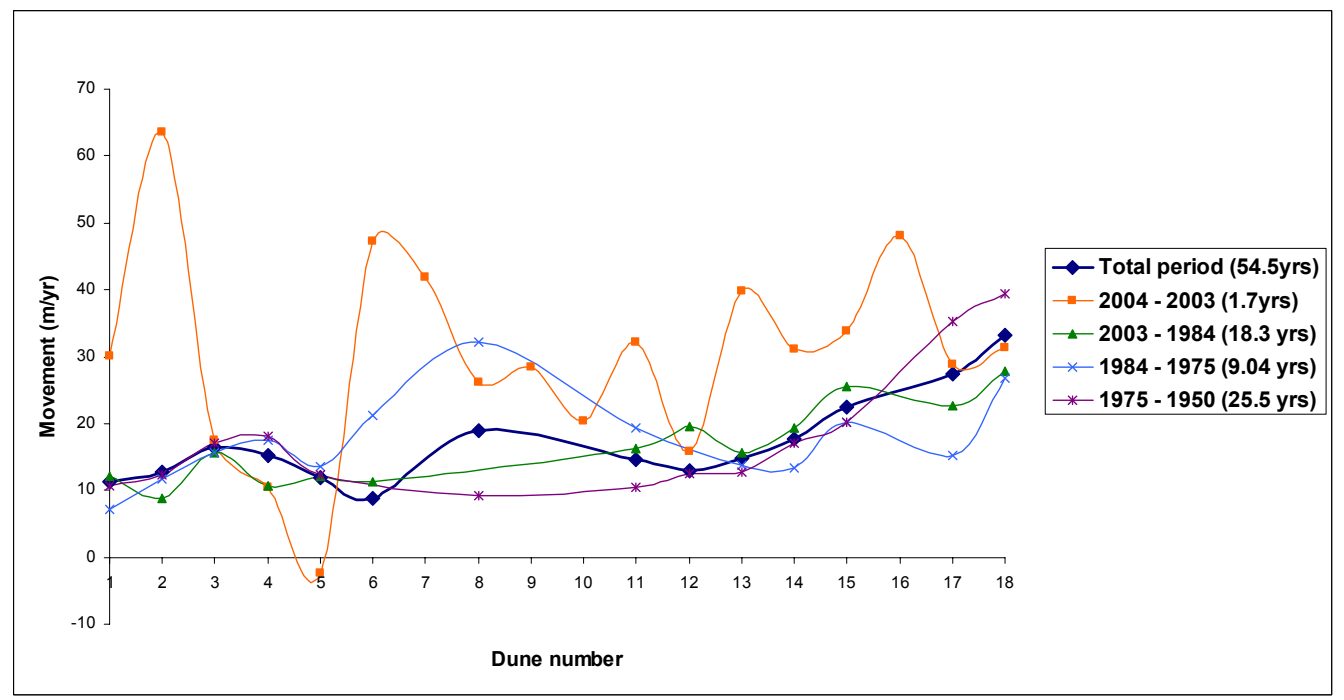

Figure 5.8: The average per annum migration rate of each barchan dune on Farewell Spit. Each line represents the dune movement between each period of the photograph runs, including the overall yearly average rate for the whole 54.5 year period. 


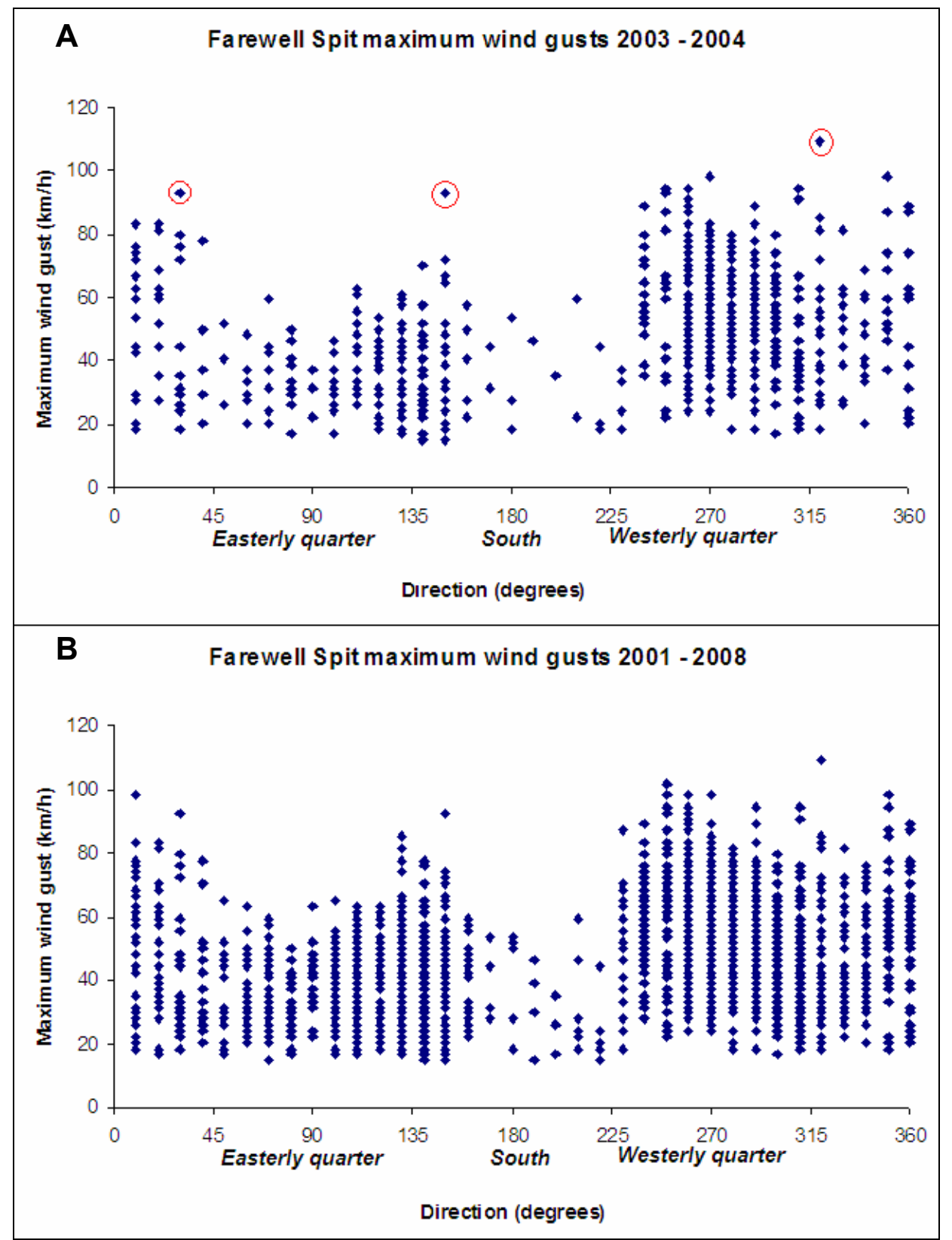

Figure 5.9: Direction and speed of the maximum wind gusts along Farewell Spit. A) For the $2003-2004$ period. B) For the $2001-2008$ period (NIWA, 2008a). The extreme wind gusts for the whole 7 year period which occur during 2003 2004 are circled in red.

While some barchans such as dunes 12 and 14 retain their classic crescent shapes as they move along the Spit, their morphology can also dramatically change throughout the marching process. Dune 3 has a double crescent in the 1950 photograph (figure 5.6) which slowly dissipates through the subsequent figures into a defined single crescent shape by 2004 . This dune moved a total of $862.5 \pm 16 \mathrm{~m}$ (figure 5.7 ) over the 54.5 year period, and has the most consistent average movement 
$(\sim 16 \mathrm{~m} \mathrm{p} / \mathrm{y})$ over all of the aerial photograph sets (figure 5.8$)$. The area change of the western slope of dune 3 between 2003 and 2004 however is more a function of the 2003 photograph quality rather than the dune having dramatically diminished over the 1.7 year period.

In contrast dune 4, which is crescent shaped in 1950, appears to have developed a second crescent by 1975 (figure 5.6). This is the smaller dune between dunes 3 and 4 in the 1950 photograph which attaches onto dune 4 in 1975, by 1985 it is enveloped, then emerges ahead of dune 4 by $2003-2004$. This pattern is also evident in dune 5 which is large and irregularly shaped in 1950 appearing to slowly split into two distinct barchan dunes by 2003 (dunes 5 and 6). Dune 5 has a fairly consistent yearly rate of movement $(12.5 \pm 4 \mathrm{~m} / \mathrm{y})$ and while the emergent dune 6 looks to be smaller it starts its movement at a slower average yearly speed $(8.8 \pm 4 \mathrm{~m} / \mathrm{y})$, although this does more than double in speed from 1984 onwards (figure $5.7 \& 5.8$ ). Figure 5.8 however, shows that dune 5 anomalously moves $2.3 \mathrm{~m}$ backwards, against the prevailing westerly wind between 2003 and 2004. Although easterly wind gusts occurred during this period (figure 5.9A) indicating some incongruous dune movement could have taken place, they probably would not be consistent enough to cause distinct dune movement. Although the small measurement could be a function of aerial photographs representing antecedent conditions, as this is the only occurrence of backward moving dunes in this instance it is attributed to the 2003 photograph quality.

\subsubsection{Southern Dune System}

The southern, vegetated dune system consists of predominantly linear dunes, orientated west to east; these tend to be more abundant on Farewell Spit in the area east of Mullet Creek. Near the Airstrip more than five dune ridges occur (figure 5.10), which range in height from 5 - 
6.8m AMSL, the widest ridge being on the northern side $(84.1 \mathrm{~m})$, with the other four ranging between 34.7 and $49.7 \mathrm{~m}$ wide. Figure $5.11 \mathrm{~A} \& \mathrm{~B}$ shows the linear dunes which are visible as the light green strips between the darker swamp vegetation. These tend to be orientated slightly southwest following the curvature of the Spit at this end. The two longest dunes on the 2004 photograph appear to follow the 1950 vegetation boundary (figure $5.11 \mathrm{~B} \& \mathrm{C}$ ).

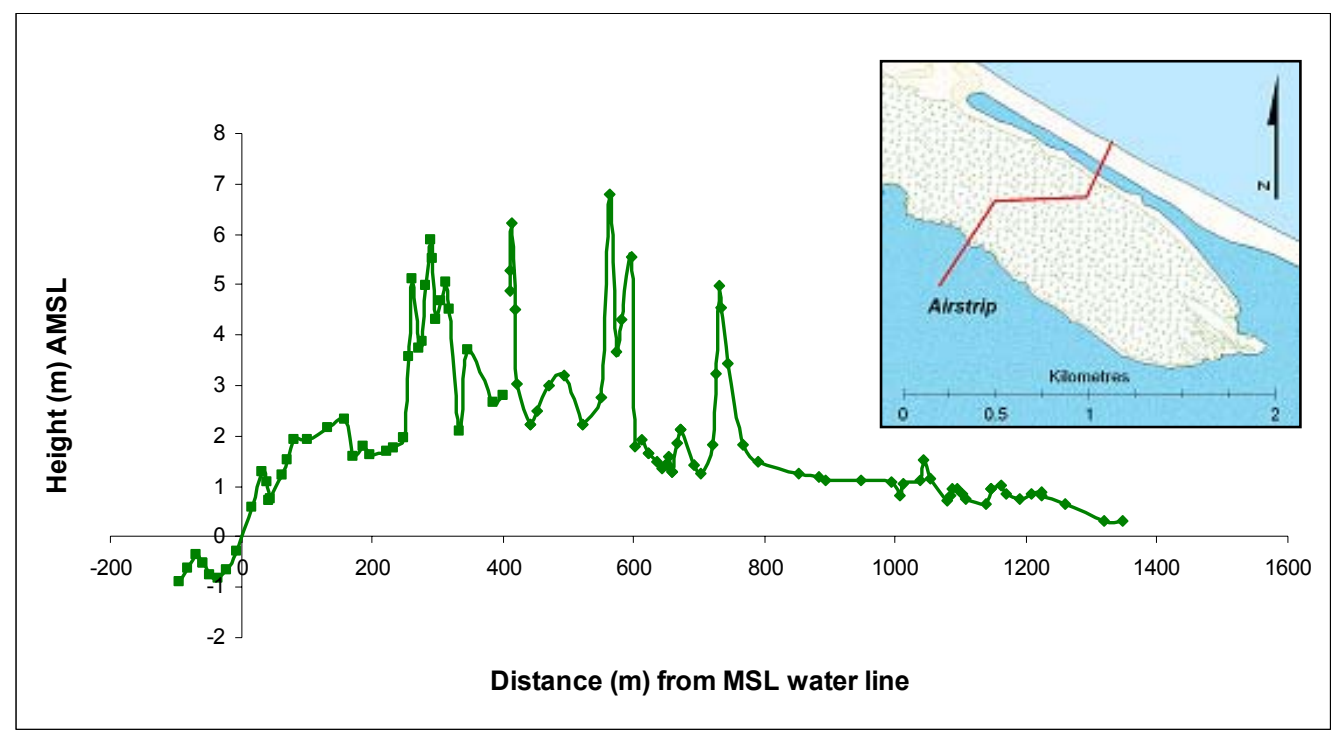

Figure 5.10: Surveyed transects of the vegetated dunes across the tip of the Spit near the Airstrip. The intersection of the $X$ and $Y$ axes represents the Collingwood MSL of $2.6 \mathrm{~m}$. Note this particular survey is not a continuous north-south transect but done in two parts, which doglegs (inset) across this area because of access issues with blackberry. The first transect started at Ocean Beach at the eastern end of the airstrip across to the $400 \mathrm{~m}$ point on the graph. The second began at the western side of the airstrip and out to the tidal flats. 


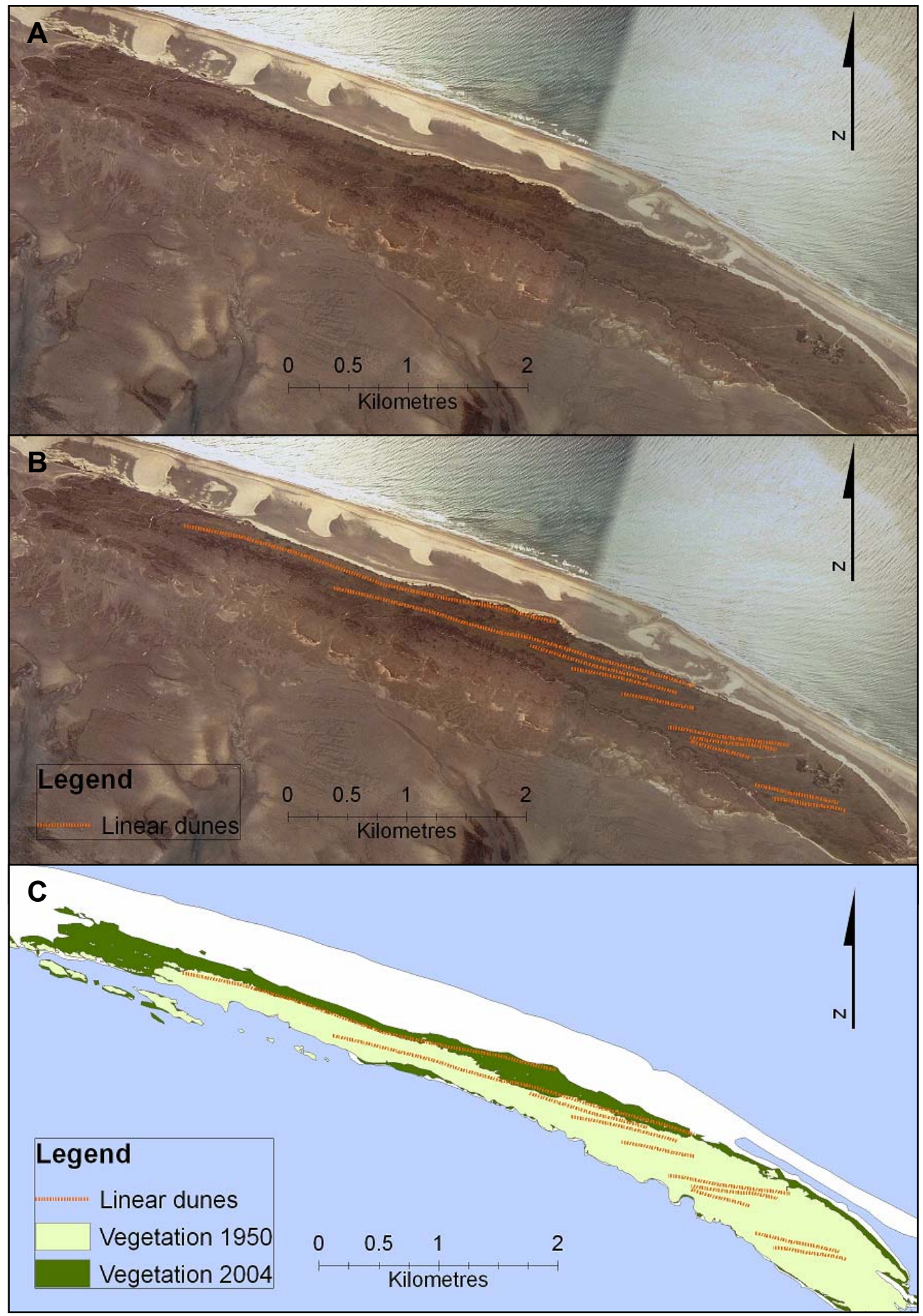

Figure 5.11: A) 2004 aerial photograph with lineated dune sequences visible by vegetation lines. B) GIS layer highlighting the dune sequences. C) map of dune sequences overlain on the 1950 and 2004 vegetation limits. The two longest linear dunes appear to be related to the 1950 vegetation limit. 
There are fewer linear dunes evident in the western segment of Farewell Spit, from the base towards Mullet Creek, and generally up to two foredunes line the south western edge of the Spit. However, this area has the highest vegetated dunes, the tallest of which are found on the Puponga Farm Park where they rise to $\sim 50 \mathrm{~m}$ AMSL. The heights of dunes then decrease considerably from Whale Dune (37.2m AMSL) at the base to $13.9 \mathrm{~m}$ AMSL at Froggies then down to $6.8 \mathrm{~m}$ and $5 \mathrm{~m}$ AMSL at the Airstrip and Lighthouse profiles respectively (figure 5.12).

These dunes are exposed to easterly generated wind waves and along some sections erosion scarps (up to $\sim 7 \mathrm{~m}$ ) are evident. The distance between these foredunes vary from wider gaps at Froggies and the Airstrip (156m and $119.2 \mathrm{~m}$ wide respectively) to relatively narrow (46m) at Stockyard Lake. Extensive flat areas are also found between these dune sequences and the mobile sand sheets; the Stockyards Lake area for example measured $322.7 \mathrm{~m}$ wide. Semi-permanent fresh water lakes can form within the swampy interdune hollows such as Froggies (figure 5.13) and Stockyard Lakes, both of which are $\sim 0.35 \mathrm{~m}$ deep. These lakes collect only a shallow cover of organics $(\sim 0.05 \mathrm{~m})$ indicating their ephemeral nature. III-defined hummocky terrain can also occur within the wider areas (figure 5.14) which can be subject to blow-out like erosion. 


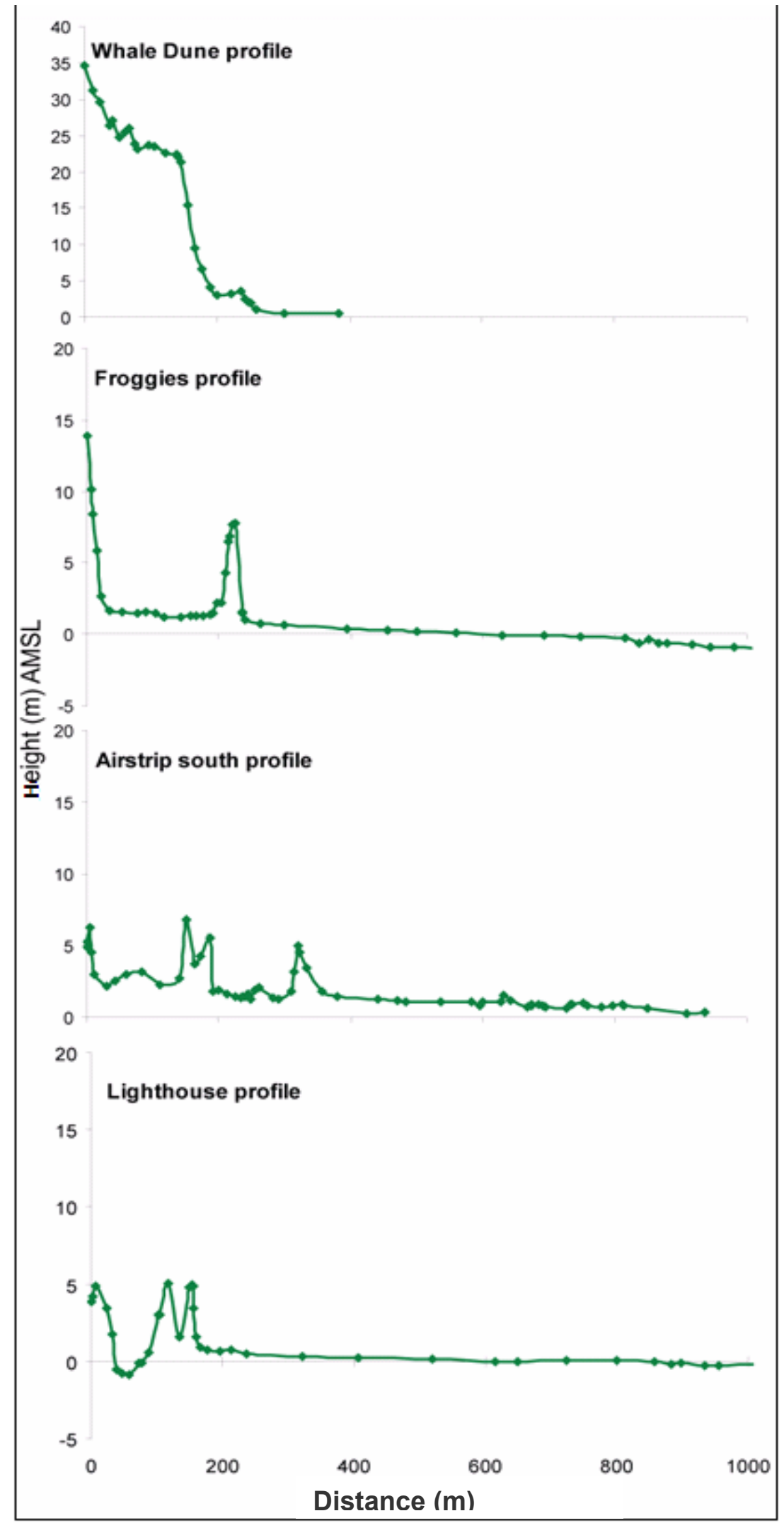

Figure 5 12: Profiles taken from the second fore dune towards the tidal flats on the southern side of F arewell Spit. 


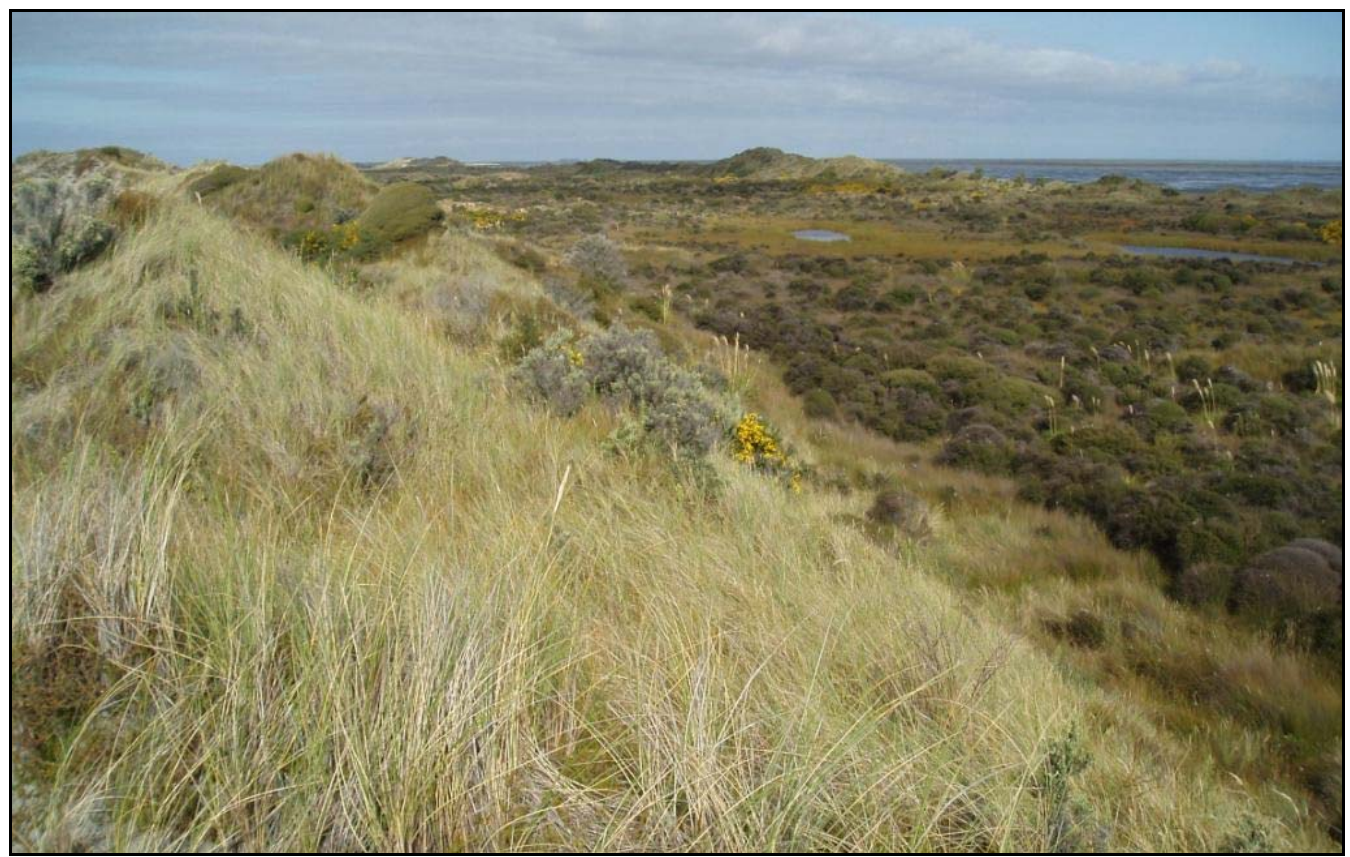

Figure 5.13: Looking eastward towards Froggies semi-permanent fresh water lake within the interdune hollow between the first and second foredunes (Photograph: Helen Tribe, 2007).

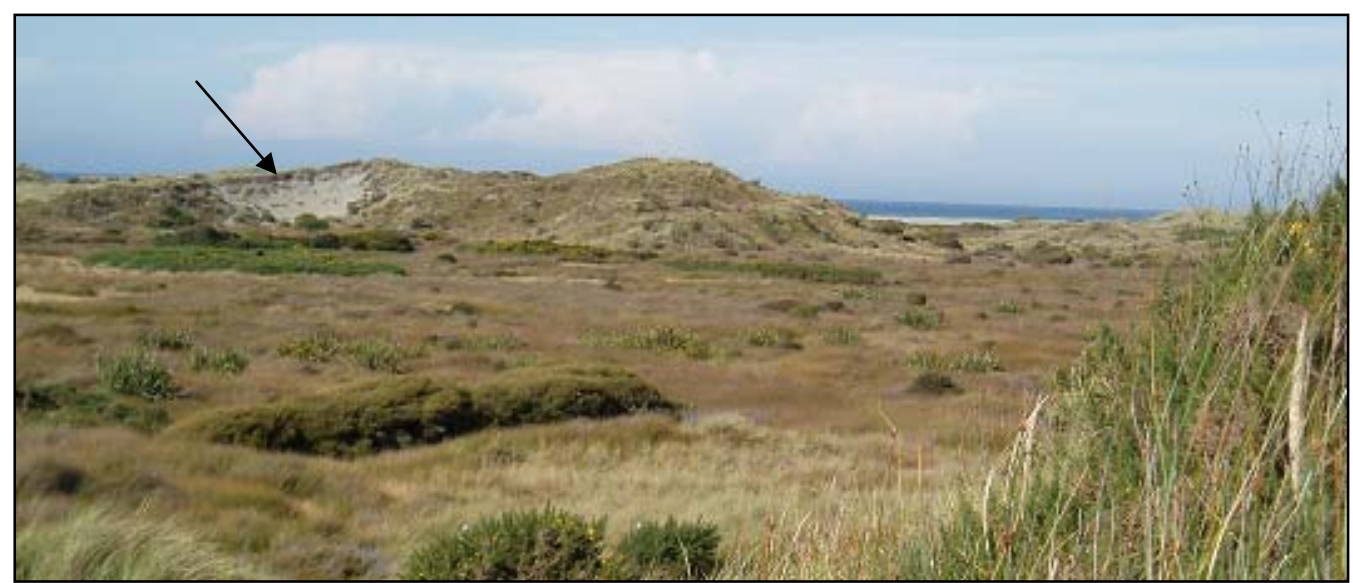

Figure 5.14: Hummocky dune terrain showing a dune blow-out (indicated by arrow) (Photograph: Helen Tribe, 2007).

The vegetation associated with the southern dune system has increased by $74.7 \%$ since 1950 , to cover $45.6 \%$ of Farewell Spits total subaerial area in 2004 (figure 5.15A \& B, table 5.2). Subsequently the area of mobile sand decreased by $35.7 \%$ from 1950 to 2004 (figure $5.16 \mathrm{~A} \& \mathrm{~B})$. The greatest yearly average rate of change was between 1950 and 1975 where vegetation cover increased 2.3\%/y and sand cover decreased $1.2 \% / y$. 


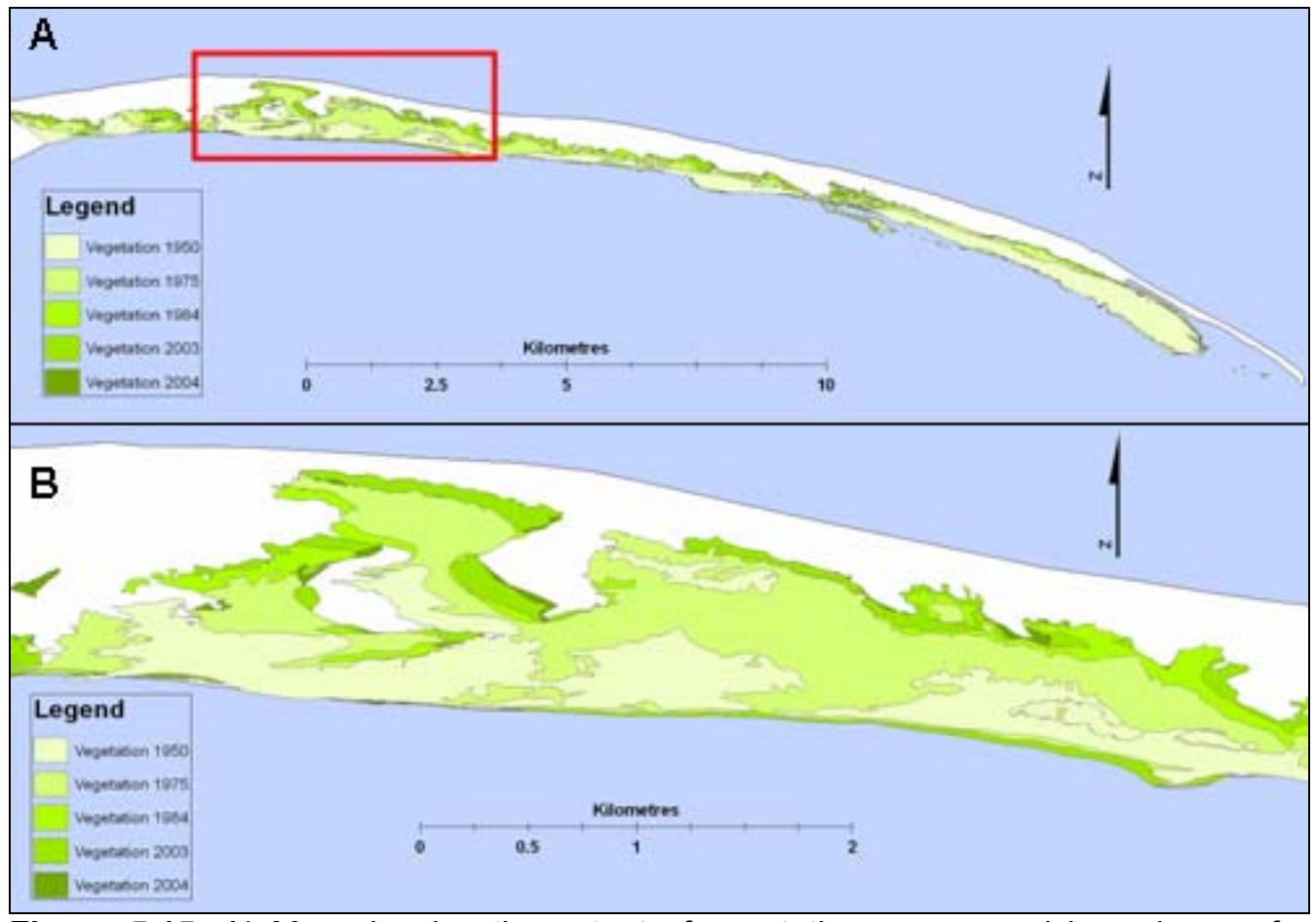

Figure 5.15: A) Map showing the extent of vegetation as mapped by polygons for each aerial photograph set. The red box indicates the detailed area as shown in figure B.

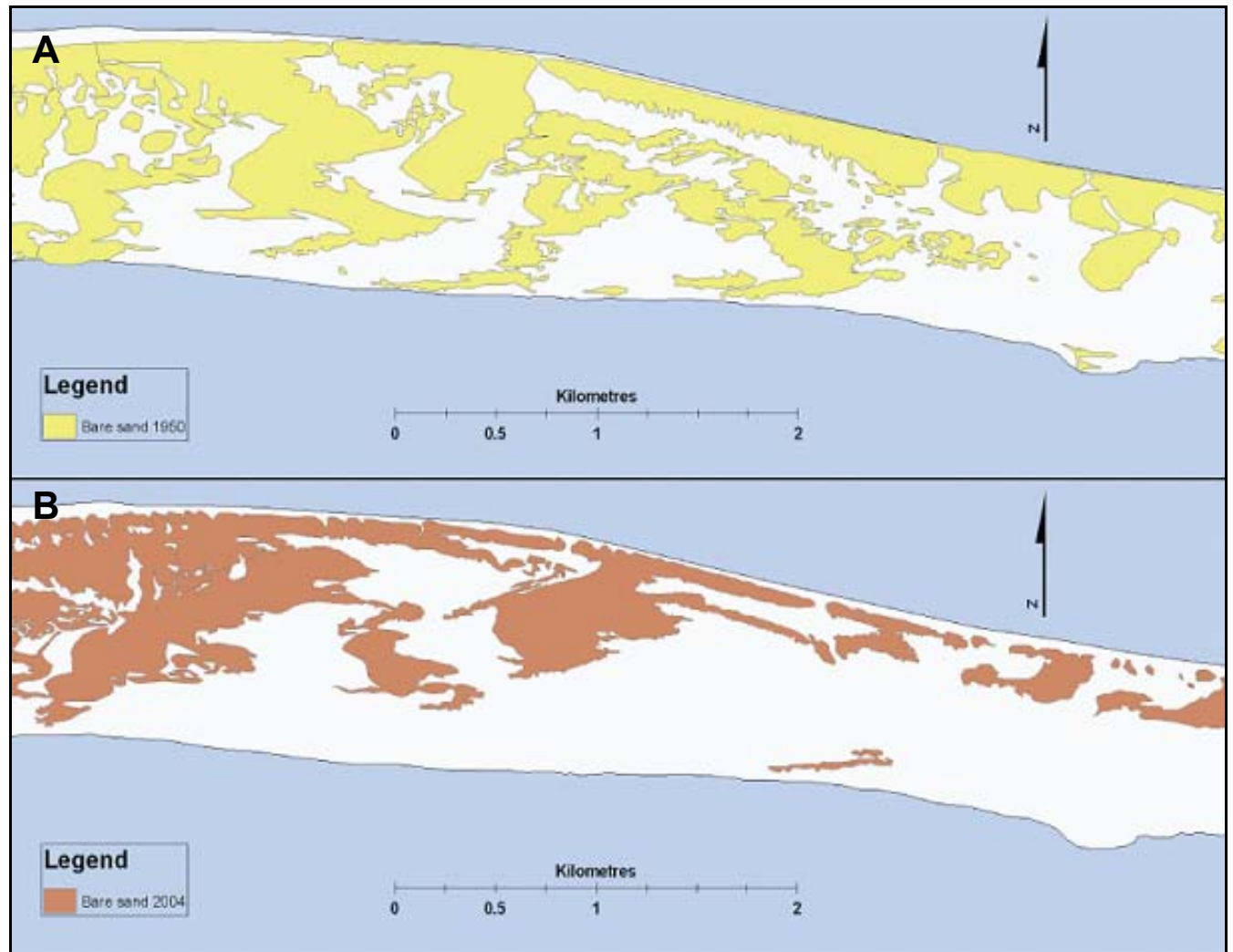

Figure 5.16: Map of same area showing the subsequent decrease of sand cover from A) 1950 to B) 2004 for comparison with figure 5.15. 
Table 5.2: Calculated coverage of vegetation and bare sand on Farewell Spit from aerial photograph. ${ }^{*} T o t a l$ landmass of Farewell Spit above high water mark is 1960ha.

\begin{tabular}{|c|c|c|c|c|}
\hline \multicolumn{5}{|c|}{ Vegetation } \\
\hline Year & $\begin{array}{c}\text { Coverage } \\
\text { (ha) }\end{array}$ & $\begin{array}{c}\% \\
\text { cover }\end{array}$ & $\begin{array}{c}\% \\
\text { change }\end{array}$ & $\begin{array}{c}\% \text { changel } \\
y\end{array}$ \\
\hline 1950 & 511.7 & 26.1 & - & \\
\hline 1975 & 810.8 & 41.38 & 58.6 & 2.3 \\
\hline 1984 & 826.9 & 42.2 & 2.0 & 0.2 \\
\hline 2004 & 893.6 & 45.6 & 8.1 & 0.4 \\
\hline total ha* & 1960.0 & & & \\
\hline \multicolumn{5}{|l|}{ Sand } \\
\hline Year & $\begin{array}{c}\text { Coverage } \\
\text { (ha) }\end{array}$ & $\begin{array}{c}\% \\
\text { cover }\end{array}$ & $\begin{array}{c}\% \\
\text { change }\end{array}$ & $\begin{array}{c}\% \text { changel } \\
y\end{array}$ \\
\hline 1950 & 837.9 & 42.8 & - & \\
\hline 1975 & 592.2 & 30.2 & -29.3 & -1.2 \\
\hline 1984 & 667.7 & 34.1 & 12.8 & 1.4 \\
\hline 2004 & 539.2 & 27.5 & -19.3 & -0.9 \\
\hline total ha* & 1960.0 & & & \\
\hline
\end{tabular}

\subsubsection{The Salt marshes}

Salt marshes occur on the southern, side of the Spit, eastwards from Stockyard Point to Bush End Point. They occupy 320ha (Muirhead, 1981), are semi-horizontal sloping at $0.1^{\circ}$ and range between $0.3-1.5 \mathrm{~m}$ AMSL. These salt marshes are inundated diurnally by tidal water and field investigation showed a variable vegetation succession dominated by J. maritimus. Profiling the airstrip transect (figure 5.17), the $A$. arenaria and $P$. aquilinum var esculentum covered dunes lead down to the J. maritimus and L. simplex rush-lands which extend out $\sim 400 \mathrm{~m}$, their density thinning and mixing with Salicornia spp. fields towards the end (at about $\sim 630 \mathrm{~m}$ ). The Salicornia spp. dominates the outer edges of the salt marshes becoming gradually sparser; having dissipated by $\sim 900 \mathrm{~m}$ where sand dominates the tidal flats. 


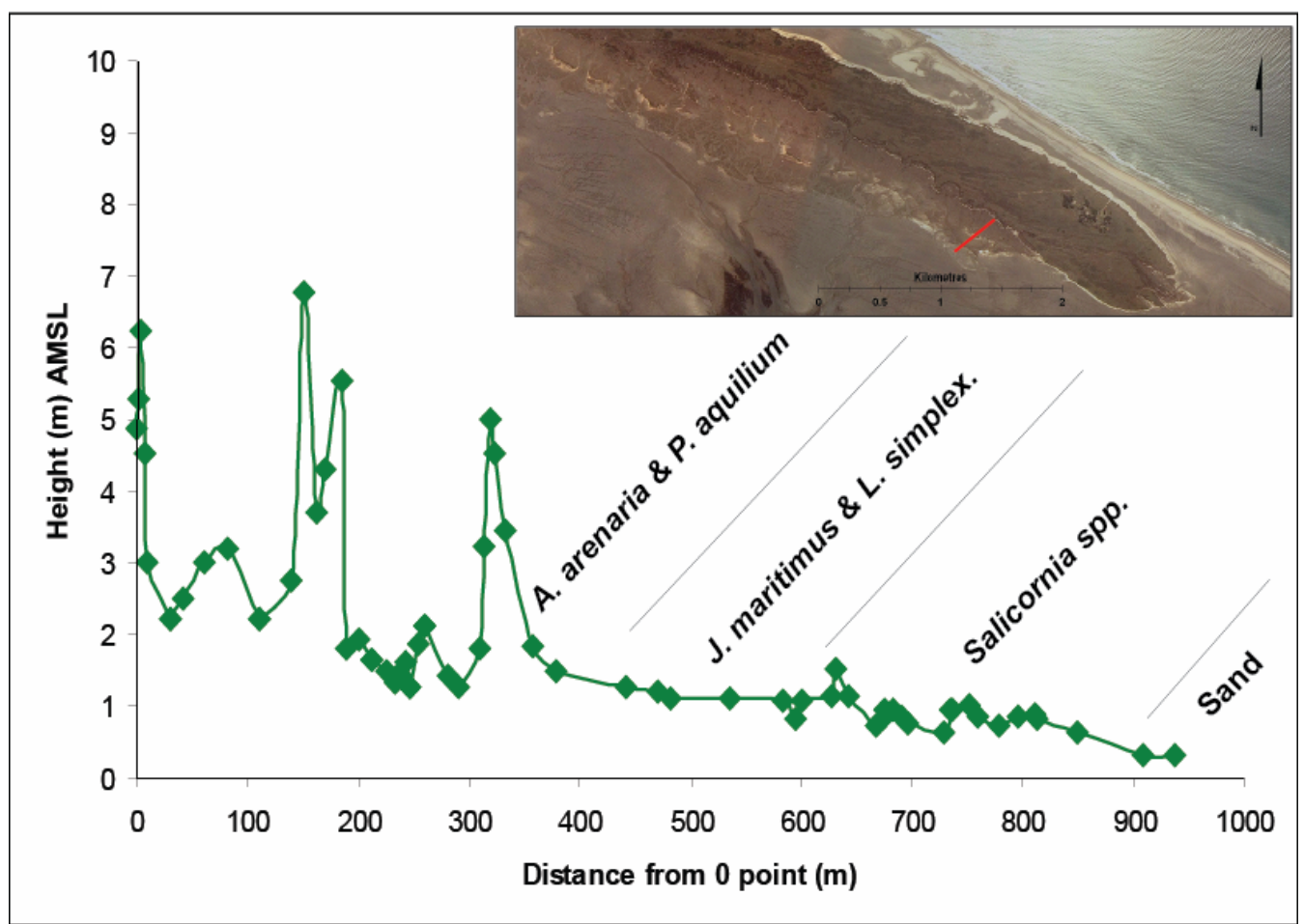

Figure 5.17: Southern Airstrip profile. Showing the succession of vegetation leading out from the foredunes through the salt marsh to the tidal flats. Inset, location of transect through the salt marshes visible on the southern side of the Spit.

There is a band of small hummocks (rising up to $\sim 3 \mathrm{~m}$ above the tidal flat) in the intertidal zone of the salt marshes. These become ephemeral islets at high tide (figure 5.18A) and are subject to erosion (figure 5.18B). Clusters of stones of various sizes (figure 5.18C) were found near one of these hummocks, the largest of which was $\sim 15 \mathrm{~cm}$ in length. Ballance et al. (2006) also found isolated stones up to $40 \mathrm{~cm}$ long on the tidal flats, which were attributed to be delivered by tree root masses, washed out of the rivers into Golden Bay.

Near Bush End Point, the fresh water swamp environments grade into the salt marshes where the dune sequences terminate. This change from fresh to salt water environments was observed by the change in dominant flora from $P$. tenax and other fresh water species into rushlands, around the high tide limit. 


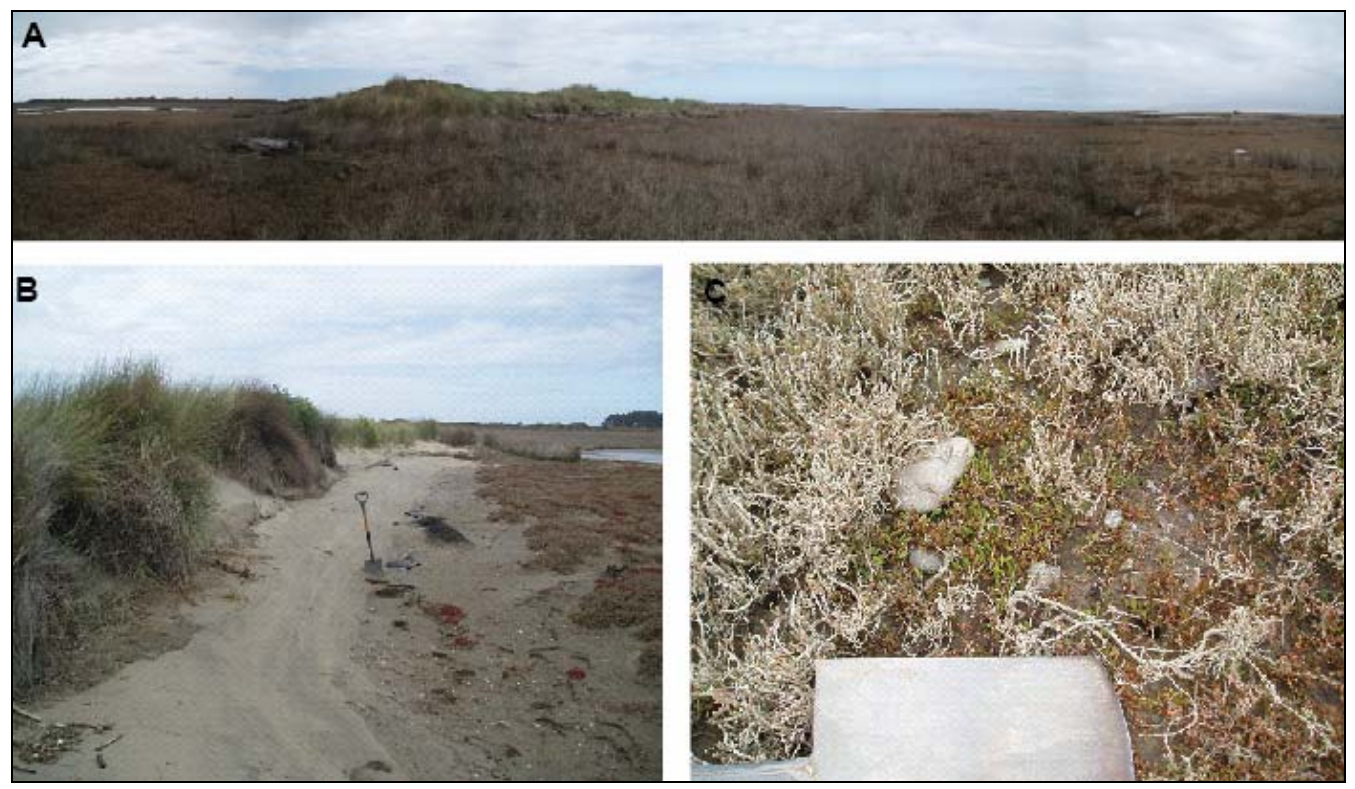

Figure 5.18: A) Higher hummocks which become ephemeral islets during high tide cycles. (Photograph: Helen Tribe, 2007). B) Detail of erosion affected mound (Photograph: Helen Tribe, 2007). C) Clusters of stones found in situ within the salt marsh area (Photograph: Helen Tribe, 2007).

\subsubsection{Tidal Flats}

Tidal flats which occur south of the Spit have a very low gradient (averaging $0.1^{\circ}$ ) with a total area of $\sim 200 \mathrm{~km}^{2}$ out to the $10 \mathrm{~m}$ bathymetric contour (Ballance et al., 2006) (figure 5.19). Forming a triangular shape they extend up to $\sim 8 \mathrm{~km}$ into Golden Bay, narrowing to $1 \mathrm{~km}$ near the base of the Spit and terminating $\sim 5 \mathrm{~km}$ south east of Bush End Point (figure 5.20). These intertidal flats are covered to varying densities by $Z$. muelleri beds. They are crossed by tidal channels which concentrate the incoming and outgoing tidal waters. The smaller channels sinuously weave across the flats, forming the tributaries into the 6 major channels (ranging $\sim 130 \mathrm{~m}-450 \mathrm{~m}$ wide). Analysis of these tidal channels since 1975 (the earliest photograph which includes the channels) shows that their paths have not noticeably altered. 


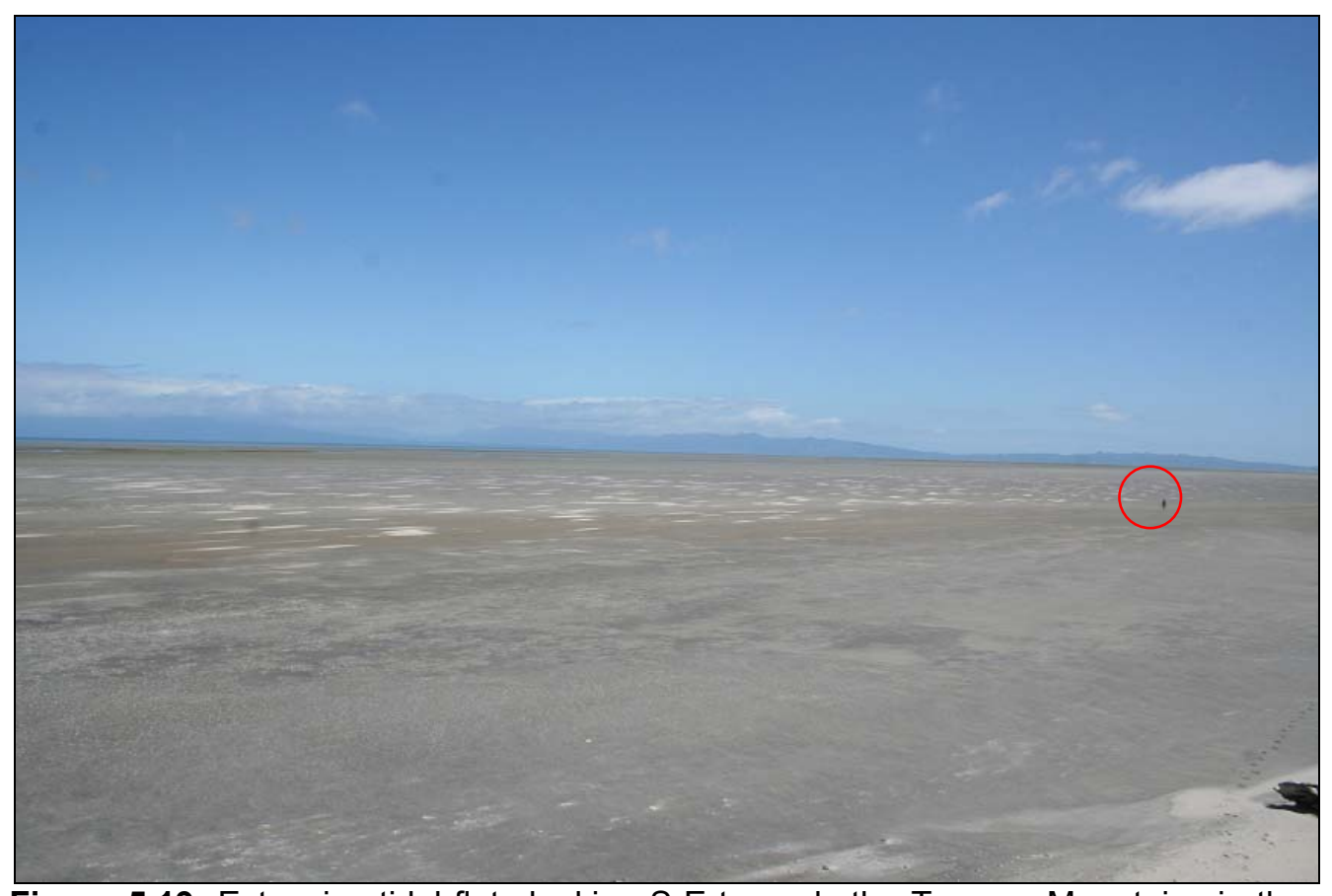

Figure 5.19: Extensive tidal flats looking S-E towards the Tasman Mountains in the distance (Photograph: Rod Boys, 2007). Note for perspective the person (circled).

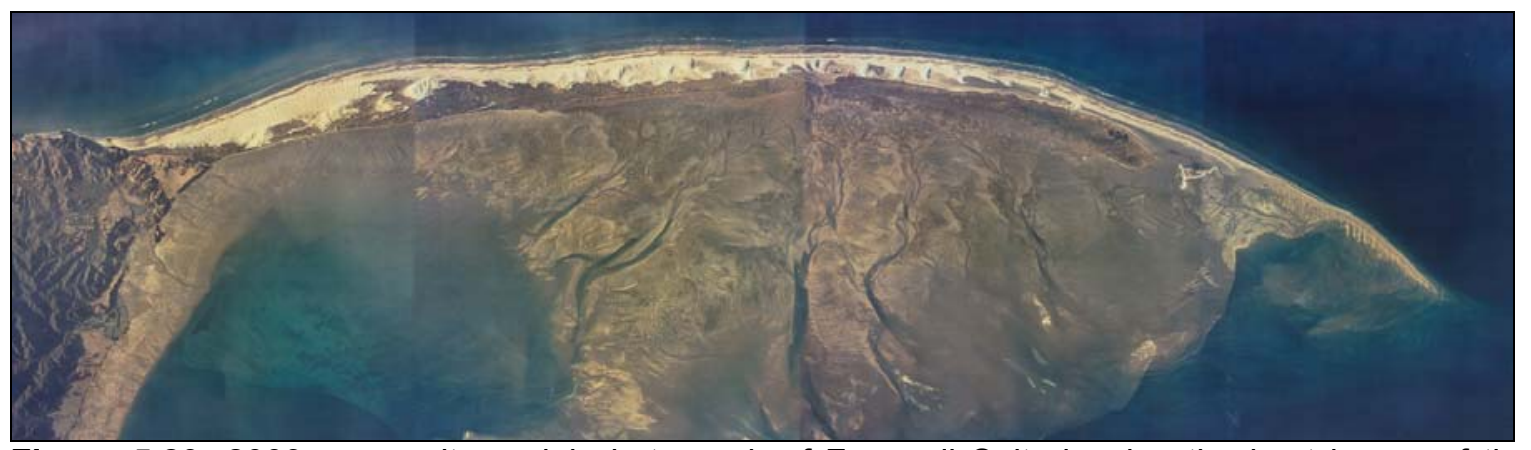

Figure 5.20: 2003 composite aerial photograph of Farewell Spit showing the best image of the channel cut tidal flats extending into Golden Bay (Photograph: NZ Aerial Mapping Ltd, 2007).

Batterly et al. (2005) found diverse benthos taxa on the tidal flats listing 99 species, including Austrovenus stutchburyi (New Zealand cockle), Paphies australis (Pipi) and Eliminius modestus (esturine barnacle) being the most common mollusk taxa. Of these, A. stutchburyi was found to dominate the biomass (Batterly et al., 2005). 


\subsubsection{The Shellbanks}

The Shellbanks, situated at the eastern tip of the Spit, are a low lying ( 2m ASL) consolidated deposit of shells, (figure 5.21), in particular $A$. stutchburyi. They are sparsely vegetated by $A$. arenaria and isolated from the Spit during high tide. In 1896 locating shells for concrete during the construction of the lighthouse was reported as difficult, therefore it is assumed that the Shellbanks had not developed at this point (Petyt, 1999). However, Herbert Guthrie-Smith noted their presence in 1924 and there is some mention of them as early as 1919 (Petyt, 1999).

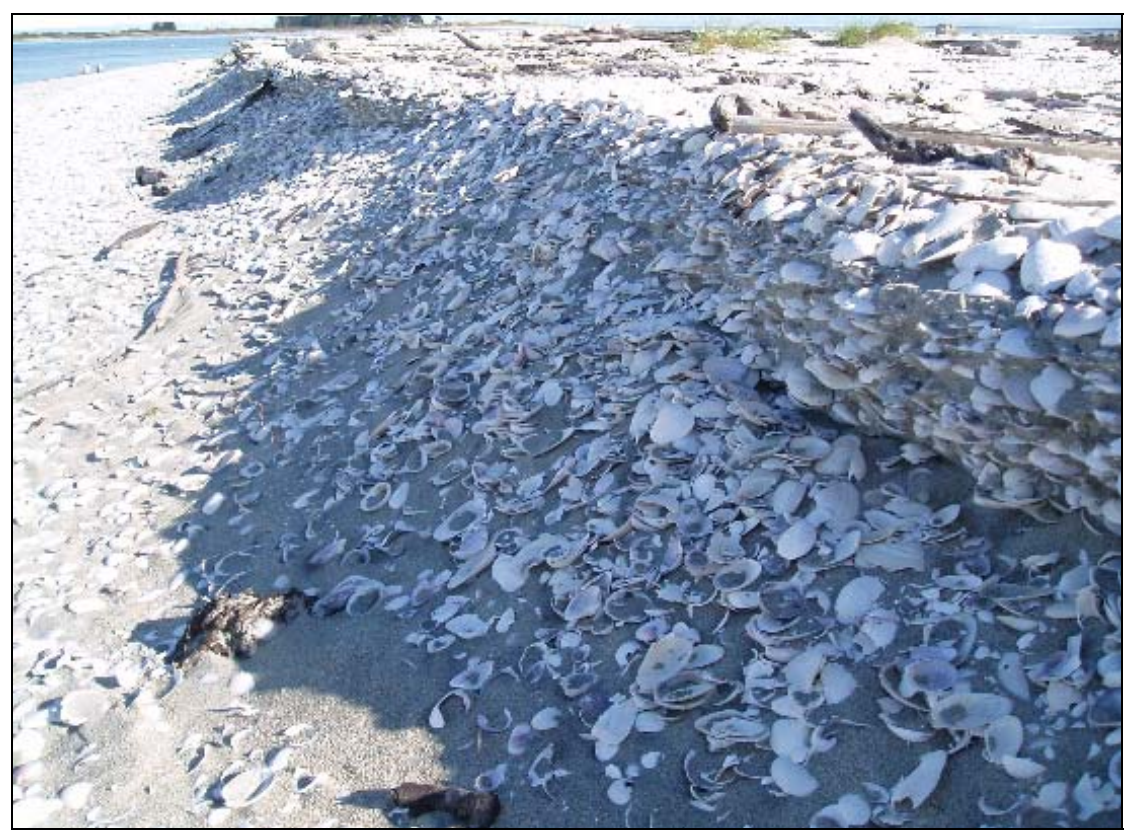

Figure 5.21: Profile of erosion on The Shellbanks. Bush End Point and the lighthouse pines are visible in the background (Photograph: Helen Tribe, 2007).

The Shellbanks are unstable and extremely vulnerable to large wave events, such as Cyclone Drena in 1997 (Petyt, 1999). The Shellbanks increased in area from 7.3ha in 1950 to 16.2 ha by 1984 (table 5.3), while also displaying a general shape change and clockwise rotation of the alignment (figure 5.22A \& B). However, it is evident that by 2004 the Shellbanks had not recovered their loss of material from Cyclone Drena showing a 33.9\% decrease in area from 1984 and also a slight northward relocation of the main mass of material (figure 5.22C \& D). 
Table 5.3: Calculated coverage of the Shellbanks from aerial photograph analysis. *Total landmass of Farewell Spit above high water mark is 1960ha.

\begin{tabular}{|l|c|c|c|c|}
\hline \multicolumn{2}{|c|}{ Shellbanks } & & & \\
\hline Year & $\begin{array}{c}\text { Coverage } \\
\text { (ha) }\end{array}$ & \% cover & \% change & \% change/y \\
\hline $\mathbf{1 9 5 0}$ & 7.3 & 0.4 & - & - \\
\hline $\mathbf{1 9 8 4}$ & 16.2 & 0.8 & 121.3 & 3.4 \\
\hline $\mathbf{2 0 0 4}$ & 10.7 & 0.5 & -33.9 & -1.7 \\
\hline${ }^{*}$ total ha & 1960.00 & & & \\
\hline
\end{tabular}




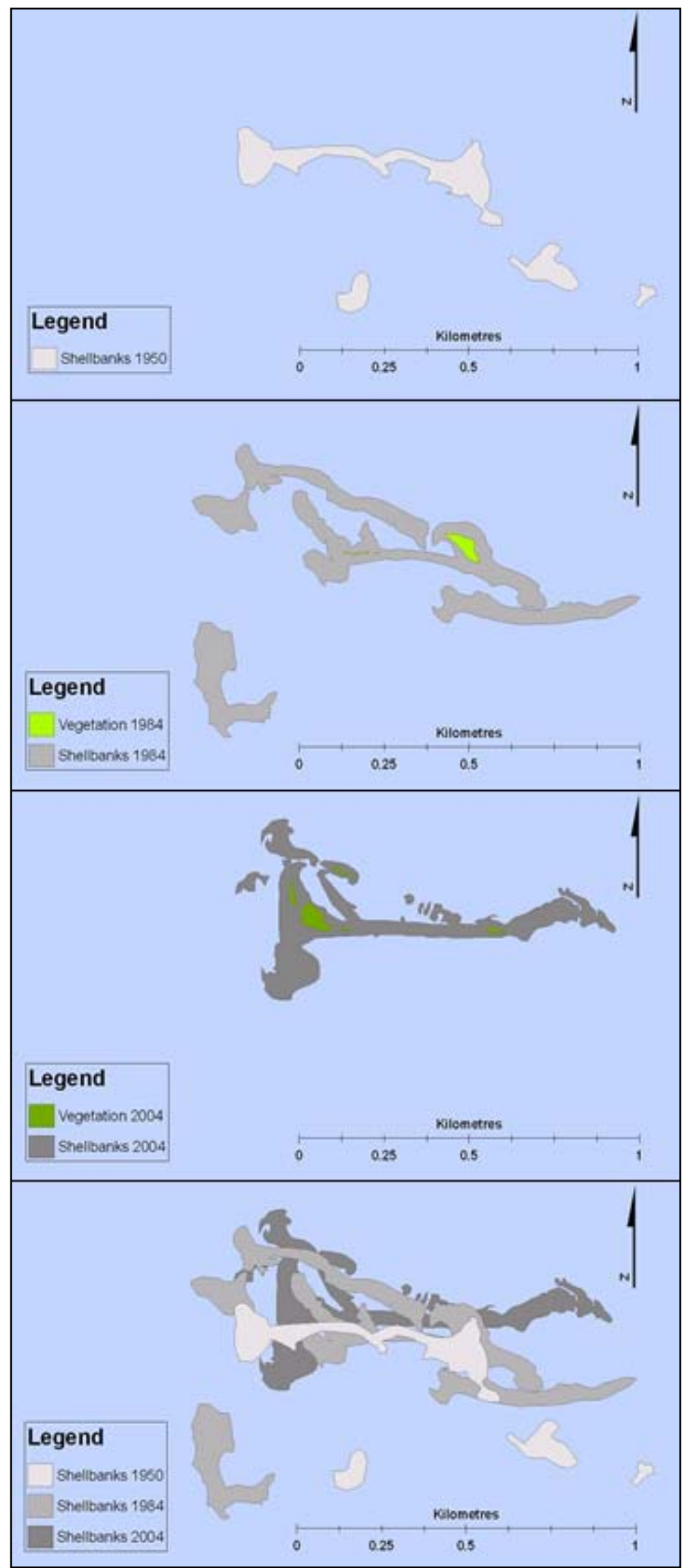

Figure 5.22: Maps of Shellbanks changes over time. A-C) Polygons showing the Shellbanks from 1950, 1984, 2004 separately, D) polygons overlaid to illustrate the dynamic nature of the Shellbanks movement. 


\subsection{Shoreline change}

The planform profile of Farewell Spit has shown some considerable morphological alterations at Bush End and Stockyard Points. Although these areas have shown good examples of morphological change over the aerial photograph sets, little else has occurred on the rest of Spit.

\subsubsection{Bush End Point}

Net recession has occurred at Bush End Point over the 54.5 years. It Initially accreted in a northeasterly direction $\sim 90 \mathrm{~m}$ from 1950 to 1975 , although it then receded $\sim 100 \mathrm{~m}$ in a northwesterly direction between 1975 and 1984, then again $\sim 82 \mathrm{~m}$ from 1984 - 2003/ 2004 (figure 5.23). The general orientation change of the point between 1984 and 2003 is presumably related to damage incurred in 1997 by Cyclone Drena. This variation is also reflected in the $\sim 100 \mathrm{~m}$ northward shift of the sand bar post 1984 (figure 5.23). Although the length of the bar appears to be growing this is more a function of the water levels from differing tides than quantifiable sand accretion or erosion.

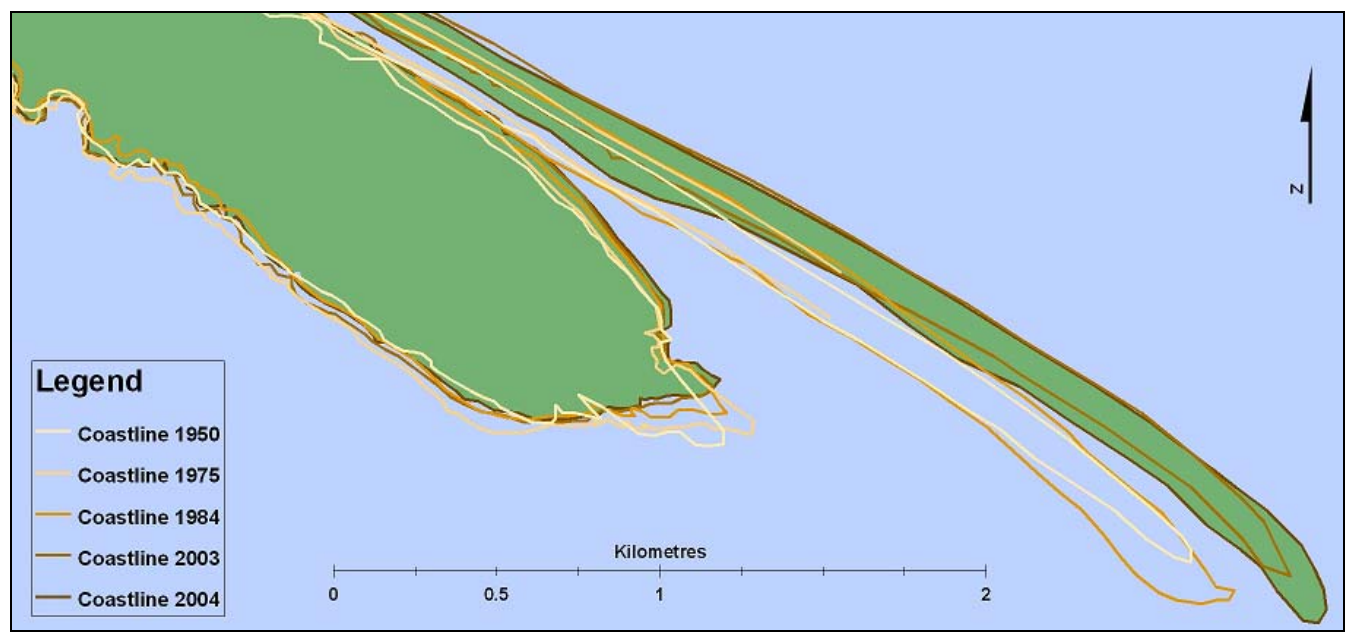

Figure 5.23: Map of Bush End Point showing the shorelines from $1950-2004$. These GIS layers illustrate a net recession and general upturn of the shape of the point, as well as a northward drift of the sand bar. 


\subsubsection{Stockyard Point}

Although the same general shape stays intact at Stockyard Point, the bulge thickens from $\sim 243 \mathrm{~m}$ across its base in 1950 to $\sim 412.4 \mathrm{~m}$ in 2004 (figure 5.24). The majority of this thickening occurs from 1984 to 2004 where it grows in width $\sim 126 \mathrm{~m}$. The north and south movement of the positioning of the point is more a function of georeferencing issues than actual shoreline movement of this magnitude.

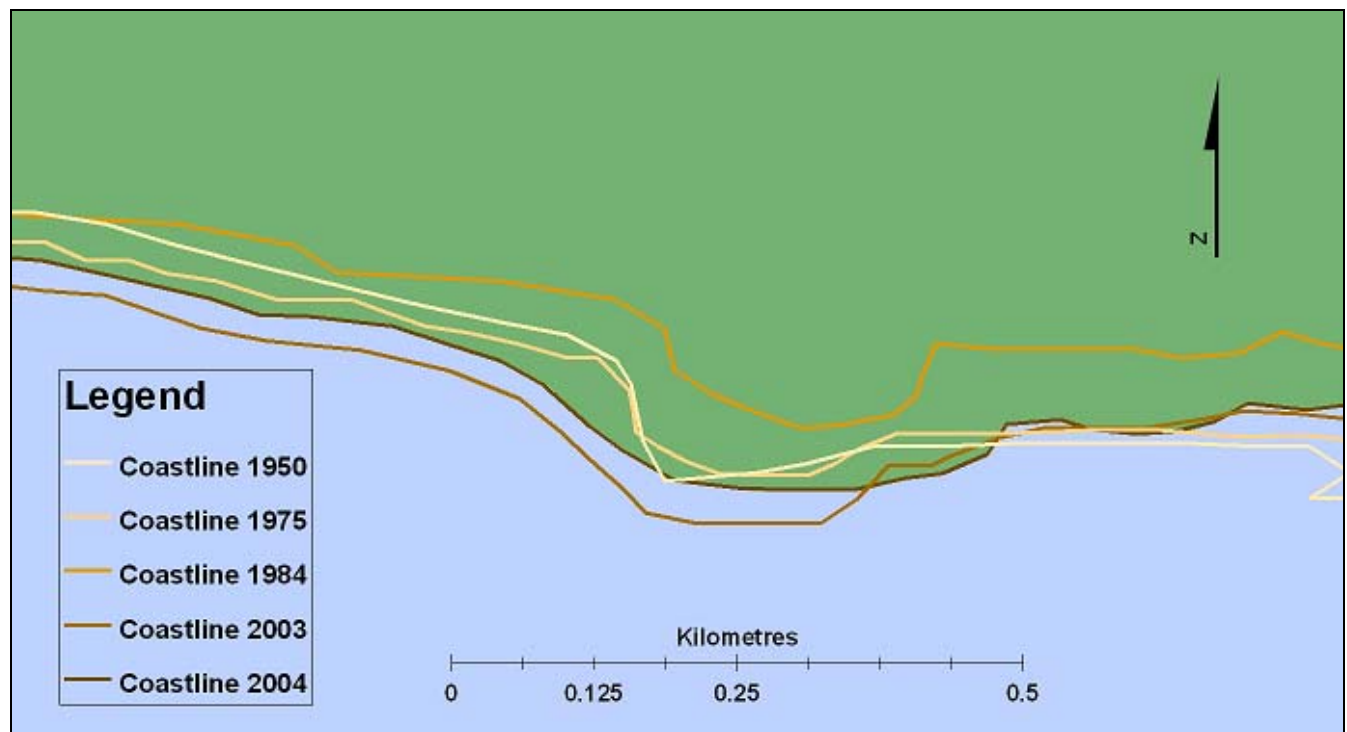

Figure 5.24: Map of Stockyard Point showing the shorelines from $1950-2004$. These GIS layers illustrate the widening of the point.

\subsubsection{Average total shoreline change}

The breadth of the Spit was measured to establish the average total accretion along its length. These data were also split into thirds to determine if any particular sections of the Spit were accreting or eroding more than others. Overall the Spit appears to have accreted $54.6 \mathrm{~m}$ in the 54.5 time frame at a rate of $\sim 1 \mathrm{~m} / \mathrm{y}$ (table 5.4 ). The eastern end has experienced the greatest accretion, 52m from $1950-1975$ at a rate of $2 \mathrm{~m} / \mathrm{y}$, which has subsequently slowed to $0.5 \mathrm{~m} / \mathrm{y}$ during the latter time frame. The middle third suffered erosion of $0.3 \mathrm{~m} / \mathrm{y}$ from $1950-1975$ which then reverted to $1 \mathrm{~m} / \mathrm{y}$ accretion during $1975-2004$. 
Table 5.4: Average accretion of Farewell Spit from Spit width data.

\begin{tabular}{|l|c|c|c|c|c|c|c|c|}
\hline Year & $\begin{array}{c}\text { Average } \\
\text { accretion } \\
\text { total Spit }\end{array}$ & $\begin{array}{c}\text { Rate } \\
\mathbf{m} / \mathbf{y}\end{array}$ & $\begin{array}{c}\text { Average } \\
\text { accretion } \\
\text { over 1/3 }\end{array}$ & $\begin{array}{c}\text { Rate } \\
\text { m/y }\end{array}$ & $\begin{array}{c}\text { Average } \\
\text { accretion } \\
\text { over 2/3 }\end{array}$ & $\begin{array}{c}\text { Rate } \\
\mathbf{m} / \mathbf{y}\end{array}$ & $\begin{array}{c}\text { Average } \\
\text { accretion } \\
\text { over 3/3 }\end{array}$ & $\begin{array}{c}\text { Rate } \\
\mathbf{m} / \mathbf{y}\end{array}$ \\
\hline $\mathbf{1 9 7 5 - 2 0 0 4}$ & 30.5 & 1.0 & 49.8 & 1.7 & 28.9 & 1.0 & 14.7 & 0.5 \\
\hline $\mathbf{1 9 5 0 - 1 9 7 5}$ & 24.1 & 0.9 & 24.8 & 1.0 & -7.9 & -0.3 & 52.0 & 2.0 \\
\hline
\end{tabular}

\subsection{Sedimentology}

\subsubsection{General grain size:}

Previous studies of surface sediments along Farewell Spit show that the mobile dunes and Ocean Beach backshore are predominantly well sorted (ranging $0.21-0.37 \Phi$ ), fine sand (figure 5.25). While the inshore and foreshore samples are a well to moderately well mix of fine and medium sand (1.72 - 2.24Ф) (Kasper-Zubillaga et al., 2006). The tidal flats on the other hand are predominantly well sorted (ranging $0.41-$ $0.55 \Phi$ ), medium sand (ranging $1.20-2.03 \Phi$ ) (figure 5.25) (Ballance et al., 2006). The subsurface tidal flats samples follow the same well to moderately well sorted patterns evident in the surface samples (ranging $0.35-0.60 \Phi$ ) (figure 5.25). However, the mean grain size data of these is extended to include fine as well as medium size sand within the subsurface (ranging $1.57-2.44$ ) (figure 5.26 ). 


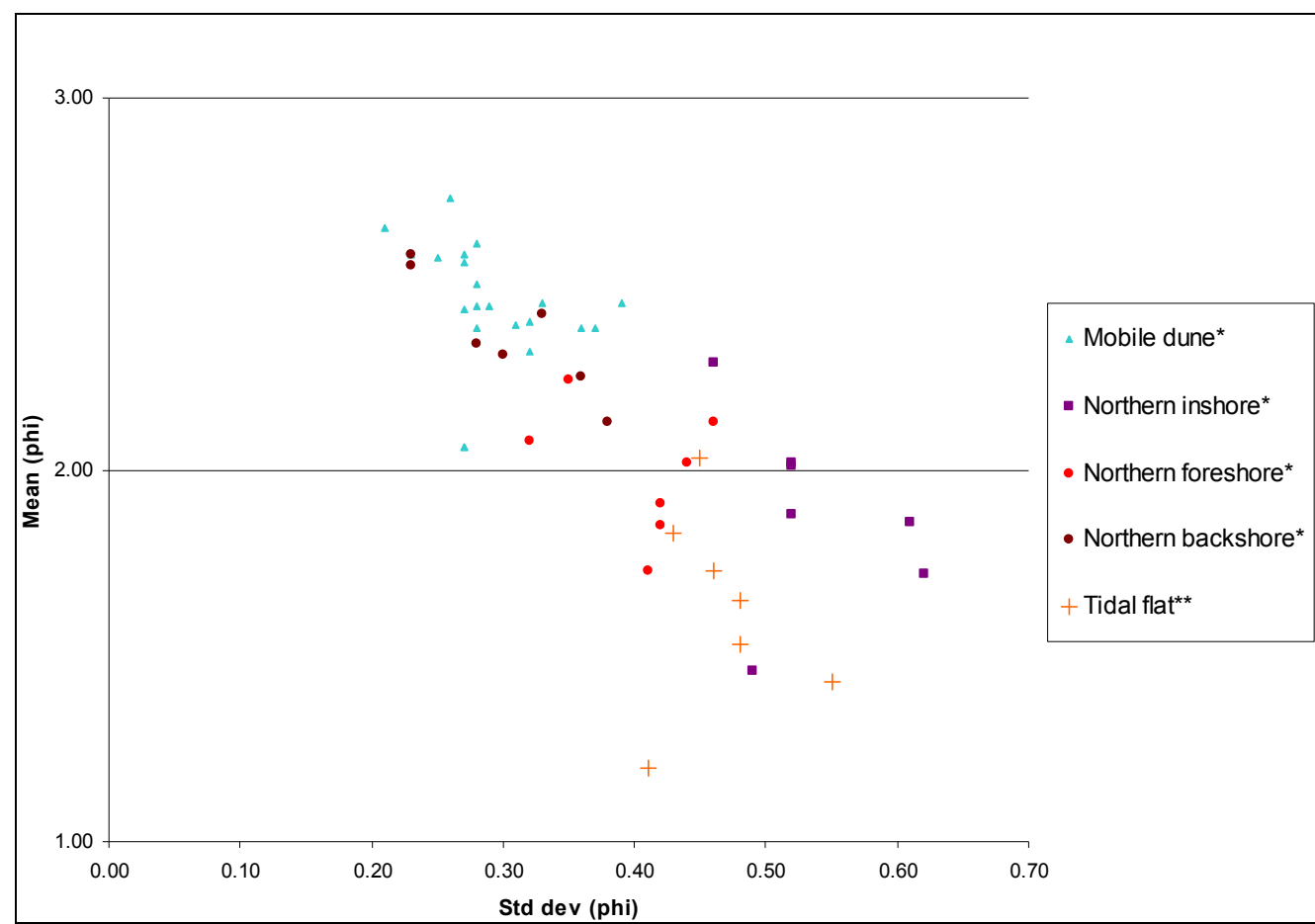

Figure 5.25: Bivariate plot of mean and sorting for surface sediments collected at Farewell Spit northern dunes, beaches and tidal flats. * Data from Kasper-Zubillaga et al. (2006). ** Data from Ballance et al. (2006).

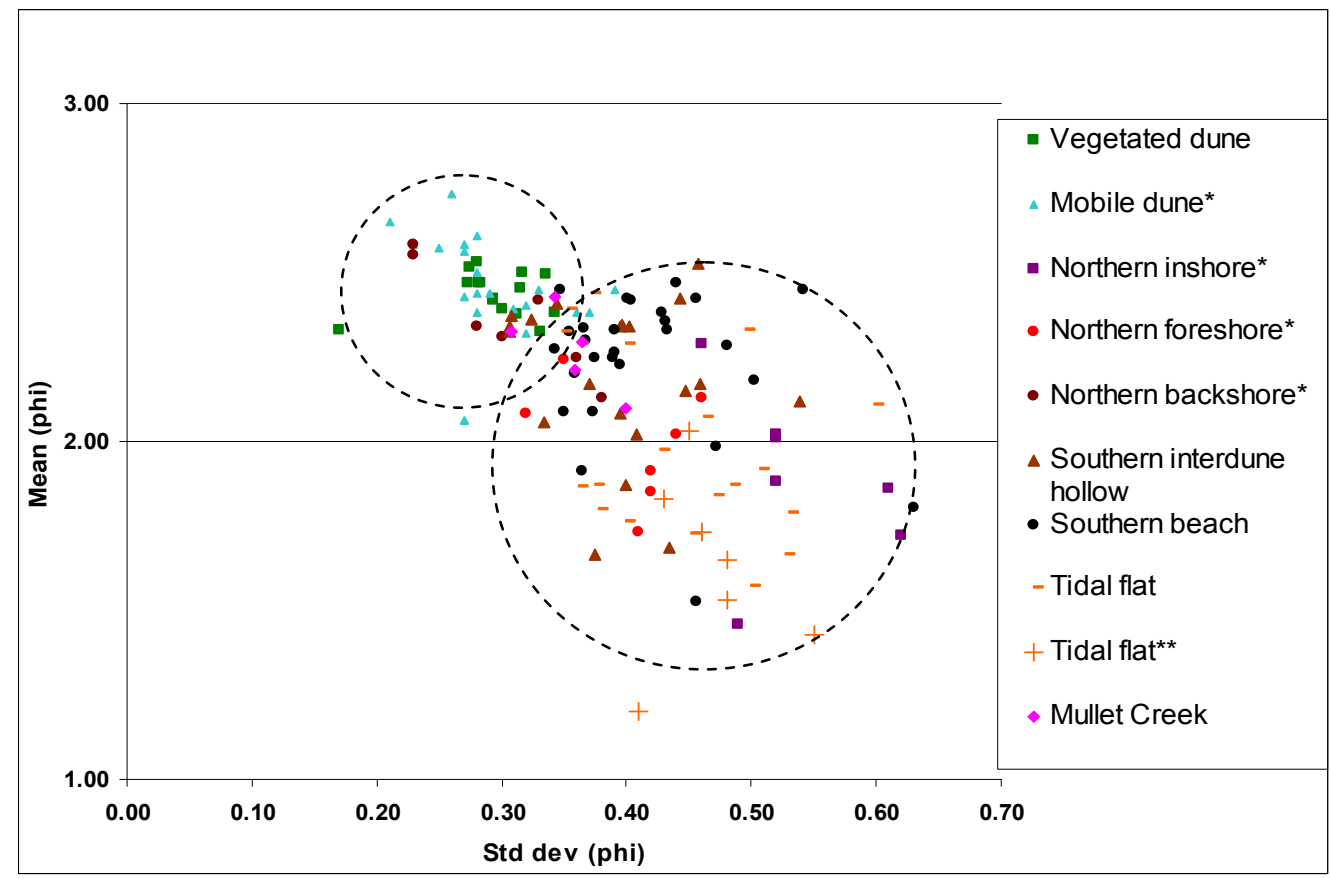

Figure 5.26: Bivariate plot of mean and sorting for subsurface and surface sediments collected at Farewell Spit northern and southern environments. Dotted circles indicate the populations with similar data ranges. * Data from Kasper-Zubillaga et al. (2006). Data from Ballance et al. (2006). 
Two distinct data clusters are evident when comparing these studies to the core data of this project. Firstly, the vegetated dunes are very similar to the mobile dunes and northern backshore environments, being very well sorted, fine sand (figure 5.25). The vegetated dunes form a slightly tighter grouping of mean grain size and sorting; ranging $2.32-2.52 \Phi$ and $0.27-0.34 \Phi$ respectively, they are also nearly symmetrical (ranging 0 - 0.1) (figure 5.26). The second and larger cluster includes the northern inshore and foreshore, the southern interdune hollows, beach and tidal flats. Data for which are all predominantly within well to moderately sorted (ranging $0.32-0.63 \Phi$ ), medium to fine sand (ranging $1.43-2.52 \Phi)$ (figure 5.27).

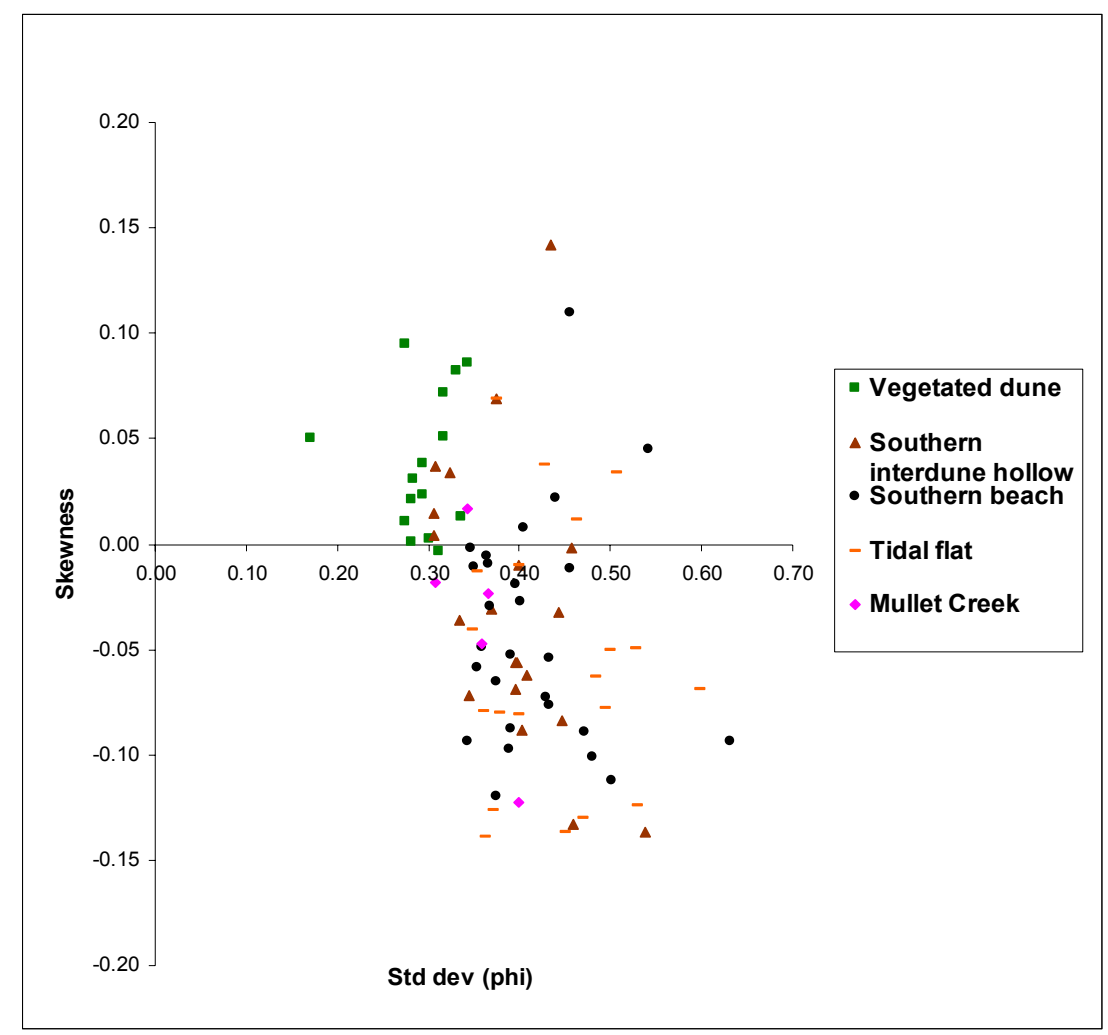

Figure 5.27: Bivariate plot of sorting and skewness for subsurface sediments collected within the Farewell Spit southern environments.

The Mann-Whitney $U$ analysis of grain size parameters of the subsurface core samples show that the two clusters are significantly different. The mean, sorting and skewness of the vegetated dunes samples all show significant differences, to $99 \%$ confidence interval $(\mathrm{Cl})$ 
( $p$-values < 0.01), when compared to the same parameters of the interdune hollow, beach and tidal flat environments (table 5.5). Whereas the interdune hollow, beach and tidal flats of the larger cluster only show a significant difference in the mean grain size to $95 \% \mathrm{Cl}$ (p-values <0.05) (table 5.5) (figure 5.26). The Mullet Creek very well to well sorted, nearly symmetrical, fine sand lies between these two major cluster groups. However these samples are shown to be more related to the interdune hollow, tidal flats and beach, where only the sorting shows significant differences to that of the beach and tidal flat ( $p$-values $<0.05$ ), all other parameters being similar.

Table 5.5: Mann-Whitney $U$ test results for sieved grain size parameters at different sand source areas.

\begin{tabular}{|l|cc|cc|cc|}
\hline Sand source areas & Mean & \multicolumn{3}{c|}{ Sorting } & \multicolumn{2}{c|}{ Skewness } \\
\hline & P-value & U-value & P-value & U-value & P-value & U-value \\
\hline Dune and interdune hollow & $\mathbf{0 . 0 0 0}$ & 35.500 & $\mathbf{0 . 0 0 0}$ & 24.000 & $\mathbf{0 . 0 0 1}$ & 43.000 \\
Dune and beach & $\mathbf{0 . 0 0 0}$ & 48.000 & $\mathbf{0 . 0 0 0}$ & 1.000 & $\mathbf{0 . 0 0 0}$ & 32.000 \\
Dune and tidal flat & $\mathbf{0 . 0 0 0}$ & 13.500 & $\mathbf{0 . 0 0 0}$ & 0.000 & $\mathbf{0 . 0 0 0}$ & 27.000 \\
Dune and Mullet Creek & $\mathbf{0 . 0 1 0}$ & 7.500 & $\mathbf{0 . 0 0 7}$ & 6.500 & $\mathbf{0 . 0 0 4}$ & 5.500 \\
Interdune hollow and beach & $\mathbf{0 . 5 3 9}$ & 241.500 & $\mathbf{0 . 4 0 6}$ & 231.500 & $\mathbf{0 . 4 5 0}$ & 235.000 \\
Interdune hollow and tidal flat & $\mathbf{0 . 0 1 7}$ & 112.000 & $\mathbf{0 . 6 3 0}$ & 131.500 & $\mathbf{0 . 2 1 1}$ & 153.000 \\
Interdune hollow and Mullet Creek & $\mathbf{0 . 7 1 7}$ & 44.500 & $\mathbf{0 . 1 9 2}$ & 30.000 & $\mathbf{0 . 9 7 4}$ & 49.000 \\
Beach and tidal flat & $\mathbf{0 . 0 0 4}$ & 8.200 & $\mathbf{0 . 2 2 7}$ & 1.460 & $\mathbf{0 . 4 7 0}$ & 0.522 \\
Beach and Mullet Creek & $\mathbf{0 . 9 2 0}$ & 65.500 & $\mathbf{0 . 0 4 0}$ & 28.000 & $\mathbf{0 . 7 6 3}$ & 61.500 \\
Tidal flat and Mullet Creek & $\mathbf{0 . 0 5 1}$ & 21.000 & $\mathbf{0 . 0 1 5}$ & 15.500 & $\mathbf{0 . 4 4 7}$ & 38.500 \\
\hline
\end{tabular}

\subsubsection{Stratigraphy}

Core transects (including both hand auger and vibracore samples) of Farewell Spit's southern zones were taken for stratigraphic analyses to investigate the relationship of the subsurface sediments from the Spit and intertidal areas. The Froggies, Stockyard Point, Mullet Creek, Airstrip and Lighthouse transects were chosen to represent the vegetated dunes, interdune hollows, beaches and tidal flat environments along the length of the Spit (figure 5.28). Each of the transects also represented different environments within the interdune hollows, these being fresh water, salt marsh, salt water inundation and swamp locations at Froggies, Stockyard Point, Mullet Creek, and the 
Lighthouse respectively. The cores were measured and described before analysed for grain size, and core logs were made of the data.

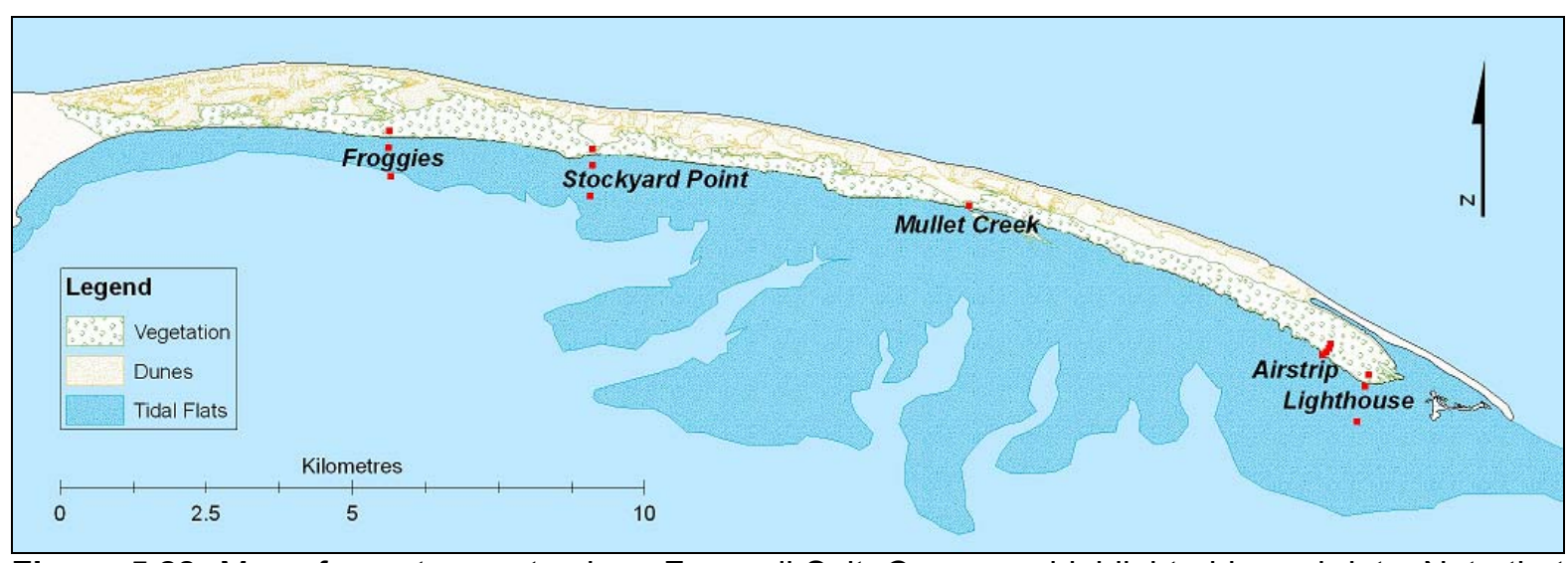

Figure 5.28: Map of core transects along Farewell Spit. Cores are highlighted by red dots. Note that the section labelled lighthouse is not the site of the actual lighthouse but the transect on the southern side of the Spit, opposite to where the lighthouse is situated.

\section{Froggies transect}

Along the Froggies transect a maximum depth of $2.4 \mathrm{~m}$ was achieved in the fresh water lake (core 6) and the beach face (core 5) was the shallowest at $1.2 \mathrm{~m}$ (figure 5.29). The more landward cores have organic staining and roots which are not apparent in the tidal flat (core 4); this however has shell material signifying the marine environment (figure $5.30)$.

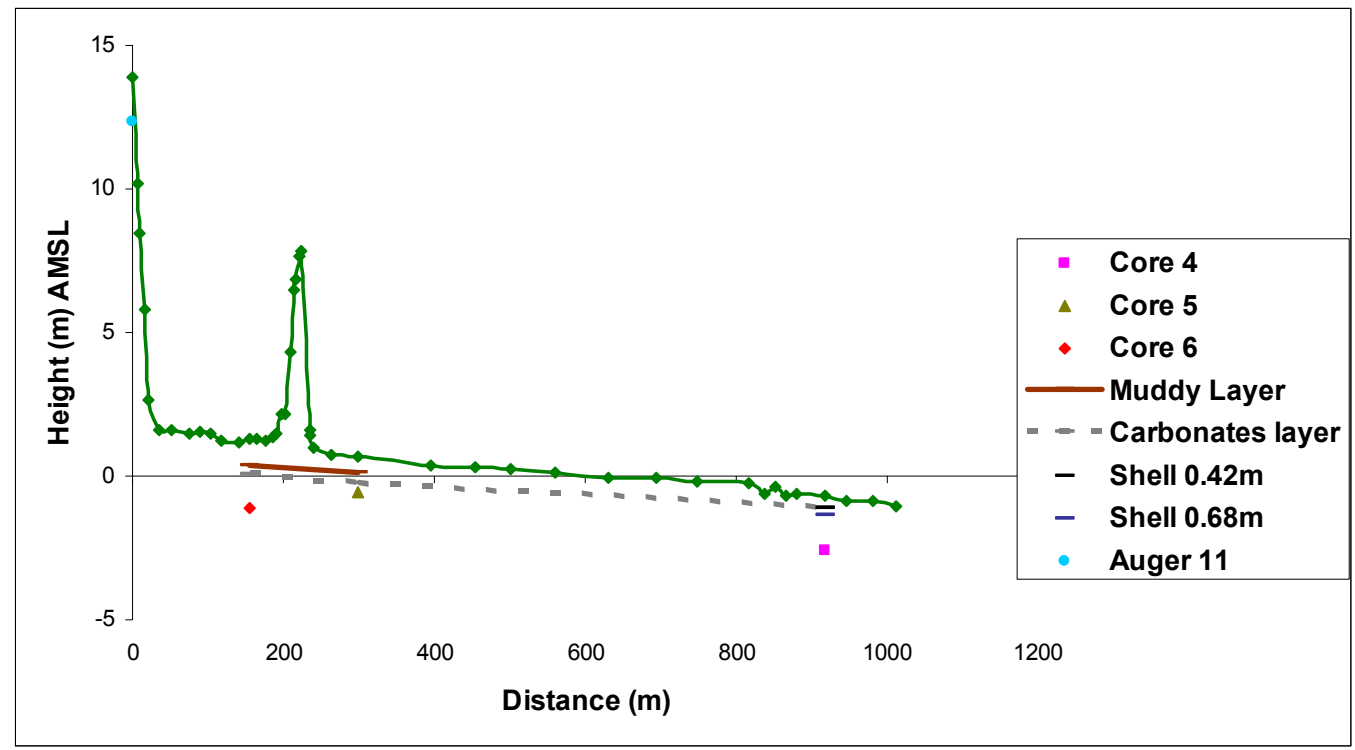

Figure 5.29: The Froggies transect indicating the position of each vibracore site. Also the depth at which the shells were found for ${ }^{14} \mathrm{C}$ dating and the muddy layer underlying the foredune. 


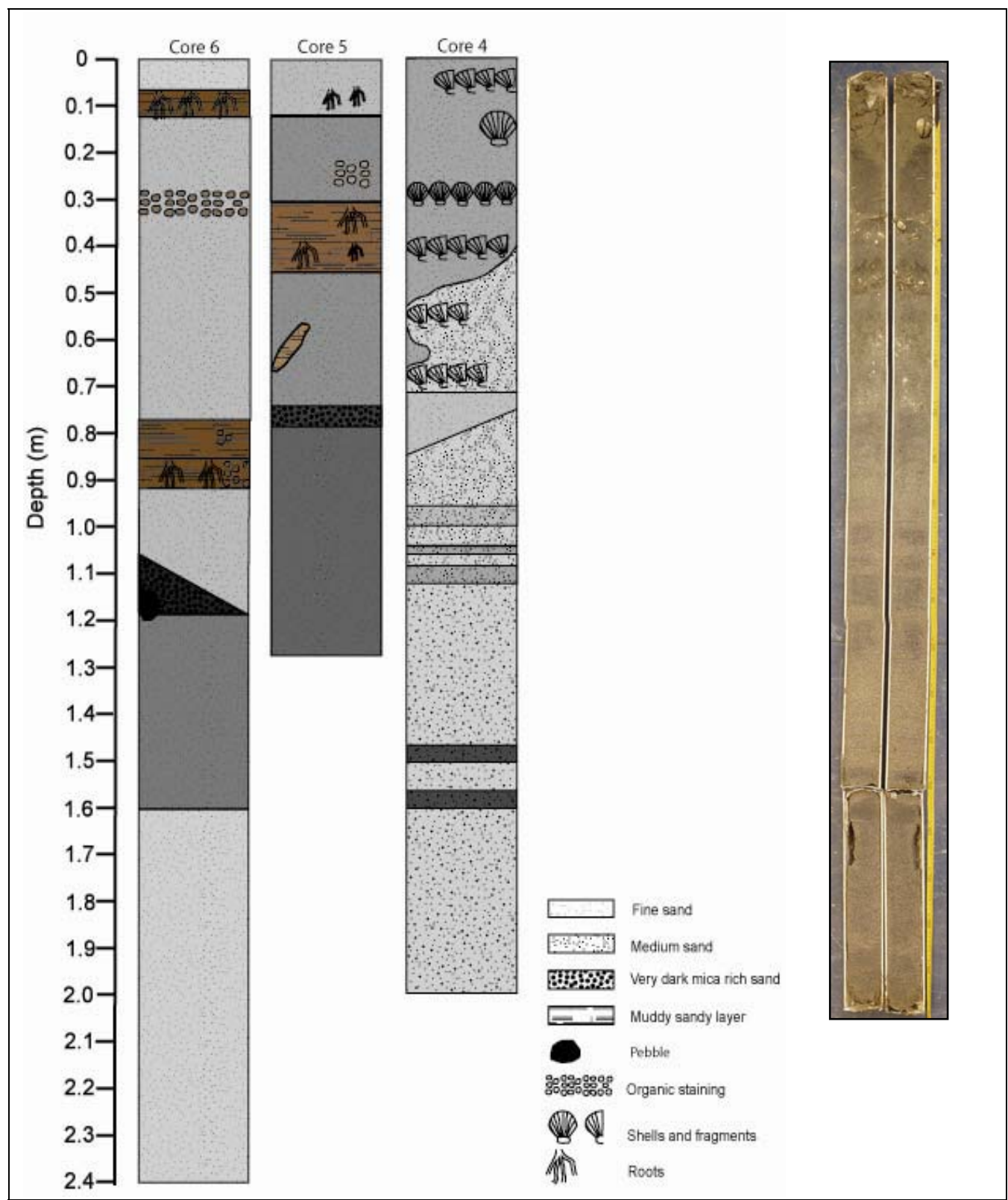

Figure 5.30: Core logs of the Froggies subsurface transect from freshwater lake (core 6 ), beach (core 5) and tidal flat (core 4). Inset is the original tidal flat core immediately after opening (Photograph: Helen Tribe, 2007).

Fine to medium, well sorted sand tending towards negative skewness dominates the subsurface core samples (figures 5.31). This contrasts with the vegetated $1.5 \mathrm{~m}$ deep sample from the second foredune (auger 11 , appendix 3 ) which is nearly symmetrical, very well sorted, fine sand.

Muds and organics are present at low levels (averaging $\sim 2 \%$ ) throughout the profile. At $0.9 \mathrm{~m}$ depth a muddy layer occurs within core 6 
(figure 5.31a) where silt and clay account for up to $6.7 \%$ of the sediment. This layer can be traced to core 5 where a muds peak of $6.1 \%$ occurs at $0.59 \mathrm{~m}$ depth. This indicates the presence of a $0.1^{\circ}$ southward dipping stratigraphic unit (figure 5.29), which has the same gradient as the current tidal flat. A similarly dipping unit $0.3 \mathrm{~m}$ below the muddy layer could also be inferred from the carbonate peaks within these cores. The highest peak ( $8.3 \%)$ occurs at $0.4 \mathrm{~m}$ in the tidal flat, corresponding to a layer of shell fragments. While the beach face peak $(6.1 \%$ at $0.95 \mathrm{~m})$ has no visible shell matter it is associated with a band of moderately well sorted medium sand. 


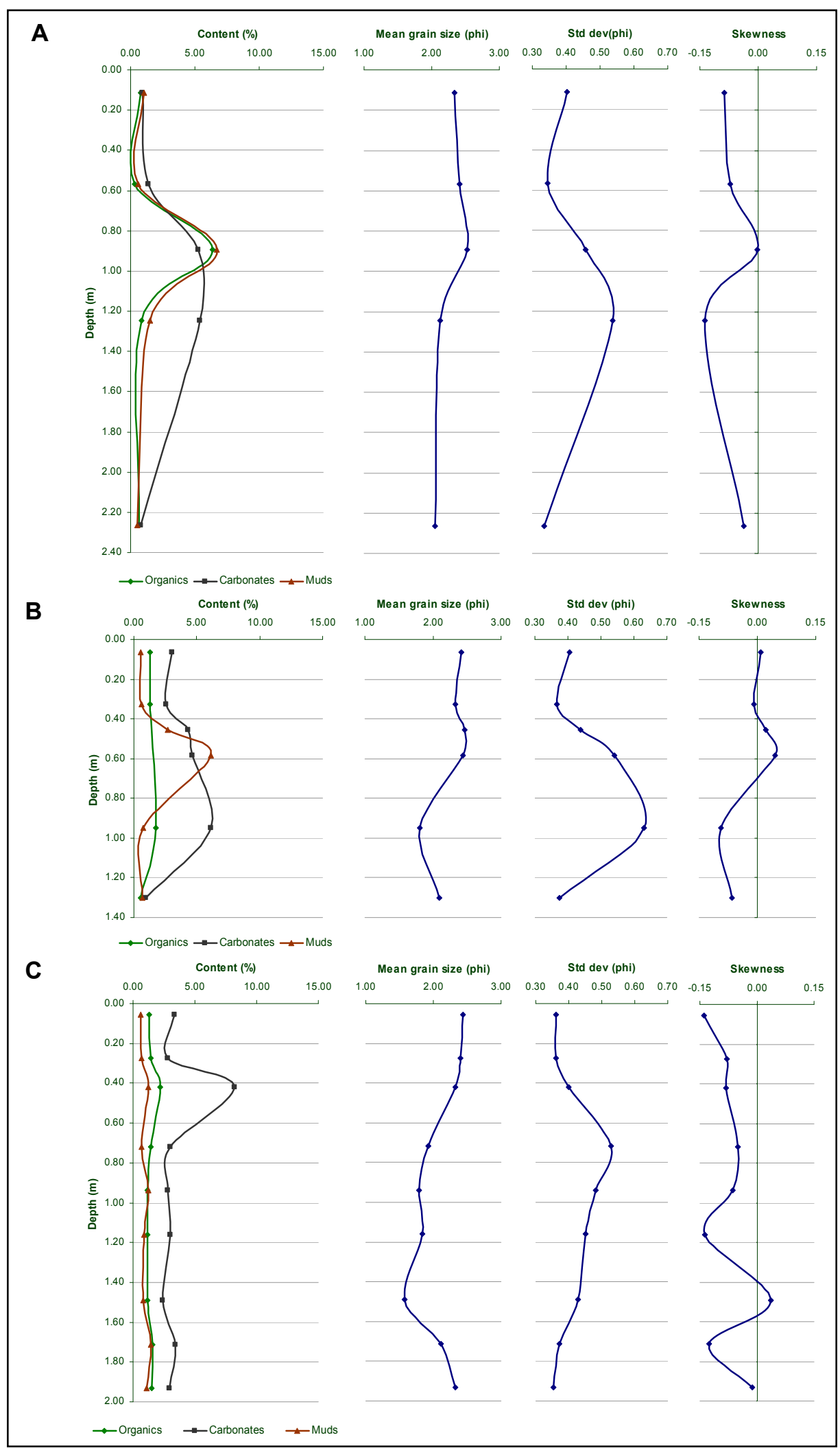

Figure 5.31: Results of grain size analysis of cores along the Froggies transect A) Froggies freshwater lake, B) Froggies beach. C) Froggies tidal flat. 
Radiocarbon ages from the $A$. stutchburyi shells within core 4 indicate that it is a very young feature. The conventional ages range from $\sim 420-$ $\sim 590 \mathrm{BP}$ (table 5.6), the deeper shell fragment was found to be $\sim 100$ years older than the intact shell $0.26 \mathrm{~m}$ above it.

Table 5.6: Radiocarbon dates from Froggies tidal flat core shells including conventional and calibrated ages.

\begin{tabular}{|c|c|c|c|c|c|c|}
\hline $\begin{array}{c}\text { Lab } \\
\text { number }\end{array}$ & $\begin{array}{c}\text { Sample } \\
\text { number }\end{array}$ & $\begin{array}{c}\text { Depth } \\
(\mathbf{m})\end{array}$ & Material & $\begin{array}{c}\mathbf{\delta}^{13} \mathbf{C} \\
(\%)\end{array}$ & $\begin{array}{c}\text { Conventional } \\
\text { age (years } \\
\text { BP } \pm \mathbf{1 \sigma})\end{array}$ & $\begin{array}{c}\text { Calibrated } \\
\text { age } \\
\text { (years BP) } \\
(\mathbf{6 8 . 2 \%} \text { Prob) }\end{array}$ \\
\hline Wk - 21854 & FS4/ 0.42 & 0.42 & A. stutchburyi & $0.7 \pm 0.2$ & $\mathbf{4 5 1 \pm 3 0}$ & $120-$ present \\
\hline Wk - 21855 & FS4/ 0.68 & 0.68 & A. stutchburyi & $1.3 \pm 0.2$ & $\mathbf{5 6 0 \pm 3 0}$ & $271-132$ \\
\hline
\end{tabular}

Auger 11 within the vegetated dune has some minor organic matter down to $0.1 \mathrm{~m}$ and shows only low amounts of organics, muds and carbonates; $4.3 \%, 0.5 \%$, and $1.5 \%$ respectively at the $1.5 \mathrm{~m}$ sample depth. This feature has also proved to be very young being the only site along Farewell Spit to test positive for the presence of ${ }^{137} \mathrm{Cs}$ during the initial OSL age determination process (table 5.7). Thus at $2 \mathrm{~m}$ depth the sand was exposed, most likely around 1965 and later covered, where the remaining samples showed no ${ }^{137} \mathrm{Cs}$ and therefore are considered to be older than 1952. Results of comprehensive OSL dates for these samples are currently still being processed.

Table 5.7: Levels of ${ }^{137} \mathrm{Cs}$ within samples taken along the vegetated dunes for OSL dating.

\begin{tabular}{|l|c|c|}
\hline \multicolumn{1}{|c|}{ Site } & ${ }^{137}$ Cs detected & Age \\
\hline Whale Dune (6m) & No & $>1952$ \\
\hline Pa Dune (4m) & No & $>1952$ \\
\hline Froggies (2m) & Yes & $\sim 1965$ \\
\hline Airstrip (2m) & No & $>1952$ \\
\hline
\end{tabular}




\section{Stockyard Point transect}

Stockyard Point is $3.7 \mathrm{~km}$ east of Froggies (figure 5.28). This transect includes a salt marsh (core 3 ) and beach (core 1) which have prograded in the last 20 years as shown in figure 5.21. The cores range in depth from $1.2-1.6 \mathrm{~m}$ and are similar to the Froggies cores in showing decreasing levels of organics and increasing amounts of medium sand from the salt marsh to the tidal flat (core 2) (figure 5.32).

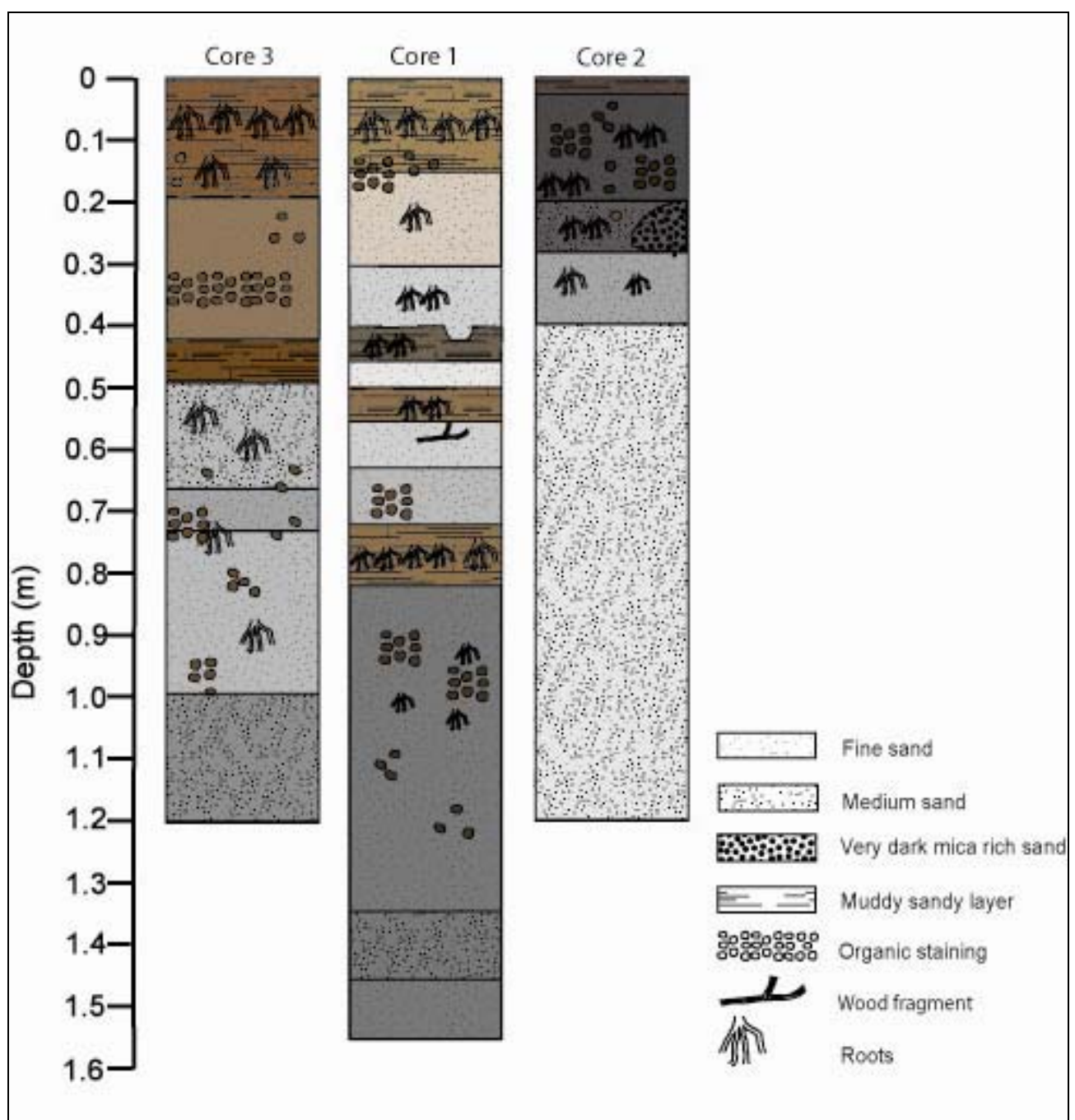

Figure 5.32: Core logs of the Stockyard Point subsurface transect including the salt marsh (core 3), beach (core 1) and tidal flat (core 2).

The Stockyard Point cores are dominated by well sorted, nearly symmetrical fine to medium sand (appendix 1A-C). The organic contents are $\sim 5 \%$ in the salt marsh, decreasing to $\sim 1.5 \%$ at the tidal 
flats. The muds content follow a similar pattern ranging $\sim 3.5 \%$ to $\sim 1 \%$ and a muddy layer is also evident within the interdune hollow where silt and clay accounts for $6.48 \%$. This can also be traced under the small dune to the beach where silt and clay is $12.55 \%$ at $0.83 \mathrm{~m}$ depth, forming a similar stratigraphic unit to the Froggies profile, with a $0.5^{\circ}$ gradient, underlying the foredune (figure 5.33). The carbonate content averages $\sim 3 \%$, peaking to $\sim 5 \%$ at the same depths as the organics and muds (appendix 1A-C).

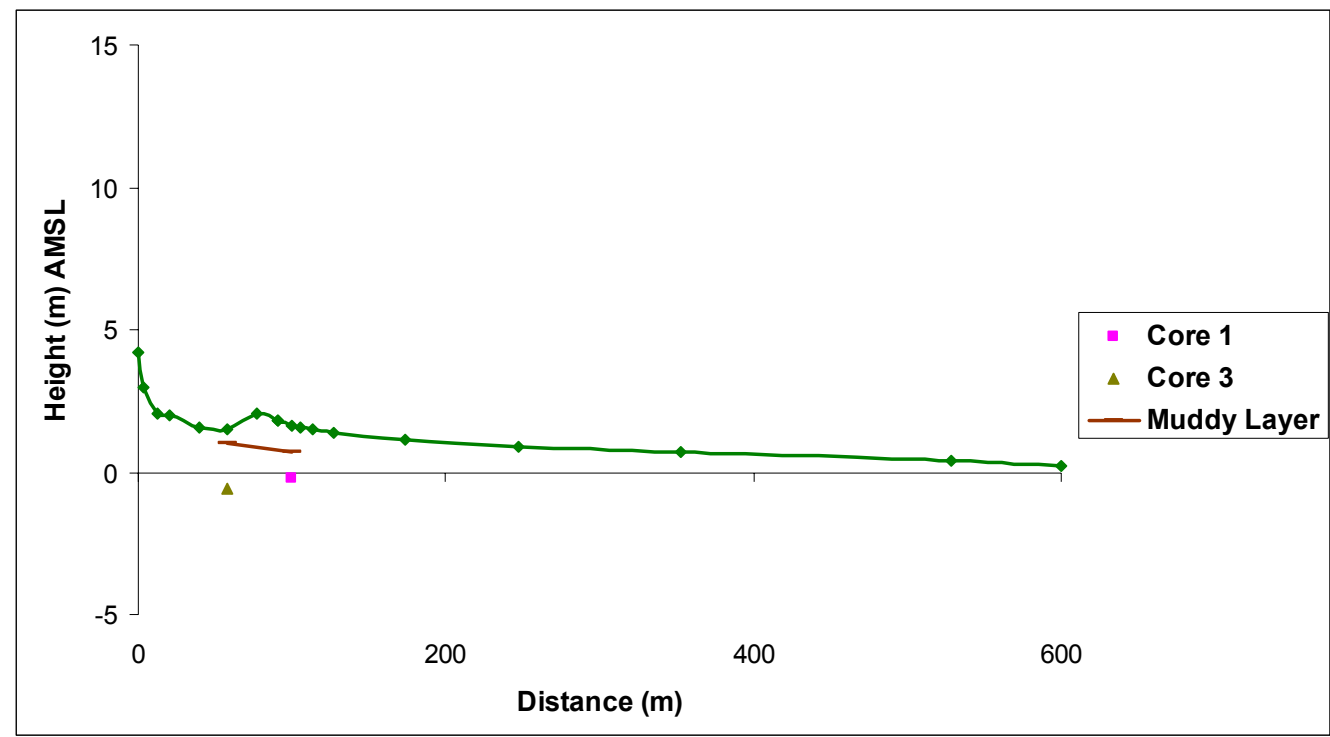

Figure 5.33: Stockyard Point transect indicating the position of each vibracore site except the tidal flat core, and the muddy layer underlying the foredune. 


\section{Mullet Creek Core}

Mullet Creek is a low lying area $6.5 \mathrm{~km}$ west of Stockyard Point which inundates during higher tides (figure 5.28). The Mullet Creek core (core 10) shows very little organics, carbonates and muds (all $<1.2 \%$ ), after their slightly higher upper profile levels (figure 5.34). The moderately well sorted to well sorted, fine sand is nearly symmetrical, with a coarse skew at $1.97 \mathrm{~m}$ which corresponds to the medium sand layer (appendix 2).

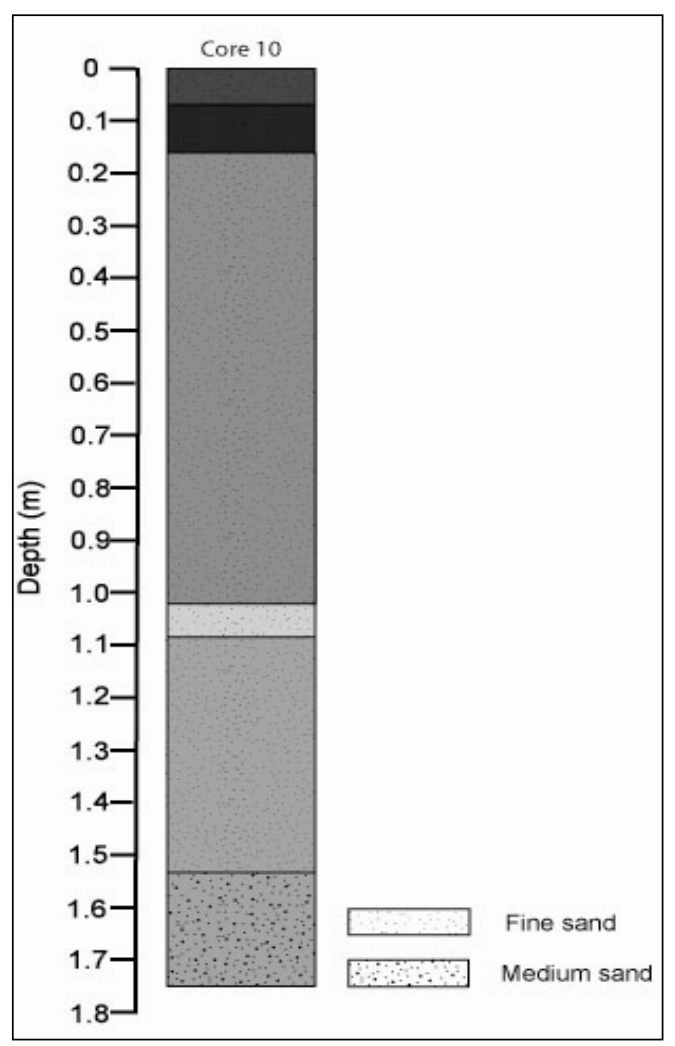

Figure 5.34: Core log of Mullet Creek.

\section{Airstrip transect}

The series of hand augered cores were taken through the vegetated dunes on the southern side of the airstrip (A3-8) (figure 5.28). These penetrated to depths between 0.63 and $0.75 \mathrm{~m}$ which were just below the water table level (figure 5.35). Well sorted fine sand with little organics, carbonates or muds (all $<3 \%$ ) occur with limited soil development apart from an organic layer of $\sim 0.05 \mathrm{~m}$ in the swamps (appendix $3 A-C$ ). Root matter is found to depths of $0.08 m-0.17 m$. These parameters are very similar to the vegetated dunes at Puponga Farm Park (Whale Dune A1 \& Pa Dune A2, appendix 3A-C). No ${ }^{137} \mathrm{Cs}$ was found in any of these dunes indicating that these dunes have been stable since at least 1952 (table 5.7). 


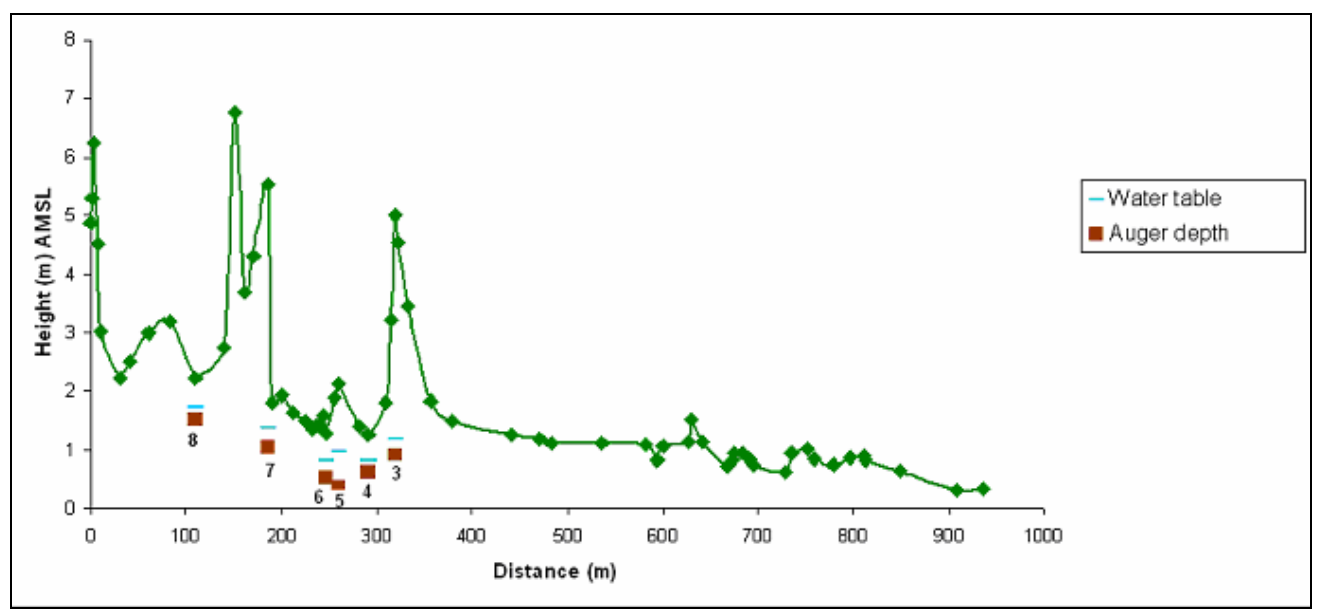

Figure 5.35: Airstrip south transect indicating the position and depth of each auger site and the water table level.

Lighthouse transect

The lighthouse transect is $\sim 100 \mathrm{~m}$ east of the Airstrip transect (figure 5.28). The shallowest of all the cores (core 9 ) reached $1 \mathrm{~m}$ depth within the swamp, and $1.3-1.5 \mathrm{~m}$ at the beach (core 7) and tidal flat (core 8) respectively (figure 5.36). The organics, carbonates and muds are most prevalent within the swamp core (averaging $\sim 4.5 \%$ ), decreasing towards the bottom (appendix 4A). Throughout the rest of the transect the organics and muds average $<2 \%$, despite some brown staining in the top $0.1 \mathrm{~m}$ of the tidal flat, and the carbonates average $<3 \%$ (appendix $4 \mathrm{~B}$ $\& \mathrm{C})$. A large angular stone $(\sim 70 \mathrm{~mm}$ long) was found at $0.15 \mathrm{~m}$ depth within core 7 as well as the only shell found within any beach core (figure 5.36). The swamp and beach cores are mostly fine sand, very well to well sorted nearly symmetrical sand, although a coarse, positively skewed layer is evident at $1.52 \mathrm{~m}$ within the beach core (appendix 4A \& B). Whereas the tidal flats sand is dominated by medium, moderately well sorted sand tending towards a coarse skew (appendix 4C). 


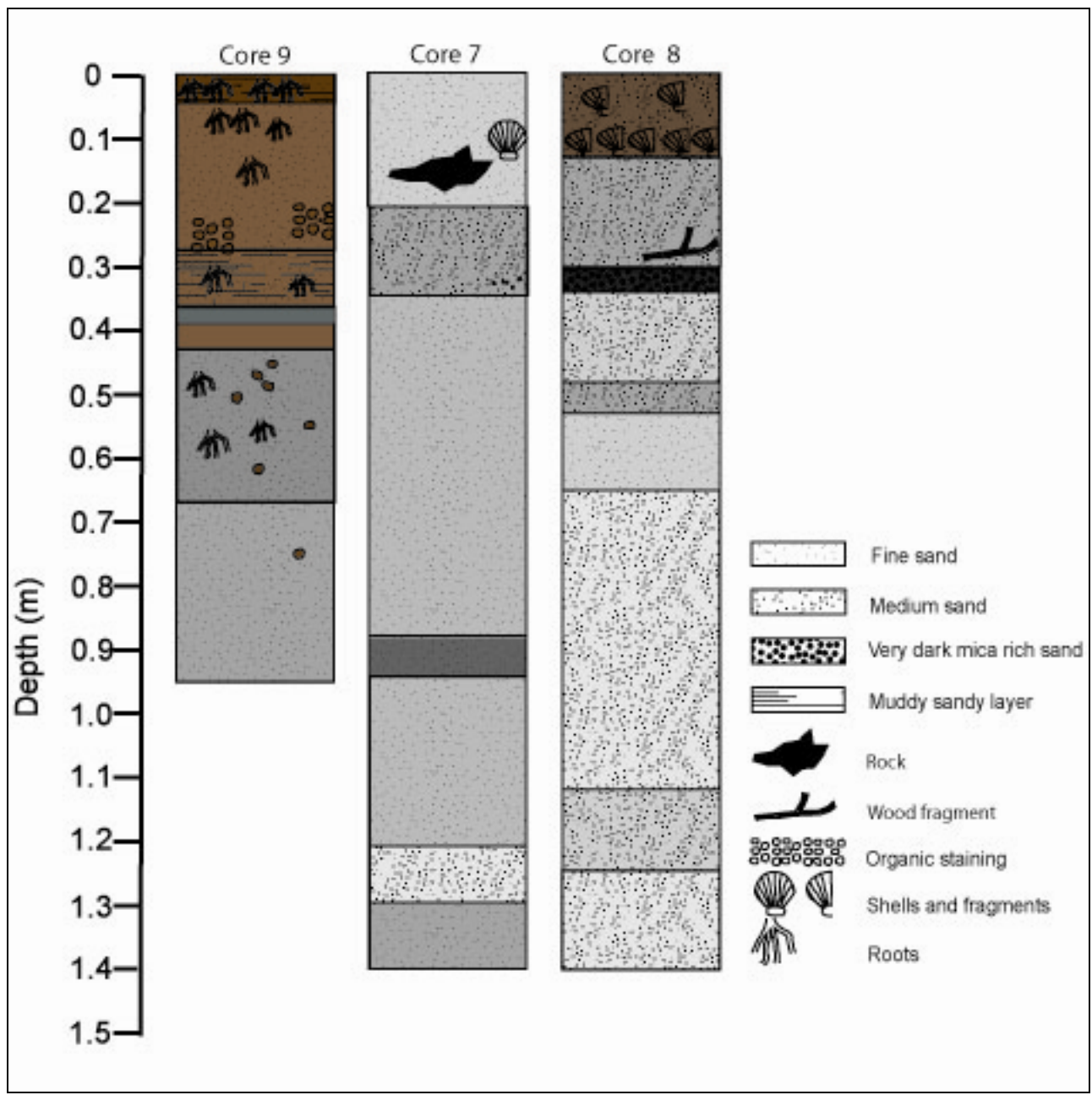

Figure 5.36: Core logs of the Lighthouse subsurface transect including the swamp (core 9), beach (core 7) and tidal flat (core 8).

\subsection{Projected sea-level rise and inundation of Farewell Spit}

Several low lying areas cut across the width of the Spit, some of which inundate at high tide. Mullet Creek completely floods, linking the open ocean and tidal flat coasts at perigean high tides (figures 5.37A \& B). This area is also subject to dune erosion on account of the fluctuating tidal water levels (5.37C). Other low lying areas which have shown to act in a similar way are the two smaller creeks $\sim 1 \mathrm{~km}$ to the east of Mullet Creek (pers. obs.). The Roadway and Stockyard Lake are also deemed to be vulnerable and although do not currently inundate, they could do so in the future. 


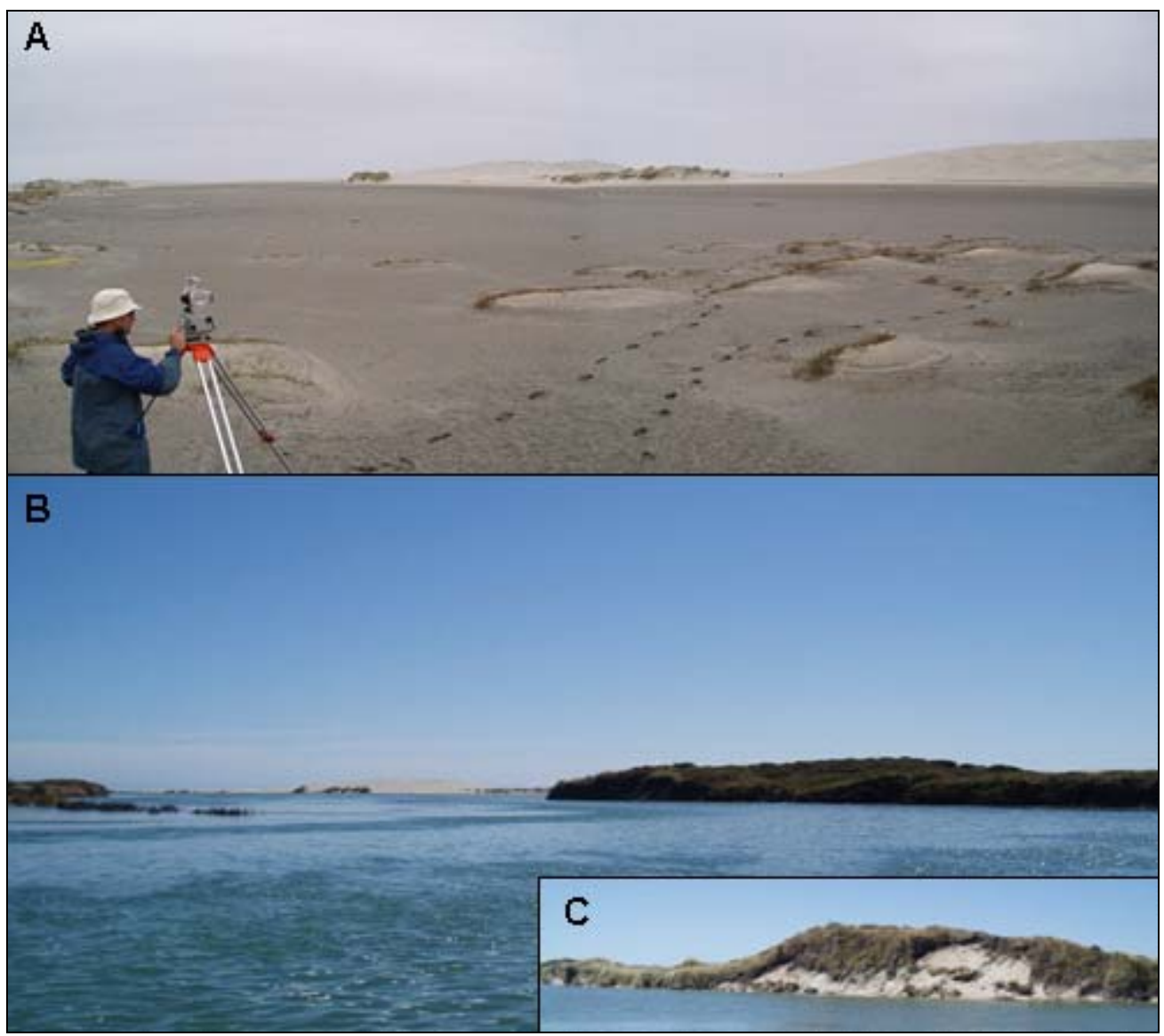

Figure 5.37: A) Surveying through Mullet Creek at 17 February 2007 low tide. (Photograph: Helen Tribe, 2007). B) Mullet Creek at 4.89m spring tide, 18 February 2007. Note the sand dunes in the background here are the same as those pictured in figure 5.18A. (Photograph: Rod Boys, 2007). C) Dune erosion scarp 2m high at southern end of Mullet Creek (Photograph: Helen Tribe, 2007)

The mean high water spring (MHWS) level for Collingwood is $4.7 \mathrm{~m}$, this only just floods the entire cross section of Mullet Creek (figure 5.38), without the aid of storm surge or wind wave set-up. The $0.48 \mathrm{~m}$ projected sea-level rise (IPCC, 2007) would bring this level up to $5.18 \mathrm{~m}$, which is shown to easily overtop this area. As does the highest astronomical tide (HAT), being $5.02 \mathrm{~m}$ in 2007 , thus under projected sea-level rise would flood at a much deeper water level $(5.66 \mathrm{~m})$. 


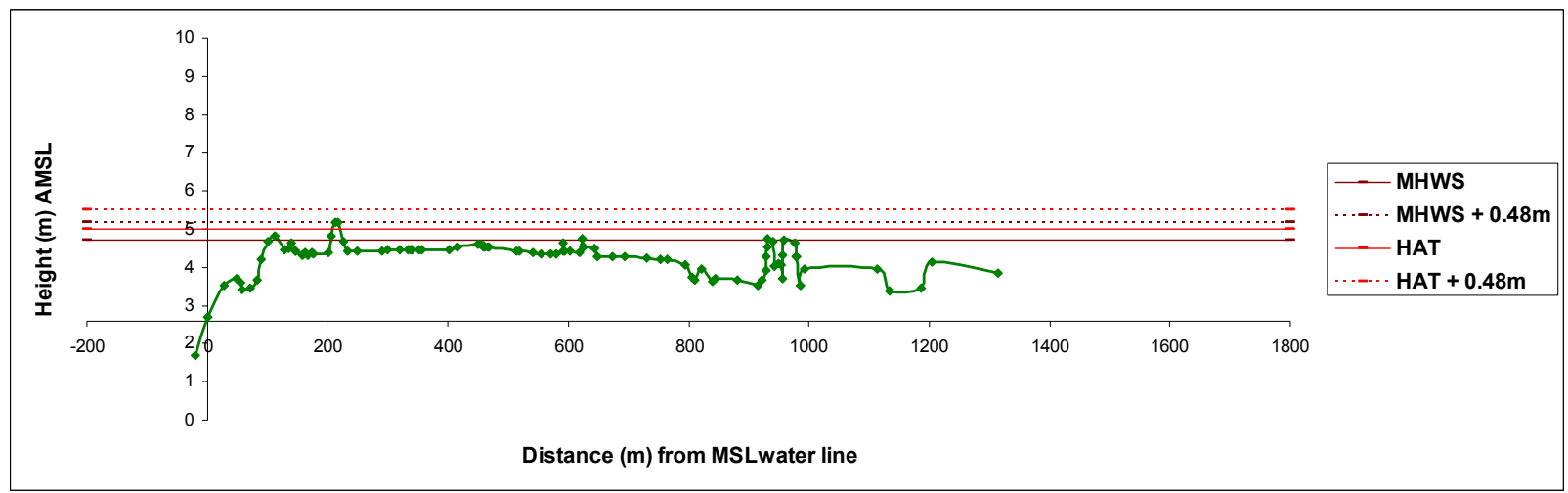

Figure 5.38: Sea-level rise modelling on the north to south profile across Mullet Creek, $X$ and $Y$ axes cross at the Collingwood mean sea-level line. The $0.48 \mathrm{~m}$ projected sea-level rise is superimposed on MHWS and HAT levels for Collingwood tide gauge.

The same projected sea-level rise modelling was also used on the Roadway, Stockyard Lake and Airstrip transects. Although none of the sea-level scenarios over-tops the Roadway (figure 5.39A) which rises $5 \mathrm{~m}$ above the Whanganui Inlet MSL of $1.4 \mathrm{~m}$, storm surge and/or wave set-up sitting on top of these projected higher base sea-levels could inundate this section. The Stockyard Lake profile similarly does not currently flood under current or projected conditions (figure 5.39B). However, water is being held back out of this area only by a $31 \mathrm{~m}$ mobile dune on the northern side and a $32 \mathrm{~m}$ wide vegetated dune on the southern side. The Airstrip (figure 5.39C) by contrast does not appear to be vulnerable to inundation under any of the sea-level scenarios because of the pronounced dune ridges at the eastern end of the Spit. 


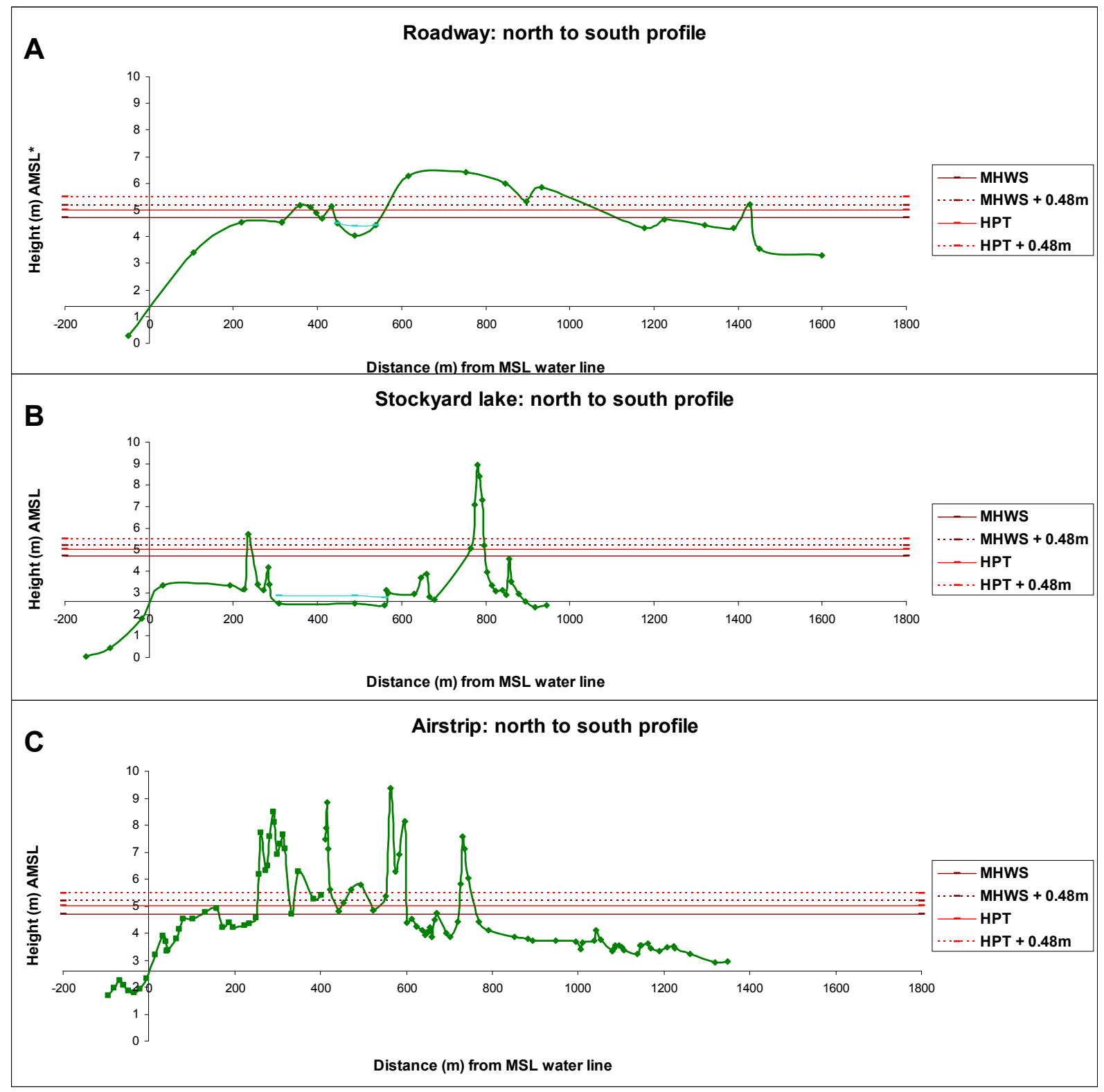

Figure 5.39: Sea-level rise modelling on the north to south profiles across other lowlying areas on Farewell Spit. A) The Roadway, B) Stockyard Lake and C) The Airstrip. All X and $Y$ axes cross at the Collingwood mean sea-level line except for the roadway which is closest to the Whanganui Inlet* mean sea-level line. The $0.48 \mathrm{~m}$ projected sea-level rise is superimposed on MHWS and HAT levels for Collingwood tide gauge.

\subsection{Summary}

This chapter presented the results obtained from the study on Farewell Spit to fulfil the objectives of this thesis. The geomorphic zones and their associated transformations were all described in detail. The Shellbanks showed the greatest geomorphic change over the time frame while the northern dune system moved the fastest. Shoreline 
change was identified at Bush End and Stockyard Points and an average total accretion rate of $1 \mathrm{~m} / \mathrm{y}$ was ascertained for Farewell Spit. Mullet Creek and two other creeks to the east currently totally flood, while the Roadway and Stockyard Lake were also identified as low lying areas, vulnerable to sea-level rise. Dates obtained from shell and sediment samples indicate that Farewell Spit is a young and dynamic environment. 


\section{Chapter Six: Discussion}

\subsection{Introduction}

Oceans act as heat reservoirs in the global climate system as they retain their temperatures for longer periods than the atmosphere. This means under the current scenarios of climate warming a lag of several centuries will occur between climate warming and oceanic response (Hansen et al., 2005; Wigley, 2005). Thus even if greenhouse gas emissions were immediately reduced to pre 2000 levels the sea would continue to respond (Bell et al., 2001, NIWA, 2007b). Vulnerable sand barriers such as Farewell Spit therefore are likely to experience some degree of morphological change as a result of anthropogenically forced sea-level rise, even if $\mathrm{CO}_{2}$ emissions were reduced today. This thesis has analysed the upper end of the global average projections of 0.21 $0.48 \mathrm{~m}$ sea-level rise by 2100 (IPCC, 2007). This is the IPCC sea-level prediction for the A1B scenario, under which global economic considerations play a major role within a balanced use of all energy sources (IPCC, 2007). While this is not the most extreme case IPCC prediction it was chosen as a conservative scenario given the current political/environmental climate; whereby the global economy is continuing to aspire to rapid economic growth, while technologies are looking to more efficient use of resources, including the use of renewable energy.

\subsection{Geomorphology of spit}

Barriers are an example of a system that incorporates many landform elements, which migrate and alter their morphology primarily in response to sea-level variation. Farewell Spit is a mixed energy barrier spit, the smooth arcuate northern edge being typical of a high mesotidal, wave-dominated shoreline as described in Fitzgerald et al. (1984). 
The backbarrier Golden Bay environment is tidal-dominated, containing extensive tidal flats and salt marshes. Although the Spit is low lying relative to the surrounding landscape it is a high profile barrier, including complex dune systems of mobile barchan dunes (up to $25 \mathrm{~m} \mathrm{AMSL}$ ) on the northern edge and linear vegetated ridges (up to $\sim 20 \mathrm{~m}$ ) on the southern side.

Farewell Spit has been hypothesised to have linearly extended eastward from Cape Farewell as an accumulation of sediment delivered by longshore drift up the Westcoast over $\sim 6.5 \mathrm{ka}$ (figure 6.1) (McLean, 1978; Gibb, 1979; Mueller, 1990 In Petyt, 1999; Ballance, 2006). The West African spit Langue de Barbarie formed in a similar way and exhibits bulges along its edge which are evidence of past terminus points, associated with this longshore growth over time (Bird, 2005a).

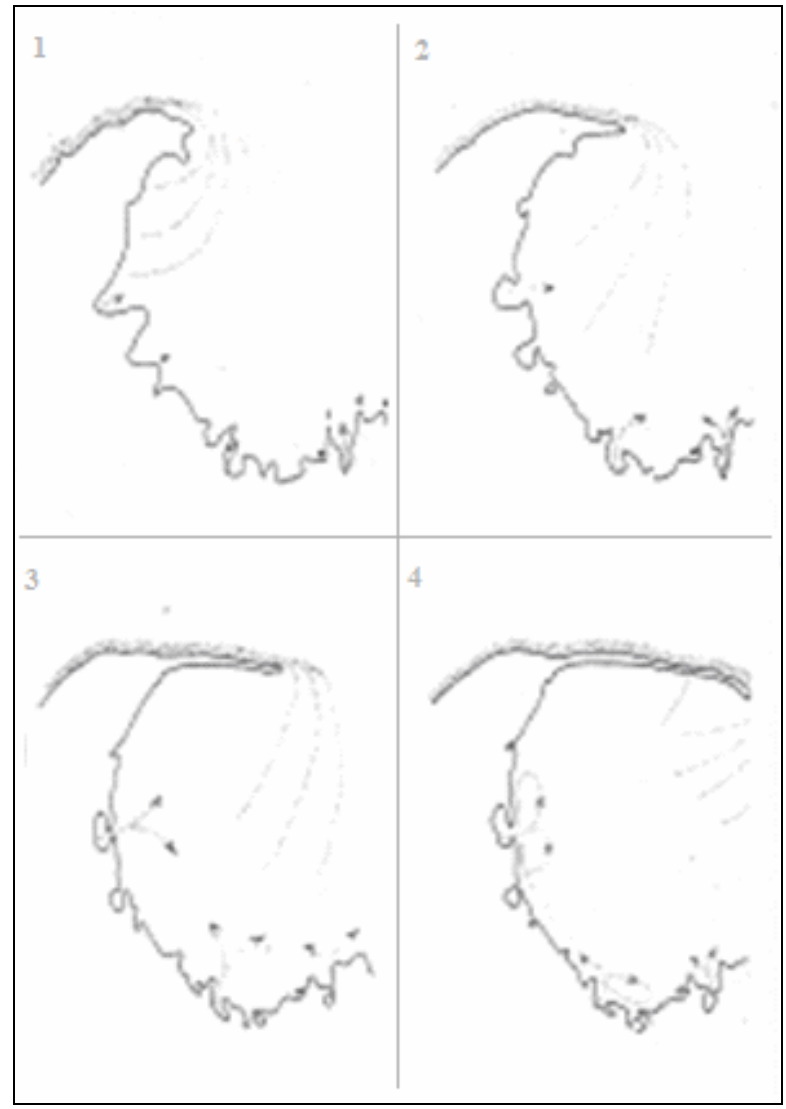

Figure 6.1: Illustration showing the growth of Farewell Spit from 6.5ka to present (Petyt, 1999). 
Although the planform of Ocean Beach is a relatively smooth curve there are 2 - 3 wide lobes along its length, reminiscent of a drift aligned beach (Bird, 2005b). However, these are related to the general widening of the Spit in these areas (figure 6.2) after which the angle of the Spit alters slightly. The southern side of the Spit also has some more defined bulges, the most notable being just west of Mullet Creek (figure 6.2). The Spit terminates with a slight recurve, identifiable by widening towards Golden Bay, while the sand bar also reticulates toward the Shellbanks (figure 6.2).

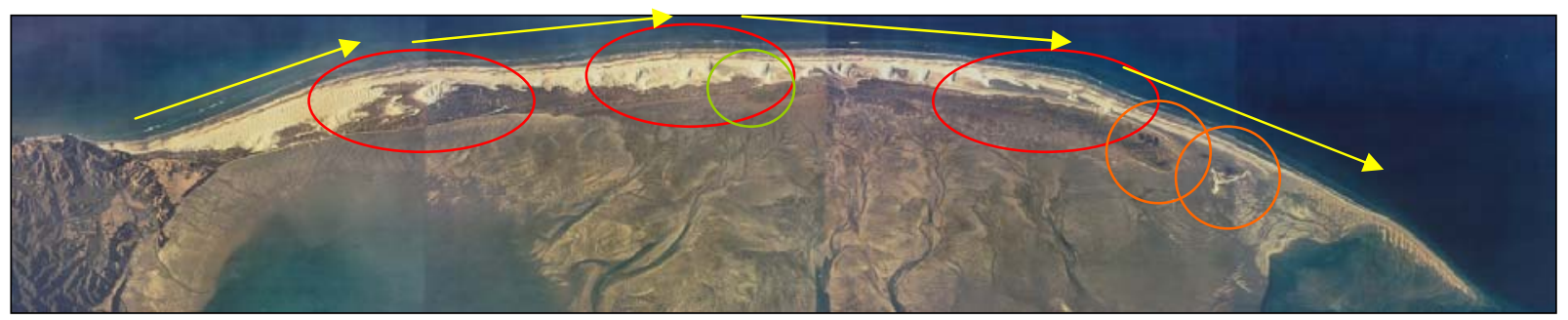

Figure 6.2: 2003 composite aerial photograph of Farewell Spit. Note: wide lobes related to general Spit widening (red circles), changing angles of the Spit (yellow arrows), the southern edge bulge west of Mullet Creek (green circle), and the Spit terminus and sandbar recurves (orange circle) (Photograph: NZ Aerial Mapping Ltd).

There is a possibility that the sandbar could connect to the Shellbanks and sand infill between this environment and Bush End Point, and in doing so, extend the subaerial portion of Farewell Spit. As such, the areas of Spit widening could be representative of past terminus points. However, as the ${ }^{137} \mathrm{Cs}$ results from the preliminary OSL dating have determined the samples along the Spit are very young and relate more to the mobility of sand on the upper layers $(2-4 m)$, the testing of this theory therefore remains inconclusive.

The Shellbanks show the greatest morphological change over the 54.5 year time frame (figure 5.22) with their planform shape transforming quickly in response to major storms. Ex tropical cyclone Drena during 10 - 12 January 1997 was responsible for their almost total destruction (Petyt, 1999), and likely also the $\sim 100 \mathrm{~m}$ northward movement of the offshore bar and Bush End Point (figure 5.23). The Shellbanks have 
subsequently reformed and rotated anticlockwise while $A$. arenaria has been re-established on them.

In a study of washover penetration on barrier islands of the Atlantic and Gulf Coasts, Morton and Sallenger (2003) found that although many storms can cause beach erosion, generally only extreme storms and cyclones over category 3 intensity (wind gusts $170-225 \mathrm{~km} / \mathrm{h}$ ) are large enough to cause geologically preserved morphological responses. Drena was below a category 1 cyclone $(<125 \mathrm{~km} / \mathrm{h}$ winds) by the time it reached Farewell Spit which received winds up to $\sim 60 \mathrm{~km} / \mathrm{h}$ mainly from southeast and southwest directions (figure 6.3). Thus the resultant damage shows the fragile nature of these landforms, although they have recovered suggesting their mobility imparts some degree of resilience to such storms they cover $34 \%$ less area than their pre storm morphology.

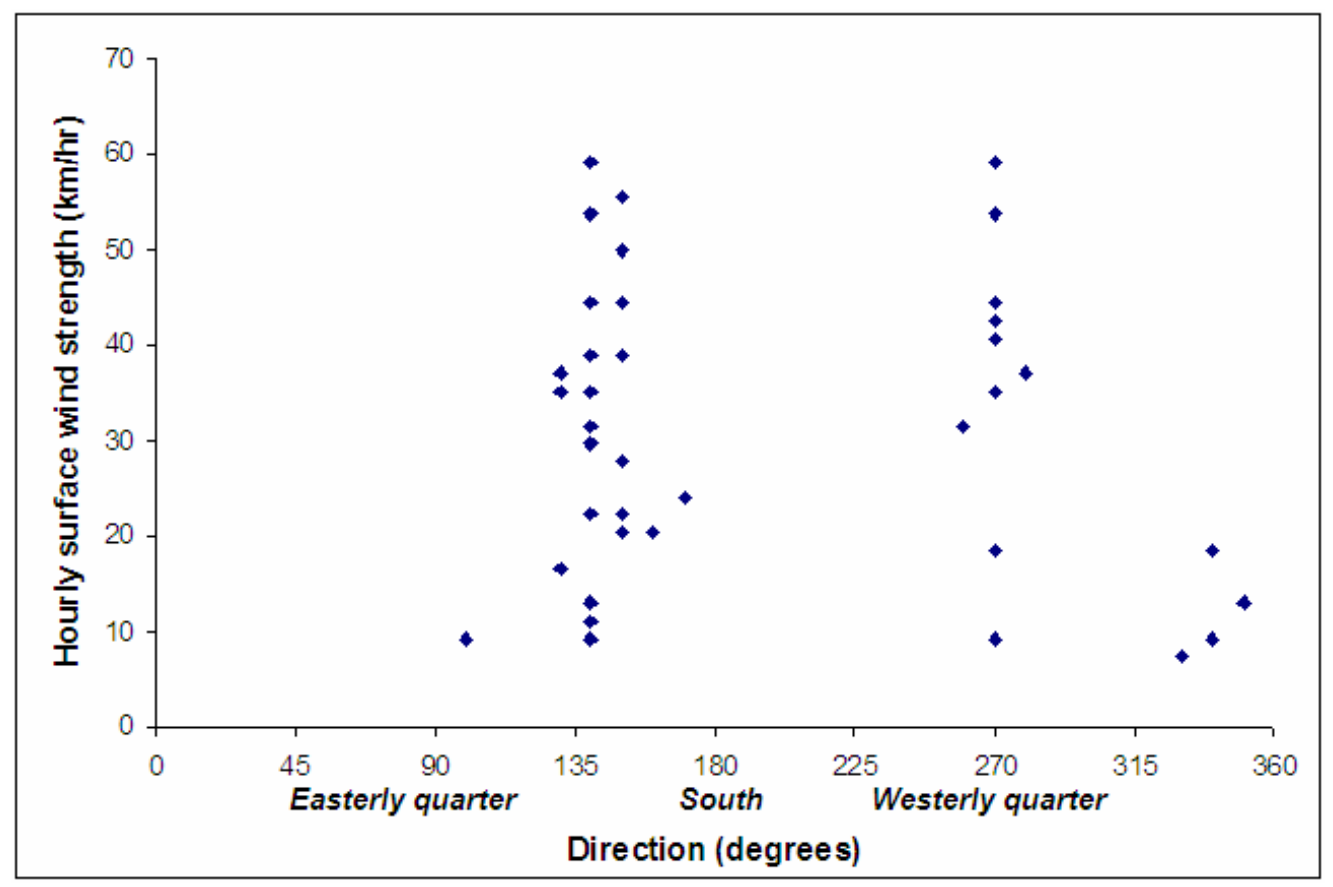

Figure 6.3: Direction of the hourly surface winds on Farewell Spit for the period 10 12 January, 1997 (NIWA 2008b).

Despite the large morphological changes in the Shellbanks their distance from the subaerial Spit end does not seem to change 
significantly, while always remaining in the shadow of the offshore bar (figure 6.4). As wave energy from the north would be dissipated on this bar the most influential weather factors controlling the morphology of the Shellbanks must come from the southwest quarter where energy can penetrate through the entrance of Golden Bay from Cook Strait.

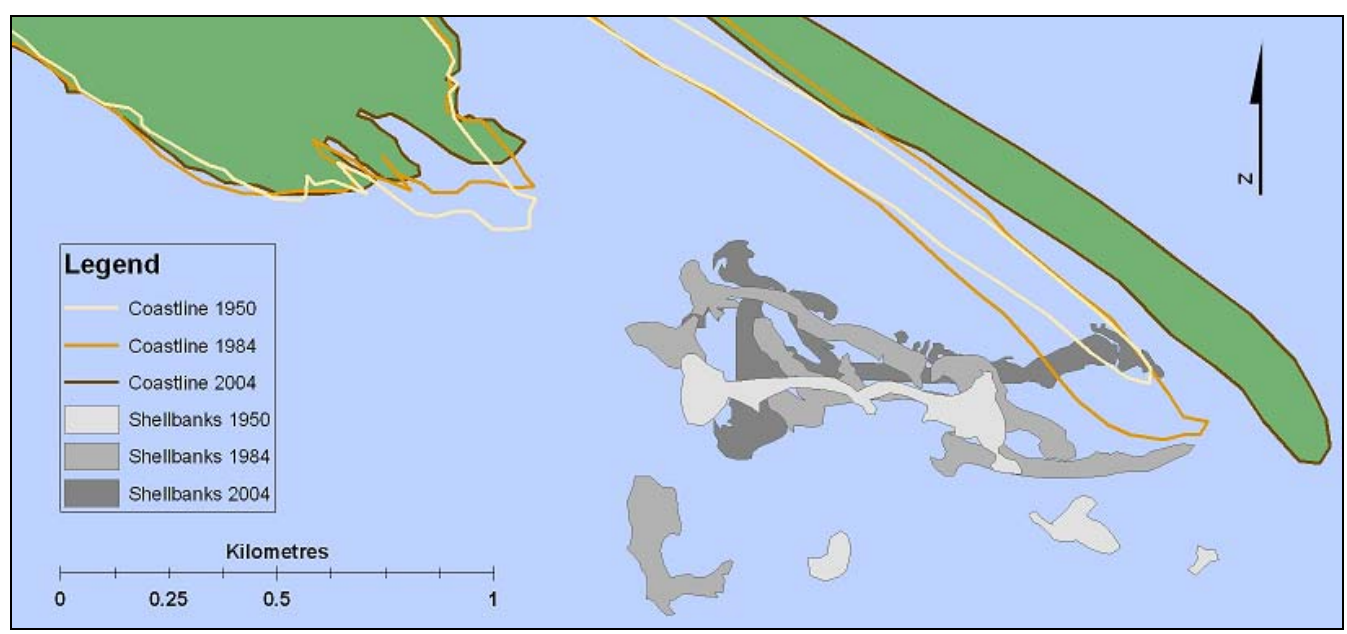

Figure 6.4: Map of Bush End Point showing the shorelines from 1950 - 2004. These illustrate the changes of Shell Bank morphology as well as the northward movement of the offshore bar and Bush End Point. Green shading represents the 2004 extent of Farewell Spit.

The $75 \%$ increase in vegetation on the Spit from 1950 to 2004 is mainly because of the rapid colonisation of $A$. arenaria which has shown exponential growth patterns elsewhere. In Mason Bay, Stewart Island, for example 17.9 ha of $A$. arenaria has grown from the 1.4 ha originally planted in 1958 (Hilton et al., 2005). This resulted in an altered dune morphology and $50 \mathrm{~m}$ seaward progradation of the coastline over 44 years (Hilton et al., 2006). The high colonisation rates of these sand binding plants has also morphologically changed the southern dune system on Farewell Spit, in particular the $169 \mathrm{~m}$ thickening of the bulge at Stockyard Point. Here the colonising $A$. arenaria has aided in the capturing of sand and subsequent growth of dunes which have added to the area of the point (figures $6.5 \& 6.6 \mathrm{~A}$ ). 


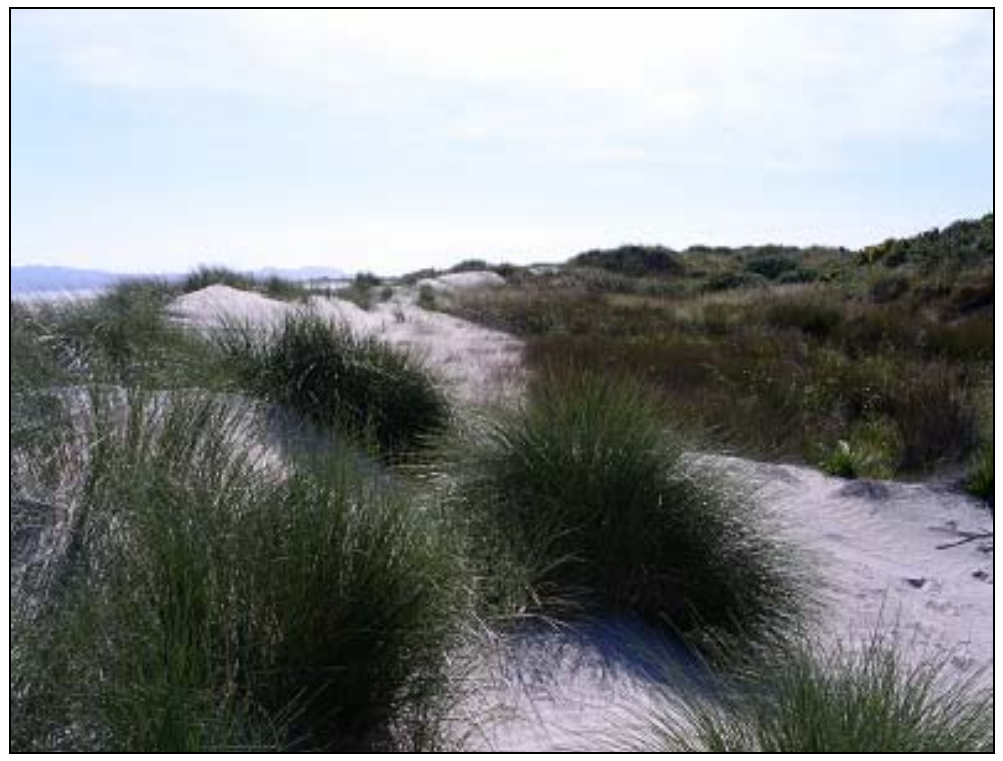

Figure 6.5: Vegetation aiding in the capturing of sand at Stockyard Point (Photograph: David Kennedy, 2007).

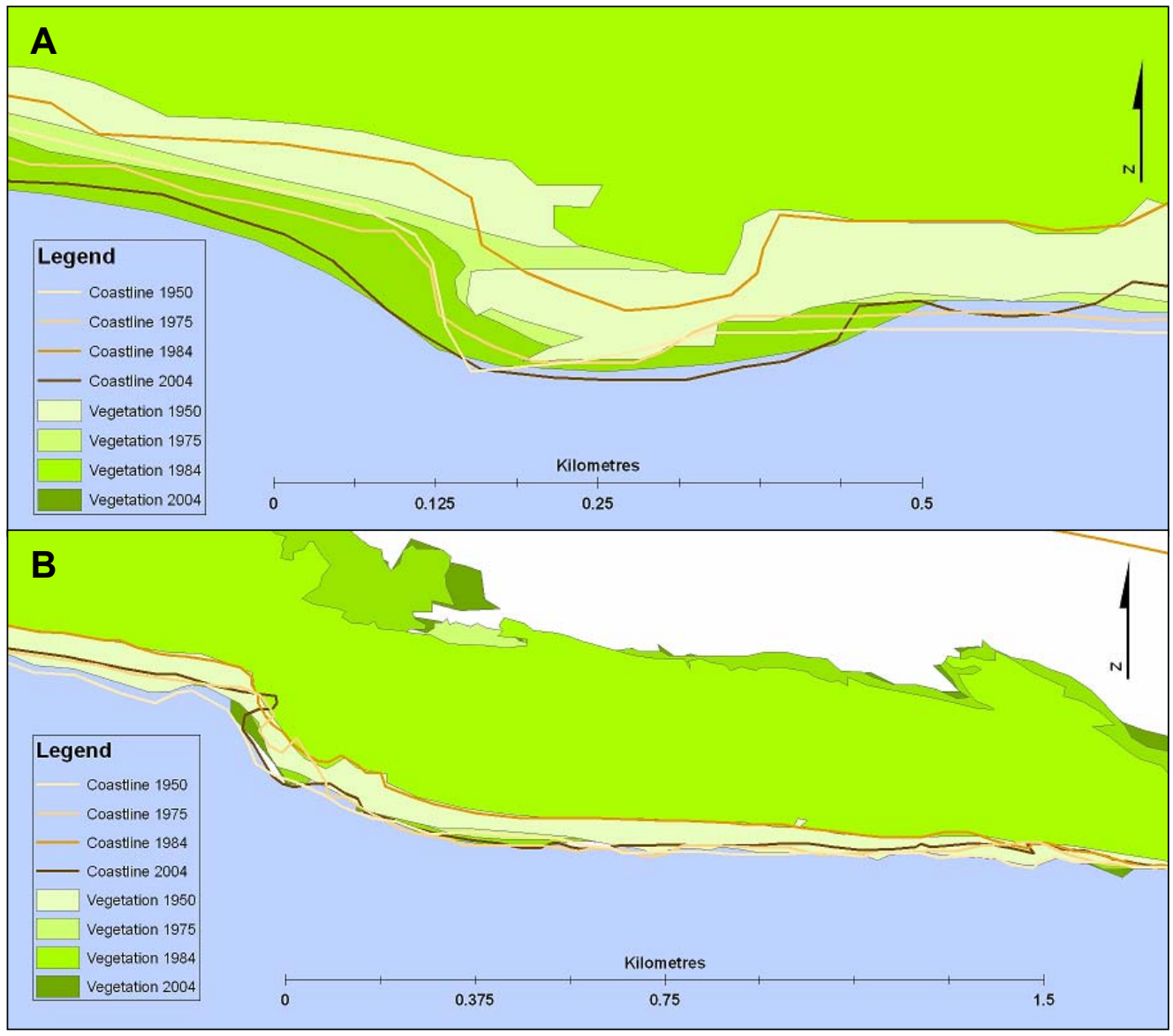

Figure 6.6: Maps showing shoreline and vegetation limits on sections of farewell Spit. A) Stockyard Point from 1950 - 2004. B) West of Mullet Creek from 1950 - 2004. Note the north south movement of the shoreline positioning of these maps are more a function of georeferencing than actual shoreline movement of this magnitude. 
The larger bulge just west of Mullet Creek (figure 6.6B) maintains a standard size and shape throughout the aerial photograph sets and the vegetation is constant on this feature. Therefore this feature is much older than Stockyard Point and could be a large paleo-washover feature. However, this would require an extreme storm and Farewell Spit to have been thinner and of a low profile as dunes and barrier width have a major control on overwash occurrences (Matias et al., 2007).

Large storms such as the Great Storm of 1936 and Cyclone Giselle (1968) have had nation wide significance in New Zealand, causing damage as far south as Picton and Southland respectively (Te Ara, 2008). Significant storms are well documented in the high resolution sediment core from Lake Tutira, which although situated on the East coast of the North Island is a useful indicator of very large storms within the last 2250 years. Within this time New Zealand has experienced six stormy periods, the most severe of which lasted over 200 years (2090 1855 Cal BP), and with the majority of storms in these periods related to La Niña cycles (Eden \& Page, 1998). Therefore it is possible that an extreme storm could have migrated down as far as Farewell Spit in the past; although further research into the evolution of the Spit is required to ascertain if it was ever morphologically prone to allow such an overwash. Alternatively this bulge could represent a past terminus of the Spit as mentioned above.

Investigating accretion using hydrographical charts and aerial photographs Gibb (1978) showed that Farewell Spit widened over its entire length by $0.88 \mathrm{~m} / \mathrm{y}$ from $1851-1938$. While during $1938-1964$ the first $1 / 3$ of its length eroded by $2.46 \mathrm{~m} / \mathrm{y}$ and the last $2 / 3 \mathrm{rds}$ widened $10.38 \mathrm{~m} / \mathrm{y}$ (Gibb, 1978). Average accretion data for the total length of the Spit from this study agrees with Gibb, widening $\sim 1 \mathrm{~m} / \mathrm{y}$ from $1950-$ 2004. However, during this time frame, which overlaps that of Gibb's, 
erosion was found to be at a much lesser extent $(0.3 \mathrm{~m})$ and had moved from the $1 / 3$ rd to the $2 / 3$ rd of the Spits length. Similarly while the last $2 / 3$ rds of the Spit has continued to widen $(\sim 1.2 \mathrm{~m} / \mathrm{y})$, these rates are almost an order of magnitude less than Gibb's data. Gibb (1978) reports the highest net rate of coastal accretion $(68.89 \mathrm{~m} / \mathrm{y})$ in New Zealand occurred on Farewell Spit between the first and last surveys of 1938 and 1964. This however is measured to the low water mark whereas the data in this thesis is measured from the high water mark (HWM) which may explain the magnitude of difference.

\subsection{Topography and inundation}

Farewell Spit is dynamic on a temporal and spatial scale over the 54.5 years of aerial photograph sets analysed. Research has shown that barriers can respond quickly to sea-level change in terms of in situ flooding and morphological response such as washover, shoreline erosion and total barrier transgression through washover processes.

\subsubsection{Sea-level rise}

Sea level around New Zealand is envisaged to closely follow the IPCC global average predictions of $0.21-0.48 \mathrm{~m}$ rise by 2100 (MfE, 2007). Although Woodroffe (2002) states that regional processes such as isostatic adjustments, tectonics, sea surface temperature (SST) and ENSO variations make sea levels on specific coastlines harder to predict. As the northwest Nelson area shows little vertical tectonic movement (Williams, 1991), SST and ENSO are therefore most likely to affect the sea levels around the Spit. The scenario bringing the highest sea levels would be during La Niña years, where waters around New Zealand are $\sim 0.1-0.2 \mathrm{~m}$ higher (Bell et al., 2002). This is due to warmer SST of these negative ENSO episodes which can also cause a higher incidence of ex-tropical cyclones, thus also related storm surge and waves. The effects of storm surge and wind stress increase 
exponentially as shorelines get shallower (de Lange et al., 2003), which means Farewell Spit will be most vulnerable on the shallow $(<40 \mathrm{~m}$ deep) Golden Bay side. For example ex-tropical cyclone Funa caused an estimated $0.33 \mathrm{~m}$ storm surge on top of a $\sim 4 \mathrm{~m}$ tide within Golden Bay on 21 January 2008 (Kiong, 2008). Three weeks later ex-tropical cyclone Gene, which caused heavy swells on the east coast of the North Island, brought a $\sim 0.5 \mathrm{~m}$ storm surge but no large swells into the Bay (Gillooly, 2008a, pers. comm.). This coincided with $4.65 \mathrm{~m}$ tides resulting in high water levels which inundated the Spit in areas expected of a HAT. Thus the projected sea-level rise with an ex-tropical cyclone storm surge during a La Niña year could potentially add $\sim 1.2 \mathrm{~m}$ onto the 2.6m MSL at Farewell Spit. Cyclone Drena (1997) occurred during spring tides; therefore the base water level could reach $\sim 5.9 \mathrm{~m}$ or $6.2 \mathrm{~m}$, if the above sea-level scenario combined with the MHWS and HAT respectively; upon which storm waves could sit. This would flood the Mullet Creek area to an average of $\sim 1.6 \mathrm{~m}$ depth and also inundate the majority of the Roadway and all but the vegetated dune at Stockyard Lake (figure 6.7).

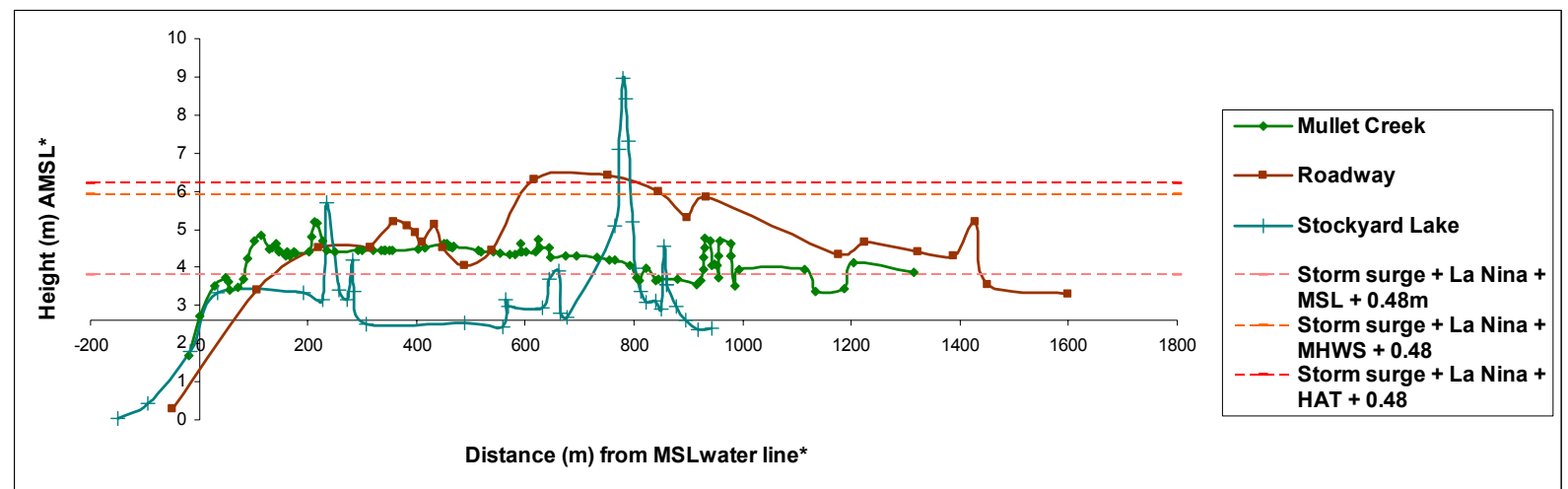

Figure 6.7: Sea-level rise as modelled on potential storm surge, La Niña and MHWS and HAT water levels for Mullet Creek, The Roadway and Stockyard Lake. Note $X$ and $Y$ axes cross at the Collingwood* MSL.

Currently the average significant wave height affecting the northern edge of the Spit is $\sim 1-3 \mathrm{~m}, \mathrm{~T}=6-9$ seconds from the south and southwest directions (combined Westcoast and Maui platform data derived from Pickrill \& Mitchell, 1979). In relation to projected climate 
change, Farewell Spit may be subject to increased westerly winds and also a higher frequency of heavy swells (NIWA, 2007b). This will increase the energy delivered to the Spit and potentially augment the longshore drift along Ocean Beach and therefore also heightening the mobility of sediment. The Golden Bay side would be less affected by this because the Spit itself would block much of this energy.

\subsubsection{Vulnerable zones}

The approach of adding the predicted $0.48 \mathrm{~m}$ sea-level rise onto MHWS and HAT levels is a simple model which assumes uniform sea-level rise to assess areas susceptible to in situ flooding. Susceptibility to inundation depends on a number of factors such as; A) the current position of channels, lakes and saltpans and their linkages to the sea; B) protective dune ridges; and C) human impacts. Four areas along Farewell Spit have been identified as vulnerable areas to inundation (figure 6.8), while the Airstrip area having higher dune ridges is not considered susceptible.

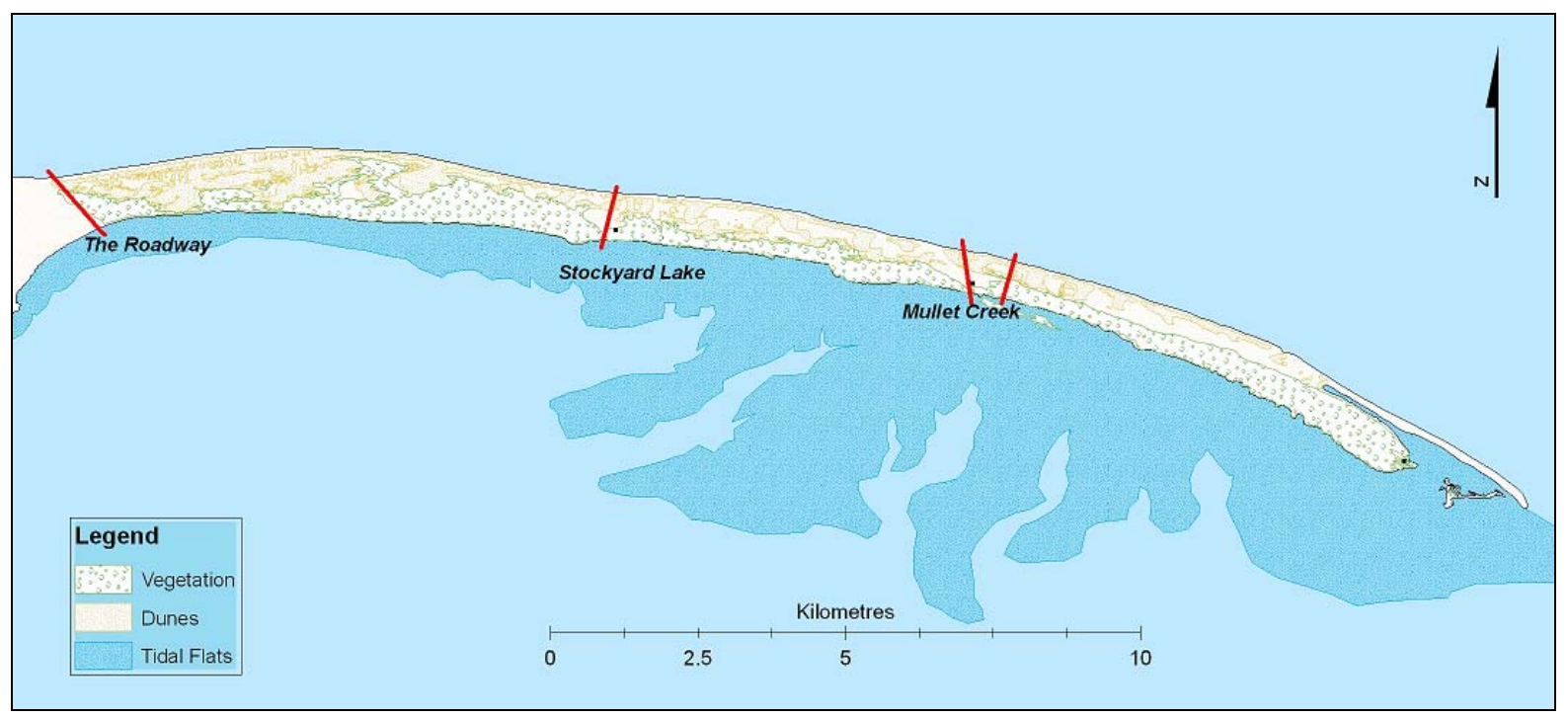

Figure 6.8: Map of zones along Farewell Spit identified as areas of concern in regards to inundation. Currently Mullet Creek and a smaller stream further eastward completely flood across the width of the Spit and are subject to erosion. Where as the Roadway at the base of the Spit and Stockyard Lake may potentially flood under projected sea-level rise. 


\section{Current positions of channels:}

As Mullet Creek is inundated by current MHWS tides, linking Golden Bay to the Tasman Sea, all higher water level scenarios will flood the area to greater depths (figure 5.38). The vegetated dunes of Mullet Creek are currently eroding (figure $5.37 \mathrm{C}$ ) because of the fluctuating water through the area. Erosion will most likely exacerbate because higher sea levels will increase the frequencies of inundation events. At least two other minor creeks exist within the low lying area up to $\sim 1 \mathrm{~km}$ east of Mullet Creek (figure 6.8), these were identified on the aerial photographs and ground truthed as flooding across the Spit during spring tides. Thus these creeks have also been identified as a zone vulnerable to inundation, similar to that which Mullet Creek is likely to experience.

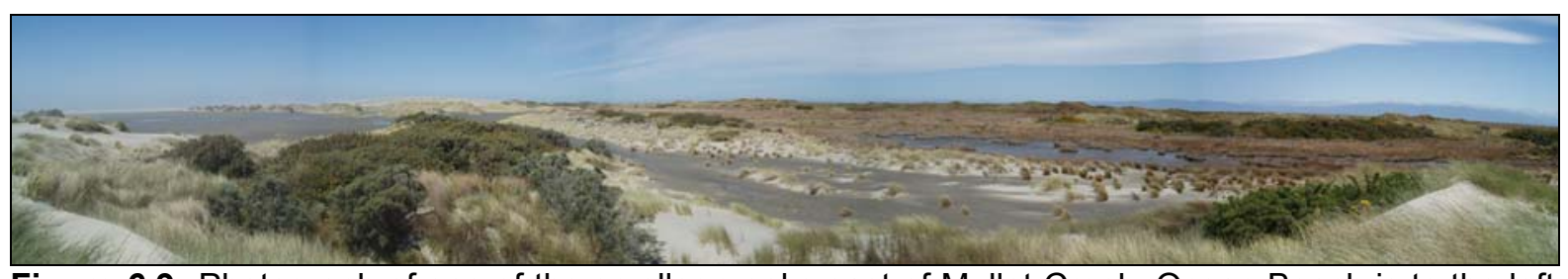

Figure 6.9: Photograph of one of the smaller creeks east of Mullet Creek, Ocean Beach is to the left and the creek links this to Golden Bay during spring tides (Photograph: Helen Tribe, 2007).

\section{Protective dune ridges}

High dune ridges such as the vegetated dune at Stockyard Lake effectively acts as a levee, preventing sea-water inundation at both current levels and projected rises from the Golden Bay side (figure 5.39B). At the northern edge of the Stockyard Lake profile a mobile dune acts similarly, although given the high rate of dune migration this is only a temporary barrier.

Managed dunes, stabilised by planted grasses, on the Outer Banks, North Carolina, successfully resist overwash, although do suffer erosion where storm waves mobilised the sand offshore Komar (1998). Essentially, these dunes became immobile and acted as sea walls 
which were quickly scarped. $A$. arenaria is invasive, displacing less burial tolerant native species and is recognised as a threat to the ecology of active dunes in New Zealand, which have declined by $70 \%$ since the1950's (Hilton, 2006). In the 1970's dune systems north and south of Dunedin were stabilised by $A$. arenaria and used for farming or development, these now suffer serious scarping issues (Hilton, 2006). Similar erosion problems may occur on the Stockyard Lake vegetated foredune, but to a lesser degree as it is facing the low energy Golden Bay. No scarping currently occurs at the Stockyard Lake vegetated dune as much of the wave energy is dispersed on the wider tidal flats and $\sim 100 \mathrm{~m}$ of salt marsh and rush-lands (figure 6.10 ). Both tidal flats and salt marshes have a buffering effect against wave energy which is dissipated before reaching the beach. Moller et al. (1999) found that salt marshes in north Norfolk dissipate on average $82 \%$ of wave energy where tidal flats average $29 \%$. Evidence of erosion scarps (up to $\sim 1 \mathrm{~m}$ ) on the ephemeral islets (figure 5.18B) further east along the Spit shows that some wave energy can be transported over the tidal flats, salt marsh and rush-land terrain. The predicted higher sea levels would also provide a base level for waves to sit on, the height of which could potentially reach $\sim 2 / 3$ rds the height of the dune (given that the maximum wave generated within Golden Bay is $\sim 1 \mathrm{~m}$ ) if the required winds coincided with the future MHWS or HAT. 


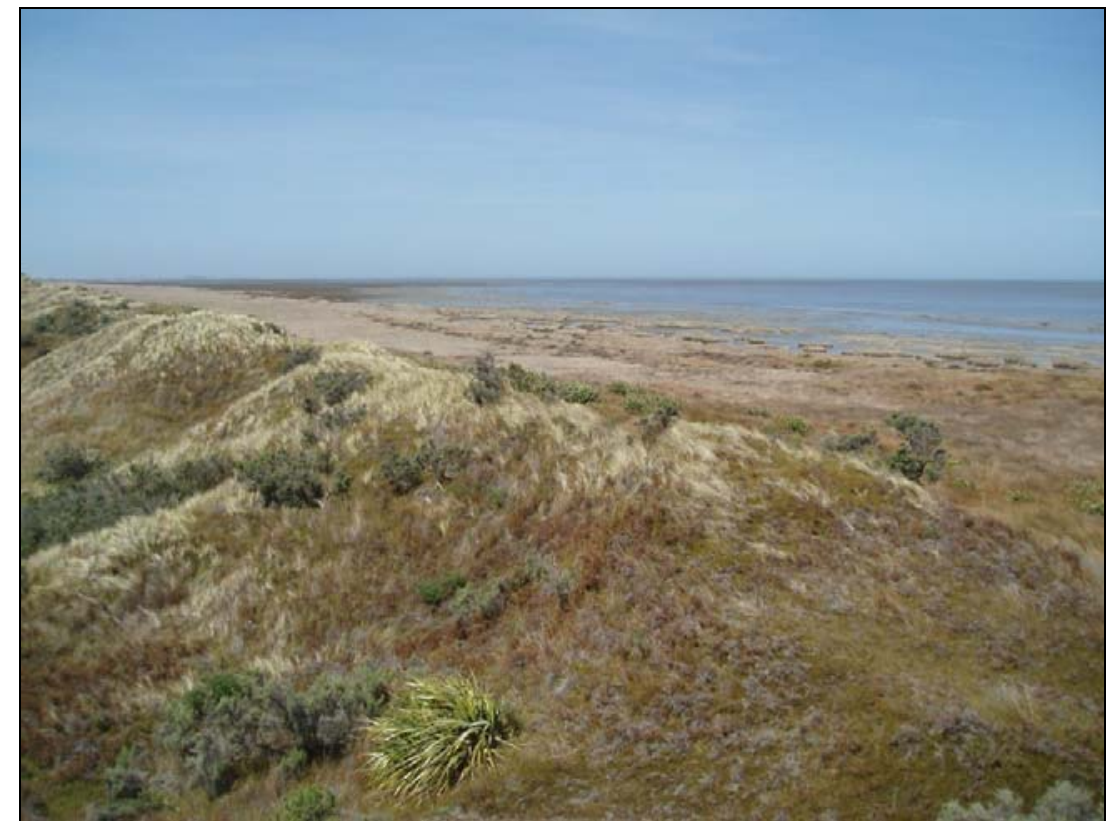

Figure 6.10: Looking eastward across the Stockyard Lake foredune, with the rush-land, salt marsh and tidal flats on the right (Photograph: Helen Tribe, 2007).

The stretch of dunes from the Roadway to Froggies is dominated by $A$. arenaria (figure $6.11 \mathrm{~A}$ ) and range in height from $\sim 3-8 \mathrm{~m}$. This is an area with no salt marshes and relatively small tidal flats $(<1 \mathrm{~km}$ wide) and the $\sim 5-7 \mathrm{~m}$ AMSL dune scarps around Froggies (figure 6.11B) illustrate that it is much less protected from wave energy. Therefore this area could suffer erosion and the removal of sand out onto Golden Bay similar to the Outer Banks, North Carolina (Komar, 1998). 


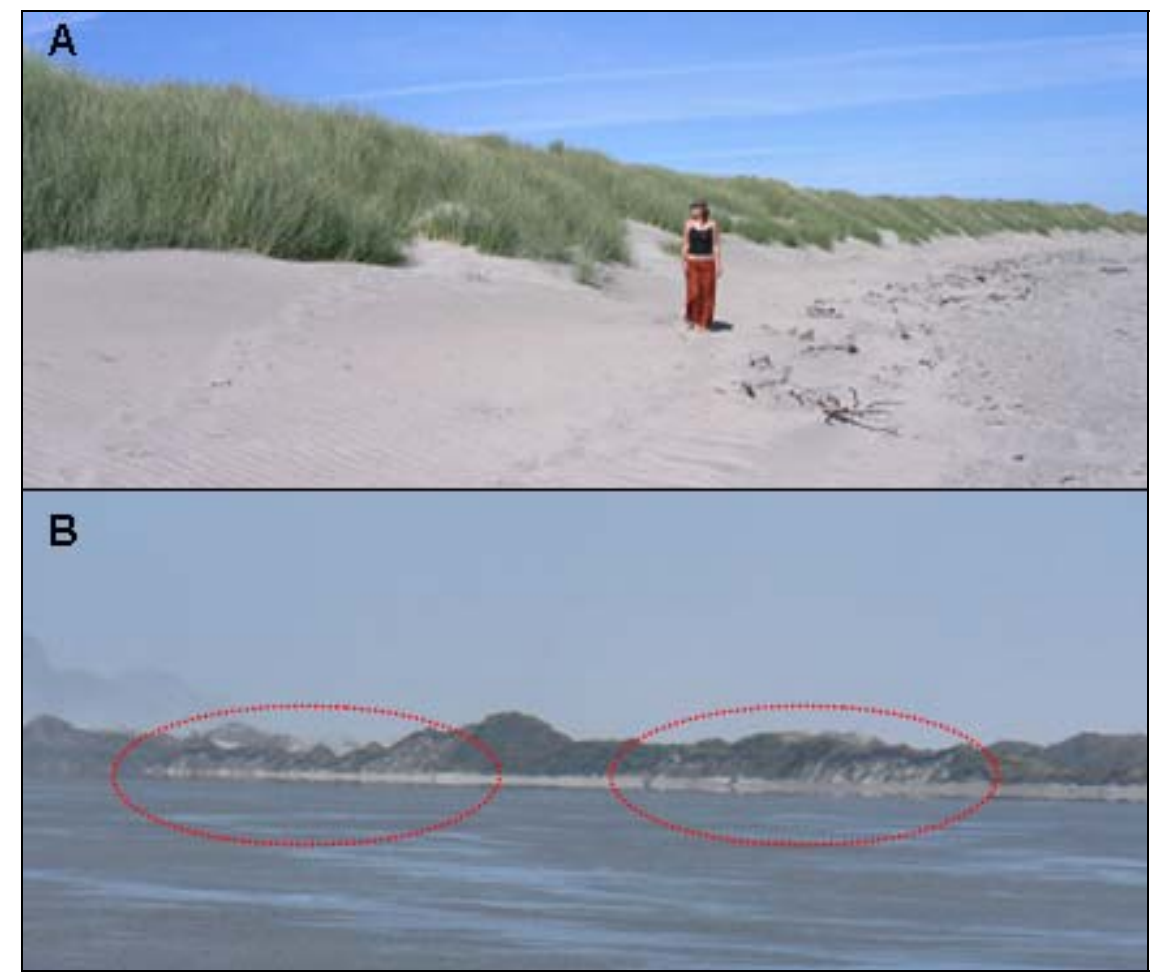

Figure 6.11: Dune scarping along the southern edge of Farewell Spit. A) $A$. arenaria dominated fore-dunes along the stretch of coast near the Roadway where only minor scarping is evident (Photograph: David Kennedy, 2007). B) Higher dune scarps reaching $\sim 5-7 \mathrm{~m}$ (circled) around the Froggies area (Photograph: Matt Ward, 2007).

\section{$\underline{\text { Human impacts }}$}

Human impacts such as dune modification can impede the natural resistance of a barrier to sea-level variability. Although water levels would need to rise above $6.4 \mathrm{~m}$ for the Roadway to inundate it has historically been over-washed by a tsunami (de Lange \& Healy, 1986) and has no dune ridges to obstruct encroaching water. The Roadway is also affected by $4 \times 4$ wheel tourist buses and vans which can pass the road up to ten times a day. These may cause mechanical scouring of the road and thereby lower this profile, thus increasing the vulnerability to inundation. However, much of this transect is the open pasture of the adjacent farmland which also includes $\sim 200 \mathrm{~m}$ wide stand of established L. scoparium. Morton and Sallenger (2003) state that dense vegetation limits or inhibits washover for even the most powerful storms. Therefore, this would effectively reduce the scouring ability of waves and bottom 
currents within this section if water levels were to reach levels high enough to inundate this area.

Flooding has historically been an issue at the lighthouse precinct where the grounds around the principal lighthouse keeper's cottage were submerged under two feet of water in 1916 as a result of heavy rains coinciding with spring tides (Petyt, 1999). During the 1950's this problem was rectified by the bulldozing of a dune to fill in the hollows, where previously raised walking platforms linked the lighthouse to the buildings (Petyt, 1999).

\subsubsection{Overwash and inlet breaching potential}

Areas of barriers which are low lying and narrow are more likely to experience overwash events leading to barrier breaching (Vila-Concejo et al., 2006). The low lying area of most concern for overwash on Farewell Spit is Mullet Creek, the erosion susceptibility (ES) of which was analysed using the storm wave susceptibility quotient (equation 2.5). This quotient provides a quantifiable estimate of how likely this process is to occur on any given sector of a barrier. For example the Trabucador Bar, Spain, which is a low lying ( $1.5 \mathrm{~m}$ above MSL), $5 \mathrm{~km}$ long bar, ranging in width $100-200 \mathrm{~m}$, connecting a spit to the Elbro Delta, was calculated to have a high erosion susceptibility $(E S=0.8)$ near to where this bar breached during a storm (Sanchez-Archilla \& Jimenez, 1994). The same equation was used for all across barrier surveys along Farewell Spit using estimates of the depth of the longshore bar (table 6.1). Mullet Creek had the highest erosion susceptibility of these areas, $E S=\sim 0.4$ if the highest mobile sand dune was used and $E S=\sim 0.6$ if the average height of the creek was considered. However, these are probably not high enough to warrant expecting overwash to occur here because the width of the Spit becomes the major factor in dissipating wave energy across it. The other transects tested were all very low; the Roadway $E S=\sim 0.1$; 
Stockyard Lake ES $=\sim 0.03$ and the Airstrip ES $=\sim 0.02$ and are not considered vulnerable by this equation. It is also apparent that no high energy breaching has historically occurred within Mullet Creek because only dune derived sand was recovered in the core and wave action introduces shoreface sediment into such inlets.

Table 6.1: Parameters used in the storm wave susceptibility quotient. Data from aerial photograph and survey analysis and field reconnaissance.

\begin{tabular}{|l|c|c|c|c|}
\hline \multicolumn{1}{|c|}{ Site } & $\begin{array}{c}\text { Estimated } \\
\text { longshore bar } \\
\text { depth }(\mathbf{m})\end{array}$ & $\begin{array}{c}\text { Barrier height } \\
\text { above } \mathbf{M S L} \\
\mathbf{( m )}\end{array}$ & $\begin{array}{c}\text { Barrier width } \\
\mathbf{( m )}\end{array}$ & $\begin{array}{c}\text { Distance } \\
\text { between } \\
\text { longshore bar } \\
\text { to shoreline } \\
\mathbf{( m )}\end{array}$ \\
\hline Roadway & 3.0 & 5.0 & 831.7 & 166.1 \\
\hline $\begin{array}{l}\text { Stockyard } \\
\text { Lake }\end{array}$ & 1.6 & 7.6 & 854.0 & 128.9 \\
\hline Mullet Creek & 3.8 & 2.5 or 1.8 & 749.7 & 120.5 \\
\hline Airstrip & 0.9 & 6.7 & 742.9 & 237.9 \\
\hline
\end{tabular}

\subsubsection{The Barrier Island Model}

The Barrier Island Model (equation 2.3) is useful for estimating the landward and upward movement of the barrier profile in relation to sealevel rise (Dean \& Maurmeyer, 1983 In Komar, 1998). This was modelled on the same transects along Farewell Spit as in the storm wave susceptibility quotient above, using water depth derived from a bathymetric map (table 6.2). This model suggests that the influence of a $0.48 \mathrm{~m}$ sea-level rise is likely to move the Spit landward by $592 \mathrm{~m}$ at the Roadway; $1,558 \mathrm{~m}$ at Stockyard Lake; $6,747 \mathrm{~m}$ at Mullet Creek and the end of the Spit by $2,474 \mathrm{~m}$. These rates of transgression are very large and highly unlikely because the Barrier Island Model assumes a semi closed backbarrier environment which generally abuts onto the mainland. This is therefore inappropriate for Farewell Spit where the backbarrier environment stretches up to $8 \mathrm{~km}$ into Golden Bay which is open to Cook Strait at its eastern end; meaning sediment could be lost through this. This semi open marine morphology of Golden Bay also has implications for inlet development and maintenance. Inlets allow water to escape from lagoons and theoretically, if Golden bay was 
closed, the high tidal prism here would facilitate the increase in size or numbers of inlets by the water volume (Davis \& Hayes, 1984). However, much of this water is released out through the Bay itself. For the same reason, although Mullet Creek regularly inundates, the loss of concentrated tidal energy reduces the potential energy for scouring sediment from its base (Orford, 2004) and so although this area will flood to deeper levels, the base may not erode down to form a deeper inlet type feature. The higher fluctuating water levels would potentially aid in lateral erosion by intensifying the current scarping of the surrounding vegetated dunes (figure, $5.37 \mathrm{C}$ ).

Table 6.2: Parameters used in the Barrier Island Model. Data from aerial photograph and survey analysis and field reconnaissance.

\begin{tabular}{|l|c|c|c|c|c|}
\hline \multicolumn{1}{|c|}{ Site } & $\begin{array}{c}\text { Ocean side } \\
\text { nearshore } \\
\text { width }(\mathbf{m})\end{array}$ & $\begin{array}{c}\text { Barrier } \\
\text { width } \mathbf{( m )}\end{array}$ & $\begin{array}{c}\text { Lagoon } \\
\text { side } \\
\text { nearshore } \\
\text { width }(\mathbf{m})\end{array}$ & $\begin{array}{c}\text { Estimated } \\
\text { ocean side } \\
\text { water depth } \\
\mathbf{( m )}\end{array}$ & $\begin{array}{c}\text { Estimated } \\
\text { lagoon side } \\
\text { water depth } \\
(\mathbf{m})\end{array}$ \\
\hline Roadway & 577.3 & 831.7 & 1247.5 & 4.0 & 1.8 \\
\hline $\begin{array}{l}\text { Stockyard } \\
\text { Lake }\end{array}$ & 424.4 & 854 & 3490.7 & 5.0 & 3.5 \\
\hline $\begin{array}{l}\text { Mullet } \\
\text { Creek }\end{array}$ & 379.2 & 749.7 & 5899.9 & 5.0 & 4.5 \\
\hline Airstrip & 558.6 & 742.9 & 3748 & 5.0 & 4.0 \\
\hline
\end{tabular}

\subsection{Geomorphic stability of Features}

\subsubsection{Ocean Beach}

Ocean Beach runs the length of the northern edge of Farewell Spit and is a high energy dissipative beach with multiple bars within the swash zone and further offshore. Opposite the lighthouse the beach forms into a sandbar which extends past the subaerial Spit. Longshore bars have some control over the stability of the barrier, a higher sea-level base would likely result in the activated sand bar (figure 6.12) migrating inland and welding to the beach under high energy storm conditions as seen in Denmark on Skallingen (Aargaard et al., 2004a; Christiansen et al., 2004). This may cause progradation of the beachface and protection from the wave energy as increased sediment is supplied to it, allowing 
the system to remain in equilibrium with sea-level rise. This shoreline progradation also assists dune building as more sand becomes available on the beach when it is dry for wind transport (Christiansen et al., 2004).

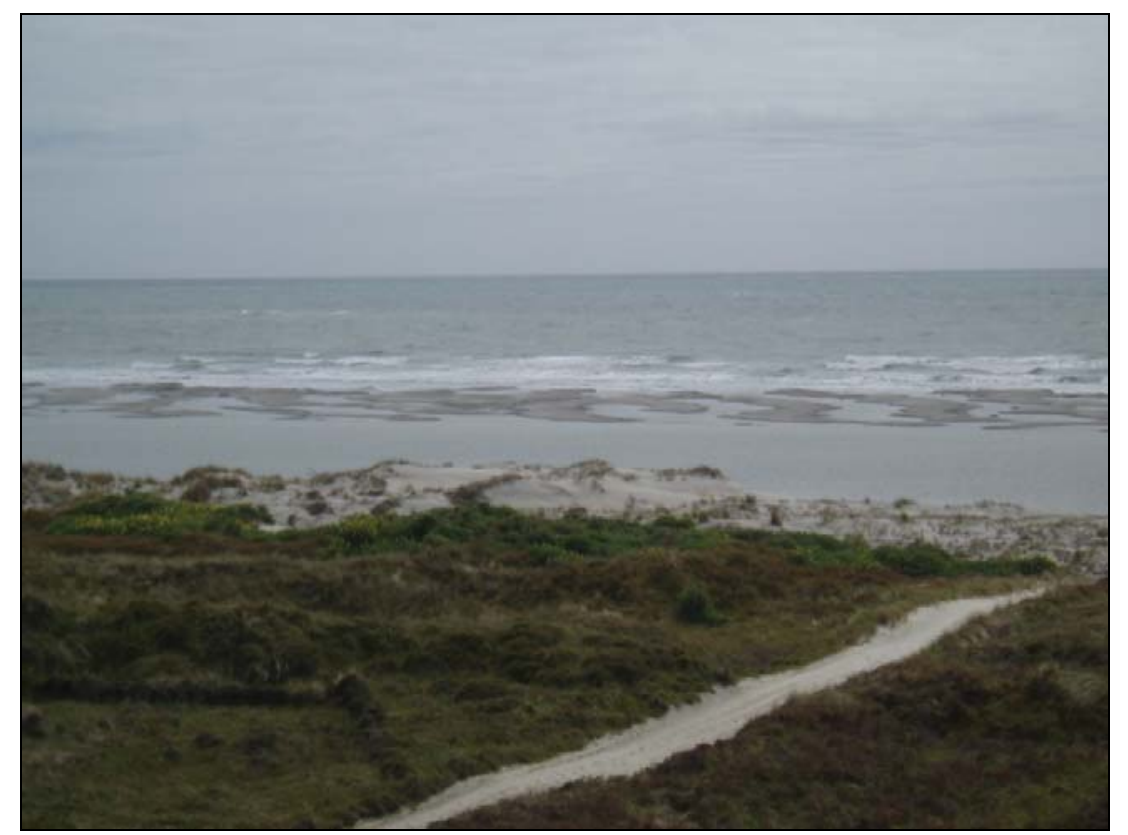

Figure 6.12: The sandbar as seen from the Lighthouse. Here it is activated by the spring high tide $(4.89 \mathrm{~m}$ on 27 October, 2007) where water levels reached the foot of the road over to the lighthouse. The activated sand bar is the highest berm along this beach (Photograph: Helen Tribe, 2007).

\subsubsection{Northern dune system}

The results have shown Farewell Spit to be a highly dynamic environment with the dunes along Ocean Beach being the most active features at both micro and macro scales. Micro-scale dynamics are best illustrated on the highest berm across from the lighthouse which runs along the Spit, extending into an offshore bar past Bush End Point. This sand mass responds to wind very quickly and can change from a flat bar to an environment covered by small $(\sim 0.5 \mathrm{~m})$ dunes in a matter of days (figure 6.13) (Gillooly, 2008b). 


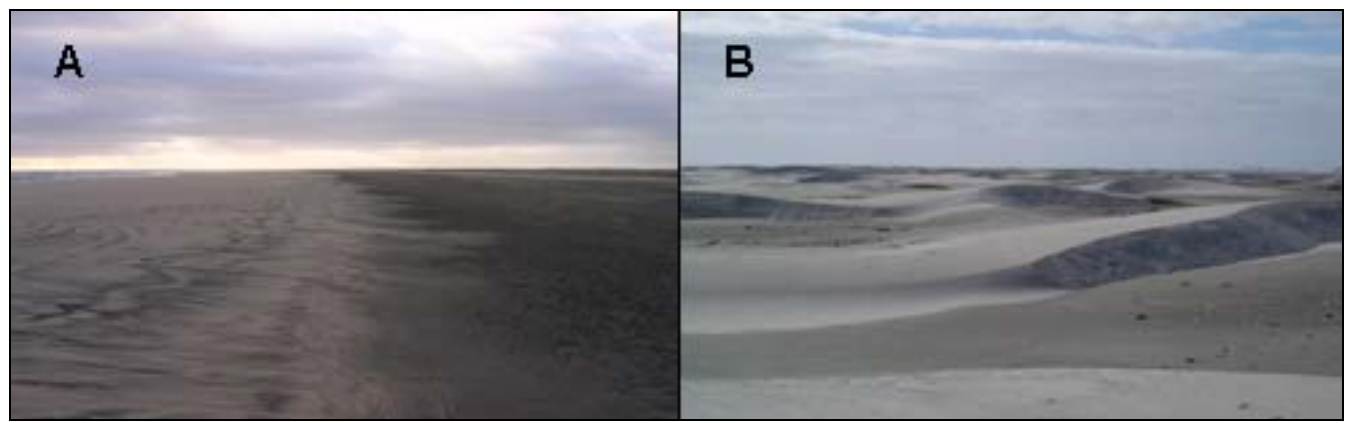

Figure 6.13: Photographs of the sandbar opposite the lighthouse. A) Showing a flat morphology in February (Photograph: David Kennedy, 2007). B) Showing small dune morphology during October (Photograph: Helen Tribe, 2007).

Wind energy generates waves and currents which supply sediment to barriers and also forms and transports dunes. Aeolian processes are important and sometimes become dominant on a SDB, determining the subaerial dune morphology (Shepherd \& Hesp, 2003, Orford, 2004) and may also contribute to shoreward sand movement. On a larger scale the barchan dunes respond to the prevailing westerly wind; controlled by their size and wind velocity. The smaller dunes move faster than their larger counterparts as their speed is inversely proportional to their size (Bagnold, 1941 In Gay, 1999). This is illustrated on Farewell Spit where larger dunes (15 - 20m AMSL) move at an average rate of $15 \mathrm{~m} / \mathrm{y}$ whereas the smaller dunes ( 10m AMSL) toward the end of the Spit move an average of $20-30 \mathrm{~m} / \mathrm{y}$ (figure 5.7 ). The more erratic rates of movement over short time scales (figure 5.8) indicate that this is event based, most likely due to windier periods. The fastest movement recorded is dune 2 travelling $>60 \mathrm{~m}$ during $2003-2004$, part of which was a dune horn accelerating away from the rest of the dune. During this time Farewell Spit recorded some of the most extreme gusts $(\sim 100 \mathrm{~km} / \mathrm{h})$ in seven years from the westerly quarter (NIWA, 2008b).

Many natural factors such as non steady winds or inclined ground surfaces may lead to normally crescent shaped barchan dunes becoming more asymmetrical (Herrmann et al., 2005). Some of the Farewell Spit barchans are asymmetrical and many change shape over time. Dunes 4, 5 and 6 are irregularly shaped and are representative of 
dunes attaching or separating from each other over the 54.5 years (figure 5.6). On Farewell Spit this occurs because faster travelling, smaller dunes essentially 'sideswipe' larger dunes, temporarily merging with them before passing on (figure 6.14). During this process the small dune retains its approximate size and shape (Gay, 1999). A similar process was described by Gay (1999) who used aerial photograph analysis to track the movement and interaction of varying sized barchan dunes in southern Peru, finding also that smaller dunes were absorbed by larger ones if they collided by a 'direct hit'.

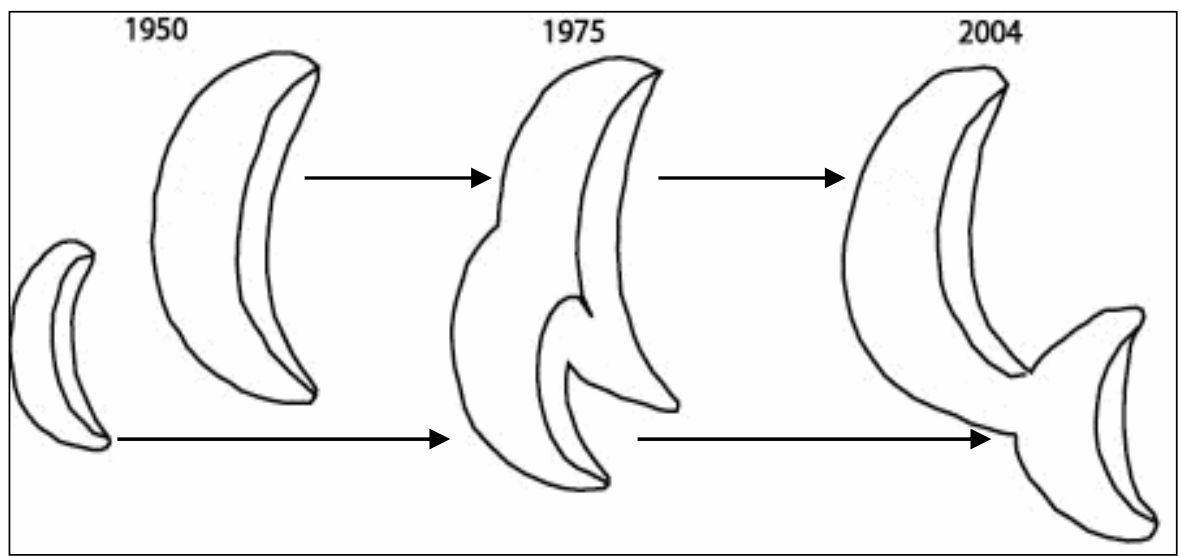

Figure 6.14: Schematic drawing illustrating the smaller barchan dune 'sideswiping' dune 4. The two dunes which were separate in 1950 had merged by 1975 and by 2004 the smaller dune was passing the larger. The arrows indicate the speed and direction at which the two dunes are travelling.

The average winds on the Spit are above the $12 \mathrm{~km} / \mathrm{h}$ entrainment threshold to initiate saltation of $0.2 \mathrm{~mm}$ (fine sand) grains (Ballance et al., 2006). While the prevailing westerly winds are the dominant control on the dunes eastward movement, winds from the northerly quarter occur $\sim 30 \%$ of the time with $\sim 12 \%$ of these being $>30 \mathrm{~km} / \mathrm{h}$ (NIWA, 2007a). The large amounts of dune sand within the tidal flat core samples suggest that it is these winds that transport material to the tidal flats (figure 6.15). 


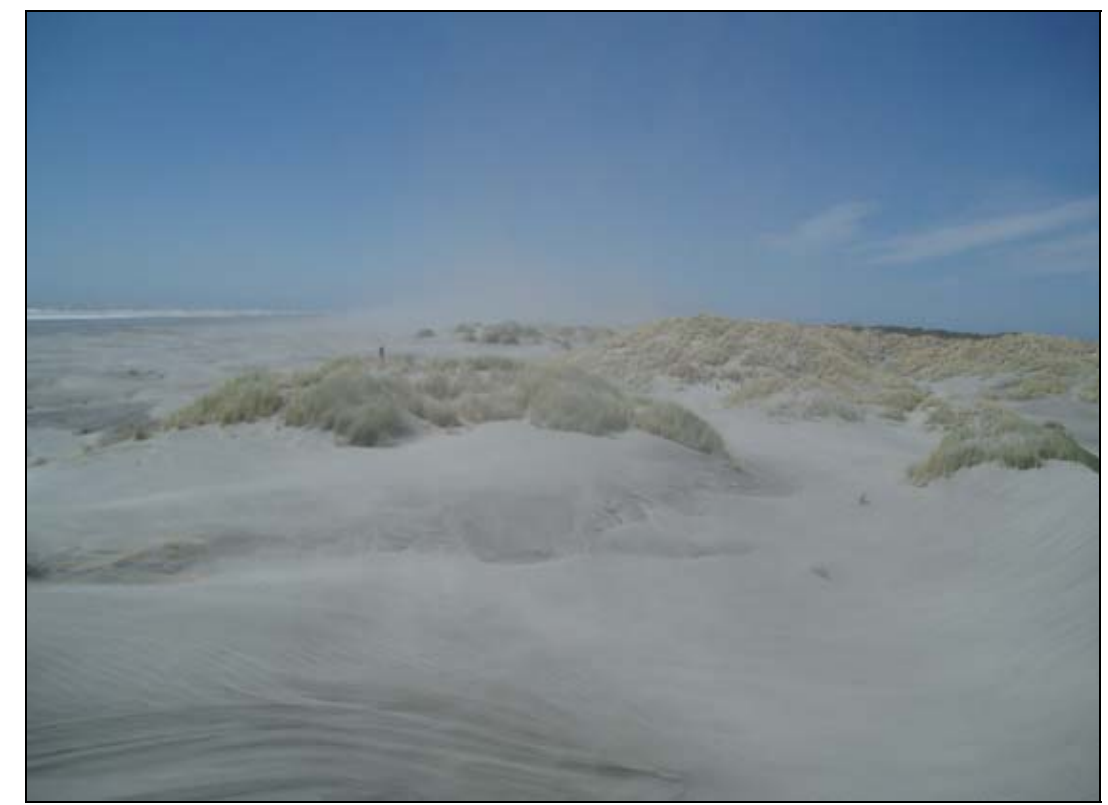

Figure 6.15: Looking east from the Roadway along Farewell Spit during strong winds in October 2007. The haze in the background is a sand storm (Photograph: Helen Tribe, 2007).

Assuming current migration rates continue it is likely that the barchan dunes will periodically block any creeks which allow for cross barrier inundation created by sea-level rise as they move along the Spit. While forming a barricade to sea water when closely spaced together; they also would also allow for creek/inlet development when spaced far apart. However, the sediment transported across the Spit during storms will also continually infill deflation hollows and inlets. This would therefore further reduce the potential net loss of sand from inlets by currents as incised channels would rapidly refill.

An almost constant sand supply to the South Island's West Coast is currently transported by the predominant southwesterly swell generating northward moving currents (Hilton \& Nichol, 2003). Although sediment availability increases during episodes of sea-level rise due to coastal erosion (Carter et al., 1990), it is however harder to predict if the ocean currents will remain the same for future sediment supplies to Farewell Spit to remain steady. 


\subsubsection{Southern dune system}

The southern dune system is also very dynamic, especially at the western end. The 1950 aerial photograph set shows that most of this area contains active dunes, including the exposed tops of the large dunes at Puponga Farm Park. The $74.7 \%$ increase of vegetation since 1950 is the most noticeable change (figures $5.15-5.16$ \& table 5.2); the initial vegetation recovery was rapid $(2.3 \% / y)$ occurring during 1950 1975. This is most likely due to the introduction of $A$. arenaria, $R$. fruticosus and $U$. europaus $L$. in the early twentieth century. Along with the re-establishment of $P$. aquilinum var esculentum and other natives, these flora have stabilised a great deal of previously bare sand area which has decreased by $35.7 \%$. The sand binding and dune building qualities of the vegetation is evident on the Spit east of Mullet Creek towards Bush End Point. Here the two longest linear dunes have developed at previous vegetation limits (figure 5.11). Therefore these are unlikely, as Oertal (1985) suggests of such patterns, to be indicators of previous shorelines because Ocean Beach has a wide, dissipative beach environment leading up to the vegetation limits, throughout all aerial photograph sets.

The eastern end of the Spit has the most spatially consistent vegetation coverage throughout the 54.5 year time frame (figure 5.15A). The absence of ${ }^{137} \mathrm{Cs}$ at $2 \mathrm{~m}$ depth on the secondary foredune on the airstrip confirms that it has been relatively stable for the last century or so despite the surrounding area being bulldozed for its construction. The morphology of the shorter linear dunes near the end of the Spit (figure 5.11), which are not necessarily associated with previous vegetation limits, therefore are likely to be indicative of how the rest of the Spit may have looked prior to human interference. However, this linear dune morphology may have been obliterated by the severe vegetation loss west of Mullet Creek, which would have mobilised sand and promoted the more hummocky terrain between the widely spaced fore and 
secondary dunes (figure 5.14). This may give us an indication to how the Spit looked prior to the establishment of the initial vegetation and also how the shorter linear dunes developed. The hummocky terrain is subject to blowouts, which induce parabolic dunes and it is thought that these linear dunes could be their trailing arms. The aerial photographs of the area just inland from Froggies Lake show a good example of this process (figure 6.16). Here an active parabolic-like dune is seen in 1950, the trailing arms becoming more vegetated by 1975 and by 2004 the leading edge has advanced eastward $\sim 270 \mathrm{~m}$, leaving a $\sim 880 \mathrm{~m}$ long straight dune immediately behind Froggies Lake. The average dune movement rate of $5 \mathrm{~m} / \mathrm{y}$ here is slower than the $\sim 17 \mathrm{~m} / \mathrm{y}$ for a $6 \mathrm{~m}$ high dune travelling over scrub, during a 22 year period within the Manawatu dune field (Muckersie \& Shepherd, 1995). This dune field is similar to Farewell Spit being at the same latitude and has parabolic dunes which are resultant from blown out transverse dunes (Muckersie \& Shepherd, 1995).

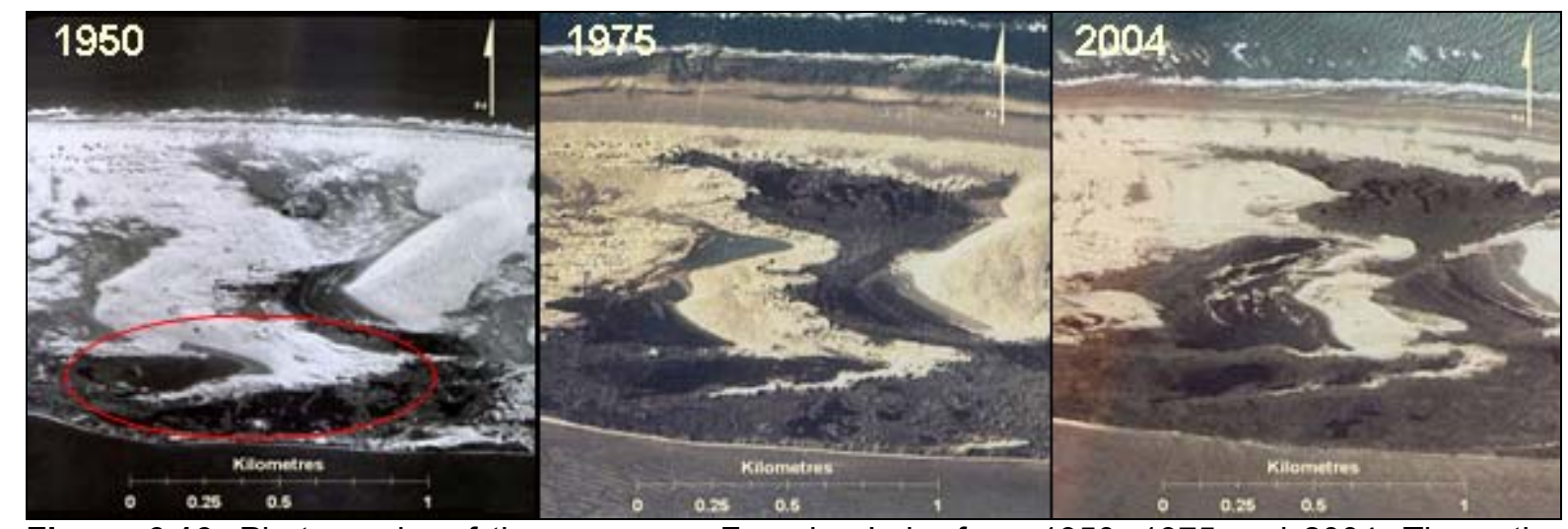

Figure 6.16: Photographs of the area near Froggies Lake from 1950, 1975 and 2004. The active parabolic dune (circled) near Froggies Lake as seen in 1950 extends and becomes more defined in 1975 and 2004. Ground truthing found the bottom arm of this dune to be completely vegetated in 2007 and having the appearance of a secondary foredune when viewed from the Lake.

Ground truthing at the Froggies site in 2007 showed that the trailing arms have the appearance of a secondary foredune. The detection of ${ }^{137} \mathrm{C}$ in the $2 \mathrm{~m}$ core sample taken from this dune confirms that this has been exposed, most likely around 1965 . Therefore at least $2 \mathrm{~m}$ of sand has accumulated on these dunes during their active phase in the recent past. These 'linear' dunes at Froggies are however at different 
orientation to those at the eastern end of the Spit. Both sets tending to point the same angle as the curve of the Spit at their respective positions, suggesting that the direction of the wind may diffract slightly around the curve of the Spit.

Salt marshes act as a primary data source of tidal level in backbarrier environments (van Heteren \& van de Plassche, 1997) and Kraft and John (1979) have shown there is a link between barrier stratigraphy and water levels. Core sampling at the Froggies and Stockyard Point transects show evidence of previous salt marsh/tidal flat levels $\sim 0.5-$ $0.8 \mathrm{~m}$ under the current respective beach faces (figures $5.29 \& 5.33$ ). This indicates that the southern dune system has grown out over the tidal flats at least $142 \mathrm{~m}$ at Froggies and $42 \mathrm{~m}$ at Stockyards. However, as the dunes have rolled over the tidal flats at Froggies and Stockyard Point it is also likely that the beaches have concurrently accreted as a result of the mobilised sand. Given the history of the area and comparable rates of shoreline progradation to Mason Bay, Stewart Island, this dune system growth is probably a result of storm influences on the destabilised dunes and the subsequent invasion of $A$. arenaria. Although no cores were taken from the Ocean Beach side of the Spit, no tidal flat sediments were observed within this environment, indicating that barrier roll over or regression are not occurring at Farewell Spit. This further supports the theory that the Spit has developed since sealevel stillstand (Gibb, 1979; Harris, 1990).

\subsubsection{Tidal flats}

The tidal flats are a relatively stable feature as the sinuous drainage channels do not appear to have changed their patterns over thirty years. However, layers of fragmented shells within the tidal flat cores indicate some reworking of the sediment probably by storm processes has occurred. 
The Froggies tidal flat core shows three separate layers of fragmented shells being evidence of such events. The deepest and presumably oldest of these layers was determined to be 271 - 132yrs Cal BP, from ${ }^{14} \mathrm{C}$ analysis of a fragmented shell at $0.68 \mathrm{~m}$. Another shell which was intact was found just above the second layer at $0.42 \mathrm{~m}$ and dated. This was assumed to have been subject to much less reworking and because of the near sedentary behaviour of $A$. stutchburyi, as described by Gibb (1986), may have been found in situ. Therefore the ${ }^{14} \mathrm{C}$ age of the intact shell shows the tidal flats were $\sim 0.42 \mathrm{~m}$ lower $120 \mathrm{yrs}$ - present Cal BP. The sea-level around New Zealand has risen $0.16 \mathrm{~m}$ over the past century (Hannah, 2004), as this upper shell is within $0.2 \mathrm{~m}$ of this level it is therefore a good approximation for this inter-tidal landform. This result can be also be compared with a calibrated age $120 \mathrm{BC}-140$ $A D{ }^{14} \mathrm{C}$ date obtained from an $A$. stutchburyi taken at $0.4 \mathrm{~m}$ depth from an old beach ridge within Triangle Flat in Puponga Farm Park (Walton \& Bagley, 2007). While acknowledging both tidal flats and beach ridge shells may have been subject to some reworking, there is potentially a 1950 year lag between the beach ridge and tidal flat development $\sim 5 \mathrm{~km}$ to the east (at similar depths).

The predominance of medium sand within the tidal flat cores agrees with surface sediment data from van der Linden (1969) who noted a band of this medium sand mainly on the southern edges of the tidal flats to the $10 \mathrm{~m}$ depths of Golden Bay (figure 6.17). This indicates that the same sediment transport processes have been operating within the Bay for some time. The source of this sediment is the Takaka and Aorere Rivers which Ballance et al. (2006) attribute to entering the system within the root balls of floating trees coming out of these rivers; reasoning that the combination of tide, wind and wave action is not sufficient to move the coarser sand significant distances. While this may be true for the occasional stones, the volumes of this medium sand now known to be within the tidal flats may require a new hypothesis. 
Most sediment movement occurs in the area of breaking waves which is roughly the same depth as the wave height, while significant movement rates occur at $0.25 \mathrm{~L}$; where $\mathrm{L}=$ wave length $\times 1.56 \mathrm{~T}^{2}$. Wave heights and significant motion depths for maximum fetch waves generated within Golden Bay from the south and west show there is sufficient energy to move the medium sand grains around the southern parts down to the $6.5 \mathrm{~m}$ water depth on the tidal flats (table 6.3).

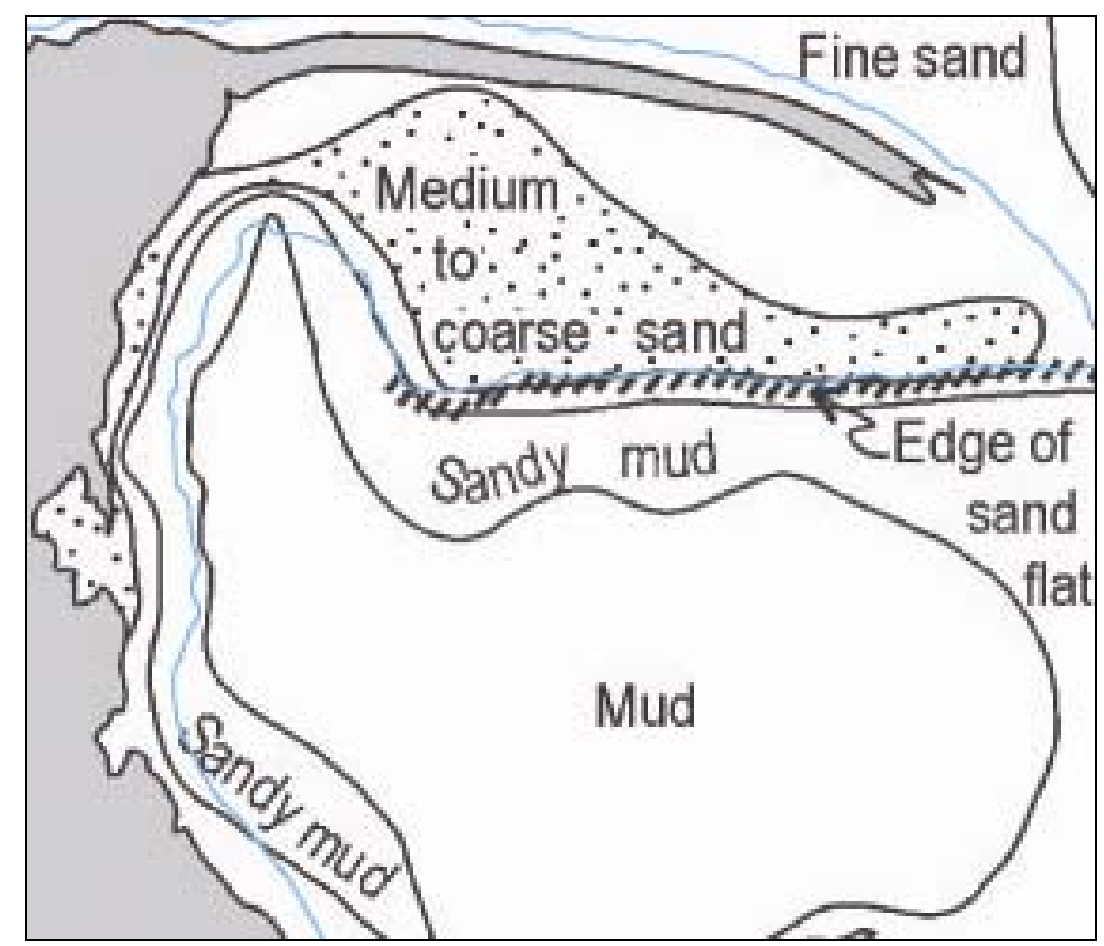

Figure 6.17: Sediment map of Golden Bay (Ballance et al. 2006) with the $10 \mathrm{~m}$ bathymetry line (blue).

Table 6.3: Wave breaking and significant motion depths for wave energy generated from maximum fetch within Golden Bay from the south and west.

\begin{tabular}{|l|c|c|c|c|}
\hline \multicolumn{1}{|c|}{$\begin{array}{c}\text { Depth of } \\
\text { movement }\end{array}$} & $\begin{array}{c}\text { Wave from } \\
\text { southerly } \\
\text { wind }(\mathbf{1 7 m} / \mathbf{s}) \\
\mathbf{0 . 0 0 1 \%} \\
\text { occurrence }\end{array}$ & $\begin{array}{c}\text { Wave from } \\
\text { southerly } \\
\text { wind }(\mathbf{1 3 m} / \mathbf{s}) \\
\mathbf{0 . 2 5 \%} \\
\text { occurrence }\end{array}$ & $\begin{array}{c}\text { Wave from } \\
\text { westerly wind } \\
\mathbf{( 1 7 m / s )} \\
\mathbf{0 . 1 1 \%} \\
\text { occurrence }\end{array}$ & $\begin{array}{c}\text { Wave from } \\
\text { westerly wind } \\
\mathbf{( 1 3 m / s )} \\
\mathbf{1 0 . 6 \%} \\
\text { occurrence }\end{array}$ \\
\hline Wave Breaking & $1.7 \mathrm{~m} ; \mathrm{T}=5.3$ & $1.2 \mathrm{~m} ; \mathrm{T}=4.8$ & $1.3 \mathrm{~m} ; \mathrm{T}=4.6$ & $0.9 \mathrm{~m} ; \mathrm{T}=4.1$ \\
\hline $\begin{array}{l}\text { Significant } \\
\text { motion (0.25L) }\end{array}$ & $11.0 \mathrm{~m}$ & $9.0 \mathrm{~m}$ & $8.3 \mathrm{~m}$ & $6.7 \mathrm{~m}$ \\
\hline
\end{tabular}




\subsection{Summary}

The results of the previous chapter have been discussed and placed into a wider context using the available literature. Inundation of the lowlying areas has been discussed in light of storm surge and ENSO effects and the Spit was found to be too wide to experience breaching from overwash processes. The Barrier Island Model was also found to be inappropriate for use on this barrier spit. The morphological change in the main zones has been discussed, finding A. Arenaria responsible for many morphological changes within the Farewell Spit system. 


\section{Chapter Seven: Conclusions}

\subsection{Introduction}

The increase in global average temperature over the last century has most likely been related more to recent anthropogenic influences than natural climate cycles (IPCC, 2007). As oceans retain this heat for potentially centuries (Hansen et al., 2005; Wigley, 2005) the related sea-level rise will have temporally and spatially far reaching consequences, even if carbon emissions were reduced today. Farewell Spit is an important and iconic New Zealand landform, functioning as both a wildlife sanctuary and a barrier for Golden Bay against the high energy Tasman Sea. Therefore the Spit's response to sea-level rise is of interest to Golden Bay which is not currently adjusted to high energy wave regime. This study identifies Farewell Spit as a natural system which defends the Golden Bay area from potentially high erosion problems and is itself at risk of erosion and inundation from sea-level rise. Therefore policy 3.4.2 of the New Zealand Coastal Policy Statement 1994 applies to this SDB. This thesis provides a detailed geomorphic overview of Farewell Spit to further understand its dynamic nature in order to ascertain its stability and vulnerability to projected sea-level rise.

\subsection{Geomorphology and evolution of Farewell Spit}

Field observations, surveying, GIS analysis of aerial photograph sets from $1950-2004$ and sediment analysis of 102 samples from 10 hand auger and 10 vibracored subsurface cores were employed to satisfy the first three objectives. Firstly to provide a detailed geomorphic description of Farewell Spit; secondly to establish the geomorphic stability of its features; and thirdly to establish an age and chronology of 
Farewell Spit's development, through the use of ${ }^{14} \mathrm{C}$ dates from standard AMS methods.

Farewell Spit is a high-profile, headland barrier spit with a complex dune system. It developed during sea-level stillstand $\sim 6.5 \mathrm{ka}$, extending out from the mainland through gradual accretion of sand sourced from the West Coast. The Spit's growth has been episodic, with bulges appearing along the Spit length related to past terminus points. As the tidal flats are composed of large amounts of dune sand, they most likely developed after the barrier itself. Unlike other similar spits worldwide, barrier rollover does not appear to have occurred in the spits development as there is no obvious evidence of backbarrier sediments along Ocean Beach.

Although some sections of the Spit are eroding, the overall breadth of the subaerial Spit is accreting at an average rate of $\sim 1 \mathrm{~m} / \mathrm{y}$, suggesting a positive sediment budget. The grain size analysis of the subsurface are fairly consistent throughout the cores (up to $\sim 2.5 \mathrm{~m}$ depth) in each environment examined. This indicates that similar wind and marine processes have been at work on the Spit for some time.

Farewell Spit is a dynamic environment with high rates of change found in the Shellbanks and the two dune systems. The Shellbanks have been shown to undergo the greatest morphological change and are vulnerable to major storms from the southerly quarter. The northern dune system is the most active environment, with barchan dunes 'marching' eastward at rates of $\sim 10-30 \mathrm{~m} / \mathrm{y}$, the rate being inversely proportional to dune height/volume. At short timescales these average yearly rates of movement were found to be erratic. This is particularly noticeable from 2003 - 2004, a period of exceptionally high winds, suggesting that much of the dune movement is event based. 
Stock grazing and fires decimated much of the vegetation on the Spit during the early settler period, although since 1950 the vegetated area has grown by $\sim 75 \%$. The initial fast rates of regrowth have been attributed to the rapid colonisation by introduced $A$. arenaria. Several new foredunes have grown in the eastern sector of the southern dune system. The Froggies foredune has prograded $142 \mathrm{~m}$ while Stockyard Point has widened by $\sim 170 \mathrm{~m}$ and prograded $42 \mathrm{~m}$. Aerial photograph analysis and ${ }^{137} \mathrm{Cs}$ identification have shown these areas as being active in the recent past. This movement is therefore assumed to be related to $A$. arenaria and wind processes because no such evidence is found along the coast near the Airstrip where vegetation has been spatially more consistent. Aerial photograph analysis of the southern dune system has also indicated that the shorter linear dune ridges have developed from the trailing arms of parabolic dunes becoming vegetated. A similar process has been described in the Manawatu dune field at the same latitude $200 \mathrm{~km}$ to the east of Farewell Spit (Muckersie \& Shepherd, 1995).

\subsection{Sea-level response}

The fourth objective, to establish areas vulnerable to seawater inundation and potential future inflow channels into Golden Bay, was ascertained through the surveying of low-lying areas and modelling sealevel rise onto current MHWS and HAT levels. This highlighted four zones of concern along Farewell Spit; the Roadway, Stockyard Lake, Mullet Creek and the two smaller creeks further to the east. Total inundation events will increase at Mullet Creek and the two smaller creeks which will flood to between $0.5-1.6 \mathrm{~m}$ above current levels. This is dependent on other more local sea-level controlling factors such as storm surge and ENSO cycles further affecting the under lying eustatic sea-level rise. 
A barriers width is a major controlling factor on overwash events (VilaConcejo et al., 2006). The erosion susceptibility quotient has shown that overwash is unlikely to occur even within Farewell Spits low-lying areas because the wave energy will be dissipated before reaching the other side. Despite this, the more frequent and larger inundation events will further scarp the vegetated dunes surrounding Mullet Creek and the two smaller creeks. This will exacerbate the lateral erosion currently occurring making these channels wider.

While Golden Bay has a macro-tidal range it is also semi marine, therefore much of the energy from the tidal prism escapes through the mouth of the bay. As the across barrier channels of Farewell Spit have less energy running through them the tidal prism is not hydraulically efficient enough to cut them into full inlets. Therefore Farewell Spit is not likely to break into islands; reminiscent of Gilbert's sand spit breaching theory of barrier island development. Further, the barchan dunes are moving at such a rate that any channels will be ephemeral as the massive dunes periodically infill them. Also if the barrier sediment budget remains positive it will grow with the sea-level rise (Eitner, 1996).

The Roadway and Stockyard Lake are low lying and do not completely inundate under any sea-level scenario considered in this model. However, much of Stockyard Lake is flooded under the worst case scenarios of eustatic sea-level rise, storm surge and ENSO effects, and a single $A$. arenaria covered dune ridge protects its southern boundary from total inundation. While most of the wave energy is dissipated over tidal flats and salt marshes along this part of the Spit, this dune ridge may still suffer some erosion as has occurred at similar dunes at the eastern end. Areas with less tidal flat frontage such as the dunes around Froggies which are already heavily scarped will endure further erosion with higher sea-levels. 
Although $A$. arenaria has been successful in stabilising masses of drifting sand on Farewell Spit, this species is now nationally considered as invasive and a 'threat to the ecology of active dune systems outside its natural range' (Hilton, 2006 p175). As well as out competing native grasses such as $D$. spiralis and $S$. sericeus it may be stabilising some dunes which otherwise naturally would be active. As active transgressive dunes aid a barriers landward transgression in response to sea-level rise, dune systems dominated by $A$. arenaria are unlikely to respond to climate fluctuations in the same way (Hilton et al., 2006).

Management policy 4.2.1 of the Farewell Spit Nature Reserve Management Plan aims to protect as far as possible this landform and ecosystems from unnatural disturbance, which should include $A$. arenaria. However, it would be unwise to remove this plant completely as is occurring in other parts of the country (Hilton et al., 2006) as it would remobilise much of the sand. Although Farewell Spit currently experiences elevation of the surrounding seas from extreme storms, the barrier is currently too wide to allow overwash events; the process by which some barriers move inland. Therefore the projected sea-level rise is unlikely to mobilise the barrier. It would be more beneficial for the protection of Farewell Spits integrity to manage and promote the growth of native sand binding species so as to compete successfully with $A$. arenaria. To protect the Spit from further human interference $4 \times 4$ traffic should continue to be restricted to current levels and scouring of the roadway monitored to lessen the risk further reducing its height above MSL.

Farewell Spit is a dynamic landform which has developed since the Holocene sea-level stillstand, which according to Gibb (1986) has experienced fluctuations of a few decimetre in the past 6.5ka. The geomorphic analysis within this study found no evidence of these fluctuations affecting the barrier. It is therefore thought that despite local 
inundation effects, the projected sea-level rise will have little large scale affect on the barrier. However, this thesis was conservatively based on the IPCC A1B scenario, should a higher sea-level occur Farewell Spit is likely to experience more severe effects.

\subsection{Recommendations for future studies}

A large amount of literature is written on the evolution of SDB's, factors affecting their morphology and response to sea-level rise, although many of the theories are centred on barriers islands. Although a barrier, Farewell Spit differs in that its backbarrier environment is a semi-open marine bay with the associated tidal flow and currents. Very few barrier spits have been studied in detail, Skallengin, Denmark, being the most widely investigated. Further study into Farewell Spit would add to the global understanding of these landforms. The next stage in improving understanding of barrier spits would be to develop 3D computer translation models specifically designed for such systems. Such a model would require more information than is currently available. As such potential further research on Farewell Spit should focus on quantifying the sediment budget. In particular measuring the sediment loads transported to the Spit by the Westland and D'Urville Currents, which currently remain as vague estimations. Also the amount of sand transported to the backbarrier environment during sand storms and what quantity ultimately leaves the bay. A detailed study of tidal current flows across the flats and analysis of what combination of tide and wave action would be required to move this sand would further our understanding of sediment transport processes within Golden Bay. A digital elevation model (DEM) of the Spit would offer a more detailed analysis of inundation zones and also illustrate where the salt marsh/swamp interface is likely to occur at differing sea-levels. 
This thesis has raised interesting questions beyond its scope, in particular the phenomenon of the angles of the short linear dunes differing along the length of the Spit. A thorough wind direction study would ascertain if this landform diffracts airflow along it. The bulge at the western end of Mullet Creek is thought to be indicative of a past terminus point or alternatively a massive paleo-washover, further analysis would ascertain if such severe storms occurred in New Zealand to create such a feature. 


\section{References:}

Aagaard, T., R. Davidson-Arnott, B. Greenwood, and J. Nielsen. 2004a. Sediment supply from shoreface to dunes: linking sediment transport measurements and long-term morphological evolution. Geomorphology $60(1$ - 2):204 - 224.

Aagaard, T, J Nielsen, S G Jensen, and J Friderichsen. 2004b. Longshore sediment transport and coastal erosion at Skallingen, Denmark. Geografisk Tidsskrift 104 (1):5 - 14.

Aagaard, T, J. Orford, and A. Murray. 2007. Environmental controls on coastal dune formation; Skallingen Spit, Denmark. Geomorphology 83:29-47.

Ascough, P., G. Cook, and A. Dugmore. 2005. Methodological approaches to determining the marine radiocarbon reservoir effect. Progress in Physical Geography 29 (4):532-547

Bal, A., and D. W. Lewis. 1994. A Cretaceous - early Tertiary macrotidal estuarine succession: Puponga Coal Measures in Whanganui Inlet, onshore Pakawau sub-basin, northwest Nelson, New Zealand. New Zealand Journal of Geology and Geophysics 37:287-307.

Ballance, P.F., R. Schuckard, D.S. Melville, and P.F. Battley. 2006. Dual sand sources on Farewell Spit intertidal sand flats, New Zealand: partitioning during redistribution. New Zealand Journal of Geology and Geophysics 49:91-99.

Ballarini, M., J. Wallinga, A. Murray, S. Van Heteren, A. Oost, A. Bos, and C. van Eijk. 2003. Optical dating of young coastal dunes on a decadal time scale. Quaternary Science Reviews 23:1011-1017

Bell, R.G., D. G. Goring, and W. P. de Lange. 2002. Sea-level change and storm surges in the context of climate change. IPENZ Transactions 27 (1):1-10.

Bindoff, N.L., J. Willebrand, V. Artale, A. Cazenave, J. Gregory, S. Gulev, K. Hanawa, C. Le Quere, S. Levitus, Y. Nojiri, C.K. Shum, L.D. Talley, and A. Unnikrishnan. 2007. Observations: oceanic climate change and sealevel. In Climate Change 2007: The Physical Science Basis. Contribution of Working Group 1 to the Fourth Assessment Report of the Intergovernmental Panel on Climate Change, edited by $\mathrm{S}$. Solomon, D. Qin, M. Manning, Z. Chen, M. Marquis, K. B. Averyt, m. Tignor and H. L. Miller. Cambridge, United Kingdom and New York, United States of America: Cambridge University Press.

Bird, E. 2005a. Barrier. In Encyclopedia of Coastal Science, edited by M. L. Schwartz. Netherlands: Springer.

2005b. Drift and swash alignments. In Encyclopedia of Coastal Science, edited by M. L. Schwartz. Netherlands: Springer. . 1968. Coasts. Canberra: Australian National University Press.

Bishop, P., C. B. Campbell, L. Heights, and S. C. McFadden. 1991. Absence of Caesium-137 from recent sediments in eastern Australia indications of catchment processes? Catena 18:61-69.

Blum, M. D., A. E. Carter, T. Zayac, and R. Goble. 2002. Middle Holocene sealevel and evolution of the Gulf of Mexico. Journal of Coastal Research Special Issue 36:65-80.

Boyd, R., and S Penland. 1984. Shoreface translation and the Holocene stratigraphic record: examples from Nova Scotia, the Mississippi Delta and eastern Australia. Marine Geology 60:391-412. 
Bronk Ramsey, C. 2008. OxCal program v3.10 2005 [cited 14 May 2008] available from http://www.rlaha.ox.ac.uk/oxcal/oxcal.htm

Brown, E. A. 1978. Vegetation patterns across the Farewell Spit dune system. Tane 24:9-19.

Carter, R.W.G., K.F. Nordstrom, and N.P. Psuty. 1990. The study of coastal dunes. In Coastal dunes: form and process, edited by K. F. Nordstrom, N. Psuty and R. W. G. Carter. Chichester: John Wiley and Sons.

Chang, T. S., B. W. Flemming, A. B. Tilch, and R. Wostmann. 2006. Late Holocene stratigraphic evolution of a back-barrier tidal basin in the East Frisian Wadden Sea, southern North Sea: transgressive deposition and its preservation potential. Facies 52:329-340.

Christiansen, C, T Aagaard, J Bartholdy, M Christiansen, J Nielsen, N Nielsen, J.B.T Pedersen, and $\mathrm{N}$ Vinther. 2004. Total sediment budget of a transgressive barrier-spit, Skallingen, SW Denmark: A review. Geografisk Tidsskrift 104 (1):107 - 126.

Clark, A. B. S., and S. C. Thoms. 1978. Notes on the Geology of Cape Farewell and Farewell Spit, northwest Nelson. Tane 24:5-8.

Cooper, J. A., and O. H. Pilkey. 2004. Sea-level rise and shoreline retreat: time to abandon the Bruun Rule. Global and Planetary Change 43:157-171.

Court, A.A. 1978. Some archaeological sites from Farewell Spit, Nelson. Tane 24:43-48.

Cowell, P. J., P.S. Roy, and R. A. Jones. 1995. Simulation of large-scale coastal change using a morphological behaviour model. Marine Geology 126:45-61.

Culver, S. J., C. A. Grand Pre, D. J. Mallinson, S. R. Riggs, D. R. Corbett, J. Foley, M. Hale, L. Metger, J. Ricardo, J. Rosenberger, C. G. Smith, C. W. Smith, S. W. Snyder, and D. Twamley. 2007. Late Holocene barrier island collapse: Outer Banks, North Carolina, USA. The Sedimentary Record 5 (4):4-8.

Davis Jr, R. A., and M. O. Hayes. 1984. What is a wave dominated coast? Marine Geology 60:313-329.

Davis Jr, R. A., K. E. Yale, J. M. Pekala, and M. V. Hamilton. 2003. Barrier island stratigraphy and Holocene history of west-central Florida. Marine Geology 200:103-123.

de Lange, W. P., R.G. Bell, R. Gorman, and S. Reid. 2003. Physical oceanography of New Zealand. In The New Zealand Coast: Te Tai Aoteraroa, edited by J. R. Goff, S. L. Nichol and H. L. Rouse. Palmerston North: Dunmore Press.

de Lange, W. P., and T. R. Healy. 1986. New Zealand tsunamis 1840 - 1982. New Zealand Journal of Geology and Geophysics 29 (1):115-134.

de Lange, W. P., T. R. Healy, and Y. Darlan. 1997. Reproducibilty of sieve and settling tube textural determinations for sand-sized beach sediment. Journal of Coastal Research 13 (1):73-80.

Dean, R.G., and E. M. Maurmeyer. 1983. Models for beach profile response. In Handbook of coastal processes and erosion, edited by P. D. Komar. Florida: CRC Press.

Department of Conservation. 2008. New Zealand Coastal Policy Statement 1994 [cited 17 March 2008]. Available from http://www.doc.govt.nz/upload/documents/conservation/marine-andcoastal/coastal-management/nz-coastal-policy-statement.pdf

Dubois, R.N. 1977. Predicting beach erosion as a function of rising water levels. Journal of Geology 85:470-476. 
2002. How does a barrier shoreface respond to sea-level rise? Journal of Coastal Research 18 (2):iii-v.

Eden, D. N., and M. J. Page. 1998. Palaeoclimatic implications of a storm erosion record from late Holocene lake sediments, North Island, New Zealand. Palaeogeography. Palaeoclimatology. Palaeoecology 139:3758.

Eitner, V. 1996. Geomorphological response of the East Frisian barrier islands to sea-level rise: an investigation of past and future evolution. Geomorphology 15:57-65

Elmore, D., and M. Phillips. 1987. Accelerator mass spectrometry for measurement of long-lived radioisotopes. Science 236:543-550.

Fairbridge, R. W. 1976. Shellfish - eating preceramic Indians in coastal Brazil. Science 191 (4225):353-359.

Feathers, J.K. 2003. Single-grain OSL dating of sediments from the Southern High Plains, USA. Quaternary Science Reviews 22:1035-1042.

Fisher, J. J. 1968. Barrier island formation: discussion. Geological Society America Bulletin 79:1421-1426.

- 1982. Barrier Islands. In The Encylopedia of Beaches and Coastal Environments, edited by M. L. Schwartz. Stroudsburg: Hutchinson Ross.

Fitzgerald, D. M., S. Penland, and D. Nummedal. 1984. Control of barrier island shape by inlet sediment bypassing: East Frisian Islands, West Germany. Marine Geology 60:355-376.

Folk, R., and W. Ward. 1957. Brazos River Bar: a study in the significance of grain size parameters. Journal of Sedimentary Petrology 27:3-26.

Furkert, F.W. 1947. Westport Harbour. Transactions of the Royal Society of New Zealand 76 (3):373-402.

Gale, S.J., and P.G. Hoare. 1991. Quaternary Sediments: Petrographic Methods for the Study of Unlithified Rocks. London: Belhaven Press.

Gay, S.P. 1999. Observations regarding the movement of barchan sand dunes in the Nazca to Tanaca area of southern Peru. Geomorphology 27 (34):279-293.

Gibb, J.G. 1978. Rates of coastal erosion and accretion in New Zealand. New Zealand Journal of Marine and Freshwater Research 12 (4):429-456. 1979. Late Quaternary shoreline movements in New Zealand, Unpublished Ph.D. thesis. Department of Geography, Victoria Unversity of Wellington.

- 1986. A New Zealand regional Holocene eustatic sea-level curve and its application to determination of vertical tectonic movements: a contribution to IGCP-Project 200. Royal Society of New Zealand Bulletin 24:377-395.

Gillooly, P. 2008a. Email communication about storm surges and tides. , 21 February, 2008.

2008b. Big changes among the dunes at Farewell Spit [cited 9 April 2008]. Available from http://blog.farewellspit.com/

Goodwin, I. D. 2005. A mid shelf, mean wave direction climatology for southeastern Australia, and its relationship to the El Nino - Southern Oscillation since 1878 A.D. International Journal of Climatology 25:1715-1729.

Goudie, A.S., M Anderson, T. Burt, J. Lewin, K. Richards, B. Whalley, and P. Worsley. 1990. Geomorphological Techniques (2nd edition). London: Routledge. 
Griffiths, G.A., Glasby, G.P. 1985. Input of river-derived sediment to the New Zealand continental shelf: I. Mass. Estuarine, Coastal and Shelf Science 21:773-787.

Grindley, G. W. 1971. Sheet S8 - Takaka. In Geological map of New Zealand 1:63360. Wellington: Department of Scientific and Industrial Research.

Hannah, J. 2004. An updated analysis of long-term sea-level change in New Zealand. Geophysics Research Letters 31:L03307, doi:10.1029/2003GL019166.

Hansen, J., L. Nazarenko, R. Ruedy, M. Sato, J. Willis, A. Del Genio, D. Koch, A. Lacis, K. Lo, S. Menon, T. Novakov, J. Perlwitz, G. Russell, G. Schmidt, and N. Tausnev. 2005. Earth's energy imbalance: confirmation and implications. Science 308 (5727):1431-1435.

Harris, T.F.W. 1990. Greater Cook Strait: Form and Flow. Wellington: DSIR Marine and Freshwater.

Hawke, R.M., and J.A. McConchie. 2006. Dune phases in the Otaki - Te Horo area (New Zealand): a geomorphic history. Earth Surface Processes and Landforms 31:633-645.

Healy, T. 1991. Coastal erosion and sea level rise. Zeitschrift fur Geomorphologie N.F. Supplementband 57:1-9.

Heath, R.A. 1969. Drift card observations of currents in the central New Zealand region. New Zealand Journal of Marine and Freshwater Research 3 (1):3-12.

Herrmann, H. J., G. Sauermann, and V. Schwammle. 2005. The morphology of dunes. Physica A 358:30-38.

Hesp, P. 1981. The formation of shadow dunes. Journal of Sedimentary Petrology 51:101-112.

Hesp, P. A. 2004. Coastal dunes in the tropics and temperate regions: location, formation, morphology and vegetation processes. In Coastal Dunes, Ecology and Conservation, edited by M. Martinez and N. Psuty. Berlin: Springer-Verlag.

Hesp, P. A., and A. D. Short. 1999. Barrier morphodynamics. In Handbook of Beach and Shoreface Morphodynamics, edited by A. D. Short. New York: John Wiley.

Heward, A. P. 1981. A review of wave dominated clastic shoreline deposits. Earth Science Review 17:223-276.

Heywood, I., S. Cornelius, and S. Carver. 2002. An Introduction to Geographical Information Systems. 2nd ed. Harlow: Pearson Education Ltd.

Hilton, M. 2006. The loss of New Zealand's active dunes and the spread of marram grass (Ammophila arenaria). New Zealand Geographer 62:105-120.

Hilton, M., M. Duncan, and A. Jul, 2005. Processes of Ammophila arenaria (marram grass) invasion and indigenous species displacement, Stewart Island, New Zealand. Journal of Coastal Research 21 (1):175-185.

Hilton, M., N. Harvey, A. Hart, K. James, and C. Arbuckle. 2006. The impact of exotic dune grass species on foredune development in Australia and New Zealand: a case study of Ammophila arenaria and Thinopyrum junceiforme. Australian Geographer 37 (3):313-334.

Hilton, M., and S. L. Nichol. 2003. Offshore sand systems: geomorphology and management. In The New Zealand Coast: Te tai o Aotearoa, edited by J. R. Goff, S. L. Nichol and H. L. Rouse. Palmerston North: Dunmore Press. 
Hobbs, R. J., C. H. Gimingham, and W. T. Band. 1983. The effects of planting technique on the growth of Ammophila arenaria (L.) Link and Lymus arenarius (L.) Hochst. Journal of Applied Ecology 20:659-672.

Hoyt, J. H. 1967. Barrier island formation. Geological Society America Bulletin 78 (9):1125-1136.

Hughen, K. A.; Baillie, M. G. L.; Bard, E; Beck, J. W.; Bertrand, C. J. H.; Blackwell, P. G.; Buck, C. E.; Burr, G. S.; Cutler, K. B.; Damon, P. E.; Edwards, R. L.; Fairbanks, R. G.; Friedrich, M.; Guilderson, T. P.; Kromer, B.; McCormac, G.; Manning, S.; Ramsey, C. B.; Reimer, P. J.; Reimer, R. W.; Remmele, S.; Southon, J. R.; Stuiver, M; Talamo, S; Taylor, F.W.; van der Plicht, J; Weyhenmeyer, C. E. 2004. Marine04 Marine radiocarbon age calibration, 0 - 26 Cal Kyr BP. Radiocarbon 46 (3):1059 - 1086.

Ihse, M. 1995. Swedish agricultural landscapes - patterns and changes during the last 50 years, studied by aerial photos. Landscape and Urban Planning 31:21-37.

IPCC. 2001. Climate Change 2001: Synthesis Report. A Contribution of Working groups I, II, and III to the Third Assessment Report of the Intergovernmental Panel on Climate Change. Edited by Watson, R.T. and the Core Writing Team. Cambridge: Cambridge University Press.

2007. Summary for PolicymakersClimate Change 2007: The Physical Science Basis. In Contribution of Working Group I to the Fourth Assessment Report of the Intergovernmental Panel on Climate Change, edited by S. Solomon, D. Qin, M. Manning, Z. Chen, M. Marquis, K. B. Averyt, M. Tignor and H. L. Miller. Cambridge: Cambridge University Press.

Kasper-Zubillaga, J. J., G. Ortiz-Zamora, W. W. Dickinson, J. UrrutiaFucugauchi, and A. M. Soler-Arechalde. 2006. Textural and compositional controls on modern beach and dune sands, New Zealand. Earth Surface Processes and Landforms In Press.

Kennedy, D. M., and R. P. Paulik. 2007. Estuarine shore platforms in Whanganui Inlet, South Island, New Zealand. Geomorphology 88:214225.

King, P. R., and G. P. Thrasher. 1996. Cretaceous-Cenozoic geology and petroleum systems of the Taranaki Basin, New Zealand. In Monograph 13. Lower Hutt: Institute of Geological and Nuclear Sciences.

Kiong, E. 2008. Severe weather lashes north, moving south [cited 10 March 2008]. Available from http://www.nzherald.co.nz/section/1/story.cfm?c id=1\&objectid=104878 $\underline{96}$

Klein, M., and M. Lichter. 2006. Monitoring changes in shoreline position adjacent to the Hadera power station, Israel. Applied Geography 26:210-226.

Knight, J., J. Orford, P. Wilson, S. Braley, and A. Wintle. 2002. Assessment of temporal changes in coastal sand dune environments using the loghyperbolic grain size method. Sedimentology 49 (6):1229-1252.

Komar, P.D. 1998. Beach Processes and Sedimentation (2nd Ed). New Jersey: Prentice Hall.

Komar, P.D., and B Cui. 1984. The analysis of grain-size measurements by sieving and settling-tube techniques. Journal of Sedimentary Petrology 54 (2):603-614. 
Kraft, J. C., and C. J. John. 1979. Lateral and vertical facies relations of transgressive barrier. The American Association of Petroleum Geologists Bulletin 63 (12):2145-2163.

Kreibel, D. L., and R. G. Dean. 1985. Numerical simulation of time dependent beach and dune erosion. Coastal Engineering 9:221-245.

Lang, A., and S. Hönscheidt. 1999. Age and source of colluvial sediments at Vaihingen-Enz, Germany. Catena 38:89-107

Lario, J., C. Spencer, A. J. Plater, C. Zazo, J. L. Goy, and C. J. Dabrio. 2002. Particle size characterisation of Holocene back-barrier sequences from North Atlantic coasts (SW Spain and SE England). Geomorphology 42:25-42.

Le Roux, J. P. 1998. Entrainment threshold of natural grains in liquids determined empirically from dimensionless settling velocities and other measures of grain size. Sedimentary Geology 119:17-23.

Leask, W. L. 1993. Brunner coal measures at Golden Bay, Nelson: an Eocene fluvial-estuarine deposit. New Zealand Journal of Geology and Geophysics 36:37-50.

Leatherman, S. P. 1979. Migration of Assateague Island, Maryland, by inlet and overwash processes. Geology 7 (2):104-107.

. 1983. Shoreline mapping: a comparison of techniques. Shore and Beach 51 (3):28-33.

Levin, N., and E. Ben-Dor. 2004. Monitoring sand dune stabilisation along the coastal dunes of Ashdod-Nizanim, Isreal, 1945-1999. Journal of Arid Enivironments 58:335-355.

LINZ. 2000. Topographic Map 260-M24 \& N24 Farewell Spit. In 1:50 000: Land Information New Zealand.

. 2007a. Secondary ports table for Nelson: data sourced from NZ Nautical Alminac 2007/2008 [cited 14 December 2007]. Available from http://www.hydro.linz.govt.nz/tides/Secports/ports/nelson.pdf

2007b. Secondary ports table for Westport: data sourced from NZ Nautical Alminac 2007/08 [cited 14 December 2007]. Available from http://www.hydro.linz.govt.nz/tides/Secports/ports/westport.pdf

Masselink, G., and A.D. Short. 1993. The effect of tide range on beach morphodynamics and morphology: a conceptual beach model. Journal of Coastal Research 9 (3):785-800.

Matias, A., O. Ferreira, A. Vila-Concejo, T. Garcia, and J. A. Dias. 2007. Classification of washover dynamics in barrier islands. Geomorphology doi:10.1016/j. geomorph.2007.09.010.

Matthews, K. M. 1995. Measurement of residual traces of $137 \mathrm{Cs}$ in the atmosphere in New Zealand. Journal of Environmental Radioactivity 27 (3):221-229.

McCleod, D. 2008. Telephone interview about tides, conducted 16 January 2007.

McLaren, P. 1981. An interpretation of trends in grain size measures. Journal of Sedimentary Petrology 51:611-624.

McLean, R.F. 1978. Recent coastal progradation in New Zealand. In Landform Evolution in Australasia, edited by J. L. Davies and M. A. J. Williams. Canberra: National University Press. 2004. Bruun Rule. In Encyclopedia of Geomorphology, edited by A. S. Goudie. London: Routledge. 
McManus, J. 1988. Grain size determination and interpretation. In Techniques in Sedimentology, edited by M. Tucker. Oxford. p 394: Blackwell Scientific Publications.

Ministry for the Environment. 2007. Climate Change Effects and Impacts Assessment: A guidance manual for Local Government in New Zealand 2004 [cited 19 December 2007]. Available from http://www.mfe.govt.nz/publications/climate/effects-impactsmay04/effects-impacts-may04.pdf

Mitchell, H., and J. Mitchell. 2004. Te Tau Ihu o te Waka: A History of Maori of Nelson and Marborough. Vol. Volume 1: Te Tangata me Te Whenua The People and The Land. Wellington: Huia Publishers.

Moller, I., T. Spencer, J. R. French, D. J. Leggett, and M. Dixon. 1999. Wave transformation over salt-marshes: a field and numerical modelling study from North Norfolk, England. Estuarine, Coastal and Shelf Science 49:411-426.

Morton, R. A., and A. H. Sallenger. 2003. Morphological impacts of extreme storms on sandy beaches and barriers. Journal of Coastal Research 19 (3):560-573.

Muckersie, C., and M. J. Shepherd. 1995. Dune phases as time-transgressive phenomena, manawatu, New Zealand. Quaternary International 26:6167.

Muirhead, F. J. G. 1981. Farewell Spit Nature Reserve Management Plan Draft. Nelson: Department of Lands and Survey.

Murray, A. S., and A. Wintle. 2000. Luminescence dating of quartz using an improved single-aliquot regenerative dose protocol. Radiation Measurements 37:377-381.

NABIS. 2007. Interactive Web Mapping of New Zealand's Marine Environment and Biodiversity. Ministry of Fisheries [cited 20 July 2007]. Available from https://www.nabis.govt.nz/nabis $\mathrm{prd} / \mathrm{map}$.jsp

Nelson-City-Council. 2007. Marae [cited 4 June 2007]. Available from http://www.ncc.govt.nz/aboutnelson/nelsoninfocus/lifestyle/marae.htm

NIWA. 2007a. Farewell Spit Climate Data. NIWA [cited 15 September 2007]. Available from http://cliflo.niwa.co.nz/pls/niwp/wgenf.genform1

2007b. Climate variability and change: climate change scenarios for New Zealand [cited 14 December 2007]. Available from http://www.niwa.co.nz/ncc/clivar/scenarios 2008a. El Niño and La Niña [cited 9 April 2008]. Available from http://www.niwa.cri.nz/edu/students/enln 2008b. Farewell Spit Climate Data [cited 13 March 2008]. Available from http://cliflo.niwa.co.nz/pls/niwp/wgenf.genform1

Oertel, G. F. 1985. The barrier island system. Marine Geology 63:1-18.

Ongley, M., and E. O. Macpherson. 1923. The geology and mineral resources of the Collingwood subdivision, Karamea subdivision. New Zealand Journal of Geological Survey Bulletin no 25.

Orford, J. 2004. Barrier and barrier island. In Encyclopedia of Geomorphology, Volume 1, edited by A. S. Goudie. London: Routledge.

Otvos, E. G. 1970. Development and migration of barrier islands, northern Gulf of Mexico. Geological Society America Bulletin 81:241-246.

Owens, P.N., D. E. Walling, and Q. He. 1996. The behaviour of bomb derived Caesium-137 fallout in catchment soils. Journal of Environmental Radioactivity 32 (3):169-191. 
Paulik, R. P. 2006. Shore platform development in a low energy marine environment. A case study from Whanganui Inlet, South Island, New Zealand., School of Geography, Environment and Earth Sciences, Victoria University of Wellington, Wellington.

Petyt, C. 1999. Farewell Spit a Changing Landscape. Nelson: Terracottage Books.

Pickrill, R. A., and J. S. Mitchell. 1979. Ocean wave characteristics around New Zealand. New Zealand Journal of Marine and Freshwater Research 13 (4):501-520.

Pierce, J. W. 1969. Sediment budget along a barrier island chain. Sedimentary Geology 3:5-16.

Prescott, J., and G. Robertson. 1997. Sediment dating by luminescence: a review. Radiation Measurements 27 (5/6):893-922.

Prior, C. 2007. Radiocarbon Dating. In 4th Quaternary Techniques Short Course: Measuring change and reconstructing past environments., edited by K. Faure and C. Prior: GNS Science Miscillaneous Series 11.

Ramsar. 2007. Ramsar Wetlands Information Sheet, Farewell Spit, ref: 5NZ002. 1992 [cited 10 May 2007]. Available from http://www.wetlands.org/rsis/

Rattenbury, M.S., R.A. Cooper, and M.R. Johnston. 1998. Geology of the Nelson area. Edited by Institute of Geological and Nuclear Sciences, 1:250000 geological map 9. 1 sheet + 67p. Lower Hutt, New Zealand: Institute of Geological and Nuclear Sciences Limited.

Reiser, U. 2007. Luminescence Dating. In Quaternary Techniques: Measuring change and reconstructing past environments. Wellington, New Zealand: GNS Science Miscellaneous Series 11.

Ridgeway, N.M. 1977. Currents and hydrology in Tasman and Golden Bays, South Island, New Zealand. New Zealand Journal of Marine and Freshwater Research 11 (1):95-109.

Roy, P. S., P. J. Cowell, M. A. Ferland, and B. G. Thom. 1994. Wave dominated coasts. In Coastal evolution: Late Quaternary Shoreline Morphodynamics, edited by R. W. G. Carter and C. D. Woodroffe. Cambridge: Cambridge University Press.

Sanchez-Arcilla, A., and J. A. Jimenez. 1994. Breaching in a wave dominated barrier spit: The Trabucador Bar (North-Eastern Spanish Coast). Earth Surface Processes and Landforms 19 (6):483-498.

Schmechel, F. 2001. Potential impacts of mechanical cockle harvesting on shorebirds in Golden and Tasman Bays, New Zealand. DOC SCIENCE INTERNAL SERIES 19.

Schwammle, V., and H. J. Herrmann. 2005. A model of barchan dunes including lateral shear stress. European Physical Journal E 16:57-65.

Schwartz, M. L. 1971. The multiple causality of barrier islands. Journal of Geology 79:91-94.

SCOR Working group 89. 1991. The response of beaches to sea-level changes: a review of predictive models. Journal of Coastal Research 7 (3):895-921.

Sevon, W.D. 1964. Sediment variation on Farewell Spit, New Zealand. New Zealand Journal of Geology and Geophysics 9:60-75

Shepard, F. P. 1963. Submarine geology. New York: Harper \& Row.

Shepherd, M. J., and P. Hesp. 2003. Sandy barriers and coastal dunes. In The New Zealand Coast: Te Tai o Aotearoa, edited by J. R. Goff, S. L. Nichol and H. L. Rouse. Palmerston North: Dunmore Press. 
Sherman, D. J., and S. Hotta. 1990. Aeolian sediment transport theory and measurement. In Coastal dunes: Form and Process, edited by K. F. Nordstrom and N. Psuty. New York: John Wiley \& Sons Ltd.

Simms, A. R., J. B. Anderson, and M. D. Blum. 2006. Barrier island aggregation via inlet migration: Mustang Island, Texas. Sedimentary Geology 187:105-125.

Stallins, J. A. 2002. Dune plant species diverstity and function in two barrier island biogeomorphic systems. Plant Ecology 165:183-196.

Stallins, J. A., and A. J. Parker. 2003. The influence of complex systems interactions on barrier island dune vegetation pattern and process. Annals of the Association of American Geographers 93 (1):13-29.

Stauble, D. K. 1989. Barrier Islands: dynamic coastal landforms requiring complex management decisions. In Barrier Islands: Process and Management, edited by D. K. Stauble. New York: American Society of Civil Engineers.

Stolper, D., J. H. List, and E. R. Thieler. 2005. Simulating the evolution of coastal morphology and stratigraphy with a new morphologicalbehaviour model (GEOMBEST). Marine Geology 218:17-36.

Stuiver, M., and H. A. Polach. 1977. Discussion: reporting of ${ }^{14} \mathrm{C}$ data. Radiocarbon 19 (3):355-363.

Syvisky, J. P. M., K. W. Asprey, and D. A. Clattenburg. 1991. Principles, design and calibration of settling tubes. In Principles, Methods and Applications of Particle Size Analysis, edited by J. P. M. Syviski. Cambridge: Cambridge University Press.

Te Ara. 2008. Tropical Cyclones [cited 25 May 2008]. Available from http://www.teara.govt.nz/EarthSeaAndSky/ClimateAndAtmosphere/We ather/4/en

Thom, B. G. 1983. Transgressive and regressive stratigraphies of coastal sand barriers in southeast Australia. Marine Geology 56:137-158.

Titus, J.G. 1990. Greenhouse effect, sea-level rise and barrier islands: case study of Long Beach Island, New Jersey. Coastal Management 18:6590.

Turney, C. 2006. Bones, Rocks and Stars: The Science of When Things Happened. Hampshire: Macmillan.

UNESCO. 2007. World Heritage tentative list [cited 10 June 2007]. Available from http://whc.unesco.org/en/tentativelists/state $=\mathrm{nz}$

University of Waikato. 2008. ${ }^{14} \mathrm{C}$ operating proceedures [cited 23 May 2008]. Available from http://www.radiocarbondating.com/

van de Graaff, J. 1977. Dune erosion during a storm surge. Coastal Engineering 1:99 - 134.

van der Linden, W. J. M. 1968. Offshore sediments, north-west Nelson, South Island, New Zealand. New Zealand Journal of Geology and Geophysics 12:87-103

van Heteren, S., and O. van de Plassche. 1997. Influence of relative sea-level change and tidal-inlet development on barrier-spit stratigraphy, Sandy Neck, Massachusetts. Journal of Sedimentary Research 67 (2):350363.

Vanden Bygaart, A. J., and R. Protz. 2001. Bomb-fallout ${ }^{137}$ Cs as a marker of geomorphic stability in dune sands and soils, Pinery Provincial Park, Ontario, Canada. Earth Surface Processes and Landforms 26:689-700.

Vellinga, P. 1982. Beach and dune erosion during storms. Coastal Engineering 6:361-387. 
Vila-Concejo, A., A. Matias, A. Pacheco, O. Ferreira, and J. A. Dias. 2006. Quantification of inlet-related hazards in barrier island systems. An example from the Ria Formosa (Portugal). Continental Shelf Research 26:1045 -1060.

Walton, A., and S. Bagly. 2007. An Archaeological Survey of Triangle Flat, Puponga Farm Park 2000 [cited 6 September 2007]. Available from http://www.doc.govt.nz/upload/documents/science-andtechnical//R182.pdf

Watkins, C. B. 1978. A note on the salt marsh vegetation of Farewell Spit. Tane 24:25-27.

Whitehead, N. E., R. G. Ditchburn, W. J. McCabe, W. J. Mason, J. Irwin, R. A. Pickrill, and G.R. Fish. 1998. Application of natural and artificial fallout radionuclides to determining sedimentation rates in New Zealand lakes. New Zealand Journal of Marine and Freshwater Research 32:489-503.

Whittow, J. 1984. Dictionary of Physical Geography. Middlesex: Penguin Books.

Wigley, T. M. L. 2005. The climate change commitment. Science 307 (5716):1766-1769.

Williams, M., H. Gummer, R. Powlesland, H. Robertson, and G. Taylor. 2007. Migrations and Movements of Birds to New Zealand and Surrounding Areas. Science \& Technical Publishing, Department of Conservation 2006 [cited 14 May 2007]. Available from

http://www.doc.govt.nz/upload/documents/science-andtechnical/sap232.pdf

Williams, P. W. 1991. Tectonic geomorphology, uplift rates and geomorphic response in New Zealand. Catena 18:439-452.

Wintle, A. G. 1993. Luminescence dating of aeolian sands: an overview. Geological Society, London, Special Publications 72:49-58.

Wizevich, M. C., G. P. Thrasher, M. R. Bussell, G. J. Wilson, and J. D. Collen. 1992. Evidence for marine deposition in the Late Cretaceous Pakawau Group, northwest Nelson. New Zealand Journal of Geology and Geophysics 35:363-369.

Woodroffe, C.D. 2002. Coasts: Form, Process and Evolution. UK: Cambridge University Press.

Worsley, P. 1990. Radioactive dating: principles, application and sample collection. In Geomorphological Techniques, edited by A. S. Goudie, M. Anderson, T. Burt, J. Lewin, K. Richards, B. Whalley and P. Worsley. London: Unwin Hyman.

Wright, L. D., J. D. Boon, S. C. Kim, and J. H. List. 1991. Modes of cross-shore sediment transport on the shoreface of the Middle Atlantic Bight. Marine Geology 96:19-51.

Zaremba, R. E., and S. P. Leatherman. 1986. Vegetative physiographic analysis of a U.S. northern barrier system. Environmental Geology and Water Sciences 8 (4):193-207.

Zharikov, Y., G. Skilleter, N. Loneragan, T. Taranto, and B. Cameron. 2005. Mapping and characterising subtropical esturine landscapes using aerial photography and GIS for potential application in wildlife conservation and management. Biological Conservation 125:87-100. 


\section{Appendices:}

Appendix 1

Results of grain size analysis of cores along the Stockyard Point transect.

Appendix 2

Results of grain size analysis of the Mullet Creek core.

Appendix 3

Results of grain size analysis of the hand augered cores on the vegetated dunes.

Appendix 4

Results of grain size analysis of the Lighthouse transect.

Appendix 5

Radiocarbon dating results. 


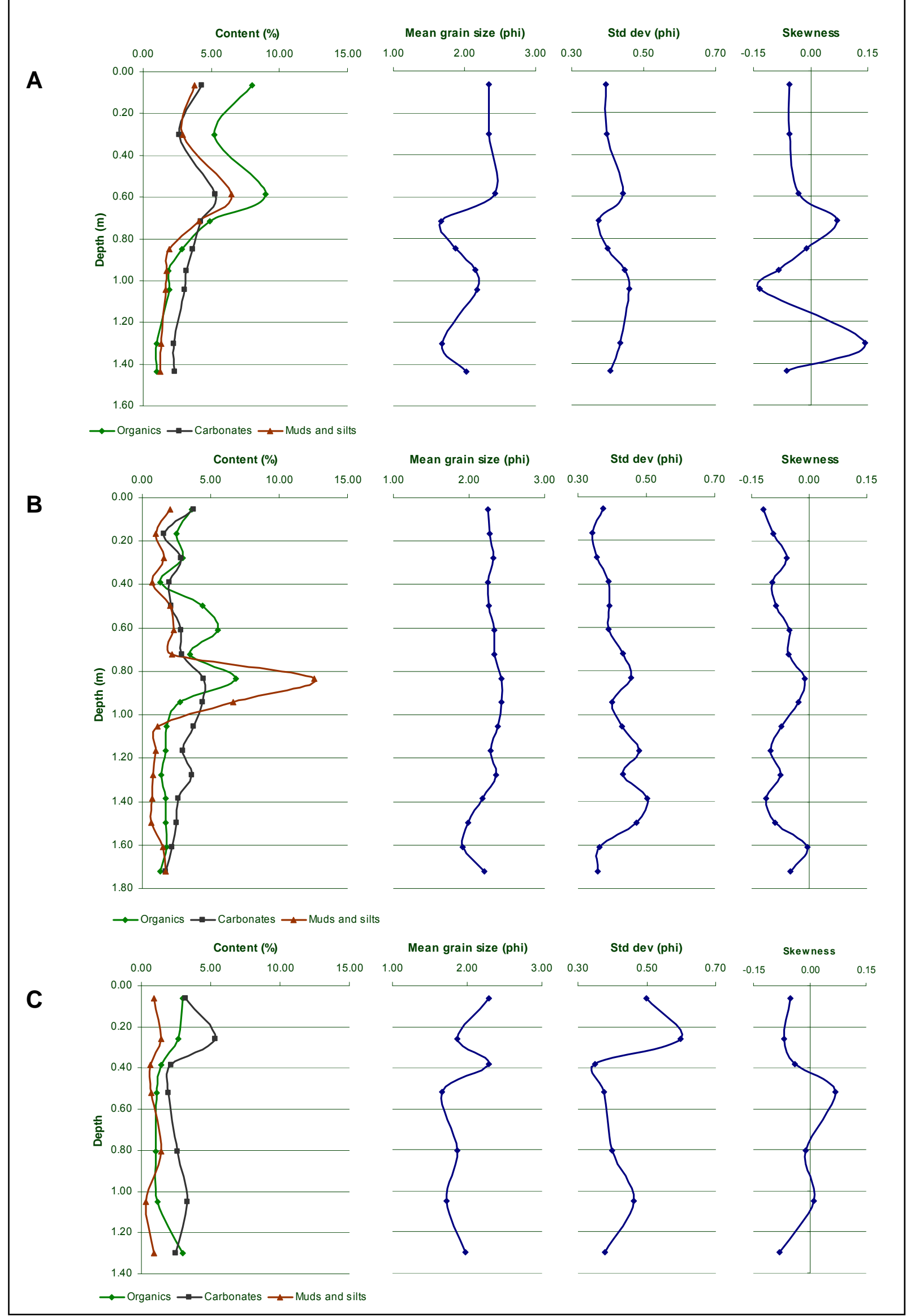

Appendix 1: Results of grain size analysis of cores along the Stockyard Point transect. A) Salt marsh. B) Beach. C) Tidal flat. 


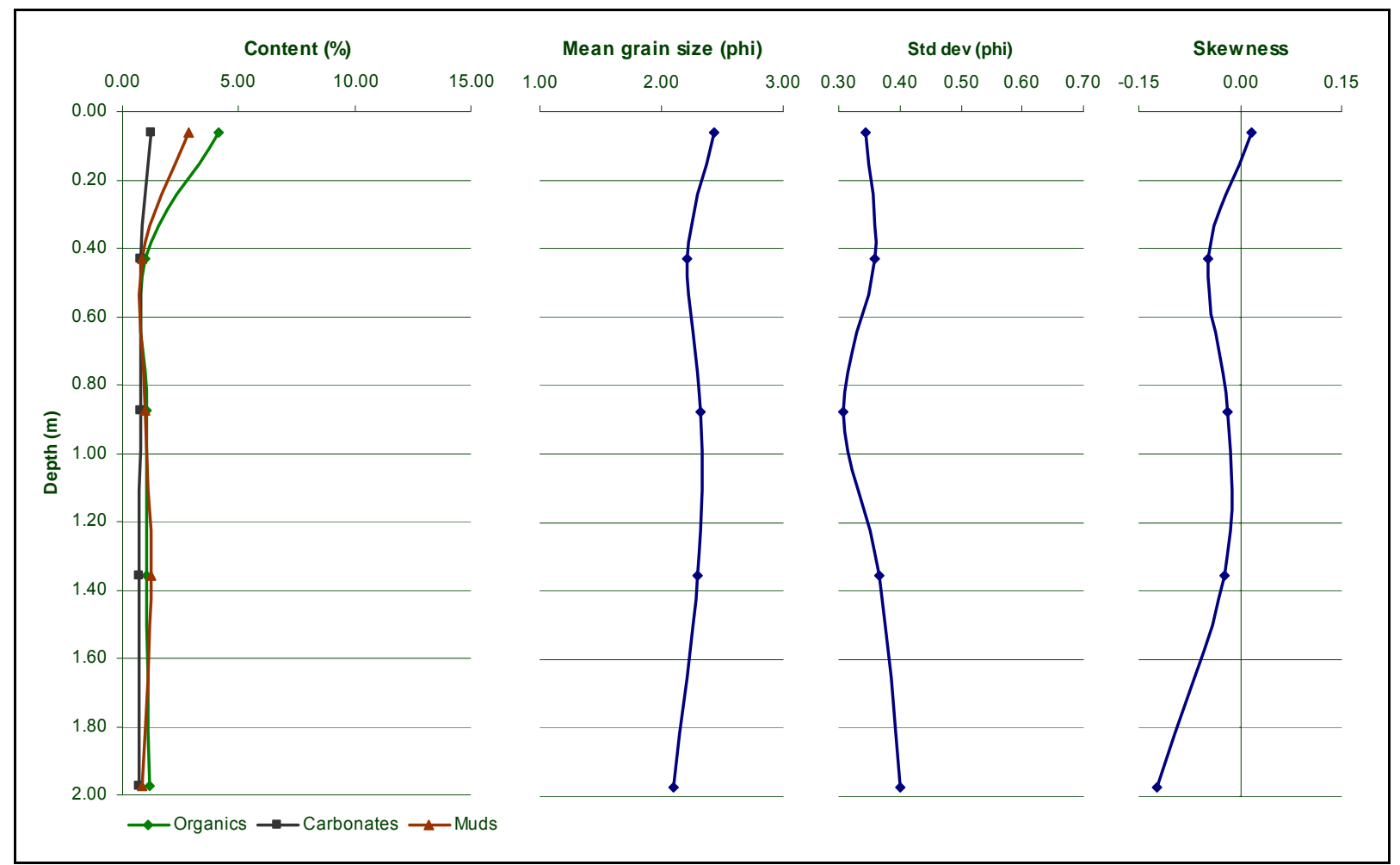

Appendix 2: Results of grain size analysis of the Mullet Creek core. 


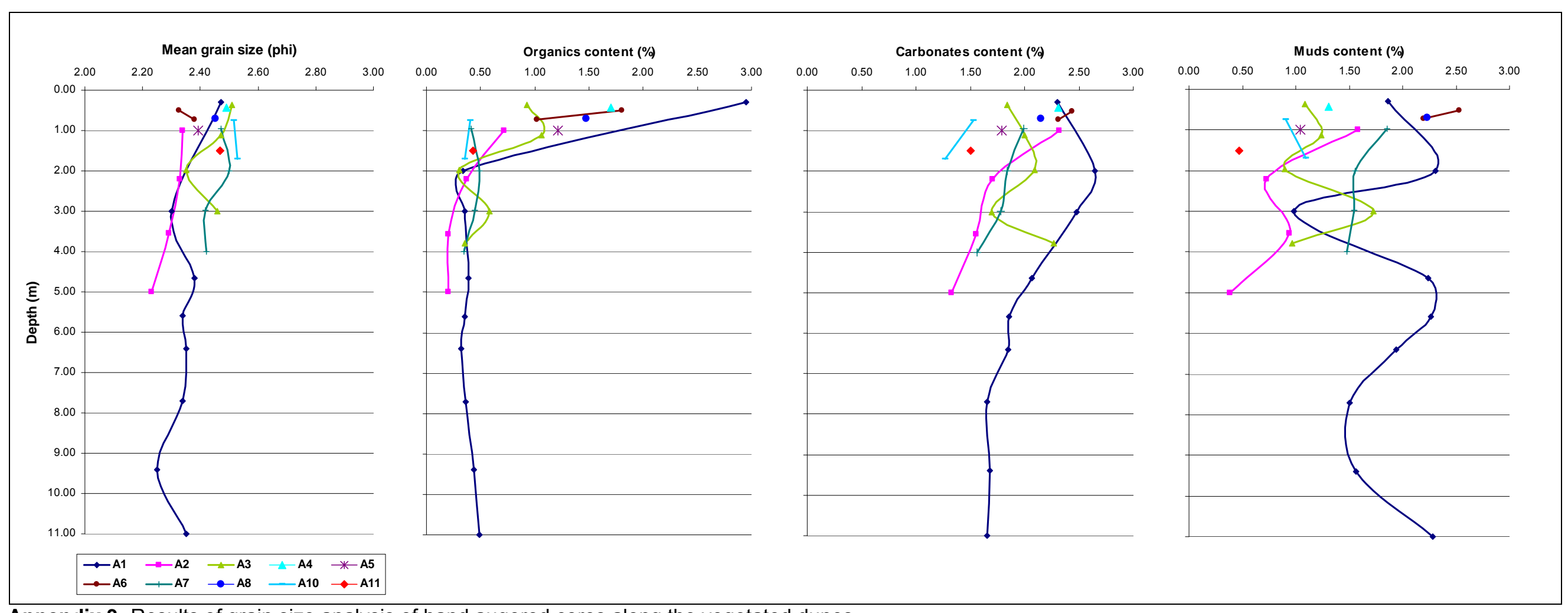

Appendix 3: Results of grain size analysis of hand augered cores along the vegetated dunes. 


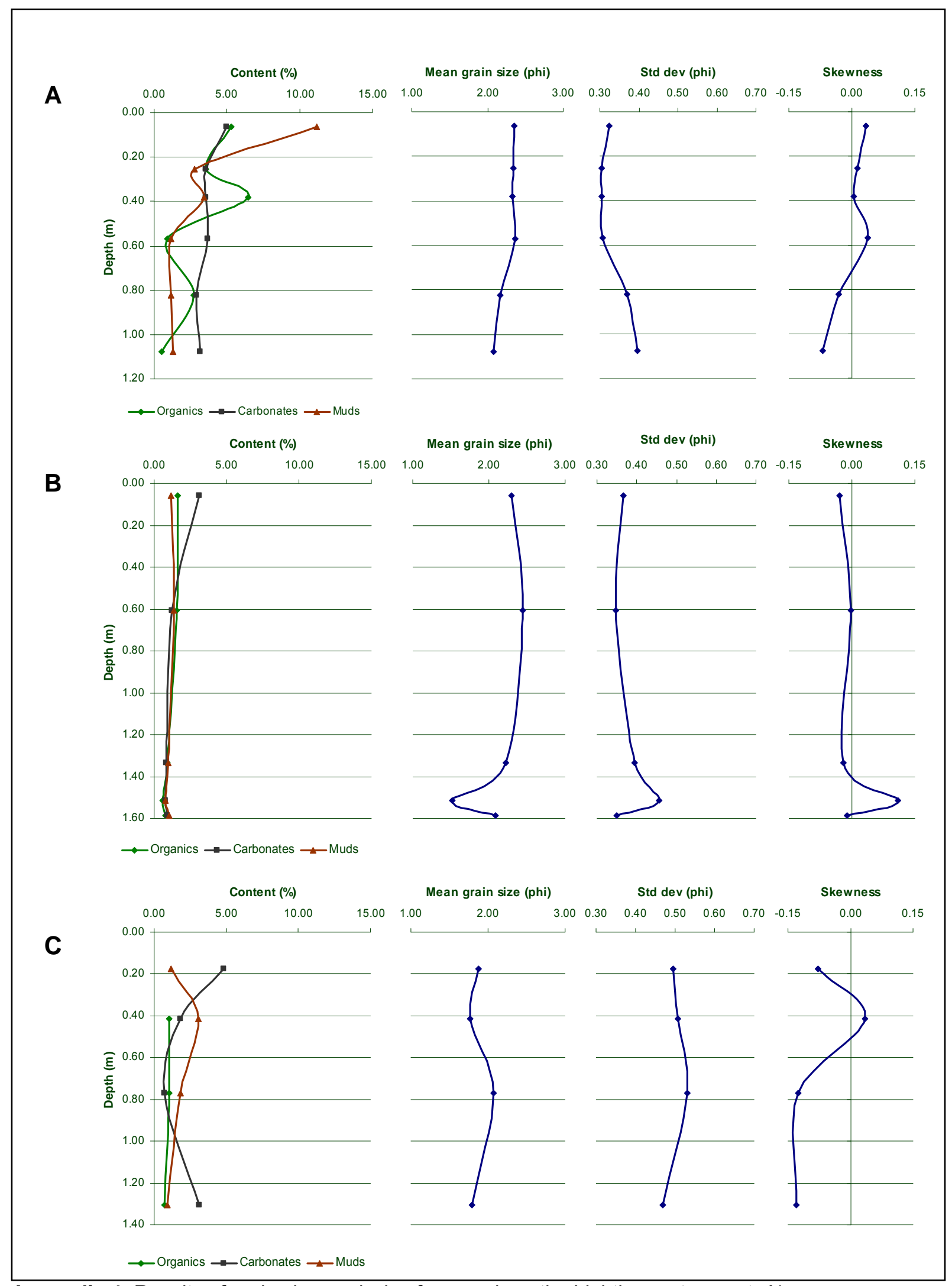

Appendix 4: Results of grain size analysis of cores along the Lighthouse transect. A) Swamp. B) Beach. C) Tidal flat. 


\section{The University of Waikato \\ Radiocarbon Dating Laboratory}

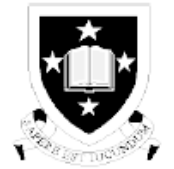

Private Bag 3105

Hamilton,

New Zealand

Fax +647838 4192

$\mathrm{Ph}+6478384278$

email c14@waikato.ac.nz

Head: Dr Alan Hogg

\section{Report on Radiocarbon Age Determination for Wk- 21854}

(AMS measurement)

Submitter

Submitter's Code

Site \& Location

Sample Material

Physical Pretreatment

Chemical Pretreatment
D.M Kennedy

FS4-42

Farewell Spit, New Zealand

A. stutchburyi

Surfaces cleaned. Washed in an ultrasonic bath. Tested for recrystallization: aragonite.

Sample acid washed using $0.1 \mathrm{~N} \mathrm{HCl}$, rinsed and dried.
$\mathrm{D}^{14} \mathrm{C}$
$-54.6 \pm 1.9 \%$
$\mathrm{F}^{14} \mathrm{C} \%$
$94.5 \pm 0.2 \%$

$0.7 \pm 0.2 \%$

Result $\quad 451 \pm 30$ BP

\section{Comments}

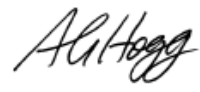

$11 / 10 / 07$

- Result is Conventional Age or \% Modern as per Stuiver and Polach, 1977, Radiocarbon 19, 355-363. This is based on the Libby half-life of $5568 \mathrm{yr}$ with correction for isotopic fractionation applied. This age is normally quoted in publications and must include the appropriate error term and Wk number.

- Quoted errors are 1 standard deviation due to counting statistics multiplied by an experimentally determined Laboratory Error Multiplier.

- The isotopic fractionation, $\delta^{13} \mathrm{C}$, is expressed as \%o wrt PDB.

- $\mathrm{F}^{14} \mathrm{C} \%$ is also known as $\mathrm{pMC}$ (percent modern carbon). 


\section{The University of Waikato}

\section{Radiocarbon Dating Laboratory}

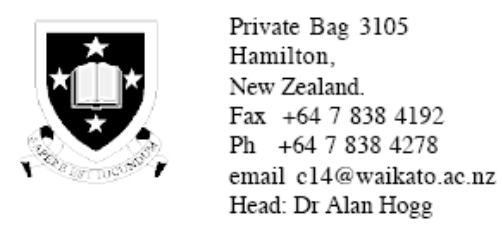

Report on Radiocarbon Age Determination for Wk- 21855

(AMS measurement)

Submitter

Submitter's Code

Site \& Location

Sample Material

Physical Pretreatment

Chemical Pretreatment
D.M Kennedy

FS4-68

Farewell Spit, New Zealand

A. stutchburyi

Surfaces cleaned. Washed in an ultrasonic bath. Tested for recrystallization: aragonite.

Sample acid washed using $0.1 \mathrm{~N} \mathrm{HCl}$, rinsed and dried.

$\begin{array}{lrl}\delta^{13} \mathrm{C} & 1.3 \pm 0.2 & \% \\ \mathrm{D}^{14} \mathrm{C} & -67.4 \pm 2.2 & \% \circ \\ \mathrm{F}^{14} \mathrm{C} \% & 93.3 \pm 0.2 & \sigma_{0}\end{array}$

Result $560 \pm 30 \mathrm{BP}$

\section{Comments}

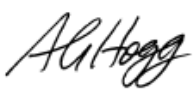

$11 / 10 / 07$

- Result is Conventional Age or \% Modern as per Stuiver and Polach, 1977, Radiocarbon 19, 355-363. This is based on the Libby half-life of $5568 \mathrm{yr}$ with correction for isotopic fractionation applied. This age is normally quoted in publications and must include the appropriate error term and Wk number.

- Quoted errors are 1 standard deviation due to counting statistics multiplied by an experimentally determined Laboratory Error Multiplier.

- The isotopic fractionation, $\delta^{13} \mathrm{C}$, is expressed as \%o wrt PDB.

- $\mathrm{F}^{14} \mathrm{C} \%$ is also known as pMC (percent modern carbon). 

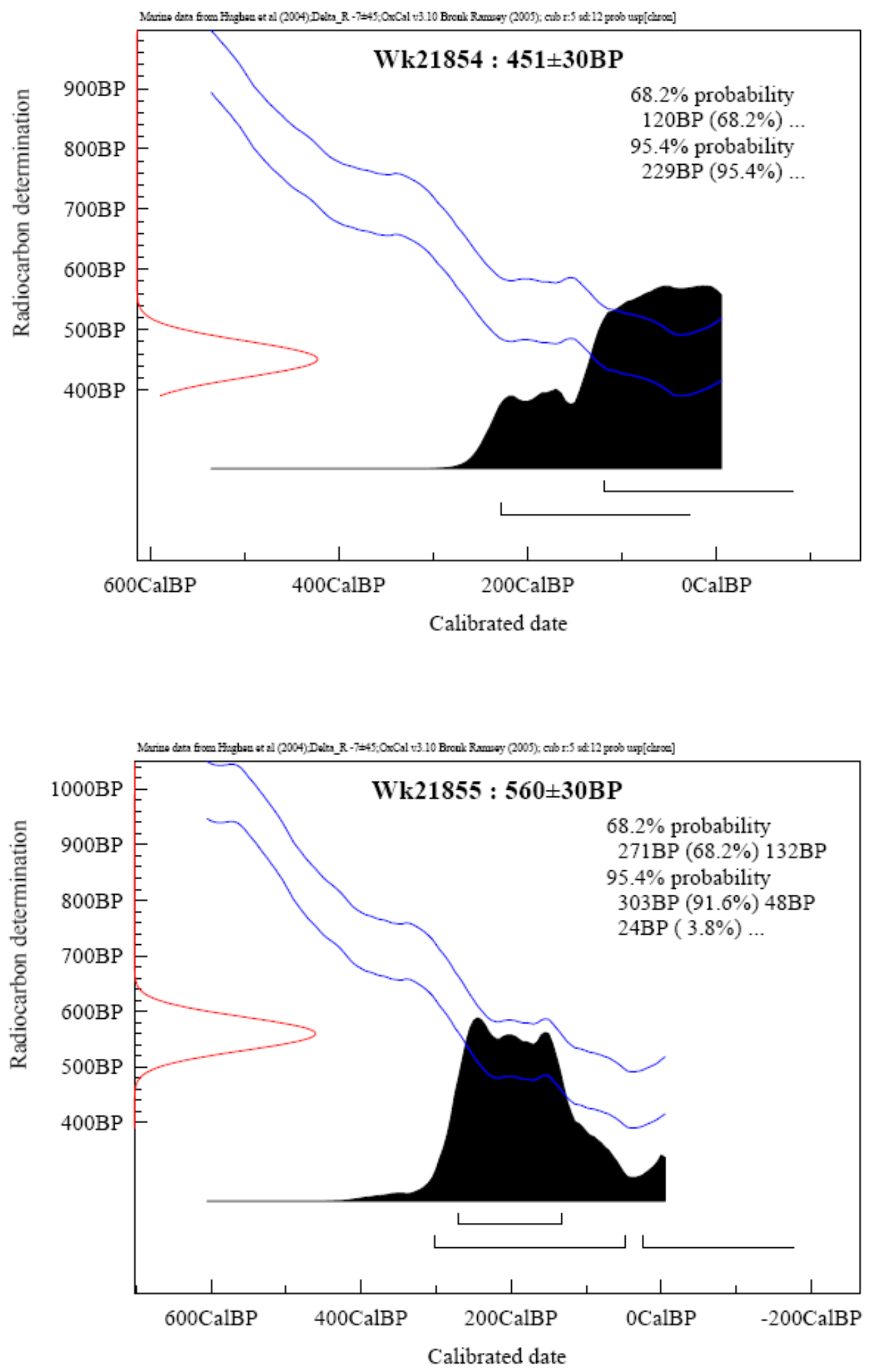